Andrews University

Digital Commons @ Andrews University

\title{
Assessing The Factors Impacting Professional Learning For Teachers In Seventh-day Adventist Schools: A Comparison of Millennials And Non-Millennials
}

\author{
Betty L. Bayer \\ Andrews University, bettyb@andrews.edu
}

Follow this and additional works at: https://digitalcommons.andrews.edu/dissertations

Part of the Teacher Education and Professional Development Commons

\section{Recommended Citation}

Bayer, Betty L., "Assessing The Factors Impacting Professional Learning For Teachers In Seventh-day Adventist Schools: A Comparison Of Millennials And Non-Millennials" (2017). Dissertations. 1634.

https://digitalcommons.andrews.edu/dissertations/1634

https://dx.doi.org/10.32597/dissertations/1634

This Dissertation is brought to you for free and open access by the Graduate Research at Digital Commons @ Andrews University. It has been accepted for inclusion in Dissertations by an authorized administrator of Digital Commons@ Andrews University. For more information, please contact repository@andrews.edu. 


\begin{abstract}
ASSESSING THE FACTORS IMPACTING PROFESSIONAL LEARNING FOR TEACHERS IN SEVENTH-DAY ADVENTIST SCHOOLS: A COMPARISON OF MILLENNIALS AND NON-MILLENNIALS
\end{abstract}

\title{
by
}

Betty L. Bayer

Chair: Janet Ledesma 


\title{
ABSTRACT OF GRADUATE STUDENT RESEARCH
}

\author{
Dissertation
}

\author{
Andrews University \\ School of Education
}

\section{Title: ASSESSING THE FACTORS IMPACTING PROFESSIONAL LEARNING FOR TEACHERS IN SEVENTH-DAY ADVENTIST SCHOOLS: A COMPARISON OF MILLENNIALS AND NON-MILLENNIALS}

Name of researcher: Betty L. Bayer

Name and degree of faculty chair: Janet Ledesma, Ph.D.

Date completed: July 2017

\section{Problem and Purpose}

Much research over several decades has established the importance of ongoing professional learning for teachers and has identified what effective professional learning should look like. Little research has been done, however, on the professional learning practices of teachers in faith-based schools, and few studies have focused on the learning needs of millennial teachers, those newest to the profession.

This study explores the professional learning practices of educators in the Seventh-day Adventist School system in North America and the factors that impact those practices, with a special focus on millennial educators. Educational leaders can use the 
results of this study to improve the learning opportunities available for the teachers they are responsible for supporting.

\section{Method}

A descriptive quantitative design was used to collect and analyze data from 749 surveys. The sample consisted of K-12 educators from across the North American Division of Seventh-day Adventists. Data was collected using a researcher-designed instrument which was administered through Survey Monkey ${ }^{\mathrm{TM}}$. SPSS ${ }^{\mathrm{TM}}$ was used for statistical analyses. Factors were identified using exploratory factor analysis, and both descriptive results and multiple regression analyses were used to assess the impact of these factors on the time spent and the number of types of professional learning that educators participate in.

\section{Findings}

The study showed that there is strong commitment to ongoing professional learning in the Seventh-day Adventist school system. It is also clear, however, that traditional forms of learning predominate and educators in general do not spend the sustained time needed for lasting instructional improvement. The factors that predicted time spent were different for millennial and non-millennial teachers. In general, nonmillennial teachers report higher satisfaction with professional learning opportunities than do millennials. Collaborative practice has the greatest impact on both time spent and variety of types of activities, but few non-millennials and even fewer millennials report opportunities for collaboration. 


\section{Conclusions and Recommendations}

The findings suggest that several areas need to be addressed in order to improve the professional learning experiences for educators in the system. Differentiated opportunities for learning, including the addition of non-traditional types, are needed to better meet the needs of all educators, especially millennials. More opportunities for collaboration among educators are needed, and ways of facilitating job-embedded learning need to be explored. Increased institutional support, including a willingness to explore new models, provide teacher leadership and collaboration opportunities, and consider policy changes that better reflect learning needs at various career stages, would increase teacher satisfaction with their learning opportunities and may, as a result, lead to improved instruction and increased student success. 
Andrews University

School of Education

ASSESSING THE FACTORS IMPACTING PROFESSIONAL LEARNING FOR TEACHERS IN SEVENTH-DAY ADVENTIST SCHOOLS: A COMPARISON OF MILLENNIALS AND NON-MILLENNIALS

\author{
A Dissertation \\ Presented in Partial Fulfillment \\ of the Requirements for the Degree \\ Doctor of Philosophy
}

by

Betty L. Bayer

July 2017 
(C) Copyright by Betty Bayer 2017

All Rights Reserved 


\title{
ASSESSING THE FACTORS IMPACTING PROFESSIONAL LEARNING FOR TEACHERS IN SEVENTH-DAY ADVENTIST SCHOOLS: A COMPARISON OF MILLENNIALS AND NON-MILLENNIALS
}

\author{
A dissertation \\ presented in partial fulfillment \\ of the requirements for the degree of \\ Doctor of Philosophy
}

by

Betty Bayer

APPROVAL BY THE COMMITTEE:

Chair: Janet Ledesma

Member: Bordes Henry Saturné

Member: Jimmy Kijai

External: James Jeffery
Dean, School of Education

Robson Marinho

Date approved 


\section{DEDICATION}

\section{"Wise men and women are always learning Always listening for fresh insights." \\ (Proverbs 18:15, The Message)}

To the many hard-working, dedicated teachers

from whom I have learned much through the years . . .

those whose classrooms I lingered in,

those with whom I have been privileged to work,

and especially those millennial teachers

from whom I continue to learn so much.

May we keep learning together

throughout eternity. 


\section{TABLE OF CONTENTS}

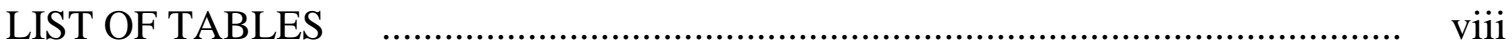

LIST OF ILLUSTRATIONS ........................................................................

LIST OF ABBREVIATIONS ................................................................. xi

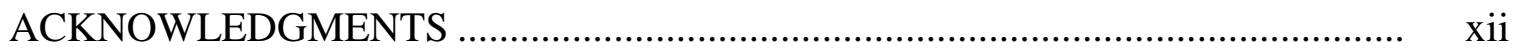

\section{Chapter}

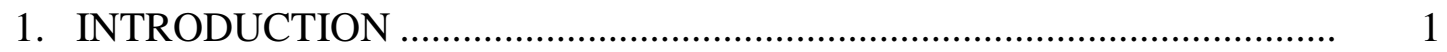

Background of the Problem..................................................................... 1

Rationale..................................................................................... 2

Statement of the Problem .......................................................................... 4

Purpose of the Study ...............................................................................

Research Questions ………………………………………………... 4

Theoretical Framework ......................................................................... 5

Conceptual Framework ………………………………………………....

Significance of the Study......................................................................... 7

Key Terms and Definitions ................................................................... 13

Limitations.............................................................................. 16

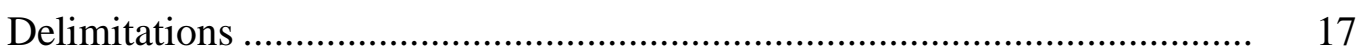

Overview of the Research Methodology ……………………………….... 18

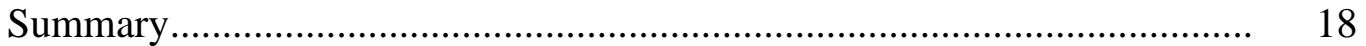

Organization of the Study ....................................................................... 19

2. LITERATURE REVIEW ................................................................ 20

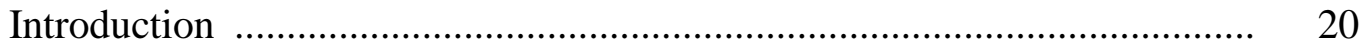

Professional Learning .......................................................................... $\quad 20$

Activity Factors ................................................................................ 23

Active Learning ...................................................................... 23

Coherence..................................................................... 24

Duration........................................................................... 25

Collective Participation ............................................................... 26

Content Focus .................................................................... 28 


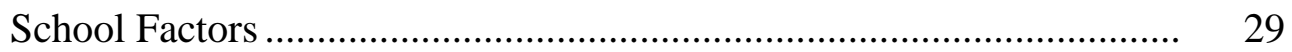

Structures and Support .......................................................... $\quad 30$

Standards and Expectations............................................................. 31

Incentives ......................................................................... 32

Accountability ...................................................................... 33

Culture ................................................................... 34

Summary ……................................................................ 35

Teacher Factors ................................................................................. 37

Prior Education and Experience.................................................... 38

Beliefs About Learning ........................................................... 39

Purposes ...................................................................... 42

Self-efficacy ....................................................................... 43

Research Model ............................................................................. 44

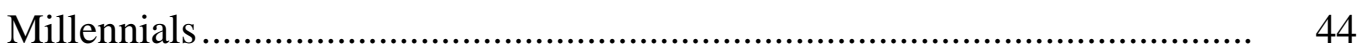

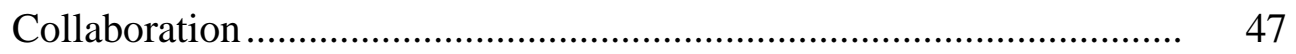

Frequent Feedback ......................................................................... 48

Technology ............................................................................ 49

Customization.............................................................................. 51

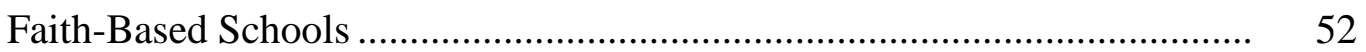

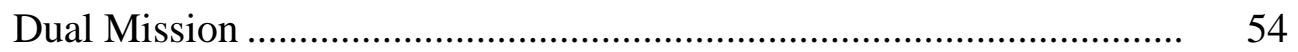

Certification Requirements ............................................................. 54

Labor Unions ............................................................................ 56

Faith-based Schools and Millennials................................................... 57

Summary .................................................................................. 58

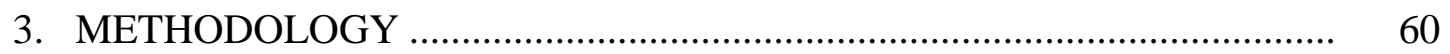

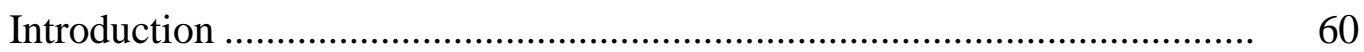

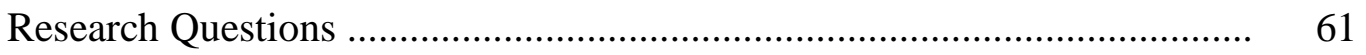

Research Design ............................................................................ 61

Population and Sample ...................................................................... 62

Context of Participants ...................................................................... 62

Selection of Participants .................................................................... 63

Instrumentation ........................................................................... 64

Survey Design .............................................................................. 64

Review of Existing Instruments ......................................................... 64

Content Validation ............................................................................ 65

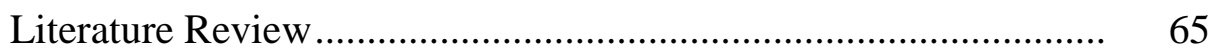

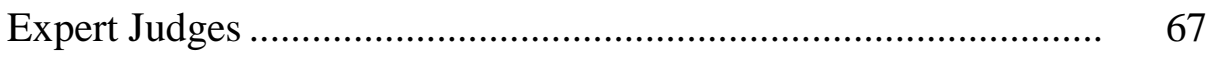

Addition of Demographic Information .......................................... 70

Length of Survey ...................................................................... 71

Negative Measures ………………………………................. 71

Additions ............................................................................ 72

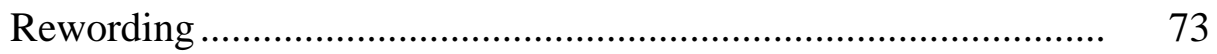

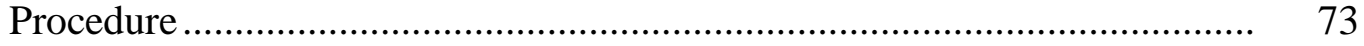

Treatment of Data ............................................................................. 
Ethics and Confidentiality .................................................................

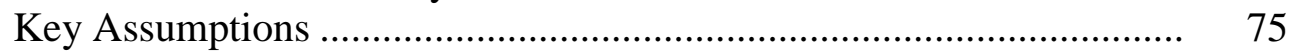

Data Analysis.............................................................................. $\quad 77$

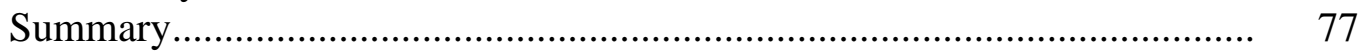

4. RESEARCH FINDINGS ………………………................................ 79

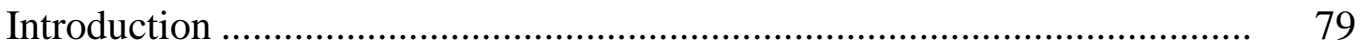

Description of Sample ......................................................................... $\quad 79$

Data Analysis Procedures.................................................................... 82

Exploratory Factor Analysis ...................................................................... 83

Test of Assumptions ............................................................................ 83

Extraction Procedures ......................................................................... 83

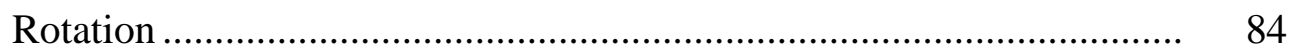

Number of Meaningful Factors Extracted............................................ 84

Description of the Five Factors ........................................................... 87

Factor 1: Collaborative Practice.................................................. 88

Factor 2: Institutional Support …………………………............ 88

Factor 3: Activity Content and Coherence...................................... 89

Factor 4: Teacher Beliefs ............................................................. 89

Factor 5: Teacher Self-Efficacy ................................................. 90

Internal Consistency Reliability ......................................................... $\quad 90$

Summary of EFA Findings ............................................................. 91

Research Question \#1 ………………................................................ 91

Time Spent ............................................................................. 92

Types of Professional Learning........................................................... $\quad 92$

Research Question \#2 ………………….......................................... 95

Research Question \#3 …………………............................................... 99

Descriptive Results ....................................................................... 100

Multiple Linear Regression ............................................................ 106

Time Spent ..................................................................... 107

Types of Professional Learning .................................................... 108

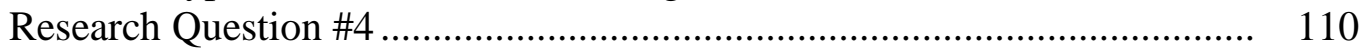

Descriptive Results ...................................................................... 110

Multiple Linear Regression .............................................................. 114

Time Spent ……............................................................ 115

Types of Professional Learning ..................................................... 117

Summary of Major Findings .................................................................. 120

5. DISCUSSION, CONCLUSIONS, AND RECOMMENDATIONS................ 123

Purpose of the Study ........................................................................... 123

Research Methodology ……………………………………................ 123

Summary of the Literature..................................................................... 124

Discussion of the Findings ……………………….............................. 125

Research Question \#1 …….............................................................. 127 
Research Question \#2 ............................................................. 130

Research Question \#3 ........................................................................ 134

Research Question \#4 .................................................................. 139

Recommendations for Practice ............................................................... 142

Recommendation 1: Meeting Millennial Needs................................ 142

Recommendation 2: Increased Collaboration ................................. 144

Recommendation 3: Job-Embedded Learning ................................ 145

Recommendation 4: Institutional Support......................................... 146

Recommendations for Further Research ............................................. 148

Appendix

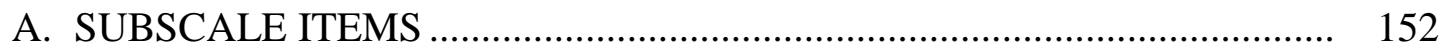

B. INSTRUCTION TO JUDGES AND SURVEY FOR FEEDBACK ............. 158

C. CONTENT VALIDITY INDEX AND SUMMARY OF COMMENTS ....... 166

D. FINAL DRAFT OF INSTRUMENT ..................................................... 178

E. SUMMARY OF SURVEY RESPONSES ............................................... 197

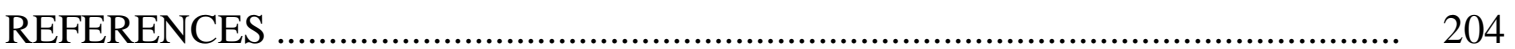

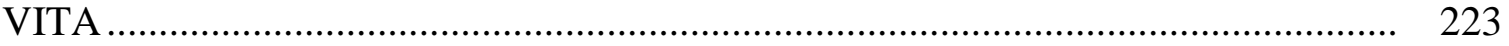




\section{LIST OF TABLES}

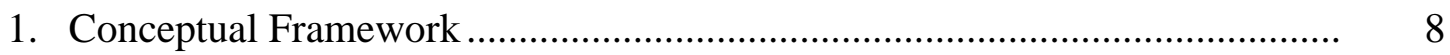

2. Summary of K-12 School Statistics, NAD of SDAs ....................................... 53

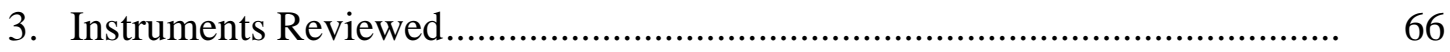

4. Teacher Professional Learning: Conceptual and Operational Definitions

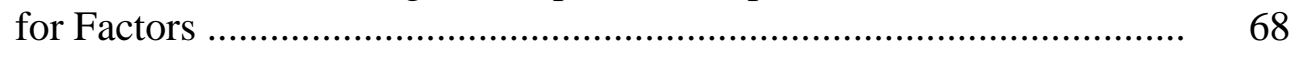

5. Descriptive Statistics: Population versus Sample ............................................ 80

6. Participant Demographics: Millennials and Non-Millennials ........................... 81

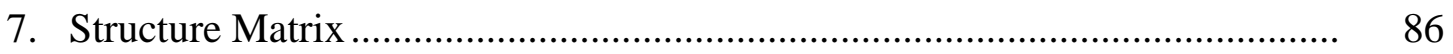

8. Internal Reliability of Factors ………………………................................... 90

9. Time and Variety in Types of Professional Learning Participation ................ 93

10. Professional Learning Participation by Type ………………………………... 94

11. Professional Learning Participation by Popularity (Face-to-Face and

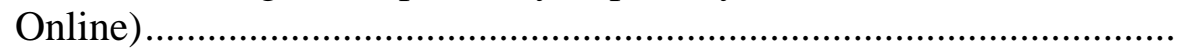

12. Time and Variety in Types of Professional Learning Participation: A Comparison of Millennials and Non-Millennials................................ 96

13. Professional Learning Participation by Type: A Comparison of Millennials and Non-Millennials

14. Professional Learning Participation by Popularity: A Comparison of Millennials and Non-Millennials ...........................................................

15. "I would be more involved if . . .": A Comparison of Millennials and Non-Millennials 100

16. Descriptive Statistics for Factors .. 
17. Descriptive Statistics for Factor 1: Collaborative Practice

102

18. Descriptive Statistics for Factor 2: Institutional Support 103

19. Descriptive Statistics for Factor 3: Activity Content/Coherence. 104

20. Descriptive Statistics for Factor 4: Teacher Beliefs 105

21. Descriptive Statistics for Factor 5: Teacher Self-Efficacy 105

22. MLR Descriptive Statistics: Time Spent in Professional Learning 107

23. MLR Results: Five Factors on Time Spent on Professional Learning 108

24. MLR Descriptive Statistics: Types of Professional Learning 109

25. MLR Results: Five Factors on Types of Professional Learning 110

26. Independent Sample T-Test Results

27. Summary of Responses: A Comparison of Millennials and Non-Millennials

28. MLR Descriptive Statistics: Time Spent in Professional Learning (Millennials) 116

29. MLR Descriptive Statistics: Time Spent in Professional Learning (Non-Millennials)

30. MLR Results: Time Spent in Professional Learning (Millennials)

31. MLR Results: Time Spent in Professional Learning (Non-Millennials) .. 118

32. MLR Descriptive Statistics: Types of Professional Learning (Millennials)....

33. MLR Descriptive Statistics: Types of Professional Learning (NonMillennials)

34. MLR Results: Types of Professional Learning (Millennials)

35. MLR Results: Types of Professional Learning (Non-Millennials) 120

36. Summary of All Survey Responses 196 


\section{LIST OF ILLUSTRATIONS}

1. Framework for Studying Teacher Professional Learning........................ 45

2. Timeline for Survey Distribution........................................................... 


\section{LIST OF ABBREVIATIONS}

ACSI Association of Christian Schools International

EFA Exploratory factor analysis

GMM Guam-Micronesia Mission

KMO Kaiser-Meyer-Olkin Measure of Sampling Adequacy

MLR Multiple linear regression

NAD North American Division

NAIS National Association of Independent Schools

NSDC National Staff Development Council

OECD Organisation for Economic Co-operation and Development

PAF Principal Axis Factoring

SDA Seventh-day Adventist

SPSS Statistical Package for the Social Sciences

STEM Science, Technology, Engineering, Mathematics

TALIS Teaching and Learning International Survey

TPD Teacher professional development 


\section{ACKNOWLEDGMENTS}

Truly no man or woman is an island, and I am indebted to so many individuals.

To my bosses and colleagues at the Seventh-day Adventist Church in Canada office who planted the seed and watered it along the way, thank you. And to my colleagues across the NAD, who continue to inspire and challenge me, and who model all that's best about Adventist education, thank you. I am blessed to work in an environment that encourages and supports ongoing professional learning.

To my advisors and professors at both the University of Calgary and Andrews University who laid a solid foundation for research and who were liberal in their affirmation and support, thank you. Special thanks to Dr. Eugene Kowch (U of C) and to my Andrews' dissertation committee_-Dr. Janet Ledesma, Dr. Jimmy Kijai, and Dr. Bordes Henry Saturné—who went above and beyond in providing advice, critique, and constant support, sometimes at odd hours and in the middle of thunderstorms. Your prayers along the journey, Dr. Ledesma, have also meant so much.

And most important of all,

To my much-loved family_ husband Peter and son Jonathan-who generously and genuinely supplied patience, encouragement, love, and never-ending support through what often seemed like a never-ending process. You are my greatest blessings. It's your turn now! 


\section{CHAPTER 1}

\section{INTRODUCTION}

\section{Background of the Problem}

For decades, educational experts have asserted that the most influential factor on school improvement and student achievement is the teacher (Archibald, Coggshall, Croft, \& Goe, 2011; Hargreaves \& Fullan, 2012; Lortie, 1975/2002, Sikes, 1992; Wiliam, 2016). "Teachers are the ultimate arbiters of change," asserts Hargreaves (2009), and "the classroom door is the gateway to implementation or the drawbridge that holds it at bay" (p. 28). When it comes to school improvement, Barber and Mourshed (2007) assert that "the quality of an education system cannot exceed the quality of its teachers" (p. 16). The key to school improvement and increased student achievement, then, is to increase teacher quality, and there is general agreement that teacher professional learning is the critical element for improving that quality (Desimone, 2009; Fullan \& Hargreaves, 1992; Goldschmidt \& Phelps, 2010; Murray \& Zoul, 2015).

The first step in any kind of school improvement, according to Fullan (2007), is the recognition that every teacher must be learning every day (p. 153). Recent research makes it clear that a one-size-fits-all approach to such learning is not effective in improving instructional practice or increasing student achievement (Harris \& Mucijs, 2005; Mitchell \& Sackney, 2011). Rather, to be effective, professional learning opportunities for teachers must be sustained over time, collaborative, embedded in active 
practice, coherent, and focused on content. Such learning must also consider the uniqueness of the teachers themselves and the contexts in which they work.

Professional learning as used in this context refers to a wide range of experiences, both formal and informal, which classroom teachers use to transform current beliefs and practices into improved practice for the purpose of increasing student learning. Though research has helped to provide a clear picture of what effective professional learning should look like, much of the professional learning opportunities available to teachers today has been found to be ineffective in improving instruction (Borko, 2004; Darling-

Hammond, Wei, Andree, Richardson, \& Orphanos, 2009).

\section{Rationale}

Elmore (2002) asserts that though there is still much to learn about teacher professional learning, there exists a huge gap between what we already know we should do and what we are actually doing. He focuses on the principle of "reciprocity of accountability," insisting that "for every increment of performance I require of you, I have a responsibility to provide you with the additional capacity to produce that performance" (p. 89). In an age of accountability, he insists that such accountability must be reciprocal and that systems must take responsibility for building teacher capacity.

More recently, Wiliam and Leahy (2014) echoed this view by suggesting that support and accountability can be thought of as "two sides of the same coin" (p. 15).

The rationale for this study rests on this "reciprocity of accountability." It emanates from my desire to better understand current professional learning practices in the Seventh-day Adventist (SDA) school system and the factors that impact it. As educational leaders in this system who acknowledge teachers as the key to increasing 
student learning, we must be intentional in providing opportunities for meaningful and ongoing learning for our teachers. By assessing the factors that impact professional learning for teachers in the K-12 schools of the North American Division (NAD) of SDAs, with special attention to the differences between millennial and non-millennial teachers, areas for improvement can be identified and later addressed.

Of special interest is our newest cohort of teachers, most members of a generation commonly referred to as millennials or Generation Y. Research shows that this group tends to bring expectations for ongoing learning to the workplace that are often at odds with the expectations of their colleagues and employers, most of whom are members of older generations (Clandinin et al., 2012; Coggshall, Ott, Behrstock, \& Lasagna, 2010; Donnison, 2007; Johnson, 2004; Martin \& Tulgan, 2006; McCrindle, 2006; Oblinger, 2010). These gaps may present challenges in school settings that, if not addressed, may have a negative impact on the ongoing professional growth of these teachers and their subsequent retention in schools or even in the teaching profession.

As denominations struggle to keep millennials in the church, faith-based schools, like the SDA school system, may also be increasingly challenged to retain millennial teachers, especially if their professional learning needs and expectations are not met. Desimone, Porter, Garet, Yoon, and Birman (2002) suggest that "an increased emphasis on the importance of strategic, systematic planning for professional development may encourage both districts and schools to focus efforts on high-quality professional development” (p. 105). By studying current realities, educational leaders will be better equipped to plan for future system needs. 


\section{Statement of the Problem}

To improve practice and build capacity, teachers need professional learning experiences that align with their real learning needs and their unique contexts (Fullan, 2016; Lieberman, 1995). Research studies have found that the professional learning opportunities available for most teachers in public school systems do not meet these criteria (Darling-Hammond et al., 2009), but data is needed regarding the professional learning opportunities available in faith-based school systems. In addition, data is needed regarding the specific expectations for ongoing learning that beginning teachers, primarily millennials, bring to faith-based schools. Because the ongoing professional learning of teachers is critical to school improvement, educational leaders in these systems must understand the factors impacting professional learning practice in order to both improve instruction and build teacher capacity.

\section{Purpose of the Study}

This research study, with its focus on the professional learning practices of educators in the SDA school system, will help to fill the research gap concerning both faith-based schools and millennial teachers. This study explores the factors impacting the professional learning practices of teachers in the SDA school system in North America. The data generated provides educational leaders with the information they need to begin to align professional learning policies and practices with research-based principles and to thus create a culture of continual improvement.

\section{Research Questions}

This research study seeks to answer the following research questions: 
1. What are the professional learning practices of K-12 educators in the SDA school system in North America?

2. To what extent do differences exist in professional learning practices between millennial and non-millennial educators?

3. What factors influence these professional learning practices?

4. To what extent do differences exist in the factors that impact the professional learning practices of millennial and non-millennial educators?

\section{Theoretical Framework}

Wright (2008) notes that "we cannot do research without theory" and that "theory shapes how we identify a research problem and then how we frame the research that will address it" (pp. 1-2). This research study is shaped by an underlying social constructivist philosophy. The emphasis on the context of the learner, specifically the practicing teacher, is grounded in a constructivist approach to learning. In Noddings' (2012) words, "knowledge is not the result of passive reception ... knowers actively construct their own knowledge" (p. 127). Important in this process are social interactions with others and reflective inquiry where individuals collaborate with others while engaging their own contexts to shape their learning and to make meaning. This socio-constructivist framework underlies the research questions and methods of this study.

Complexity thinking also underlies the approach for this research. Complex systems are "not fixed and clearly defined, but are subject to ongoing co-adaptations" (Davis \& Sumara, 2006, p. 11). Learning is not linear; it is a complex process. "Most learning occurs through experimentation and error," Elmore (2002) states, "not through a straight linear process" (p. 11). When the unique characteristics of millennials and the 
dual mission (academics and faith) of faith-based school systems are considered, the complexity increases.

In addition, "a learner is a complex unity that is capable of adapting itself to the sorts of new and diverse circumstances that an active agent is likely to encounter in a dynamic world" (Davis \& Sumara, 2006, p. 14). Opfer and Pedder (2011) suggest that "teacher learning becomes hard to define by aggregation and generalities because the nature of learning depends on the uniqueness of the context, person, and so on" (p. 379). Complexity thinking, then, provides "an important and appropriate attitude for educators and educational researchers" (Davis \& Sumara, 2006, p. xi). And for this research study.

Complexity theory also underlies the orientation toward change needed for ongoing professional learning: individuals may be required to reevaluate previous beliefs and to let go of previously learned ideas (Hammerness, Darling-Hammond, \& Bransford., 2005; Opfer \& Penner, 2011; Timperley \& Alton-Lee, 2008). The dissonance or disequilibrium between new information and existing beliefs, which serves as the trigger for new learning, is commonly recognized as a characteristic of complex systems (Opfer \& Pedder, 2011). In other words, “complex systems need to be off balance to move forward" (Opfer \& Pedder, 2011, p. 393).

Recognizing the complex nature of learning in general, and of the ongoing professional learning of teachers in particular, this study does not seek to find a causeand-effect relationship. Rather, it seeks only to describe what is in an effort to better understand what might be. It is only the first step — an important first step —in addressing the challenge of providing effective professional learning opportunities for teachers, especially those in faith-based school systems. 


\section{Conceptual Framework}

According to Bloomberg and Volpe (2008), a conceptual framework provides the scaffolding for a research study, a "working tool consisting of categories that emanate from the literature" (p. 58). In developing the conceptual framework for this study, the complex nature of learning and the interplay of three subsystems that influence that learning (Opfer \& Pedder, 2011) were considered, as were the characteristics of millennials as found in the literature with a focus on those traits with the most potential for impacting the professional learning practices of millennial teachers ( Coggshall et al., 2011). The complex interaction of learning activity, school, and teacher elements in professional learning, as well as the found preferences and practices of both millennial and non-millennial teachers, were examined to consider how learning choices are shaped by all factors. Table 1 provides an overview of the key theories and theorists that frame this study, describing how these will be applied to each of the research questions.

\section{Significance of the Study}

Twenty-five years ago, Little (1992) insisted that local staff development was needed to prepare teachers for local circumstances. Culture, working conditions, and expectations differ from school to school, and these differences are likely to be even more pronounced in faith-based schools which have distinctive missions and mandates. DeMonte (2013) emphasizes that different teachers may need different supports or types of learning to improve their practice since "what works in one school might not work in another" (p. 3). This study provides new knowledge about the professional learning of teachers in SDA schools from a system perspective, examining the factors that impact the professional learning practices of educators. The knowledge generated from this 
Table 1

Conceptual Framework

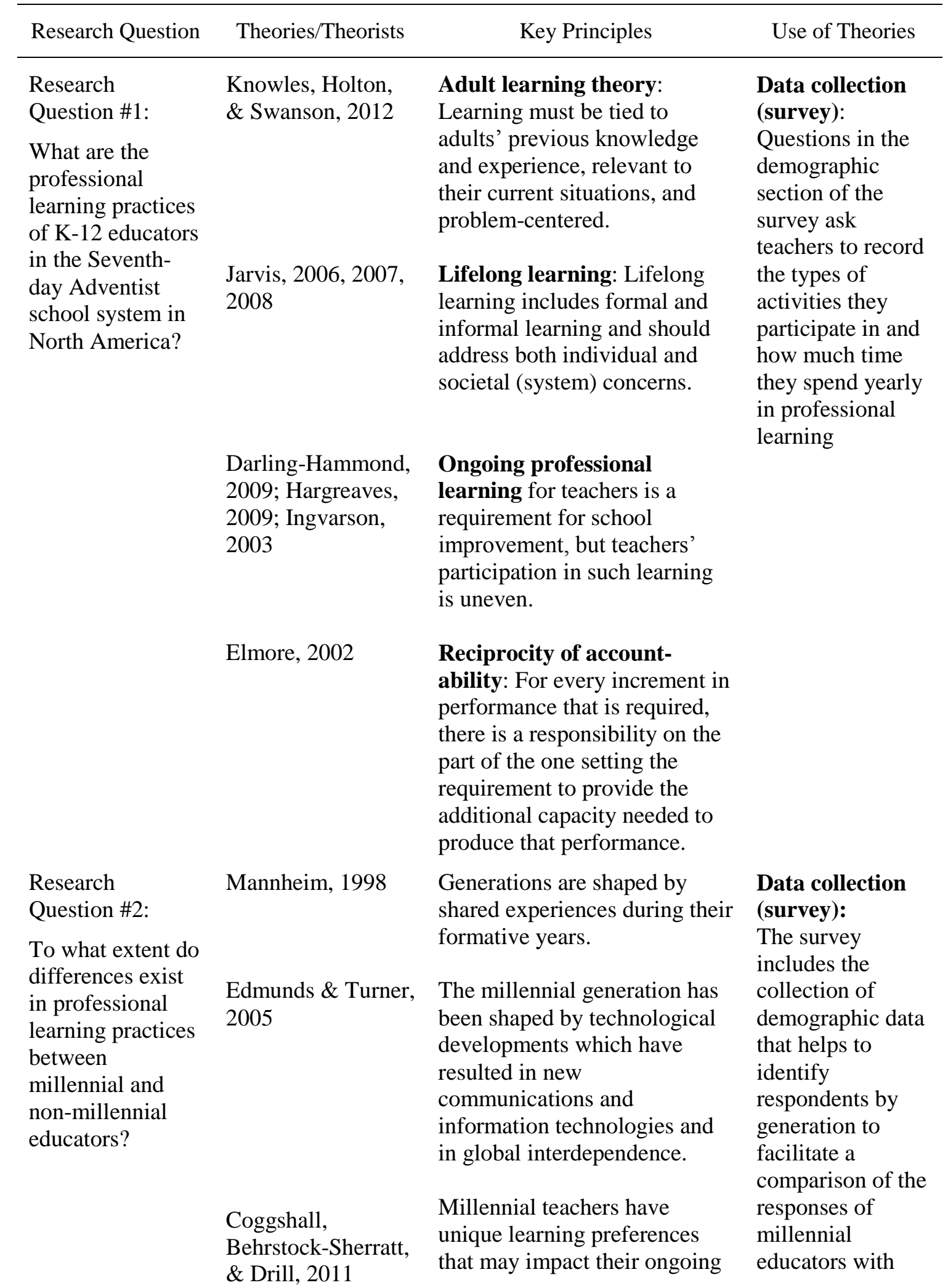




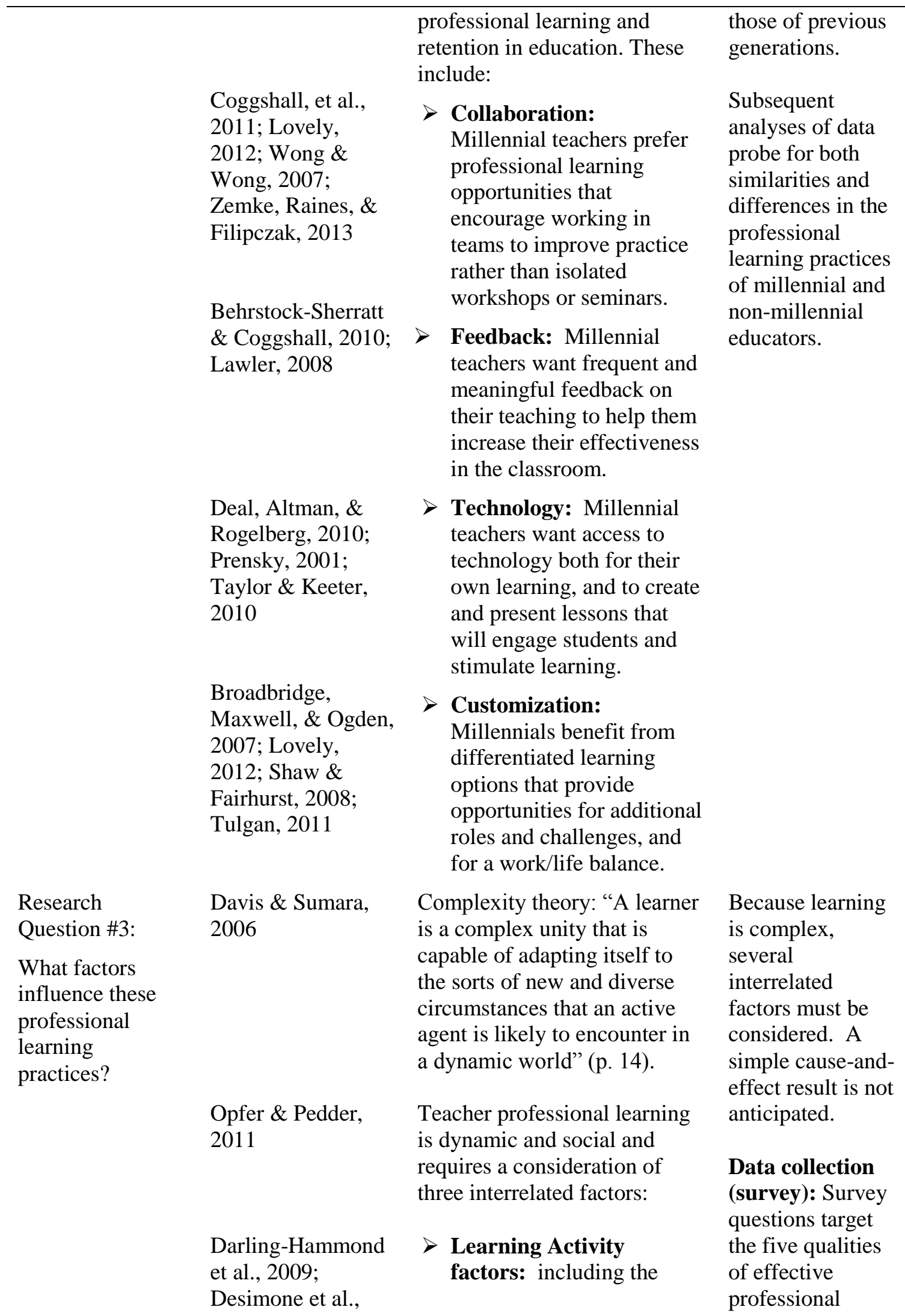




\begin{tabular}{|c|c|c|c|}
\hline & $\begin{array}{l}\text { Fullan, 2006, 2011a } \\
\text { Mitchell \& } \\
\text { Sackney, 2011; } \\
\text { Opfer \& Pedder, } \\
\text { 2011; Schön, 1995 }\end{array}$ & $\begin{aligned} &>\text { School factors: including } \\
&>\quad \text { institutional structures } \\
& \text { and supports } \\
&> \text { expectations regarding } \\
& \text { learning } \\
&> \text { incentives } \\
&> \text { accountability } \\
& \text { protocols } \\
&> \text { the underlying culture } \\
& \text { of teaching/learning }\end{aligned}$ & $\begin{array}{l}\text { learning activities, } \\
\text { as found in the } \\
\text { literature review, } \\
\text { asking to what } \\
\text { extent they are } \\
\text { active, coherent, } \\
\text { sustained, } \\
\text { collaborative, and } \\
\text { focused on } \\
\text { content. } \\
\text { Subsequent } \\
\text { analyses of data } \\
\text { probe how } \\
\text { professional } \\
\text { learning practices } \\
\text { have been shaped } \\
\text { by these factors. }\end{array}$ \\
\hline \multirow{3}{*}{$\begin{array}{l}\text { Research } \\
\text { Question \#4: } \\
\text { To what extent do } \\
\text { differences exist } \\
\text { in the factors that } \\
\text { impact the } \\
\text { professional } \\
\text { learning practices } \\
\text { of millennial and } \\
\text { non-millennial } \\
\text { educators? }\end{array}$} & $\begin{array}{l}\text { Bandura, 1993; } \\
\text { Hawley \& Valli, } \\
\text { 1999; Ingvarson, } \\
\text { 2003; Lortie, } \\
\text { 1975/2002; Opfer } \\
\text { \& Pedder, 2011; } \\
\text { Timperley \& } \\
\text { Alton-Lee, } 2008\end{array}$ & $\begin{array}{l}>\text { Teacher factors: } \\
\text { including individual } \\
\text { teachers' } \\
>\text { prior education and } \\
\text { experience } \\
>\text { beliefs about learning } \\
>\text { purposes for } \\
>\text { participating } \\
>\text { self-efficacy }\end{array}$ & \\
\hline & \multirow[t]{2}{*}{$\begin{array}{l}\text { Coggshall et al., } \\
\text { 2010; Coggshall et } \\
\text { al., } 2011\end{array}$} & $\begin{array}{l}\text { Given the unique } \\
\text { characteristics of millennials, } \\
\text { the factors that impact the } \\
\text { professional learning practices } \\
\text { of millennial teachers may be } \\
\text { different from those that } \\
\text { impact non-millennial } \\
\text { teachers. } \\
>\text { Learning Activity } \\
\text { factors: Use of } \\
\text { technology may be more } \\
\text { critical for millennials. } \\
\text { School factors: } \\
\text { Millennials may expect } \\
\text { more feedback and support } \\
\text { for ongoing learning. }\end{array}$ & $\begin{array}{l}\text { Data collection } \\
\text { (survey): } \\
\text { The survey } \\
\text { includes the } \\
\text { collection of } \\
\text { demographic data } \\
\text { that helped to } \\
\text { identify } \\
\text { respondents by } \\
\text { generation to } \\
\text { facilitate a } \\
\text { comparison of the } \\
\text { responses of } \\
\text { millennial and } \\
\text { non-millennial } \\
\text { educators. }\end{array}$ \\
\hline & & $\begin{array}{l}\text { Teacher factors: } \\
\text { Millennials may expect a }\end{array}$ & $\begin{array}{l}\text { Subsequent } \\
\text { analyses of data } \\
\text { probed for }\end{array}$ \\
\hline
\end{tabular}


more customized approach to learning with more opportunities for collaboration. both similarities and differences in the factors that impact millennial and nonmillennial educators.

Note: Throughout this study, the term "professional learning" (as opposed to "professional development" or "inservice training") is used, in keeping with the growing recognition that previous terms implied a deficit rather than a recognition that ongoing learning is expected in complex professions like teaching (Easton, 2008). Opfer and Pedder (2011) state that "development" reinforces a focus on "individual programs, activities, or individual teachers ... at the expense of context and the situatedness of teacher learning" (pp. 396-7). Murray and Zoul (2015) add that the terms "developed" and "trained" are "just a bit off-target and almost contrary to our mission of ensuring high levels of learning for all students and staff" (p. 8). Calvert (2016) also prefers "learning" because "it recognizes teachers as agents of their growth and emphasizes that learning is an experience driven largely by the learner" (p. 4).

inquiry offers new insights into the professional learning of teachers in faith-based systems in general, some of which may be unique to religious schools, and these insights in turn can help to inform policy and practice in such systems.

Faith-based school settings offer a unique context for exploring the professional learning of teachers. Often small, many rural, with limited resources and the complexity of a dual mission (education and faith), such schools are particularly vulnerable to retention challenges and often struggle to meet the complex learning needs of their teachers (Finn, Swezey, \& Warren, 2010). Though research has identified key characteristics of effective professional learning in general, the practices of teachers in faith-based school systems are not well understood and have been understudied (Grace, 2003; Neuzil, 2010; Van Pelt, Sikkink, Pennings, \& Seel, 2012). The few studies that have been done in faith-based schools do not consider millennial differences (Ezzeldine, 2004; Finn et al., 2010; Headley, 2003; Montoro, 2012; Murray, 2010). 
The principal benefactors of this research are the educational leaders and policymakers in the SDA school system who can consider the research results in their ongoing efforts to build teacher capacity and transform instructional practice. Leaders in other faith-based school systems may also benefit, as may classroom teachers in these systems if the data is used to create professional learning opportunities and plans which result in more deliberate practice that increases student learning.

This research is significant because it focuses primarily on an understudied population: educators, with a special emphasis on millennial educators, in the context of faith-based schools. Gerald Grace (2003) observes that faith-based school systems are often reticent to participate in such research, in part because such investigations risk results which may be of some concern to faith proponents. He argues, however, that faith-based schooling systems are growing in importance internationally and that this creates a need for more systematic research. "To combat ignorance and prejudice about how different forms of faith-based schooling actually operate in the contemporary world, systematic inquiry is necessary" (Grace, 2003, p. 160). This study contributes to such inquiry.

Researchers predict that by 2020 , millennials will make up $44 \%$ of the U.S. workforce (Behrstock-Sherratt \& Coggshall, 2010, p. 29). These teachers place an increased value on "personal development and continuous learning" (Shaw \& Fairhurst, 2008, p. 367) which provides an opportunity for school leaders to strengthen professional learning experiences for all educators as increasing numbers of millennial teachers enter the work force. By better understanding the factors that impact the professional learning of educators, school leaders can work together with teachers to provide relevant 
professional growth opportunities that will result in an increase in the quality of instruction and in the subsequent learning of students.

\section{Key Terms and Definitions}

Baby Boomers: The generation of individuals born between 1945 and 1964 (exact dates differ among sources), “called 'Boomers' because of the boom in their births between 1946 and 1965” (Wey Smola \& Sutton, 2002, p. 364).

Conference: Smaller administrative units within each of the nine union conferences in the NAD of SDAs. There are 58 conferences within the NAD; the NAD is one of 13 divisions in the world church.

Faith-based schools: Schools established and maintained by a religious organization. Many are also provincially or state accredited. Faith-based schools may also be referred to as denominational schools, religious schools, parochial schools, or church schools. They may be included under broader groups of non-government schools including independent schools, alternative schools, and private schools. "A faith-based school or school program is operationalized as schools or authorities that publicly selfidentify themselves as religious, openly affiliate with a religious group, or are run by, or exclusively serve, a religious group or society" (Hiemstra \& Brink, 2006, p. 1158).

Generation: Traditionally used to refer to the average time span between parents and the birth of their offspring. The more contemporary use of the word draws on Mannheim's sociological view of generations as "people of roughly the same age whose shared experience significantly distinguishes them from contemporaries in other age groups" (Spitzer, 1973, p. 1354). 
Generation X: The generation of individuals born between 1965 and 1979 (exact dates differ among sources).

Generation $Y$ : Another term for the millennial generation, those born between 1980 and 2000 (exact dates differ among sources).

Job-embedded learning: Learning that occurs while engaging in one's daily work. It includes learning by doing, reflecting on experiences, discovering new insights, and sharing with colleagues.

Lifelong learning: “. . . the combination of processes throughout a lifetime whereby the whole person-body (genetic, physical and biological) and mind (knowledge, skills, attitudes, values, emotions, beliefs and senses)—experiences social situations, the perceived content of which is then transformed cognitively, emotively or practically (or through any combination) and integrated into the individual person's biography resulting in a continually changing (or more experienced) person" (Jarvis, 2007, p. 1).

Mentoring: “. . . the personal guidance provided, usually by seasoned veterans, to beginning teachers" (Ingersoll \& Strong, 2011, p. 203).

Millennials: The generation of individuals generally thought to be born between 1980 and 2000 (exact dates differ among sources) who are typically regarded as immersed in digital technologies. Other common names for this generation include Generation Y, Echo Boomers, the Net or Internet Generation. According to Howe \& Strauss (2000), millennials is the term preferred by individuals in this generation.

New teachers: For the purpose of this study, teachers who have five years or less experience teaching in an elementary or high school classroom. 
Professional learning: A new way of looking at continued professional growth for teachers, as opposed to training or development; this approach focuses more on adult and lifelong learning theories. It is "more than a series of training workshops, institutes, meetings, and inservice days. It is a process of learning how to put knowledge into practice through engagement in practice within a community of practitioners" (Schlager \& Fusco, 2003, p. 205). Referred to by some as Continuing Professional Learning (Green \& Whitsed, 2013).

Professional learning communities: "Groups of teachers and administrators who collaborate to improve their practice" (Mindich \& Lieberman, 2012, p. ii).

Self-efficacy: "A belief that what one does makes a difference" (Loucks-Horsley et al., 1987).

Seventh-day Adventist (SDA) system of education: "The fourth largest Protestant denominational system of schools in the United States" and the second largest nongovernmental, faith-based school system in the world, second only to the Catholic system (Burton, 2012, p. 189). The SDA Church in North America operates over 800 elementary and secondary schools and 15 institutions of higher education including a medical school (Trim, 2015).

Teacher agency: "In the context of professional learning, teacher agency is the capacity of teachers to act purposefully and constructively to direct their professional growth and contribute to the growth of their colleagues" (Calvert, 2016, p. 4).

Traditional professional development: “. . one-shot workshops on programs and processes that have been developed outside the educators' context or of 'feel-good' talks by educational experts who expound their ideas on the lecture circuit" (Mitchell \& 
Sackney, 2011, p. 45). Examples include "reading research reports, listening to speeches, or attending workshops" (Hargreaves \& Shirley, 2009, p. 99).

Traditionalists: The generation of individuals born between 1925 and 1944 (exact dates differ among sources). Sometimes referred to as "Builders."

Union: Administratively, the SDA Church in the NAD is divided into nine union conferences whose territory includes a grouping of states or, in the case of Canada, an entire country.

\section{Limitations}

This cross-sectional study is limited by time and space, essentially capturing a snapshot of the participants' perceptions at this point in their experiences, recognizing that these perceptions may change as time passes and these teachers mature in their teaching and life experiences. The study is also limited in terms of its generalizability to the total population of teachers and of millennial teachers. Though it is expected that individuals share generational characteristics, it is also anticipated that the faith factor in those who choose to teach in faith-based school systems may impact their perceptions and behaviors. Subsequent research with other groups of participants will further any understanding gained by this particular study.

It is important to remember that the results derived from this study are based on self-reported data from teachers and school leaders. As such, it reflects their perceptions and beliefs but, like all self-reported data, is subjective in nature and shaped by their personal and school contexts. Such information provides valuable insight into how stated policies are carried out in practice which can subsequently be used to strengthen both policy and practice. 
Better understanding of the professional learning needs of all teachers, especially millennial teachers who will soon make up the majority of practicing classroom teachers, is an obligation of educational leaders. In this process, it is important to recognize that the real test of the effectiveness of professional learning is its impact on student learning. Determining whether or not the professional learning provided by the schools and experienced by the teachers has been effective in increasing student achievement is outside the scope of this study. By focusing on current practice, however, this study helps to identify potential gaps that may exist between teachers and school leaders and perhaps, between generations.

In the Project on the Next Generation of Teachers, researchers from the Harvard Graduate School of Education concluded that more research was needed about "the next generation of teachers entering schools today" (Johnson, 2004, p. 6). This study contributes to this body of research but is limited to teachers in one faith-based school system.

\section{Delimitation}

In the broadest sense, this study addresses the population of educators in faithbased schools across Canada and the United States. However, the vast diversity of this population in terms of the faiths represented, the locations of these schools, and the numbers of teachers employed presents a monumental undertaking. Therefore, the sample for this study has been delimited to one school system: the SDA school system in North America. This group provides a confined sample that facilitated the collection of data. It is understood that the results of the study are not generalizable to the general population. 


\section{Overview of the Research Methodology}

The research questions of this study, which focus on the professional learning practices of teachers, have been addressed using a descriptive quantitative research design. Descriptive research is "a type of quantitative research that involves making careful descriptions of educational phenomena" (Gall, Gall, \& Borg, 2007, p. 300). This study describes the current state of teacher professional learning practices in the SDA school system and the factors that impact it. The underlying intent is to describe what currently is because, as Gall et al. (2007) observe, "unless researchers first generate an accurate description of an educational phenomenon as it exists, they lack a firm basis for explaining or changing it” (p. 301).

The target population selected for this quantitative study is the population of K-12 teachers and their administrators (primarily principals and superintendents) in the NAD of the SDA school system (primarily Canada and the United States), selected to provide as complete a picture as possible of the policies and practices for professional learning in the system. Data collection was accomplished using a researcher-designed survey that was administered online using Survey Monkey ${ }^{\mathrm{TM}}$. Section I of the survey contained specific questions designed to assess factors that impact educators' professional learning practice, and Section II collected demographic information about participants' educational and teaching backgrounds, their current employment, their teaching certification, their school contexts, and their recent participation in professional learning.

\section{Summary}

Research suggests that to be effective, professional learning for teachers must consider the complex interplay of teacher, school, and activity factors, including what has 
been identified as the unique learning preferences of millennials, the newest teachers in the system. Studying professional learning in context is, therefore, important, but few studies have focused on teachers, especially millennial teachers, in the context of faith-

based schools. By assessing the factors that contribute to the alignment of current policies and practices in the SDA school system with research-based practices for teacher professional learning, the results of this study can be used to assist school leaders in their efforts to provide learning opportunities that will improve instructional practice and increase student learning. Using a quantitative survey, this study provides a description of the professional learning of teachers in the SDA school system using data collected from K-12 teachers and administrators across the NAD.

\section{Organization of the Study}

Chapter 2 presents a critical review of the relevant literature with a focus on the activity, school, and teacher factors that impact professional learning. The somewhat unique characteristics of millennial learners and faith-based schools are also reviewed. Chapter 3 provides a description of the methods used in the study, as well as a rationale for their selection. It includes participant selection, instrument design, and collection methods. Chapter 4 summarizes the research findings, assessing the findings in terms of the research questions asked. Chapter 5 summarizes the study, including conclusions reached from the analysis of the data. It goes on to discuss implications and recommendations for practice and for future research. 


\section{CHAPTER 2}

\section{LITERATURE REVIEW}

\section{Introduction}

To provide a background and context for the study, a critical review of the relevant peer-reviewed literature on research and theory is needed. Much has been written about the professional learning of teachers through the past several decades. The purpose of this literature review is to summarize that body of research, to identify possible gaps in the current research, and to describe how this study helps to fill one of those gaps. First, the literature on professional learning for teachers is summarized. Then, literature on generational theory and the millennial generation in particular is reviewed. Finally, literature on faith-based schools is considered, to provide a background for the selected context of this study. This critical literature review includes both quantitative and qualitative studies and theoretical essays.

\section{Professional Learning}

The importance of continued professional learning for teachers is a relatively new study first recognized about sixty years ago. Teacher education programs were formalized under the auspices of universities in the early 1900s, but Lortie (1975/2002) points out that it was not until the 1950s that the need for the upgrading of the quality of public education was recognized. Only in the late 1960s was serious attention given to 
the need for ongoing learning for classroom teachers that went beyond their initial teacher education programs (Rudduck, 1992).

In 1970, the National Staff Development Council (NSDC; now known as

Learning Forward) was established in the United States to address issues surrounding the continuing education of practicing teachers and school administrators. Since then, increasing attention has been given to what has, at various times, been referred to as teacher professional development (TPD), in-service training, or continuing education. During the 70 s and 80 s, teachers were encouraged to participate in various opportunities for ongoing learning, mostly in the form of workshops, conferences, and "PD days." But as Little (1992) points out, teachers had a "fundamentally passive role . . typically serving as audience for performances staged by others" (p. 177). Professional development was something done to teachers rather than by teachers.

As early as 1975, Lortie (1975/2002) observed that “"in-service training” in American public schools rarely rises above a superficial level" and that "school systems generally have not assumed responsibility for systematically improving staff performance through serious training programs" (p. 234). More than 30 years later, researchers continue to draw similar conclusions. Studies done in the past two decades have generated evidence which suggests that, in spite of the time and money spent, the professional learning activities offered to practicing teachers are having little effect on instructional practice or on student achievement (Darling-Hammond \& McLaughlin, 1999; Darling-Hammond et al., 2009; DeMonte, 2013; Mockler, 2005). It is worth noting that few of these studies have been done in faith-based school systems, and it is generally 
agreed that the professional learning practices of teachers in faith-based school systems are not well understood (Grace, 2003; Neuzil, 2010; Van Pelt et al., 2012).

Until the past decade or so, most studies relied on reports of teacher participation, satisfaction, and attitudes. Garet, Porter, Desimone, Birman, and Yoon (2001) observe that "despite the size of the body of literature, ... relatively little systematic research has been conducted on the effects of professional development on improvements in teaching or on student outcomes" (p. 917). Review of the literature also reveals that there is little consistency in the methods used, the features studied, and the results obtained. Recognizing that "randomized trials of specific professional development programs" have not contributed much to an understanding of effective professional learning (Hill, Beisiegel, \& Jacob, 2013, p. 476) and that past research has often relied on teacher selfreports, some scholars proposed a more structured approach to research on professional learning (Borko, 2004; Hill et al., 2013).

By 2009, Desimone had concluded that enough empirical evidence was available to support a "core set of features" that constitute effective professional development and have been shown to be associated with changes in knowledge and practice: content focus, active learning, coherence, duration, and collective participation. These features are consistent with those identified by many researchers (Garet, Birman, Porter, Desimone, \& Herman, 1999; Hawley \& Valli, 1999; Penuel, Fishman, Yamaguchi, \& Gallagher, 2007) and professional organizations (Archibald et al., 2011; Learning Forward, 2011; Organisation for Economic Co-operation and Development [OECD], 2005). But this focus on the activities alone does not provide a complete picture of the complex factors 
that impact teachers' participation in and the effectiveness of ongoing teacher professional learning.

In 2011, Opfer and Pedder proposed a core conceptual framework that could be used for future research on professional learning. They argued that teacher learning cannot be assessed by considering the activities alone but that learning is a complex system that must take into account three overlapping factors: the professional learning activity itself (the focus of Desimone's 2009 proposal), the school context, and the teacher. Though there is some variation in terms, several scholars have drawn similar conclusions through the years (Fullan \& Hargreaves, 1992; Guskey \& Sparks, 2002; Ingvarson, 2003; Kwakman, 2003; Loucks-Horsley et al., 1987; Mitchell \& Sackney, 2011). This model forms the framework for this study.

\section{Activity Factors}

\section{Active Learning}

Research evidence suggests that professional learning that is active (e.g., observing expert teachers, reviewing student work with colleagues, practicing what has been learned, participating in professional learning communities) is more effective than passive learning (e.g., lectures, "sit-and-get" professional development) (Archibald et al., 2011; Buczynski \& Hansen, 2010; Desimone et al., 2002; Garet et al., 2001; Lieberman, 1995; Loucks-Horsley et al., 1987). Active learning can take many different forms that can be adapted to accommodate teacher learning styles and school contexts. LoucksHorsley, Stiles, Mundry, Love, and Hewson (2010) offer a variety of strategies which, though specifically geared to science and math teachers, can be combined and adapted for use in other subject areas. These strategies, which involve hands-on learning and 
collaboration with colleagues, would also provide the flexibility and collaboration that millennial teachers look for.

A challenge for schools is that active learning activities tend to take more time than passive learning activities and often require common time for teachers to meet together which is sometimes difficult to schedule. Researchers have found, however, that the added time commitment pays off in increased teacher engagement and more sustained instructional change (Knapp, 2003; Mindich \& Lieberman, 2012). Buczynski and Hansen (2010) found that some of the greatest student achievement gains occurred at sites where multiple teachers were actively involved in professional development.

\section{Coherence}

Desimone (2009) describes two aspects of coherence: the extent to which teacher learning is consistent with teachers' knowledge and beliefs, and the consistency of professional learning activities with school and district reforms and policies. Garet et al. (2001) found that when professional learning activities aligned with their other learning experiences and with standards and school policies, teachers were more likely to change their practice. Initiatives that may require a rethinking of previously held beliefs need to focus on the connection between beliefs and practice, taking advantage of opportunities for collaboration with colleagues.

Studies by Garet and his colleagues (2001) demonstrated that when groups of teachers from the same school, subject, or grade participate collectively in professional learning, not only is that learning more coherent and active, but it also leads to improvements in teacher knowledge and skill and changes in instructional practice (p. 936). Lieberman (1995) suggests that one reason for this may be that learning new ideas that 
are unrelated to one's context and goals "have a hard time competing with the dailiness of work-even when teachers are excited about and committed to them" (p. 593).

\section{Duration}

A number of studies have suggested that the duration of professional learning activities is related to the likelihood of teacher instructional change and the lasting impact of that change. The length of time required will vary depending on the purpose for and type of learning, the individual teacher, and the school context. Yoon, Duncan, Lee, Scarloss, and Shapley (2007) found that studies where teachers had more than 14 hours of professional development showed "a positive and significant effect on student achievement" (p. 12). Desimone (2011) recommends that professional learning be spread over a semester with a minimum of 20 hours of contact time (p. 69). Darling-Hammond et al. (2009) reviewed a year-long program designed to promote inquiry-based science instruction and found that teachers who participated in 80 or more hours of professional learning were "significantly more likely to put the given teaching strategies into practice" (p. 9).

In addition to the activity itself, Loucks-Horsley et al. (1987) recommend at least a year of follow-up support to provide the practice and reinforcement needed so that teachers do not resort to their old, familiar patterns. The general consensus is that professional learning that is sustained over time is associated with stronger impact on teachers and on student learning (Darling-Hammond et al., 2009; Garet et al., 2001). This kind of sustained effort can only be accomplished if professional learning is jobembedded and collaborative. 


\section{Collective Participation}

Opportunities for collaboration provide professional learning opportunities that researchers agree are strongly associated with improved instructional practice and student success (Desimone, 2009, 2011; Desimone et al., 2002; Garet et al., 2001; Hargreaves \& Shirley, 2009). Garet et al. (2001) suggest some possible reasons for why this is so. Working together encourages ongoing discussion of the issues that arise from professional learning experiences. Teachers from the same school can support each other in the implementation and integration of their new knowledge into the school program, and can discuss student needs across classes and grade levels. Collective participation also contributes to the creation of a shared school culture of professional learning. When surveyed, teachers expressed that the opportunity to collaborate with other teachers was among the learning strategies that they valued most (Andrews, Gilbert, \& Martin, 2006; Clandinin et al., 2012; Coggshall et al., 2010).

After reviewing teacher research, policy studies, and evaluations of system reform programs, Schlager and Fusco (2003) concluded that the "conceptual thread" that runs through all of them is the benefit of communities of practice (p. 206). The emphasis in such communities is collaboration, shared decision-making, and collective responsibility. In a study of TPD programs in Chicago, Smylie, Allensworth, Greenberg, Harris, and Luppescu (2001) found that the benefits of such communities include motivation, direction, accountability, intellectual stimulation, feedback to deepen learning and promote instructional change, safety in challenging past assumptions, support for risktaking, and a willingness to experiment with new ideas (p. 50). 
A collaborative approach to professional learning is not without its challenges, however. Teaching has traditionally occurred behind closed doors. Teachers teach, for the most part, in isolation, often in the same way that they were taught (Lortie, 1975/2002). Though efforts are being made to facilitate professional collaboration, not much has changed since 1990 when Lieberman and Miller observed, "With so many people engaged in so common a mission in so compact a space and time, it is perhaps the greatest irony — and the greatest tragedy of teaching - that so much is carried on in selfimposed and professionally sanctioned isolation" (as cited in Mitchell \& Sackney, 2011, p. 6). A related concern for educational leaders and policymakers is the difficulty of building collaboration time into school schedules.

Additionally, the most recent report from the NSDC multi-year study concludes that though the research supports the effectiveness of such learning communities, there is little research on the process of beginning and sustaining them (Mindich \& Lieberman, 2012). While there is consensus that leadership is important and that successful communities require a supportive school culture and trust, it is not clear what school leaders must do to create, support, and monitor the changes in practice that are required. What is clear, however, is that to be effective, professional learning must occur in collaborative communities that are committed to continuous improvement.

The 2009 NSDC Status Report describes several examples of effective collaborative learning opportunities for teachers which are being implemented in some of the world's highest achieving countries. In Japan, teachers work together to create model lessons, observing each other and working collaboratively to improve. Teachers identify the areas of need, and meetings occur after classes end but during the teachers' regular 
work day (Darling-Hammond et al., 2009, p. 16). Similarly, teachers in Singapore work together in "Teacher's Network learning circles" to identify and solve classroom problems. This practice allows them to be "reflective practitioners" and to create knowledge rather than simply passing on learned knowledge (p. 17). In Australia, the government sponsors the "Quality Teacher Programme" which develops professional learning networks for teachers and provides funds for locally-developed initiatives and school-based research (p. 18).

The NSDC Report concludes with this key point: "The diversity of approaches indicates that schools can shape professional learning to best fit their circumstances and teacher and student learning needs" (Darling-Hammond et al., 2009, p. 18). This is an important factor to consider when it comes to faith-based schools. These school systems, which are smaller in size and often struggle to access adequate financial and personnel resources, face a particular challenge when it comes to providing ongoing professional learning for their teachers. Variations in practice are anticipated and encouraged.

\section{Content Focus}

Frequent reference is made in the literature to three types of content that teachers need and which the most effective professional learning activities include: knowledge of the subject matter, knowledge of instructional practices, and knowledge of how students learn subject content (Archibald et al., 2011; Borko, 2004; Desimone, 2009; Little, 1999; Loucks-Horsley et al., 2010). Buczynski and Hansen's (2010) case study of middle school teachers in two urban school districts found that student achievement in science "improved or at least maintained in classrooms of teachers who had been actively 
enriching their content knowledge and inquiry practices through professional development" (p. 604).

In addition to subject knowledge, teachers must understand how students learn the content, how content builds across grade levels, and what misconceptions students may have as they learn the content (Garet et al., 2001; Loucks-Horsley et al., 2010). These are important areas of focus for professional learning, and teachers need opportunities that are appropriate for their own contexts and career stages (Huberman, 1995). Scholars agree that much of this content must be learned in the context of practice (Schlager \& Fusco, 2003). Knowledge is applied situationally; it is made meaningful by the context (Cervero, 1992; Mott, 2000). Referred to as "situated cognition" (Brown, Collins, and Duguid, 1989), “situated knowledge” (Cervero, 1992), or "sticky knowledge” (Frost, 2012), the key point is that for knowledge to be meaningful, it must be learned in practice.

\section{School Factors}

School contexts have not always been considered when the effectiveness of teacher professional learning programs have been evaluated. Efforts to reform education in the past have usually consisted of top-down initiatives, dictated by governments or districts. Harris and Muijs (2005) observe that when these reforms failed, the blame usually fell on classroom teachers who were accused of being unable or unwilling to effectively implement the directive. What was rarely questioned was "whether the reform or innovation was appropriate to the needs of particular schools, in particular contexts, with particular types of pupils" (p. 130). The reality is that teachers are often absorbed with daily tasks and maintenance in an effort to reach all students, and the circumstances 
of teaching rarely "give back in the time needed for planning, constructive discussion, thinking, and just plain rewards and time for composure" (Fullan, 2007, p. 132). These school factors must be considered when planning professional learning programs.

The school context includes the "collective practices or norms of practice that exist in the school, and the collective capacity to realize shared learning goals" (Opfer \& Pedder, 2011, p. 384). Context cannot be ignored because the setting and working conditions shape how professionals assess new information and influence both the information that they seek to learn and what information they may choose to incorporate into their professional practice (Daley, 2000, p. 38). Planners and providers of professional learning need to consider, not only the context itself, but also, as Penuel et al. (2007) point out, “the program's demands on teachers and how those demands can be met within their contexts" (p. 952).

Ball and Cohen (1999) insist that to be effective, professional learning must give teachers opportunities to learn about practice in practice. "To propose otherwise would be like expecting someone to learn to swim on a sidewalk" (p. 12). School-level factors that impact professional learning include school structures and support, school standards and expectations for ongoing learning, incentives, accountability protocols, and the overall school culture.

\section{Structures and Support}

Much continues to be written about the need for new structures that build professional learning into the school day and that permit ongoing collaboration among teams of teachers focused on school-specific data and student achievement (Calvert, 2016; Darling-Hammond et al., 2009; Desimone, 2009; Fullan, 2016; Hunzicker, 2011; 
Knapp, 2003). Teachers participate more frequently and report greater change in their knowledge and skills when professional learning activities are supported by their employing organizations.

Growing numbers of empirical and theoretical research studies have focused on a restructuring of school programs including the role of instructional leadership within schools, some on the role of the principal (Johnson \& Kardos, 2005; Leithwood, 1992; Mindich \& Lieberman, 2012), and many on the growing popularity of teacher leaders and the effectiveness of professional learning communities within departments and schools (Beatty, 2000; Carroll, Fulton, \& Doerr, 2010; Coburn, 2001; Lieberman \& PointerMace, 2010; Mitchell \& Sackney, 2011).

In addition to structures, schools can provide support for professional learning in the form of time, financial assistance, and programs/personnel designated to support instruction, particularly for new teachers. Archibald et al. (2011) found that instructional improvement is more likely to happen when schools and school districts build time into the school day for teachers to meet on a regular basis to discuss student work, instructional strategies, and student performance. In this way, professional learning becomes part of a teacher's daily work rather than an "add-on" that takes place outside of school hours.

\section{Standards and Expectations}

Closely connected to school structures are the standards and expectations in place that promote ongoing professional learning for teachers. Pre-service teacher education programs cannot prepare teachers for everything they will face in their specific contexts or for future changes and initiatives that are impossible to predict. Many districts have 
consequently included an expectation for ongoing learning, either as part of the requirements for maintaining a teacher certificate or license, or as a criterion for performance evaluation.

Schools that maintain high expectations for ongoing professional learning for their teachers generally produce teachers who are more actively involved in ongoing professional learning. The NSDC found that by 2009 , more than 40 states had adopted standards which required "effective professional development for all educators accountable for results in student learning" (Darling-Hammond et al., 2009, p. 3). Such expectations demonstrate the importance that the district places on continual learning, but it is only one of several factors that must be considered in making professional learning effective for improving practice.

\section{Incentives}

Hill (2009) observes that, though many would like to think that every teacher is naturally a "continual learner," the reality is that "teachers, like other professionals, respond to the incentives, norms, and models that surround them" (p. 454). Financial incentives, like the possibility of increased salary for additional qualifications, are one type of incentive. Equally, if not more, important is that teachers perceive the benefit of participating. Incentives may also include alternate career structures that provide opportunities for instructional leadership other than becoming a principal (e.g., coach, mentor, consultant, content specialist). Coggshall et al. (2010) found that a lack of advancement opportunities was one of the reasons teachers, particularly millennials, gave for leaving the profession. Bassett, Grossman, Allan, Allen, Cook, and Olney (2013) noted that "While many professions are moving from vertical career ladders to horizontal 
career lattices, allowing for more flexibility in advancement and in work situations, teaching is still locked into the one or two leaders per school model, in which a teacher must choose to leave the classroom in order to serve in a leadership role" (p. 7).

All four of the "professionally active" states selected for study by a Stanford University research team provided a range of supports and incentives for their teachers (Jaquith, Mindich, Wei, \& Darling-Hammond, 2010). One of the conclusions of the 2005 OECD report was that teacher development should be viewed as a continuum, and that most countries need to focus more on providing incentives and resources for ongoing teacher professional learning (p. 132).

\section{Accountability}

Jaquith et al. (2010) found that one of the key factors in implementing an effective professional development plan is a system-wide policy and system-wide practices that "ensure accountability and monitor professional development" (p. 4). To be

effective, professional learning must have responsibility measures built in so that teachers apply new learning to the classroom in ways that benefit student learning.

Mandated certification and renewal requirements do not in themselves guarantee effective professional learning for teachers. Researchers have suggested that internal accountability_ “a commitment to self-evaluation on the part of everyone, and to acting on evidence in order to improve" - is more important than external accountability (Alexandrou \& Swaffield, 2012, p. 161). Elmore (2002) agrees: "In the panoply of rewards and sanctions that attach to accountability systems, the most powerful incentives reside in the face-to-face relationships among people in the organization, not in external systems" (p. 31). In other words, "collective responsibility supersedes administrative 
accountability" (Hargreaves, 2009, p. 34). Professional learning communities provide opportunities for that kind of internal accountability.

Jaquith et al. (2010) advocate the development of multiple accountability systems. Included may be local professional learning committees that are responsible for creating plans aligned with district standards but based on local needs. Another element may be individual professional growth plans for teachers which give educators an opportunity, not only to have a voice in their own learning, but also to evaluate the quality of the continuing education provided to "prevent it from becoming merely an exercise in accumulating credits and hours" (p. 6).

\section{Culture}

As important as these school factors are, however, the most critical factor is the learning culture of the school because, in many ways, it provides the foundation for all the others. Much has been written about the importance of addressing culture when considering organizational change (Burke, 2011; Fullan, 2006, 2011a; Leithwood, Jantzi, \& Steinbach, 1999; Schein, 2010; Schlechty, 2009). To be effective, change efforts, including new learning, must consider the underlying culture that includes the spoken and unspoken values and beliefs, attitudes, relationships, and perceptions that influence and shape how a school functions.

Researchers have described the kind of school culture that fosters professional learning in a number of ways. Many stress the importance of valuing and encouraging collaborative learning (Archibald et al., 2010; Avalos, 2011; Fullan, 2006; LoucksHorsley et al., 2010). Frost (2012) suggests a culture where "self-evaluation, innovation, and improvement are valued and operationalized" (p. 221). Hutchens (2000) emphasizes 
a commitment to learning and growing and developing into individuals who are adept at trying new ideas.

Ingvarson (2003) describes a school characterized by collective responsibility for student learning. Other descriptors of a positive school culture include norms of caring, respect, and collegiality (Knapp, 2003), an attitude of inquiry (Levine, 2002; Easton, 2008), and learning and development that "become as varied and engaging for teachers as they are supposed to be for students" (Lieberman, 1995, p. 593). Such cultures are built on professional trust and provide "a forum for reflection and honest feedback, for challenging disagreement and for accepting responsibility without assigning blame" (Lieberman \& Miller, 2008, p. 18).

All school stakeholders contribute to the culture of their school (Long et al., 2012), but school leaders play a critical role in establishing and maintaining a positive school culture that supports professional learning. "Professional cultures cannot therefore be simply implemented; rather, they have to be cultivated through leadership" (Frost, 2012, p. 222). Changing culture is much more difficult than changing policies or structures but, as Fullan (2006) points out, cultural change is the more important change. This is, in part, because "structural change that is not supported by cultural change will eventually be overwhelmed by the culture" (Schlechty, 1997, as cited in Loucks-Horsley et al., 2010, p. 136).

\section{Summary}

One-size-fits-all activities, including workshops and conferences, will not be effective in triggering sustained improvement unless they can be applied in context and are accompanied by an ongoing "process of inquiry and discussion through which the 
knowledge can be made relevant to the 'place' where it can be used" (Wideen, MeyerSmith, \& Moon, 1996, p. 201). Citing research by Borman (2005), Mitchell and Sackney (2011) conclude that most teachers "experience a disconnection between their professional development experiences and their day-to-day classroom experiences" ( $\mathrm{p}$. 36).

Schön's (1995) metaphor which compares the high ground of research-based theory and technique to the swampy lowlands of everyday messy and confusing practice is still relevant today: "The practitioner is confronted with a choice. Shall he remain on the high ground where he can solve relatively unimportant problems according to his standards of rigor, or shall he descend to the swamp of important problems where he cannot be rigorous in any way he knows how to describe?” (Schön, 1995, p. 28).

The "high ground" of research-based theory on which many professional workshops and seminars are based often emphasizes "best practice," decontextualized strategies that are purported to be effective for all teachers in all classrooms. As a more meaningful alternative to "best practice," Mitchell and Sackney (2011) recommend "informed practice" which, by taking into account the culture of the school community, is more likely to result in improved instruction and increased learning (p. 30; see also Harris $\&$ Muijs, 2005). Focusing on how technology can assist in this process, Wiske, Perkins, and Spicer (2006) assert that "a key challenge in professional education is promoting participants' commitment and capability to interpret and apply principles of effective practice in flexible ways tuned to their own practical circumstances" (p. 50).

Attention to school context is especially important for millennial teachers who have most recently transitioned from the "high ground" of their pre-service training to the 
"swamp" of everyday practice, and may need assistance in aligning their pedagogical knowledge with the prevailing structure and practice of their school settings. The 2005 OECD study observed that there are "major concerns about the limited connections between teacher education, teachers' professional development, and school needs" (p. 8). It goes on to suggest that new teachers will not reach their full potential unless their school settings offer them appropriate support and sufficient challenge and reward (OECD, 2005, p. 9). Hammerness et al. (2005) point out that these new teachers need additional support to interpret their experiences and expand their repertoires. School support systems for these teachers must ensure that professional learning addresses their individual needs specific to their unique contexts (Rebore \& Walmsley, 2010).

\section{Teacher Factors}

Just as every school setting is unique in terms of its characteristics and needs, every teacher is also unique in abilities and brings a unique set of skills and knowledge to the classroom. All teachers bring past experiences and beliefs, prior learning, and personal goals which impact the types and effectiveness of the professional learning they may participate in. Fullan and Hargreaves (1992) suggest that the teacher as person has been neglected in past efforts to provide teacher development: "Most approaches to staff development, for example, either treat all teachers as if they are the same (or should be the same), or stereotype teachers as innovators, resisters, and the like" (p. 5). An effective professional learning program gives consideration to various teacher factors, providing room for the same kind of individualized approach to learning based on individual needs that teachers are expected to provide for their students. 


\section{Prior Education and Experience}

Adult learning theory suggests that learning must be tied to adults' previous knowledge and experience, relevant to their current situation, and problem-centered rather than subject-centered (Knowles et al., 2012; Merriam, Caffarella, \& Baumgartner, 2007). Ingvarson (2003) found that professional learning programs that focused first on influencing teacher knowledge were more successful than those that promoted specific pedagogical practices. Programs that recognize teachers as knowledgeable professionals, not just "empty vessels waiting to be filled with the knowledge of staff developers" (Stoll, 1992, p. 105), will allow room for teacher choice and voice. This kind of professional learning builds capacity by assuming that teachers have a "wealth of information and professional knowledge upon which to build" (Mitchell \& Sackney, 2011, p. 50).

At the same time, teachers cannot be expected to know everything. Areas of weakness are anticipated and accepted. Mitchell and Sackney (2011) maintain that these "knowledge gaps" are both natural and desirable, "natural because they are always part of everyone's knowledge base, and desirable because they constitute areas for professional growth" (Mitchell \& Sackney, 2011, p. 50). At the same time, teachers must be respected and valued for their professional expertise. One-size-fits-all professional learning opportunities ignore what some teachers may already know. Starting with what they already know and do "opens them up to critique, to learning, and to expanding their repertoire" (Lieberman \& Pointer-Mace, 2010, p. 86). 


\section{Beliefs About Learning}

The effectiveness of professional learning rests, in part, on the knowledge and beliefs that teachers bring to the experience. Borko and Putnam (1995) assert that "it is through their existing knowledge and beliefs that teachers come to understand recommended new practices and activities. These understandings, in turn, determine how the instructional tools are actually used in their classrooms" (p. 59). Sometimes it may be necessary to give up or modify existing beliefs in order to accommodate the new learning. Knowing what to give up and what to keep is, according to Hammerness et al. (2005), "a big part of what it means to be a lifelong learner and an adaptive expert" (p. 363). This process is often challenging. Prior "entrenched" beliefs can actually interfere with the learning of new knowledge (Elmore, 2002, p. 17).

Some studies have suggested that teachers are more likely to adopt practices that align with their own beliefs and practices than they are to embrace those that contradict these personal realities (Thompson \& Zeuli, 1999). Lortie (1975/2002) posits that this is the result of the "apprenticeship-of-observation" period where, as students, teachers begin to develop attitudes and values toward teaching that serve as "an ally of continuity rather than of change" (p. 67). Timperley and Alton-Lee (2008) emphasize that teachers approach professional learning with "rich theories about how students learn, how best to teach them, and what constitutes desired content and outcomes" (p. 348-9). These authors go on to assert that attempts to build professional knowledge without acknowledging these prior beliefs fail to recognize the complexity of the situation. Frost (2012) observes that because change in practice may require a change in values and beliefs, it is not surprising that efforts to implement new instructional initiatives are often superficial and 
short-lived if they do not address the teachers' fundamental orientations to teaching and learning. New knowledge alone will not bring about lasting change.

Some researchers suggest that a change in belief must precede a change in practice (Fishman, Marx, Best, \& Tal, 2003; Frost, 2012; Tom, 1986). Others insist that beliefs change only after a change in practice provides evidence of improved student learning (Ball \& Cohen, 1999; Guskey, 1986). Elmore (2002) theorizes that "practice and values change in concert. Both are important and both should be the focus of new learning for teachers and administrators" (p. 18). More important than when a change in belief occurs, however, is the recognition that such a change is needed for any improvement in instructional practice to be sustained.

Timperley and Alton-Lee (2008) found that teachers seldom assumed that their beliefs about the subject or student learning needed to change. Rather, teachers entered professional learning activities already convinced of the kinds of knowledge that would be most relevant to their practice (p. 351). Lortie (1975/2002) points out that because teachers often internalize the practices of their own teachers, unless they are made aware of these preconceptions and internalizations, the learning of any new methods or strategies may be wasted. As Daley (2000) observed in his study of expert nurses, professionals must not only be able to recognize the connection between new knowledge and their experience, but also be willing to change their practice based on that learning.

When considering the teacher, therefore, Opfer and Pedder's (2011) model focuses on the "interaction and intersection of knowledge, beliefs, practices, and experiences that constitute a teacher's individual orientation to learning" (p. 388). It acknowledges that change can begin at any point in the process, focusing on the complex 
interconnections that exist between beliefs and practice rather than what needs to change first. Opfer and Pedder (2011) argue that not only is teaching influenced by beliefs, but the act of teaching itself leads to a modification of belief. This interaction of experience and belief determines the decisions teachers make regarding instruction and also what they are willing to learn.

To translate new knowledge into new beliefs and new practices, teachers need what Opfer and Pedder (2011) refer to as a "dissonance between personal expectations and sense of efficacy." It is this self-doubt, and playing with that doubt, that may trigger reflection and provide the motivation for teachers to learn something new (Wheatley, 2002). Classroom research by Cobb, Wood, and Yackel (1990) focused on the role of this “cognitive conflict” in creating opportunities to learn (p. 133). Referred to as “disjuncture" (Jarvis, 2006, p. 7), a "discrepancy" between new information and the existing pattern of thinking (Thompson \& Zeuli, 1999, p. 347), "cognitive dissonance" (Loucks-Horsley et al., 2010, p. 58), and, by complexity theorists, as the "edge of chaos" (Opfer \& Pedder, 2011, p. 388), it is this disequilibrium between current beliefs and new knowledge that provides the "catalyst to seek new learning and change" (Opfer \& Pedder, 2011, p. 389).

In other words, before teachers can adopt new beliefs or new practices, they may need to unlearn or reconstruct previously held beliefs. If the discrepancy is too large, teachers may reject the new ideas as irrelevant to their context (Coburn, 2001; Timperley \& Alton-Lee, 2008). Effective professional learning activities create that dissonance between current and new practice while providing opportunity for teachers to reflect on their deeply held beliefs and examine the impact of various forms of instruction on 
student learning and achievement (Jaquith et al., 2010). This kind of learning is not merely additive, but transformative (Thompson \& Zeuli, 1999).

\section{Purposes}

Teachers participate in ongoing professional learning for various reasons: external requirements for maintaining teacher certification, salary increases, promotions, mandated top-down curriculum initiatives, a felt need to acquire new knowledge and skills. The most effective motivator, however, is the desire to positively impact student learning. This is the "moral imperative" that Fullan $(2003,2011 b)$ sees as success for all students and an education that improves lives and societies.

The key to enacting this moral purpose is continuous learning (Fullan, 2006). Referring to Peter Senge, a well-known authority on systems and organizational development, Fullan (1995) suggests that when we have a clear picture of our vision (what we want and what we are striving for) and our current reality (where we are in relation to where we want to be), only then will we feel the "creative tension" that is needed to motivate new learning. He stresses that school change happens at the teacher level, and that teachers will change only when they feel that creative tension (p. 256). "Teachers become believers," he later wrote, "(and their moral commitment and energy zooms) when they themselves experience and are part and parcel of significant new achievement" (Fullan, 2010, p. 63).

Knapp (2003) recognized that the classroom practices that result in improved student learning shape the effectiveness of professional learning, both the motivation for participating, and the take-aways that result from that participation. Teachers who are 
empowered to innovate in their classrooms for the purpose of improving student learning are more likely to experience the deep learning that results in improvement (Frost, 2012).

When creating policy and providing professional learning programs for schools, then, districts would do well to remember that, because schools are "ultimately in the business of educating students, not teachers," student learning should be the criteria for measuring the effectiveness of professional learning programs. The focus should be effectiveness rather than compliance (Darling-Hammond, 2009). This kind of meaningful learning happens through "deep engagement with other colleagues and with mentors in exploring, refining, and improving their practice" in an environment where "this not only can happen but is encouraged, rewarded, and pressed to happen" (Fullan, 2007, p. 55).

Teachers themselves have expressed that their greatest rewards come from reaching a student or groups of students. In her interviews with 50 new teachers in Massachusetts, Johnson (2004) found that most entered the profession because they were looking for meaningful work. Millennial teachers in particular seek a profession that makes a difference and promotes social justice (Coggins, Zuckerman, \& McKelvey, 2010). It is this purpose that results in the most effective professional learning.

\section{Self-efficacy}

A sense of efficacy - the belief that one can make a difference-is a powerful motivator for ongoing participation in professional learning. Effective professional learning, particularly that done in collaborative professional communities, increases teacher efficacy. Talbert and McLaughlin (2002) demonstrated that strong professional learning communities resulted in increased feelings of efficacy and professionalism. Teachers who see an increase in student engagement and learning as a result of 
professional learning experiences that meet their specific needs and expectations are in turn more motivated to participate in such learning on an ongoing basis. A good indicator of how effective a professional learning program is for teachers is whether or not their participation has helped to increase their self-efficacy and their confidence in their abilities as professionals.

\section{Research Model}

Unlike frameworks for designing and implementing professional learning (Learning Forward, 2011; Loucks-Horsley et al., 2010) or those designed to evaluate professional development programs (Guskey, 2000), Opfer and Pedder (2011) use complexity theory to generate a conceptual model intended to guide research focused on professional learning. Their model forms the basis for my conceptual framework (see Figure 1) which includes three subsystems (learning activity, teacher, and school) that interact in different ways to impact teacher learning. This framework facilitates a more holistic examination of professional learning by recognizing the importance of context and teacher factors in addition to activity factors.

\section{Millennials}

The current workforce is made up of members from four generations (Shaw \& Fairhurst, 2008). It has been estimated that in 2010, millennials made up at least $20 \%$ of practicing teachers and that, if the numbers continue to reflect the growing numbers of millennials in the general workforce, this number could grow to $44 \%$ by 2020 (Behrstock-Sherratt \& Coggshall, 2010). As school leaders plan professional learning for 


\section{EFFECTIVE PROFESSIONAL}

LEARNING

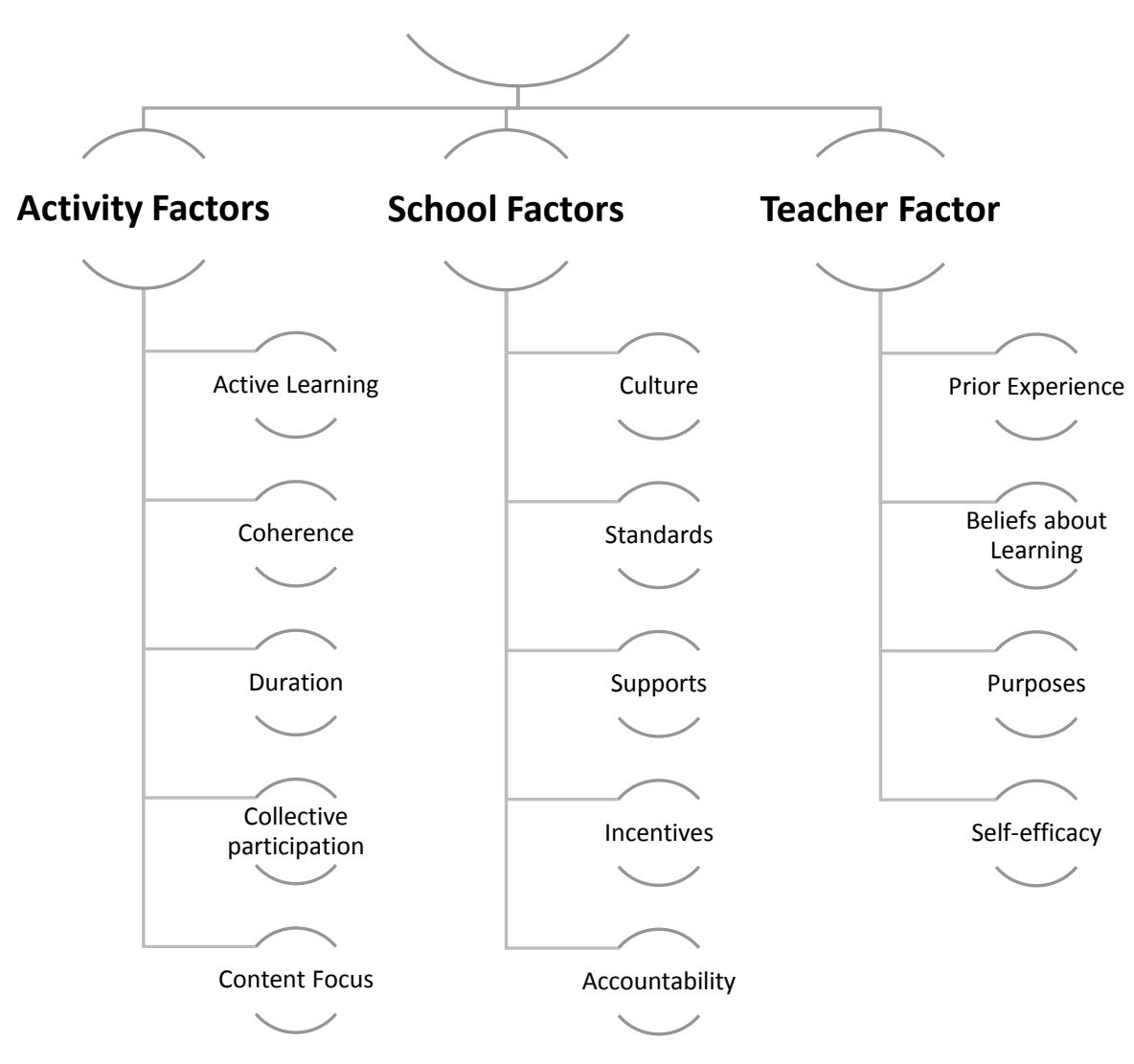

Figure 1. Framework for studying teacher professional learning

their teachers, it is important for them to consider the expectations and needs of this newest generation of teachers.

The millennial generation is often characterized by the value they place on advancing their skills and continuing to learn in the workplace (Lowe, Levitt, \& Wilson, 2008). "This rapidly changing world has," according to Jarvis (2007), "produced a situation where individuals are compelled to learn all the time in order to find their place 
in society" (p. 5). Unlike many of their predecessors, millennial workers often enter employment with an expectation for ongoing training and development.

Though ongoing learning may not be uncommon in the teaching profession, where educators have always been expected to keep up with the times and are frequently handed change initiatives to implement, millennials bring a somewhat different perspective to continuing education, even in school settings. Maybe, as Shaw and Fairhurst (2008) suggest, it is the value millennials place on education in general and on "personal development and continuous learning" (p. 367). Martin (2005) calls them the "education is cool" generation (p. 43). Even more important than salary are "meaningful learning opportunities," according to the millennial teachers surveyed by Learning Points Associates (Coggshall et al., 2011, p. 7). This desire for continual growth and improvement provides an opportunity for school leaders to strengthen professional learning experiences for all teachers as increasing numbers of millennials enter the classrooms.

It is important to remember that generational characteristics are generalizations and do not necessarily manifest themselves in all individual members of that generation. Some characteristics may be attributed to millennials because they are more common in their generation than in previous generations, even though not every, or at times even most, members will fit the description (Twenge, 2010). Millennials have been described by various authors as team-oriented, financially savvy, entitled, technology-immersed, connected, multi-taskers, and in need of frequent feedback (Coley, 2009; McCrindle, 2006; Pham, Bosak, Miyake, Case, \& Gil, 2010; Pham, Miyake, Case, \& Gil, 2008; Rebore \& Walmsley, 2010). 
Of all the traits consistently recorded in popular and practitioner literature as typical of millennials, Coggshall et al.'s (2011) study identified five key characteristics that impact the workplaces of teachers. Four of these characteristics have been selected as part of this literature review because of their potential impact on teacher professional learning and because they appear most frequently in peer-reviewed research with empirical evidence: (a) orientation toward collaboration, (b) desire for frequent feedback, (c) attitudes toward and use of technology, and (d) an expectation for customization which permits a work-life balance.

\section{Collaboration}

The Retaining Teacher Talent Study found that all teachers, not just millennials, welcome meaningful collaboration with colleagues (Coggshall et al., 2010). In contrast to many older teachers, however, millennials are "graduating from teacher preparation programs well-versed in the benefits of teamwork and collaboration" and "expect to work directly with their peers to make their schools better, not just next door to them" (Lovely, 2012, p. 57). According to Wong and Wong (2007), "to ask a Generation Y teacher to go solo in a networked world is writing that teacher's epitaph" ("Flying Solo," para. 5).

Howe and Strauss (2003) point out that changes in pedagogy and educational practice are often credited as the cause for the millennial generation's collaborative orientation (as cited in Donnison, 2007). "For Millennials, collaborative learning became as popular as independent study was for Baby Boomers or open classrooms for Gen Xers" (Zemke et al., 2013).

This orientation toward collaboration suggests that millennials may prefer professional learning opportunities that encourage working in teams to improve practice 
rather than isolated workshops or seminars which may or may not have relevance to their own contexts. Isolation and lack of support are frequently cited by new teachers as reasons for leaving the profession (Dauksas \& White, 2010; Ingersoll, 2003; Johnson \& Kardos, 2005).

Collaboration lessens that isolation and helps to improve the quality of instruction by adding diversity, by providing support for the implementation of new ideas, and by creating an ongoing professional community that will continue to seek ways to improve instruction. "Articulating and sharing practice knowledge, reflecting on one's practice, collaborating, and engaging in dialogue are desirable aims in and of themselves and are likely to lead to changes in the instruction of students" (Whitehouse, Breit, McCloskey, Ketelhut, \& Dede, 2006, p. 19). Coggshall et al. (2010) found that not only is there a strong connection between collaboration and increased student success, but also between collaboration and improved retention among new teachers (p. 16).

\section{Frequent Feedback}

Regular collaboration also provides opportunities for frequent and meaningful feedback, a strategy often cited as essential for the retention of millennials (Coggshall et al., 2011; Lowe et al., 2008; Martin, 2005; Meier \& Crocker, 2010; Mokoena, 2012). The Retaining Teacher Talent study describes the desired feedback as "sustained, constructive, and individualized," the kind of feedback intended to help teachers become more effective in their teaching practice (Coggshall et al., 2010, p. 13). Unlike many of their predecessors, millennial teachers in general do not prefer to teach behind a closed door which discourages regular dialogue among staff. "More than the generations of 
teachers before them, they value regular feedback on their performance" (BehrstockSherratt \& Coggshall, 2010, p. 30).

Lawler (2008) underlines the importance of personal feedback by suggesting that one strategy for successfully recruiting the highest quality millennials is to "promise them feedback about their strengths and weaknesses and how they are evaluated by the firm" (p. 16). Such a promise is often difficult to make for schools where "the evidence to date suggests that few principals have made the time and demonstrated the ability to provide high-quality instructional feedback to teachers" (Leithwood \& Louis, 2012, p. 6).

\section{Technology}

In 2001, Marc Prensky coined the now widely used term “digital natives" to describe millennials, and few have questioned the role that technology has played in shaping the newest generation of students and teachers. Prensky (2001) asserted that because of their interaction with technology, millennials think and process information differently from previous generations. Critics have pointed out that little empirical research has been done to support these claims, asserting as well that such a generalization neglects those who may not be as skilled or as interested in technology (Bennett, Maton, \& Kervin, 2008). Once again, it is important to remember that differences exist within as well as between generations, and that any descriptions of generational characteristics apply only to trends and not to every individual within a group.

Though technology has certainly impacted all generations to some extent, Deal et al. (2010) suggest that "technology use and comfort with technology is partially a result of age of exposure, which means it is essentially a function of generation rather than age 
or maturation level" (p. 197). Though differences may exist among millennials regarding their exposure to and use of various technologies, literature in the last decade provides some evidence that, compared to previous generations, millennials in general spend more time using the internet, accessing social networking sites, and communicating using cell phones and text messaging (Donnison, 2009; Hershatter \& Epstein, 2010; Taylor \& Keeter, 2010). This immersion in technology does not necessarily mean that millennials have a distinct learning style that makes more traditional professional learning strategies ineffective. The learning and application of new knowledge and skills is still most important (Oblinger, Oblinger, \& Lippincott, 2005); technology simply provides additional tools for accessing and producing knowledge.

Part of the reason that millennials are drawn to technology is that it gives them the flexibility to deal with tasks at their convenience (Hershatter \& Epstein, 2010; Richardson, 2011). The implications for the ongoing professional learning of teachers are clear. Various technologies can facilitate "just-in-time" professional learning that is easily accessible and allows all teachers to connect with the information they need at the times and in the places that work best for them.

Online professional learning opportunities have grown in response to this need for flexibility because they can be customized to fit teachers' busy schedules, provide access to resources not available locally, and deliver "real-time, ongoing, workembedded support" (Whitehouse et al., 2006, p. 13). Not only would tech-assisted options give teachers more choice in how to satisfy their individual professional learning needs, but technology could also facilitate interactive learning, encourage reflection as required for written responses, and provide the immediate feedback that millennials have 
come to expect (Dede, 2006; Dede, Eisenkraft, Frumin, \& Hartley, 2016; Richardson, 2011).

\section{Customization}

Several researchers have suggested that generic learning activities and single-path careers will not meet the needs of millennials (Broadbridge et al., 2007; Dede, 2005; Shaw \& Fairhurst, 2008; Tulgan, 2011). Millennial teachers expect the individualized learning for themselves that they are being asked to provide for their students. They expect learning opportunities that are related to their job assignment (Lovely, 2012) and that will help them to meet both their personal and their professional goals (Hershatter \& Epstein, 2010). The professional learning experiences that will engage millennials are customized and flexible (Shaw \& Fairhurst, 2008).

Referring to several studies, Tamir and de Kramer (2011) conclude that beginning teachers need at least three to five years to develop their teaching potential. Coggins et al. (2010) agree, stating that "the average teacher is likely to hit his or her stride by year 5" (p. 71). Ongoing professional learning and support that is geared to the individual needs of these millennials during this critical window in particular may provide what they need to develop this potential. In addition, a customized approach to professional learning allows millennials to maintain a balance between their work and their personal lives.

While many in previous generations craved higher salaries (Wey Smola \& Sutton, 2002), "making a lot of money tends to be less important to Generation $\mathrm{Y}$ than enjoying a full and balanced life" (Broadbridge et al., 2007, p. 535). Shaw and Fairhurst (2008) assert that "giving Millennials the workplace flexibility to live the lifestyle they want outside of work is no longer a 'perk' as it may have been seen by earlier generations. For 
Millennials it is a fundamental right" (p. 373). Hershatter and Epstein (2010) point out that most employees, regardless of their generation, want this kind of work-life balance, but "Millennials may have the confidence and conviction to demand it from their employers" (p. 219).

Johnson (2004) asserts that "school structures and practices forged in a bygone era are no longer adequate to support either teachers' development or students' learning” (p. 8). To attract and retain the next generation of teachers, she suggests, school leaders must first understand who they are. In theory, understanding the learning needs of this new generation of teachers should assist school leaders to better meet the needs of all teachers as they strive to improve teaching and learning.

\section{Faith-Based Schools}

In general, faith-based schools, regardless of denomination or affiliation, emphasize the religious dimension of education and the importance of a growing faith. This personal religious faith is an important motivator for teachers in faith-based school systems who usually receive lower salaries and fewer benefits than do teachers in public schools and do not, for the most part, belong to teacher unions with negotiated employment contracts (Farkas, Johnson, \& Foleno, 2000; Finn et al., 2010; Jeynes, 2012; Tamir \& de Kramer, 2011).

The SDA church operates "the fourth largest Protestant denominational system of schools in the United States" and the second largest non-governmental, faith-based school system in the world, second only to the Catholic system (Burton, 2012, p. 189). It includes almost 8,000 elementary to graduate schools around the world, and employs more than 90,000 teachers (Trim, 2015). In North America alone, the church operates 
over 800 elementary and secondary schools and 15 institutions of higher education including a medical school (Trim, 2015).

The growing bureaucracy associated with a growing system has brought with it the challenges of leadership and the management of change. Fluctuating economies and the secularization of society continue to chip away at enrollments in North America (see Table 2) and to challenge traditional approaches. Like educators in all school systems, Adventist educational leaders at all levels wrestle to maintain high standards while meeting each student's individual needs. Postmodern thought challenges fundamentalist conventions, and Adventist schools are faced, not only with the changes brought by a growing knowledge and technology society, but also with the challenge of ensuring that faith remains relevant, especially for the youth. Expected to teach faith and nurture spirituality, in addition to teaching academics, new teachers in the system, in particular, may require different types of support than teachers in non-faith systems and teachers of previous generations (Finn et al., 2010).

Table 2

Summary of K-12 School Statistics, NAD of SDAs

\begin{tabular}{lrrrrrrrr}
\hline & 2006 & 2007 & 2008 & 2009 & 2010 & 2011 & 2012 & 2013 \\
\hline $\begin{array}{l}\text { K-12 } \\
\text { Schools }\end{array}$ & 979 & 1009 & 946 & 864 & 848 & 838 & 830 & 839 \\
K-12 & 5,574 & 5,563 & 5,184 & 5,024 & 4,941 & 4,841 & 5,009 & 4,905 \\
Teachers & & & & & & & & \\
K-12 & 57,402 & 58,257 & 54,074 & 52,809 & 52,170 & 51,866 & 53,455 & 51,835 \\
Enrollment & & & & & & & & \\
\hline
\end{tabular}

Note. Data obtained from Trim (2015) 


\section{Dual Mission}

Finn et al. (2010) observe that "professional development within the Christian school community provides a unique challenge and opportunity in that the Christian school assumes a spiritual mission in addition to an academic one" (p. 10). Referring to this dual responsibility, Sullivan (2006) asserts that these teachers "are required to be bifocal in their aims and bilingual in the way they communicate-addressing both religious and professional concerns" (p. 938). Teachers are expected to learn the art and craft of teaching with the added responsibility of learning how to integrate faith with learning (Brock \& Chatlain, 2008).

Teacher education programs in Christian universities include this component. Not

all teachers in faith-based schools complete their pre-service training in Christian institutions, however. Professional learning opportunities may be needed to fill these gaps for these teachers, most of whom are members of the millennial generation, and to equip all teachers for a changing world.

\section{Certification Requirements}

Not all faith-based schools require teachers to be certified, but many do. The SDA school system in the NAD requires its teachers to be certified according to the requirements set out by the Division. Union conferences, through their offices of education, implement the policies set out by the Division. These policies are "essentially similar to those used by the states in certifying public school teachers. However, the standards also require basic coursework in religious studies to prepare a teacher not only for teaching the doctrines of the church but also its history and philosophy" (Furst, 2012). In many cases, the requirements to maintain a SDA Teaching Certificate are more 
demanding than maintaining state or provincial certificates, some of which require only the payment of annual dues.

Some conferences also require their teachers to meet state or provincial certification requirements. The funds available to support these and other kinds of professional learning are often limited in faith-based school systems, however (Neuzil, 2010). Jeynes (2012) reports that teachers in faith-based school systems usually earn about $70 \%$ of the salary earned by teachers in public systems. Stodolsky, Dorph, and Rosov (2008) suggest that such teachers may resist participating in professional learning activities that require time for which they are not being paid. Policies that mandate ongoing learning to maintain teaching certification may require additional attention to the policy provision of funding for that learning.

But mandated certification requirements do not in themselves guarantee professional learning for teachers. As Hirsch, Koppich, and Knapp (2001) point out, many states that require professional learning activities for license renewal simply require "clock hours" with little guidance or regulation of the quality or content of activities that will be recognized. "The deficiencies of such systems are all too obvious: Almost anything counts as 'professional development,' and there is little that brings it to bear on the improvement of professional practice” (Knapp, 2003, p. 142). Murray and Zoul (2015) agree: "When school leaders use seat time as the measurement tool, they're measuring the wrong end of the learner" (p. 3). In contrast, it is the time spent and the credits earned that really are, or should be, irrelevant. "The learning outcome is what matters most" (Murray \& Zoul, 2015, p. 37). 
The SDA school system, like those described above, requires professional learning activities for the renewal of its teaching certificates, stipulating the number of continuing education hours that must be completed, but paying little attention to the content or relevance of the activities in improving instruction (NAD, 2017). Jaquith et al. (2010) suggest that involving teachers in the process and including a means to evaluate the quality of the learning provided can prevent professional learning systems from becoming "merely an exercise in accumulating credits and hours" (p. 6). Wiliam (2014) goes even further, calling re-certification requirements "bureaucratic distractions" (p. 12). "We need to help teachers change habits rather than acquire new knowledge," he insists. Rather than seat hours or credits, we need teachers to make "a career-long commitment to the continuous improvement of classroom practice, and an agreement to develop in their practice in ways that are likely to improve outcomes for their students" (p. 13). This is the kind of learning described in the literature as most effective in bringing about sustained school improvement.

\section{Labor Unions}

The absence of labor unions in most faith-based schools may also have an impact on the professional learning practices of teachers. As Bangs and MacBeath (2012) suggest, teacher unions have the potential to influence policies that determine the opportunities and resources available for ongoing teacher professional learning. Coggshall et al. (2011) highlighted three case studies of successful teacher support systems, all of which involved the teachers' union as a "crucial partner in reform" (p. 31).

Without such a teacher-advocacy body, policies in faith-based school systems tend to be formulated by system-level educational leaders often without direct input from 
the teachers who are most impacted by these policies. Mitchell and Sackney (2011) note that teachers often resist participating in change efforts for which they have had no input and suggest that teacher resistance and reluctance "often signal a flaw in the system rather than a weakness in the individual" (p. 88). "They are required to change themselves and what they do to meet specifications laid down by policy makers who neither know them or the contexts in which they work" (Sikes, 1992, p. 36).

\section{Faith-based Schools and Millennials}

Research has also shown that millennials view faith somewhat differently than previous generations. Wuthnow (2007), for example, suggests that millennials' approach to religion is the same as their approach to life in general: they "tinker," choosing ideas and resources, refusing to rely on only one way of doing or believing (p. 13). Many millennials consider spirituality as something separate from religion, and as a result, fewer are choosing to be involved in their faith communities (Kinnaman, 2007, 2011; Rainer \& Rainer, 2008; Rebore \& Walmsley, 2010; Wuthnow, 2007). This may impact the numbers of millennial teachers who choose to teach in faith-based schools as well as the kinds of support those schools may need to provide to retain the ones that do.

Education has not been quick to respond to a changing world, continuing to operate in much the same way as it has for decades. Faith-based schools, with their rich histories and established traditions, may find change even more difficult. The research on millennials suggests that millennial teachers will not do well in such a conventional environment (Hurst \& Good, 2009). Either they will conform and lose their enthusiasm for teaching or they will leave to pursue a career that provides more opportunity for growth. Further research on the experiences of millennial teachers in these settings is 
needed to assist school leaders and policymakers in finding ways to capitalize on the talents and skills that millennials bring to their classrooms and to build cross-generational educational teams that can work together to fulfill the mission of these faith-based schools in the $21^{\text {st }}$ century.

Darling-Hammond et al. (2009) recommend that by examining professional learning opportunities available to teachers in a variety of contexts, education leaders and policymakers can begin the process of assessing system needs and considering how to best support teacher learning. By exploring the intersection between millennial characteristics, professional learning, and faith-based contexts, this study provides a better understanding of the complex reality in the SDA school system.

Faith-based school systems, including the SDA school system, are different from publicly-funded systems in ways that impact both policy and practice. These include differences in certification requirements for teachers, school size, available resources, and the role of labor unions. Policies in faith-based school systems need to reflect the realities of the school contexts and consider the present and prior experiences of the teachers in these systems. Data from such systems is needed to inform any change in policy.

\section{Summary}

The literature on professional learning for teachers supports the importance of considering adult learning theory and acknowledging the complexity of such learning. In short, current literature suggests three main factors that must be considered when conducting research on professional learning for teachers: the professional learning activity, which should be active, coherent, sustained, collaborative, and focused on content; the school context, including school structures and support, standards and 
expectations regarding learning, incentives and accountability measures, and the general culture of teaching and learning; and the teachers themselves, including their prior experiences and knowledge, their beliefs about learning, their purposes for learning, and their sense of self-efficacy. These three factors, together with the unique characteristics and expectations of millennials and of faith-based schools, provide the conceptual framework for this research study. 


\section{CHAPTER 3}

\section{METHODOLOGY}

\section{Introduction}

A quantitative research design was selected because it best fits the research questions of this study which explores the professional learning practices of teachers in the SDA school system in North America, and the measurable factors that impact these practices. For the purpose of this study, the professional learning of teachers has been conceptualized as teacher participation in professional learning activities and the time they spend in participation. The learning activities included in the study reflect the literature as well as the recertification requirements for maintaining a SDA teaching certificate, and therefore represent the kinds of ongoing learning that teachers in the SDA K-12 school system in North America are likely to participate in.

Educators in the NAD were invited to participate in this study by completing an online survey that asked them to describe their professional learning practices and to respond to various statements designed to assess the impact of fourteen items on that practice. The analysis of the data collected contributes to the effort to describe the learning practices of educators in faith-based school systems and the factors that impact those practices. The results of the study can be used to assist educational leaders and policymakers in these systems to better evaluate systemic needs in their ongoing efforts to fulfill their unique missions. 


\section{Research Questions}

This research study seeks to answer the following research questions:

1. What are the professional learning practices of K-12 educators in the SDA school system in North America?

2. To what extent do differences exist in professional learning practices between millennial and non-millennial educators?

3. What factors influence these professional learning practices?

4. To what extent do differences exist in the factors that impact the professional learning practices of millennial and non-millennial educators?

\section{Research Design}

A cross-sectional, non-experimental quantitative design was selected for this research study. The research questions of this study, which seek to describe professional learning practices of teachers in measurable terms, can best be answered using a descriptive quantitative research design. Descriptive research is "a type of quantitative research that involves making careful descriptions of educational phenomena" (Gall et al., 2007, p. 300). This study describes the current state of teacher professional learning practices in the SDA school system in North America and the factors that impact it.

The data for this quantitative study was gathered using a self-administered survey distributed and completed online. Respondents were asked to provide demographic information related to their education, employment, and professional learning practices, and to respond to a series of Likert scale questions that addressed the activity, teacher, and school factors that impact professional learning practices, as identified in the literature. 


\section{Population and Sample}

\section{Context of Participants}

The SDA Office of Education for the NAD maintains its own K-12 teacher certification requirements above and beyond provincial or state requirements for teacher certification, even for independent schools. Because these certification policies include continual professional growth requirements, both academic and non-academic, teachers in this system provide a pool of teachers who, in theory, must participate regularly in professional growth activities.

The SDA school system provides a unique context for this research study. With its $800+$ elementary and secondary schools and almost 5,000 teachers, it is smaller than many public school districts, but large enough to warrant a growing bureaucracy. This bureaucracy includes "conference" administrations, each with its own superintendent and K-12 Board, as well as head offices in Canada and throughout the United States and a divisional office for North America located in Maryland. This Division office develops curriculum, teacher certification requirements, and school evaluation processes and policies that are applied throughout the NAD. Of the new teachers hired each year, most are members of the SDA Church and come with a varied range of educational experiences including degrees earned in both public and accredited Christian universities.

My own contextual background has certainly influenced my interest in this topic, an interest which stems in part from my belief in the moral responsibilities of educators and of an educational system to meet the learning needs of both students and teachers, preparing them to serve their fellowman and to make a positive contribution to society. This is, to use Fullan's term, the "moral imperative" of education (Fullan, 2003, 2011b). Education in general, and faith-based education in particular, has a moral obligation to 
"create a learning society where children, citizens of the future, learn to play their citizenship roles, just as much as, or even more importantly than they learn to play their occupational ones" (Jarvis, 2008, p. 219).

Part of what makes faith-based schools distinct is their dual emphasis on academics and on faith development, a combination intended to prepare students to demonstrate their commitment to God through service to others. The aim of SDA education goes beyond a preparation for a career. "It has to do with the whole being, and with the whole period of existence possible to man. It is the harmonious development of the physical, the mental, and the spiritual powers" (White, 1903, p. 13). No teacher education program alone can adequately prepare teachers for this complex task. It is important for school leaders to support ongoing professional learning, using their limited resources wisely to meet the needs of all teachers. This need provides, in part, the impetus for this study.

\section{Selection of Participants}

The target population selected for this quantitative study is the pool of teachers and administrators of the SDA school system in North America, selected to provide as complete a picture as possible of the policies and practices for professional learning in the system. Permission to collect information about these practices, and to contact the almost 5,000 educators in the K-12 SDA school system in North America, was obtained from Dr. Larry Blackmer, NAD Vice President with responsibility for Adventist Education (personal communication, May 23, 2016). This target pool of participants was invited to respond to a survey that asked them to describe their professional learning practices. 


\section{Instrumentation}

Data collection was accomplished using a researcher-designed survey administered online. Collecting data using this type of survey has several advantages: (a) it allows for distribution to a wide selection of geographically-dispersed participants (such as those in the SDA school system across North America), (b) it is relatively inexpensive to administer, (c) it reduces biasing error caused by the characteristics and skills of an interviewer, and (d) it provides greater anonymity for respondents (Phellas, Bloch, \& Seale, 2012, p. 184). The speed of both distribution and responses is an added advantage.

\section{Survey Design}

Section I of the survey contained specific questions designed to assess the impact of activity, school, and teacher factors on professional learning practices (research question \#3). Correlating these responses with the demographic data that identifies the respondent by generation addresses research questions \#2 and \#4. Section II of the survey collected demographic information about participants' educational and teaching backgrounds, school contexts, and participation in professional learning (research question \#1). The aim of this section was to collect descriptive data to help to clarify or suggest possible connections between the participant and the school context and activities provided and selected.

\section{Review of Existing Instruments}

A variety of instruments, both formal and informal, have been developed in the past twenty years to collect data on teacher professional learning, each with its own purpose and target population. Some were developed by international organizations for 
use in a global market. Others were developed by individual researchers interested in specific populations. Some were distributed online and others were paper-and-pencil instruments. A few targeted professional development providers while most focused on classroom teachers. Only two were administered to teachers in faith-based schools.

Table 3 provides a list of the instruments that were used as resources, together with a brief description and the intended purpose for each. All of these surveys provided useful information, but none addressed all three of the factor groups suggested in the literature. The distribution and collection of the survey for this study was also somewhat different from most of the surveys described in Table 3.

\section{Content Validation}

The theoretical constructs from the literature, together with information gleaned from the instruments reviewed, were used to brainstorm a long list of items intended to measure the constructs identified. Expert feedback was then enlisted to assist in the process of validating the content, and revisions were made to the survey based on the feedback received.

\section{Literature Review}

A summary of the conceptual and operational definitions for each factor, based on the literature review described in Chapter 2, can be found in Table 4. These definitions are organized around Opfer and Pedder's (2011) model which includes three subsystems (learning activity, teacher, and school) that interact in different ways to impact teacher learning. The brainstormed list included 86 items under 15 sub-factors. Table 4 contains

only a sampling of these items. A complete list of the original items generated for each of these factors can be found in Appendix A, which was used in the first draft of the 
Table 3

Instruments Reviewed

\begin{tabular}{|c|c|c|}
\hline Source & Description & Purpose \\
\hline $\begin{array}{l}\text { Alberta Teachers' Association. } \\
\text { (2012, November). Creating } \\
\text { Possibilities, Balancing } \\
\text { Priorities-the } 2012 \text { Professional } \\
\text { Development Survey. [An ATA } \\
\text { Research Report.] }\end{array}$ & $\begin{array}{l}\text { An online survey used to } \\
\text { collect data from local } \\
\text { professional development } \\
\text { committee chairs and } \\
\text { committees }\end{array}$ & $\begin{array}{l}\text { Used to capture information } \\
\text { about the number and } \\
\text { nature of professional } \\
\text { development opportunities } \\
\text { in } 54 \text { locals across Alberta }\end{array}$ \\
\hline $\begin{array}{l}\text { Association of Supervision and } \\
\text { Curriculum Development. (2013). } \\
\text { Professional Development Needs. } \\
\text { [when live, it was accessible on } \\
\text { the Association's website at } \\
\text { http://survey.ascd.org/ } \\
\text { TakeSurvey.aspx?SurveyID=n23 } \\
\text { K372] }\end{array}$ & $\begin{array}{l}\text { An online survey, especially } \\
\text { useful for collecting } \\
\text { demographic data }\end{array}$ & $\begin{array}{l}\text { Distributed to all } \\
\text { SmartBrief subscribers to } \\
\text { assess what they wanted } \\
\text { from professional } \\
\text { development }\end{array}$ \\
\hline $\begin{array}{l}\text { Denmark, V., \& Weaver, S. R. } \\
\text { (2012, June 8). Technical Report: } \\
\text { Redesign and Psychometric } \\
\text { Evaluation of the Standards } \\
\text { Assessment Inventory. Alpharetta, } \\
\text { GA: AdvancED. }\end{array}$ & $\begin{array}{l}\text { A study done to evaluate the } \\
\text { reliability and factorial } \\
\text { validity of the SAI2- } \\
\text { Learning Forward's } \\
\text { Standards Assessment } \\
\text { Inventory, a self-report } \\
\text { instrument }\end{array}$ & $\begin{array}{l}\text { Aimed at measuring } \\
\text { alignment between a } \\
\text { school's professional } \\
\text { development program and } \\
\text { Learning Forward's } \\
\text { Standards for Professional } \\
\text { Learning }\end{array}$ \\
\hline $\begin{array}{l}\text { Headley, S. (1997). The } \\
\text { Professional Development Needs } \\
\text { of Christian School Educators [a } \\
\text { survey]. Copy of survey obtained } \\
\text { from J. Swezey (personal } \\
\text { communication, August 22, } \\
\text { 2013). }\end{array}$ & $\begin{array}{l}\text { A pencil-and-paper } \\
\text { questionnaire developed in } \\
1997 \text { as part of a study of the } \\
\text { professional development } \\
\text { needs of educators in } \\
\text { Association of Christian } \\
\text { Schools International (ACSI) } \\
\text { schools }\end{array}$ & $\begin{array}{l}\text { Developed to determine } \\
\text { specific policies and } \\
\text { practices related to PD } \\
\text { offered by local schools } \\
\text { and to identify critical } \\
\text { needs in the PD of } \\
\text { administrators and teachers }\end{array}$ \\
\hline $\begin{array}{l}\text { Murray, J. M. (2010). Assessing } \\
\text { the status of professional learning } \\
\text { opportunities in U.S. Independent } \\
\text { Schools. (Doctoral dissertation). } \\
\text { Available from ProQuest } \\
\text { Dissertations and Theses } \\
\text { database. (UMI No. 3446185) }\end{array}$ & $\begin{array}{l}\text { An electronic survey (the } \\
\text { Independent School Teacher } \\
\text { Development Inventory) } \\
\text { distributed to } 3422 \text { National } \\
\text { Association of Independent } \\
\text { Schools principals as part of } \\
\text { a PhD dissertation }\end{array}$ & $\begin{array}{l}\text { Developed as part of a } \\
\text { quantitative research study } \\
\text { to collect information about } \\
\text { current professional } \\
\text { development practices in } \\
\text { NAIS schools }\end{array}$ \\
\hline $\begin{array}{l}\text { OECD. (2009). Teaching and } \\
\text { Learning International Survey } \\
\text { (TALIS). (MS-12-01). }\end{array}$ & $\begin{array}{l}\text { The Professional } \\
\text { Development section of an } \\
\text { international survey that } \\
\text { invites teachers and } \\
\text { principals to provide input }\end{array}$ & $\begin{array}{l}\text { Asked for information } \\
\text { about school education and } \\
\text { policy matters around the } \\
\text { world, allowing countries } \\
\text { to identify other countries }\end{array}$ \\
\hline
\end{tabular}




\begin{tabular}{|c|c|c|}
\hline & $\begin{array}{l}\text { into education analysis and } \\
\text { policy development }\end{array}$ & $\begin{array}{l}\text { facing similar challenges } \\
\text { and to learn from other } \\
\text { policy approaches }\end{array}$ \\
\hline $\begin{array}{l}\text { Schalock, M., Ayres, R., \& } \\
\text { Cuthbertson, L. (2008). Oregon } \\
\text { Statewide Teacher Professional } \\
\text { Development Survey. Monmouth, } \\
\text { OR: Teaching Research Institute, } \\
\text { Western Oregon University. }\end{array}$ & $\begin{array}{l}\text { An online survey sponsored } \\
\text { by the Oregon Education } \\
\text { Association and the } \\
\text { Chalkboard Project in } \\
\text { partnership with the } \\
\text { Teaching Research Institute } \\
\text { of Western Oregon } \\
\text { University }\end{array}$ & $\begin{array}{l}\text { Intended to seek input from } \\
\text { Oregon teachers and collect } \\
\text { data on educators' } \\
\text { professional development } \\
\text { needs }\end{array}$ \\
\hline $\begin{array}{l}\text { Swezey, J. (2010). Professional } \\
\text { Development Survey. (personal } \\
\text { communication August 22, 2013). }\end{array}$ & $\begin{array}{l}\text { An adaptation by Finn and } \\
\text { Swezey of Headley's } 1997 \\
\text { survey created as a fillable } \\
\text { pdf as part of a study "to } \\
\text { build upon research } \\
\text { previously conducted in the } \\
\text { area of professional } \\
\text { development for Christian } \\
\text { school teachers by Headley } \\
\text { in } 1997 \text { " }\end{array}$ & $\begin{array}{l}\text { Targeted Christian school } \\
\text { administrators and teachers } \\
\text { in the greater Virginia } \\
\text { Beach, Virginia area to gain } \\
\text { their perspectives on the } \\
\text { PD needs of teachers in } \\
\text { preschool-12 settings }\end{array}$ \\
\hline
\end{tabular}

instrument. These initial items were revised using the feedback received from the experts consulted. The process is described below, with backup documents to be found in Appendices B and C.

\section{Expert Judges}

Sixteen professional educators were contacted by email for feedback on items in the draft instrument, which was attached to the email as a fillable pdf. A response was requested within a week. Copies can be found in Appendix B.

These individuals were selected because of their expertise in and experience with adult learning. Most of the selected experts currently work or have worked in higher education at various universities. Two of them currently work at the conference level 
Table 4

Teacher Professional Learning: Conceptual and Operational Definitions for Factors

\section{Conceptual definition Operational definition}

(sample for each sub-factor)

\section{References}

Activity factors (sub-factors: active learning, coherence, duration, collective participation, content focus)

\begin{tabular}{|c|c|}
\hline $\begin{array}{l}\text { Effective professional } \\
\text { learning activities for } \\
\text { teachers involve active } \\
\text { rather than passive } \\
\text { learning, are coherent } \\
\text { with school and } \\
\text { district goals, are } \\
\text { sustained over time, } \\
\text { involve teachers } \\
\text { working together } \\
\text { collaboratively, and } \\
\text { are focused on content. }\end{array}$ & $\begin{array}{l}\text { - I have opportunities to visit } \\
\text { other schools as part of my } \\
\text { ongoing professional learning } \\
\text { activities } \\
\text { - Professional learning activities } \\
\text { are aligned with the } \\
\text { curriculum used } \\
\text { - Educators in my school/ } \\
\text { conference spend time every } \\
\text { week participating in some } \\
\text { kind of professional learning } \\
\text { - I have opportunities to plan } \\
\text { instruction together with other } \\
\text { educators } \\
\text { - Professional learning activities } \\
\text { are focused on integrating } \\
\text { technology in specific content } \\
\text { areas. }\end{array}$ \\
\hline
\end{tabular}

Andrews et al., 2006; Archibald et al., 2011; Borko, 2004; Buczynski \& Hansen, 2010; Clandinin et al., 2012; Coggshall et al., 2010; DarlingHammond \& McLaughlin, 1999; Darling-Hammond et al., 2009; Desimone, 2009, 2011; Desimone et al., 2002; Garet et al., 2001; Guskey, 2000; Hammerness et al., 2005; Hargreaves \& Shirley, 2009; Lieberman, 1995; Little, 1999; Loucks-Horsley et al., 1987; Loucks-Horsley et al., 2010; Mott, 2000; Schlager \& Fusco, 2003; Yoon et al., 2007

School factors (sub-factors: structures and supports, standards and expectations, incentives, accountability, culture)

\begin{tabular}{|c|c|c|}
\hline $\begin{array}{l}\text { To be effective, } \\
\text { professional learning } \\
\text { for teachers must } \\
\text { occur in collaborative } \\
\text { communities that are } \\
\text { committed to } \\
\text { continuous } \\
\text { improvement, } \\
\text { maintain high } \\
\text { standards for ongoing } \\
\text { learning, and build in } \\
\text { supports, incentives, } \\
\text { and accountability } \\
\text { measures for } \\
\text { professional learning. }\end{array}$ & $\begin{array}{l}\text { - Time is provided in my } \\
\text { regular work day for } \\
\text { professional learning activities } \\
\text { - My employer expects me to } \\
\text { participate annually in } \\
\text { professional learning activities } \\
\text { - My school provides adequate } \\
\text { funding to assist me with } \\
\text { ongoing professional learning } \\
\text { - After returning from off-site } \\
\text { professional learning } \\
\text { experiences, educators } \\
\text { formally share their learning } \\
\text { with their colleagues } \\
\text { - Most of the educators in my } \\
\text { school/conference participate } \\
\text { regularly in professional } \\
\text { learning activities }\end{array}$ & $\begin{array}{l}\text { Alexandrou \& Swaffield, } \\
\text { 2012; Archibald et al., 2011; } \\
\text { Beach, 2012; Burke, 2011; } \\
\text { Darling-Hammond et al., } \\
\text { 2009; Fullan, 2006, 2011a; } \\
\text { Guarino, Santibañez, \& Daley, } \\
\text { 2006; Guskey, 2000; } \\
\text { Hammerness et al., 2005; } \\
\text { Hirsch et al., 2001; Ingvarson, } \\
\text { 2003; Jaquith et al., 2010; } \\
\text { Knapp, 2003; Leithwood et al., } \\
\text { 1999; Mitchell \& Sackney, } \\
\text { 2011; OECD, 2005; Rebore \& } \\
\text { Walmsley, 2010; Schein, } \\
\text { 2010; Schlechty, 2009; } \\
\text { Stodolsky et al., 2008; Wiliam, } \\
\text { 2010 }\end{array}$ \\
\hline
\end{tabular}


Teacher factors (sub-factors: prior education and experience, beliefs about learning, purposes for participation, self-efficacy)

\begin{tabular}{|c|c|c|}
\hline $\begin{array}{l}\text { Professionals must be } \\
\text { able to recognize the } \\
\text { connection between } \\
\text { new knowledge and } \\
\text { their experience. } \\
\text { Effective teacher } \\
\text { professional learning } \\
\text { activities create } \\
\text { dissonance between } \\
\text { current and new } \\
\text { practice while } \\
\text { providing opportunity } \\
\text { for teachers to reflect } \\
\text { on instruction and } \\
\text { beliefs. Effective } \\
\text { professional learning } \\
\text { increases teacher } \\
\text { efficacy. A sense of } \\
\text { efficacy is a powerful } \\
\text { motivator for ongoing } \\
\text { participation in teacher } \\
\text { professional learning. }\end{array}$ & $\begin{array}{l}\text { - Educators' experience levels } \\
\text { are considered in the planning } \\
\text { of professional learning } \\
\text { activities } \\
\text { - The teacher professional } \\
\text { learning activities that I have } \\
\text { participated in have been } \\
\text { directly related to my past } \\
\text { experience and current needs } \\
\text { - I am a more effective educator } \\
\text { today because of my } \\
\text { participation in ongoing } \\
\text { professional learning activities } \\
\text { - My primary reason for } \\
\text { participating in professional } \\
\text { learning activities is to } \\
\text { improve student learning } \\
\text { - I am confident in my mastery } \\
\text { of the content that I teach } \\
\text { and/or the duties I am called } \\
\text { upon to perform }\end{array}$ & $\begin{array}{l}\text { Avalos, 2011; Daley, 2000; } \\
\text { Frost, 2012; Hawley \& Valli, } \\
\text { 1999; Ingvarson, 2003; } \\
\text { Ingvarson, Meiers, \& Beavis, } \\
\text { 2005; Knapp, 2003; Knowles } \\
\text { et al., 2012; Loucks-Horsley et } \\
\text { al., 1987; Mockler, 2013; } \\
\text { Murray, 2010; Opfer \& } \\
\text { Pedder, 2011; Richter, Kunter, } \\
\text { Klusmann, Ludtke, \& } \\
\text { Baumert, 2011; Talbert \& } \\
\text { McLaughlin, 2002; Thompson } \\
\& \text { Zeuli, 1999; Timperley \& } \\
\text { Alton-Lee, 2008; Torff \& } \\
\text { Sessions, 2008 }\end{array}$ \\
\hline
\end{tabular}

with specific responsibilities for the ongoing professional learning of teachers in the conference. Eleven of the sixteen individuals responded with feedback.

Two of the eleven experts who responded appear to have misunderstood their task, completing the survey as if they were describing the professional learning practices of their higher education institution rather than assessing the items as a possible instrument for a K-12 study. Comments like "This is not applicable in a higher education setting" led me to this conclusion. These two responses were not included in the content validity index found in Appendix C. 
The other nine respondents provided constructive comments that led to revisions of the original draft. Four of the nine had follow-up questions and comments, one in a lengthy phone conversation. Two of the nine did not complete the item-by-item analysis but provided summary comments only. Thus, the Content Validity Index (Appendix C) includes a total of seven responses to each item, but the summary of comments includes those of all nine experts who responded.

In the final draft of the instrument, which can be found in Appendix D, the subfactor headings were removed, the instrument was renamed, and a 5-point Likert scale was added with instructions for completion. Feedback from the experts who responded was used to clarify wording and to select the items that best reflect the factors outlined. A discussion of the more significant changes follows.

\section{Addition of Demographic Information}

The original intent was to include questions soliciting demographic information as a separate section of the instrument, and these questions were not shared with the experts for their input. At least three of the respondents picked up on the need for such information, suggesting that questions be added to the survey that captured the demographic data. Rather than add these to the content questions, I included a separate demographics section, as originally planned. These questions related to participants' educational and teaching backgrounds, school contexts, and the time spent and types of professional learning that the educators participated in. A complete survey including demographic questions can be found in Appendix D. 


\section{Length of Survey}

As observed by at least three respondents, the survey was too long. The intent was to begin with more items than needed, reducing them based on the feedback from the experts. Though the feedback regarding each item was mixed, it provided information that assisted in reducing the survey from 86 questions to 60 questions (a 30\% reduction). The original draft of 86 questions contained 5-6 questions for each of the 15 sub-factors; these were reduced to 3-5. Two of the experts rightly identified "delivery" as a sub-factor that did not really fit the construct, since it asked for preferences rather than realities. These items were deleted and a question about delivery preferences was added to the demographic information section.

\section{Negative Measures}

Four of the respondents commented on the reverse wording of a few of the questions. The wording of these questions was intentional, an effort to prevent "response sets" and "encourage participants to read each item on the questionnaire more carefully" (Johnson \& Christensen, 2013, p. 209). Only one of the four experts recommended including additional negatively worded items, and she admitted that the findings are mixed regarding the importance of reverse scoring. The other comments were more cautious, almost wary, it seemed, of the possibility of creating confusion. Johnson and Christensen (2013) cite studies on both sides of the debate, concluding with the recommendation that reverse-worded items be used "only when response sets are a major concern" (p. 209). As a result, I chose to eliminate reverse-worded items, and either reworded or deleted any such items that were part of the original draft. 


\section{Additions}

Three of the experts responded with recommendations to add items focused on a personal interest of theirs — coaching, public/provincial requirements, social media involvement, and personal networks. Though most of these suggestions, if followed, would have resulted in the collection of additional interesting data, they did not fit the model of the learning activity, teacher, and school factors as found in the literature. In fact, many of these items were more demographic in nature - asking teachers for their preferences regarding those types of professional learning and the extent to which they were involved in them. The demographic questions include items in this area, so I did not add additional items in the factor content section.

There was a difference of opinion regarding the two items (\#10,\#11) that asked about alignment with school and system (NAD) goals. On the one hand, the literature makes it clear that effective professional learning is coherent; that is, it is aligned with the mission and goals. As a faith-based school system, the underlying mission is critical to the philosophy of Adventist education and to the effectiveness of its schools and its system. On the other hand, the observation that conference and NAD goals may be "too distant or vague" is also a reality. I reworded the question to reflect an alignment with the Adventist philosophy of education rather than with specific missions at each level.

One expert suggested that most of the items included under Learning Activity Factors would fit under School or Teacher Factors, and would thus reduce the number of factors in the study from three to two. The literature does not support this change. 


\section{Rewording}

Several of the items were reworded to add clarity. Some items were reworded to be more sensitive to the realities of small schools and multi-grade classrooms, as noted by two of the respondents. The references to "the integration of faith and learning" were revised to reflect the more current usage of "Biblical perspective" and "Biblical worldview" which is emerging in Adventist circles. Other wording changes were made to improve clarity or better align the item with the construct.

In addition, "teacher" was changed to "educator" in the survey questions since the target population includes school administrators as well as classroom teachers, and "and/or conference" was added to the questions that previously listed only school, recognizing that small schools would likely not be able to provide professional learning activities for educators but would rely on the conference to do so. Cronbach's alpha was used to analyze the reliability of the items.

\section{Procedure}

Survey Monkey ${ }^{\mathrm{TM}}$ was used for the administration of the survey. Though some authorities have pointed out that web surveys discriminate against those who lack web access and technology skills (Phellas et al., 2012) and that online surveys typically have a lower response rate (Cook, Heath, \& Thompson., 2000; Donley, 2012), Fink (2013) suggests that participants are becoming accustomed to responding to online surveys (p. 11). Because the target population of teachers in this study are assumed, in general, to be frequent users of technology, the use of this medium was appropriate.

The speed and ease of distribution and response is another important factor. According to 2014 numbers, the SDA K-12 school system employs almost 5,000 K-12 
teachers (NAD, 2015), with an estimated 800 of these teachers born between 1980 and 2000 (L. Blackmer, personal communication, May 5, 2014). These teachers, and their principals and superintendents, provided the population for the survey. The survey invitation was sent out by the Office of Education of the NAD via email using Mail Chimp ${ }^{\mathrm{TM}}$. The timeline of survey reminders and responses is summarized in Figure 2.

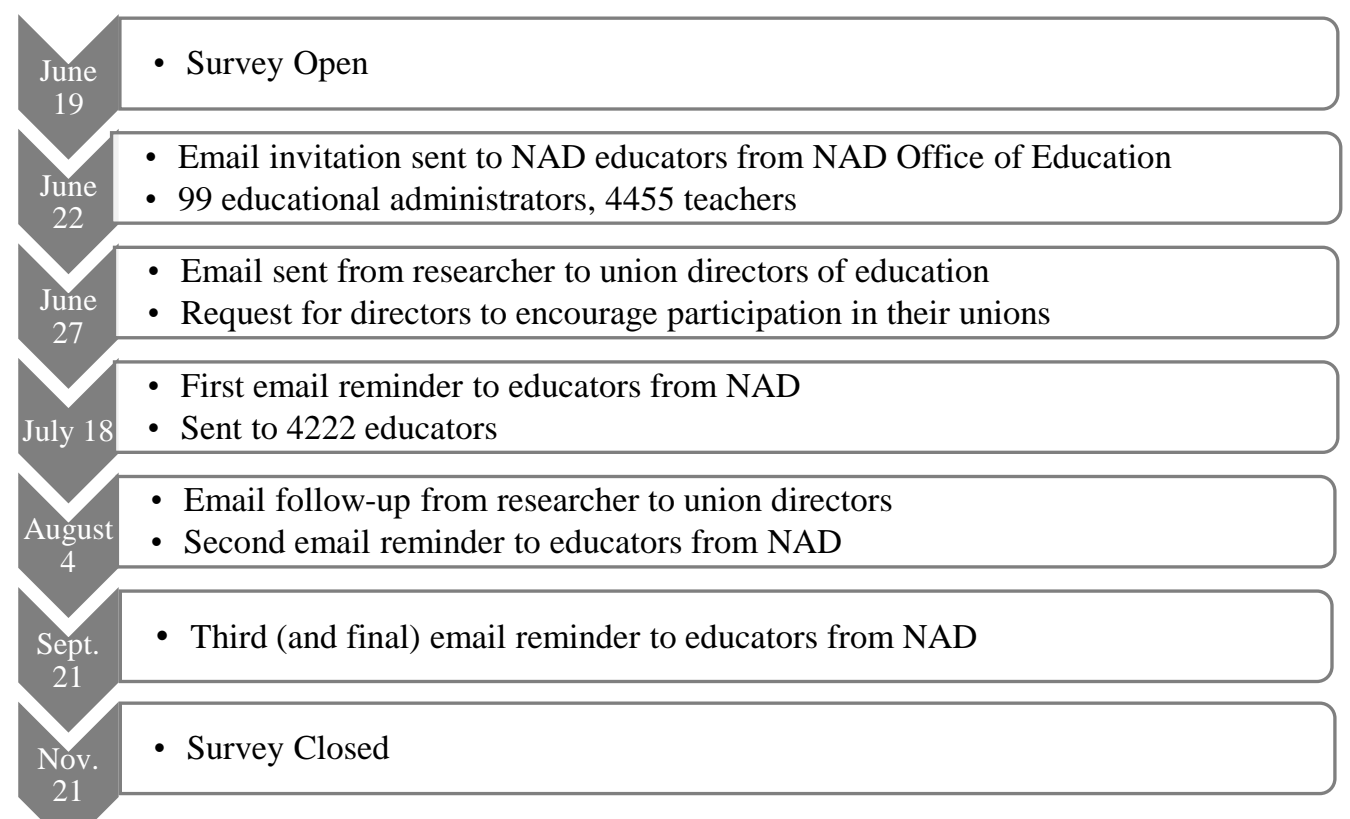

Figure 2. Timeline for survey distribution (2016)

\section{Treatment of Data}

Ethics and Confidentiality

Because this research involves human participants, ethical considerations must be acknowledged. It is likely that participants hold diverse values and beliefs about professional learning and about the expectations for such learning from both employees 
and employers. It is incumbent upon all researchers to acknowledge such diversity and respect all views expressed and those who express them.

In practical terms, this means, from the beginning, that the decision to participate in the research was completely voluntary, free of undue influence or coercion, and that the purposes for the research were transparent and clearly communicated. Such consent is recognized to be a process that begins with the "recruitment" of participants and continues throughout their involvement in the research, with the understanding that participants are free to withdraw their participation at any time. It also means that the freedom to participate in the research is restricted only by the research questions themselves.

Ethical considerations also include the expectation of confidentiality. Personal information was treated confidentially and respectfully. Personal identifying information was not collected; participants cannot therefore be personally identified in the sharing of research results. All data collected has been, and continues to be, stored securely.

\section{Key Assumptions}

As a researcher and a member of the SDA faith community, I recognize that I have an obligation to be attentive to how I am "implicated in the phenomenon studied" (Davis \& Sumara, 2006, p. 169). Because of my administrative leadership role in the SDA school system in Canada, I acknowledge Davis and Sumara's "first lesson of complexity thinking," that "we are woven into what we research, just as it is woven into us" (2006, p. 16). Complexity thinking suggests that observers cannot be totally objective in their observations since "subjective understanding is nested within objective 
knowledge" (Davis \& Sumara, 2006, p. 27). To reduce researcher bias, and the perception of such bias, therefore, the following safeguards are noted:

- The survey was distributed to all educators in the SDA school system across North America. I have had previous direct contact with relatively few of these participants and have no power of authority regarding the evaluation or employment of any of these individuals.

- Surveys were distributed electronically since participants are "more often willing to give more honest answers to a computer or by email than to a person or on a paper questionnaire" (Phellas et al., 2012, p. 188).

- Permission to contact participants was obtained from the NAD; surveys were distributed on my behalf by the NAD Office of Education.

In addition to completing core doctoral courses in educational leadership, I bring more than 35 years of experience in education to this research. I have worked as a classroom teacher for 11 years and in various educational leadership positions for more than 25 years. I acknowledge that I bring the following assumptions to this research:

- A faith-based context is unique in its dual mission of academics and faith and thus warrants separate investigation (Finn et al., 2010; Sullivan, 2006).

- Teaching is "a complex profession that can be refined over time" (Lieberman \& Pointer-Mace, 2010, p. 85).

- The data-gathering techniques used provided environments where participants in the research contributed honest, factual information that accurately reflects the realities of their workplaces and their opportunities for professional learning. 
- Participants engaged in the research because: (a) they value ongoing learning, (b) they are committed to the learning of all students, and (c) they believe their participation may assist in improving their school system and providing better opportunities for all teachers in the system.

\section{Data Analysis}

The data collected through Survey Monkey ${ }^{\mathrm{TM}}$ was entered into Statistical Package for the Social Sciences (SPSS) ${ }^{\mathrm{TM}}$ as ordinal variables. Descriptive statistics (frequency distributions, tests of central tendency, and variability) have been used to describe the sample and teacher professional learning practices. Exploratory Factor Analysis (EFA) was used to identify the main factors from the 60 survey items used to describe professional learning participation. Multiple Linear Regression (MLR) tests were used to analyze the effects of these factors (independent variables) on teacher professional learning practice, both time spent and types of activities (dependent variables), with the purpose of predicting correlations between the independent and dependent variables.

\section{Summary}

This study, which assesses the factors that impact the professional learning of educators, is best served by a quantitative approach. Spicer (2012) asserts that quantitative analysis can be used to "highlight aspects of people's lives that are measurable" (p. 486). A quantitative survey enables the collection of such measurable data from a large number of participants who are widely dispersed geographically. In addition, "surveys are playing an increasingly important role in helping to evaluate whether policies are having their intended effect" (Desimone \& Le Floch, 2004). Spicer (2012) further suggests that quantitative research can be used to identify broad patterns 
that can later be investigated further using qualitative methods to help explain the patterns (p. 489). Such studies may indeed be prompted by this quantitative study.

Using a quantitative survey, teachers and administrators in the K-12 SDA school system of the NAD (primarily Canada and the United States) were asked to respond to questions related to their professional learning practices and the factors that impact them. Using SPSS ${ }^{\mathrm{TM}}$, the data collected was analyzed for correlations between the identified factors and the professional learning practices of the respondents, both time spent and types of activities. This analysis provides a detailed description of professional learning in the SDA school system that can be used to assist educational leaders, particularly those in faith-based settings, to better meet the lifelong learning needs of all their teachers and of millennial teachers in particular. 


\section{CHAPTER 4}

\section{RESEARCH FINDINGS}

\section{Introduction}

This study explored the professional learning practices of teachers and administrators in the SDA school system across the NAD, and the factors that impact these practices. Data was collected using a survey that consisted of questions derived from a review of relevant literature. Exploratory factor analysis was used to isolate the significant factors from the survey responses, and MLR analyses were used to reveal relationships between these independent factors and the participation of educators (both time and type) in professional learning activities.

\section{Description of the Sample}

Of the 4500+ email invitations sent out by the NAD Office of Education to educators across the NAD, only half were opened by the recipients. Fewer yet clicked on the survey link. In total, 1033 responses were received, but only 749 were complete enough to include. Participation was voluntary, so this sample was compared with the total population of teachers in the NAD. With respect to union, grade level responsibility, and age, the sample of 749 educators is representative of the teacher population in the NAD as can be seen in Table 5, and shows a distribution across unions, grade levels, and age. 
Table 5

Descriptive Statistics: Population versus Sample

\begin{tabular}{lrrrr}
\hline \multirow{2}{*}{ Demographic Variable } & NAD Population & \multicolumn{2}{c}{ Study Sample } \\
\cline { 2 - 5 } & \multicolumn{1}{c}{$\mathrm{N}$} & \multicolumn{1}{c}{$\%$} & $\mathrm{n}$ & \multicolumn{1}{c}{$\%$} \\
\hline By Union** & 4481 & 100.0 & $* 673$ & 100.0 \\
Atlantic Union Conference & 333 & 7.4 & 28 & 4.2 \\
Canada, SDA Church in & 320 & 7.1 & 72 & 10.7 \\
Columbia Union Conference & 484 & 10.8 & 67 & 10.0 \\
Lake Union Conference & 299 & 6.7 & 47 & 7.0 \\
Mid-America Union Conference & 244 & 5.4 & 51 & 7.6 \\
North Pacific Union Conference & 505 & 11.3 & 77 & 11.4 \\
Pacific Union Conference & 1045 & 23.3 & 158 & 23.5 \\
Southern Union Conference & 908 & 20.3 & 107 & 15.9 \\
Southwestern Union Conference & 343 & 7.7 & 51 & 7.6 \\
Other (GMM, NAD) & -- & -- & 15 & 2.2 \\
By Grade Level Responsibility** & 4496 & 100.0 & $* 629$ & 100.0 \\
Elementary & 2990 & 66.5 & 446 & 70.9 \\
Secondary & 1506 & 33.5 & 183 & 29.1 \\
By Age*** & 4114 & 100.0 & $* 709$ & 100.0 \\
Millennials & 748 & 18.2 & 134 & 18.9 \\
Non-Millennials & 3366 & 81.8 & 575 & 81.1 \\
\hline
\end{tabular}

*only valid responses included

**personal communication with union directors of education

***Strategic Planning Actuarial Information

Detailed demographic characteristics are found in Table 6. Of the 749 responses, 204 were men and 505 were women; 40 did not indicate gender. Most of the participants $(60 \%)$ have earned Master's degrees or higher, and have more than 15 years of teaching experience. More than half hold SDA professional teaching certificates. Because two of the research questions for this study focused on differences between millennials and nonmillennials, demographics are listed by generation. Approximately $19 \%$ of participants identified as millennials (born in 1980 or later); over $80 \%$ belong to older generations (48\% Gen Xers, 33\% Boomers, < $1 \%$ Traditionalists). The majority of respondents work at the elementary level, which is also true for the NAD teacher population at large. 
Table 6

Participant Demographics: Millennials and Non-Millennials

\begin{tabular}{|c|c|c|c|c|c|c|}
\hline \multirow[b]{2}{*}{ Demographic Variable } & \multicolumn{2}{|c|}{ Millennials (n=134) } & \multicolumn{2}{|c|}{ Non-Millennials $(\mathrm{n}=575)$} & \multicolumn{2}{|c|}{ Total $(\mathrm{n}=749)$} \\
\hline & $\mathrm{n}$ & $\%$ & $\mathrm{n}$ & $\%$ & $\mathrm{n}$ & $\%$ \\
\hline Gender & $* 133$ & 100.0 & $* 574$ & 100.0 & $* 709$ & 100 \\
\hline Male & 44 & 33.1 & 159 & 27.7 & 204 & 28.8 \\
\hline Female & 89 & 66.9 & 415 & 72.3 & 505 & 71.2 \\
\hline Age & 134 & 100.0 & 575 & 100 & $* 709$ & 100.0 \\
\hline 1980-1999 & 134 & 100.0 & 0 & 0.0 & 134 & 18.9 \\
\hline $1960-1979$ & 0 & 0.0 & 340 & 59.1 & 340 & 47.9 \\
\hline 1940-1959 & 0 & 0.0 & 233 & 40.5 & 233 & 32.9 \\
\hline Before 1940 & 0 & 0.0 & 2 & 0.4 & 2 & 0.3 \\
\hline Experience & *133 & 100.0 & 575 & 100.0 & $* 711$ & 100.0 \\
\hline$<1$ year & 3 & 2.3 & 1 & 0.2 & 4 & 0.6 \\
\hline $1-5$ years & 56 & 42.1 & 16 & 2.8 & 72 & 10.1 \\
\hline $6-10$ years & 61 & 45.9 & 47 & 8.2 & 108 & 15.2 \\
\hline $11-15$ years & 11 & 8.3 & 93 & 16.2 & 104 & 14.6 \\
\hline $16-20$ years & 1 & 0.7 & 98 & 17.0 & 99 & 13.9 \\
\hline 21-25 years & 0 & 0.0 & 101 & 17.6 & 103 & 14.5 \\
\hline $26-30$ years & 0 & 0.0 & 84 & 14.6 & 85 & 12.0 \\
\hline$>30$ years & 1 & 0.7 & 135 & 23.4 & 136 & 19.1 \\
\hline Education & 134 & 100 & 575 & 100.0 & $* 712$ & 100.0 \\
\hline $\mathrm{PhD}$ & 2 & 1.5 & 28 & 4.9 & 30 & 4.2 \\
\hline Master & 54 & 40.3 & 347 & 60.3 & 401 & 56.3 \\
\hline Bachelor & 75 & 56.0 & 197 & 34.3 & 275 & 38.6 \\
\hline Associate/Diploma & 2 & 1.4 & 2 & 0.3 & 4 & 0.6 \\
\hline High School & 1 & 0.8 & 1 & 0.2 & 2 & 0.3 \\
\hline SDA Teaching Certification & *128 & 100.0 & $* 547$ & 100 & $678 *$ & 100.00 \\
\hline SDA Conditional & 18 & 14.1 & 34 & 6.2 & 52 & 7.7 \\
\hline SDA Basic & 19 & 14.8 & 12 & 2.2 & 31 & 4.6 \\
\hline SDA Standard & 47 & 36.7 & 160 & 29.3 & 209 & 30.8 \\
\hline SDA Professional & 44 & 34.4 & 341 & 62.3 & 386 & 56.9 \\
\hline Grades Taught & $* 133$ & 100 & $* 565$ & 100.0 & $* 701$ & 100.0 \\
\hline Elementary & 78 & 58.7 & 365 & 64.6 & 446 & 63.6 \\
\hline Secondary & 55 & 41.3 & 128 & 22.7 & 183 & 26.1 \\
\hline Full-time Admin & 0 & 0.0 & 72 & 12.7 & 72 & 10.3 \\
\hline Subjects Taught (teachers only) & $* 132$ & 100.0 & $* 496$ & 100.0 & $* 632$ & 100.0 \\
\hline Elementary/Jr Acad & 72 & 54.6 & 318 & 64.1 & 394 & 62.3 \\
\hline STEM & 25 & 18.9 & 71 & 14.3 & 96 & 15.2 \\
\hline Humanities & 26 & 19.7 & 77 & 15.5 & 103 & 16.3 \\
\hline Arts/PE & 9 & 6.8 & 30 & 6.1 & 39 & 6.2 \\
\hline
\end{tabular}

*only valid responses included 


\section{Data Analysis Procedures}

Using IBM's SPSS ${ }^{\mathrm{TM}} 24$, the data collected was organized and analyzed to address the four research questions that guided this study. A factor analysis was conducted using SPSS ${ }^{\mathrm{TM}}$ to determine which of the 60 survey questions (variables) corresponded to each other. The results of this factor analysis, as well as descriptive statistics and the results of MLR analyses, were all considered.

The first two research questions focus on a description of the professional learning practices of educators in the SDA school system across North America, including a comparison of the practices of millennial and non-millennial educators. Both time spent and the variety of types of participation were included. Descriptive statistics were used to address these questions, and the results are summarized in the tables that follow.

Research questions three and four explored the factors that impact these learning practices, again including a comparison between millennial and non-millennial educators. These factors were derived from 60 survey questions that considered three types of factors as found in the literature: 21 items covered Activity Factors (including active learning, coherence, duration, collective participation, and content focus); 22 items covered School Factors (including culture, expectations, supports, incentives, and accountability); and 17 items covered Teacher Factors (including experience, purpose, beliefs, and self-efficacy). An analysis of these factors required additional statistical tests beyond descriptives. The expectation was that the items within each category would be positively correlated with one another. Exploratory factor analysis was used to ascertain whether survey results were correlated as expected. 


\section{Exploratory Factor Analysis}

As Williams, Brown, and Onsman (2010) point out, "in EFA, the investigator has no expectations of the number or nature of the variables" (p. 3). In this study, the analysis itself was used to determine the number of constructs suggested by the data.

\section{Test of Assumptions}

Several authors have suggested that the sample size for factor analysis should be at least 300 (DeVellis, 2012; Hooper, 2012; Williams et al., 2010). DeVellis (2012) refers to several experts who suggest that the sample size should increase with the number of items but that "when the sample is as large as 300 , the ratio can be relaxed" (p. 157). With $N=749$ in the dataset, it can be safely assumed that the sample size is large enough for the items being analyzed. I chose to use Principal Axis Factoring (PAF) with Promax, an oblique rotation. The Kaiser-Meyer-Olkin Measure of Sampling Adequacy (KMO) was .950 which is well within the acceptable limits (Hooper, 2012, suggests .6 or above), and the Bartlett's Test of Sphericity is significant $(p<.001)$, so the data also meets this criteria.

\section{Extraction Procedures}

I began by running the PAF analysis suppressing coefficients with an absolute value below .4. Hooper (2012) asserts that PAF is better than principal components analysis because it analyzes common variance (p. 4). She also suggests three reasons for choosing an absolute value below .4: it helps to identify more clearly where particular items load, it highlights the items that may be unreliable and should perhaps be deleted, and it reveals any items that cross-load (p. 10). In keeping with Hooper's (2012) counsel to experiment with different numbers of factors until a satisfactory solution is found ( $\mathrm{p}$. 
13), I ran the PAF Promax analysis several more times, experimenting with $12,10,9,8$, $7,6,5,4$, and 3 factors.

\section{Rotation}

The purpose of rotations is to simplify the structure of a group of items by maximizing high item loadings and minimizing low item loading, to produce a simplified solution that is easier to interpret (Williams et al., 2010, p. 9). I chose the Promax (oblique) rotation since I assume that the latent factors are correlated. Hooper (2012) suggests that a Promax rotation is generally chosen because it is "quicker and simpler" (p. 9), and Williams et al. (2010) observe that this type of oblique rotation is "often seen as producing more accurate results for research involving human behaviours" (p. 9). Promax was therefore the best choice for the analysis of this particular set of data.

\section{Number of Meaningful Factors Extracted}

Osborne and Costello (2009) advise researchers, in an exploratory factor analysis, to focus on the factor structure with item loadings above .30 , no or few item crossloadings, and factors with three or more items (p. 135). After running the PAF several times with different numbers of factors, it was clear that the results of the five factor analysis most clearly fit the data. Only three of the 60 items did not load. Williams et al. (2010) suggest that such items may be unreliable indicators, so these items have not been included. The remaining 57 items loaded above .40, with 35 loading at 6 or above.

Several of the items cross-loaded, an indication that many of the factors that impact professional learning are inter-related and may often overlap. In these cases, the item was placed where it best fit the underlying theoretical construct. The identified five factors together explain $45.39 \%$ of the total variance. Though Hooper (2012) suggests 
that a minimum of $60 \%$ total variance is commonly accepted for the social sciences, I chose to stay with this analysis since the KMO and Bartlett's Test of Sphericity were within recommended levels and the Pattern Matrix showed no negative values.

Table 7 shows the items that loaded for each of these five factors; the percent of variance explained for each is also included. The survey items have been abbreviated to facilitate the reporting of data. (The unabridged survey can be found in Appendix D.) Though, as expected, the first factor accounts for the greatest amount of the variance, the other factors have numbers high enough to warrant their inclusion. As DeVellis (2012) observes, "no factoring method produces a uniquely correct solution" (p. 152). "Common sense," he goes on to state, "is needed to make the best decisions" (p. 153). The items under each of the five factors in the EFA results were carefully reviewed to find a reasonable connection among them.

Table 7 also summarizes the loadings of the items for each of the five factors. The variables with the higher loadings were used to identify and describe the underlying latent variable which each factor represents (Hooper, 2012). In doing so, as Williams et al. (2010) remind us, it was important to remember that "the labelling of factors is a subjective, theoretical, and inductive process" (p. 9). The items for each of the five factors identified in this EFA showed connections that made them relatively easy to label: collaborative practice, institutional support, activity content and coherence, teacher beliefs, teach self-efficacy. These five factors have been used to address research questions three and four. 


\section{Table 7}

Structure Matrix

\begin{tabular}{|c|c|c|c|c|c|}
\hline Item & $\begin{array}{c}\text { Factor } \\
1\end{array}$ & $\begin{array}{c}\text { Factor } \\
2 \\
\end{array}$ & $\begin{array}{c}\text { Factor } \\
3 \\
\end{array}$ & $\begin{array}{c}\text { Factor } \\
4\end{array}$ & $\begin{array}{c}\text { Factor } \\
5 \\
\end{array}$ \\
\hline Training provided on how to collaborate with others. & .754 & & & & \\
\hline Peer coaching provided. & .722 & & & & \\
\hline New initiatives followed up with ongoing support for a time. & .719 & & & & \\
\hline Opportunities to collaboratively examine student work. & .715 & & & & \\
\hline Experienced educators work closely with educators. & .676 & & & & \\
\hline Educator opportunities to plan instruction together. & .648 & & & & \\
\hline Participation in setting goals and planning for PL. & .641 & & & & \\
\hline Recognition given for expertise and leadership. & 639 & & & & \\
\hline Opportunities provided to observe and critique each other. & .630 & & & & \\
\hline Feedback given by leaders or colleagues to help improve. & .616 & & & & \\
\hline Time provided in work day for PL activities & .614 & & & & \\
\hline Formal sharing of professional learning with colleagues. & .612 & & & & \\
\hline Time every week provided for professional learning (PL). & .593 & & & & \\
\hline Ongoing PL included in regular staff meetings. & .580 & & & & \\
\hline Staff engaged in PL for $40+$ hours annually. & .572 & & & & \\
\hline Educators hold each other accountable to high standards. & .572 & & & & \\
\hline Opportunities provided to visit other schools. & .552 & & & & \\
\hline Specific provision for ongoing PL in budget. & & .712 & & & \\
\hline Supervisor who participates regularly in PL. & & .665 & & & \\
\hline Access to the kinds of professional learning needed. & & .663 & & & \\
\hline PL part of school/conference improvement plan. & & .660 & & & \\
\hline Adequate funding to assist with ongoing PL. & & .649 & & & \\
\hline Most educators participate regularly in PL. & & .645 & & & \\
\hline Supervisor who encourages application of new learning. & & .640 & & & \\
\hline Substitutes provided to facilitate participation during day. & & .582 & & & \\
\hline Expectation of annual participation in professional learning. & & .576 & & & \\
\hline Employer who values past experience and learning. & & .572 & & & \\
\hline Opportunities provided to practice new skills. & & .560 & & & \\
\hline Incentives to encourage participation in PL. & & .554 & & & \\
\hline Mentoring programs provided for new educators. & & .537 & & & \\
\hline Educators open to new ideas to improve student learning. & & .493 & & & \\
\hline PL includes reflecting Biblical worldview. & & & .739 & & \\
\hline PL includes strategies to share Biblical perspective. & & & .705 & & \\
\hline PL focused on how students learn in content areas. & & & .697 & & \\
\hline PL activities aligned with the curriculum used. & & & .680 & & \\
\hline Educators' experience considered in planning PL. & & & .675 & & \\
\hline PL selected based on analysis of educator needs. & & & .663 & & \\
\hline PL focused on content of academic disciplines. & & & .647 & & \\
\hline
\end{tabular}


Table 7--Continued

\begin{tabular}{|c|c|c|c|c|}
\hline PL aligned with Adventist philosophy of education. & & .642 & & \\
\hline PL selected based on analysis of students' needs. & & .616 & & \\
\hline PL include integrating technology in content areas. & & .612 & & \\
\hline Data used to monitor effectiveness of PL. & & .582 & & \\
\hline PL helps to identify areas for improvement. & & .558 & & \\
\hline PL is directly related to current needs. & & .519 & & \\
\hline Ability to use what is learned directly in work assignment. & & .444 & & \\
\hline Selection of PL influenced by performance evaluations. & & .411 & & \\
\hline Ongoing PL needed to stay current with education trends. & & & .703 & \\
\hline Ongoing PL assists in meeting future career goals. & & & .701 & \\
\hline All educators should be expected to participate annually PL. & & & 679 & \\
\hline Positive correlation between PL \& student achievement. & & & 656 & \\
\hline Ongoing PL results in more effective educators. & & & .557 & \\
\hline Improving student learning main reason for PL participation. & & & .556 & \\
\hline Confident in my mastery of content. & & & & 691 \\
\hline Have skills to address learning differences among students. & & & & .615 \\
\hline Confident in ability to share the Biblical perspective. & & & & .570 \\
\hline Confident in ability to use technology to support instruction. & & & & .473 \\
\hline Mastery demonstrated by academic presentations or writing. & & & & .410 \\
\hline$\%$ of variance & $29.81 \quad 5.29$ & 3.73 & 3.53 & 3.04 \\
\hline Cumulative $\%$ & $29.81 \quad 35.10$ & 38.83 & 42.36 & 45.39 \\
\hline
\end{tabular}

\section{Description of the Five Factors}

The 60 questions in the survey used were intended to assess the impact that activity, school, and teacher factors, as identified in the literature, have on the professional learning practices of teachers. Of the five factors identified by the factor analysis, Factors 1 and 3 focus primarily on activity factors (collaborative practice, activity content/coherence), Factor 2 on school factors (institutional support), and Factors 4 and 5 on teacher factors (teacher beliefs, teacher self-efficacy). As observed, these five factors account for $45.39 \%$ of the total variance. 


\section{Factor 1: Collaborative Practice}

Most of the 17 items loading on the first factor clearly relate to collaborative practice. A few items were originally intended to describe other activity factors (e.g., duration, active learning) or school factors (e.g., support, accountability, expectations, and culture). Collaborative practice is implied in all of these items, however, since all involve educators working together-in a staff meeting, for example, or holding each other accountable. This reinforces the finding of Darling-Hammond et al. (2009) that collegial work among teachers is related both to coherence and active learning opportunities (p. 20). The items that make up this factor include, for example, collective participation in school planning for professional learning, collaboration with colleagues in professional learning activities, visiting colleagues' classrooms both within and outside of their home schools, the duration of educators' participation, and the way educators within a school hold each other accountable. These 17 items together explain approximately $30 \%$ of the total variance.

\section{Factor 2: Institutional Support}

The second factor contains 14 items, all of which relate to institutional support. In

addition to the items that were originally designed to explore support, other school factors (e.g., expectations, incentives, and culture) also provide support for professional learning in the school setting and are included in this section. The one activity item and the one teacher item from the original design which loaded in this factor group also relate to institutional support: opportunities to practice new skills, and employers who value educator experience and learning. These 14 factors together account for $5.29 \%$ of the total variance. 


\section{Factor 3: Activity Content and Coherence}

Factor 3 contains 15 items which address issues primarily related to the learning activity itself. These items examine the extent to which the learning activities that educators choose to participate in relate to the content taught, the curriculum used, and the Adventist perspective. Some items assess whether the learning activities are designed based on specific student or educator needs. The original survey design separated items pertaining to activity content and activity coherence, but all of these items loaded here; all relate to the content of the professional learning activity and to what extent it aligns with teacher and school goals and philosophy. In addition, a few items originally designed to assess active learning, and a few that relate to teacher qualities, also loaded in this factor. These items relate, however, to the selection of learning activities, so they fit well within this factor that focuses on the activity and its content and coherence. The 15 items that loaded for this factor account for $3.73 \%$ of the total variance. Factors 1, 2, and 3 together account for almost $40 \%$ of the total variance.

\section{Factor 4: Teacher Beliefs}

Factor 4 contains six items that are related to teacher beliefs about professional learning. All were designed to measure teacher beliefs in the original plan for the survey. Included here are items that examine whether educators believe that their participation in ongoing professional learning helps to make them more effective teachers, whether educators believe ongoing learning should be compulsory for all educators, and whether they believe that such participation has a positive correlation with improved student achievement. Also addressed are the educators' reasons for participating in professional learning. The six items in this factor account for $3.53 \%$ of the total variance. 


\section{Factor 5: Teacher Self-Efficacy}

Factor 5 contains all five of the items from the original survey design that were intended to address teacher self-efficacy. All relate to how confident teachers are in their abilities to teach content, share the Biblical perspective, use technology, and meet the learning differences of their students. One item addresses participation in activities that demonstrate this mastery, such as presenting at educational conferences or inservice events, or publishing educational articles. Together, the five items in this factor account for $3.04 \%$ of the total variance.

\section{Internal Consistency Reliability}

Reliability is a measure of how free the scale is from random error (Hooper, 2012). It is most often measured using Cronbach's Alpha, a statistic that measures internal consistency, or the degree to which the items measure the same underlying construct. The closer the Cronbach's Alpha is to 1.0, the greater the reliability. Hooper (2012) proposes a minimum of .7, but Suhr and Shay (2006) suggest that .6 is acceptable for research purposes. Table 8 summarizes the internal consistency reliability for the five factors identified. The reliability of all five factors fall within this accepted minimum.

Table 8

Internal Reliability of Factors

\begin{tabular}{lrcc}
\hline \multicolumn{1}{c}{ Factors } & SD & $\begin{array}{c}\text { Number of } \\
\text { Items }\end{array}$ & $\begin{array}{c}\text { Reliability } \\
\text { (Cronbach's Alpha) }\end{array}$ \\
\hline Factor 1: Collaborative Practice & 13.09 & 17 & .922 \\
Factor 2: Institutional Support & 9.99 & 14 & .890 \\
Factor 3: Activity Content/Coherence & 9.96 & 15 & .908 \\
Factor 4: Teacher Beliefs & 3.42 & 6 & .813 \\
Factor 5: Teacher Self-Efficacy & 2.90 & 5 & .641 \\
\hline
\end{tabular}




\section{Summary of EFA Findings}

Sixty items designed to assess factors that impact educators' participation in professional learning were subjected to principal axis factoring to identify the underlying latent constructs of the data. On the survey, respondents were asked to use a 5-point Likert scale to respond to each item; two different scales were used to best suit the question asked. Three of the survey items did not load in the factor analysis and have thus not been included. Forty-seven of the remaining 57 items used a 5-point Likert scale that ranged from Never to Always (1:never, 2:rarely, 3:sometimes, 4:most times, 5:always), and ten items used a 5-point Likert scale that ranged from Strongly Disagree to Strongly Agree (1:strongly disagree, 2:disagree, 3:neither agree nor disagree, 4:agree, 5:strongly agree).

The Kaiser-Meyer-Olkin is .950 , which is above the recommended threshold of .6. Bartlett's Test of Sphericity is <.001, indicating that the correlations are sufficiently large for exploratory factor analysis. Five factors were extracted, and these five explain $45.39 \%$ of the variance. As mentioned, the factors were obliquely rotated using a Promax rotation. The loading of the items suggests the underlying constructs of Collaborative Practice, Institutional Support, Activity Content and Coherence, Teacher Beliefs, and Teacher Self-Efficacy. These five factors were used as the independent factors in MLR analyses, the results of which are summarized later in this chapter.

\section{Research Question \#1}

The first research question for this study, "What are the professional learning practices of K-12 educators in the SDA school system in North America," is addressed by examining both the time spent and the number of types of activities in which 
educators participate. Two survey questions addressed this question; a summary of the responses is found in Table 9.

\section{Time Spent}

Almost half of the educators who responded spend ten days or fewer each year in professional learning, including both formal and informal activities. Approximately $30 \%$ of respondents said they spend 14 or more days each year in professional learning and, if six hours is considered as the average daily time spent, these educators would spend more than 80 hours per year, a number Darling-Hammond et al. (2009) suggest would likely result in a change in teacher practice (p. 9). This would assume, however, that the time spent focused on a single area of learning, and this information was not requested in the survey. Only $2.5 \%$ report spending fewer than two days per year in professional learning.

\section{Types of Professional Learning}

Respondents were also asked to indicate which of the listed types of professional learning, both face-to-face and online, they had participated in during the past two years. $91.7 \%$ of respondents reported participation in face-to-face types of professional learning; $76.8 \%$ reported online participation. $64.0 \%$ of those who reported any participation at all said they had taken part in 8 or fewer types of activities; the majority of these participated in 5-8 types. Of the face-to-face activities listed, attendance at workshops, seminars, or conferences is the most frequently reported, while the viewing of educational videos is the most popular online activity. Table 10 provides a list by type of activity, with separate columns for online activities only, face-to-face activities only, and participation in both online and face-to-face activities. 
Table 9

Time and Variety in Types of Professional Learning Participation

\begin{tabular}{lrrr}
\hline Types of Activities & $\mathrm{n}$ & \multicolumn{2}{l}{ Cum\% } \\
\hline Time spent annually in professional & $* 709$ & 100.0 & -- \\
learning & & & \\
20 days or more & 142 & 20.0 & 20.0 \\
17-19 days & 12 & 1.7 & 21.7 \\
14-16 days & 50 & 7.1 & 28.8 \\
11-13 days & 31 & 4.4 & 33.2 \\
8-10 days & 125 & 17.6 & 50.8 \\
5-7 days & 193 & 27.2 & 78.0 \\
2-4 days & 138 & 19.5 & 97.5 \\
Fewer than 2 days & 18 & 2.5 & 100.0 \\
& & & \\
Number of different types of professional & $* 708$ & 100.0 & -- \\
learning participated in & & & \\
$29-30$ & 1 & 0.1 & 0.1 \\
$27-28$ & 0 & 0.0 & 0.1 \\
$25-26$ & 2 & 0.3 & 0.4 \\
$23-24$ & 2 & 0.3 & 0.7 \\
$21-22$ & 5 & 0.7 & 1.4 \\
$19-20$ & 8 & 1.1 & 2.5 \\
$17-18$ & 15 & 2.1 & 4.6 \\
$15-16$ & 32 & 4.5 & 9.1 \\
$13-14$ & 36 & 5.1 & 14.2 \\
$11-12$ & 58 & 8.2 & 22.4 \\
$9-10$ & 96 & 13.5 & 35.9 \\
$7-8$ & 137 & 19.4 & 55.3 \\
$5-6$ & 154 & 21.8 & 77.1 \\
$3-4$ & 126 & 17.8 & 94.9 \\
$1-2$ & 36 & 5.1 & 100.0 \\
\hline
\end{tabular}

When face-to-face and online activities are considered together, participant responses indicate that over $90 \%$ of all respondents participate in workshops, seminars, or conferences, either face-to-face, online, or both. Professional reading ranks second with over $65 \%$ participating, and the viewing of educational videos ranks third with $62.2 \%$ participating. The last two columns in Table 10, which show the participation of all teachers, both millennial and non-millennial, are arranged from highest to lowest. 
Table 10

Professional Learning Participation by Type

\begin{tabular}{lrrrrrrrr}
\hline & F2F & $\%$ & Online & $\%$ & $\begin{array}{r}\text { F2F + } \\
\text { Online }\end{array}$ & TOTAL & $\%$ \\
\hline Workshops/Seminars/Conferences & 449 & 59.9 & 39 & 5.2 & 188 & 25.1 & 676 & 90.3 \\
Professional Reading & 200 & 26.7 & 181 & 24.2 & 109 & 14.6 & 490 & 65.4 \\
Viewing of Educational Video & 100 & 13.4 & 274 & 36.6 & 92 & 12.3 & 466 & 62.2 \\
Teacher Learning Communities & 239 & 31.9 & 60 & 8.0 & 36 & 4.8 & 335 & 44.7 \\
Academic Course (non-degree) & 121 & 16.2 & 154 & 20.6 & 48 & 6.4 & 323 & 43.1 \\
Non-Academic Course (CEU) & 141 & 18.8 & 116 & 15.5 & 63 & 8.4 & 320 & 42.7 \\
Academic Course (part of degree) & 80 & 10.7 & 104 & 13.9 & 89 & 11.9 & 273 & 36.4 \\
Committee Membership & 209 & 27.9 & 13 & 1.7 & 33 & 4.4 & 255 & 34.0 \\
School Evaluation Team & 209 & 27.9 & 8 & 1.1 & 4 & 0.5 & 221 & 29.5 \\
Educational Travel & 197 & 26.3 & 10 & 1.3 & 12 & 1.6 & 219 & 29.2 \\
Mentoring & 186 & 24.8 & 11 & 1.5 & 18 & 2.4 & 215 & 28.7 \\
Peer Observation (another school) & 183 & 24.4 & 5 & 0.7 & 4 & 0.5 & 192 & 25.6 \\
Peer Observation (own school) & 184 & 24.6 & 5 & 0.8 & 0 & 0.0 & 190 & 25.4 \\
Presenting at a Conference & 151 & 20.2 & 5 & 0.7 & 16 & 2.1 & 172 & 23.0 \\
School-based Research & 59 & 7.9 & 70 & 9.3 & 34 & 4.5 & 163 & 21.8 \\
Supervision of a Student Teacher & 126 & 16.8 & 4 & 0.5 & 3 & 0.4 & 133 & 17.8 \\
Field-testing NAD Curriculum & 64 & 8.5 & 10 & 1.3 & 2 & 0.3 & 76 & 10.1 \\
Teaching a University Course & 46 & 6.1 & 4 & 0.5 & 6 & 0.8 & 56 & 7.5 \\
Publication of Article or Book & 16 & 2.1 & 16 & 2.1 & 2 & 0.3 & 34 & 4.5 \\
\hline
\end{tabular}

The most common types of activities vary somewhat when face-to-face and online activities are considered separately. A comparison by participation can be found in Table 11. Worth noting are the numbers of educators who participate in online activities. Though it is not surprising that viewing educational videos is the most popular online activity, it may be surprising to some that participation in academic courses, both as part of a degree or not, is more popular in an online format than face-to-face. Schoolbased educational research is also more commonly reported as an online, rather than a face-to-face, activity. Professional reading is still slightly more common as a face-to-face activity, though online reading is not far behind in the frequency of participation. 
Table 11

Professional Learning Participation by Popularity (Face-to-face and Online)

\begin{tabular}{|c|c|}
\hline Face-to-Face Types of Professional Learning & Online Types of Professional Learning \\
\hline Workshops/Seminars/Conferences (85.0\%) & Viewing of Educational Video (48.9\%) \\
\hline Professional Reading (41.3\%) & Professional Reading (38.7\%) \\
\hline Teacher Learning Communities (36.7\%) & Workshops/Seminars/Conferences $(30.3 \%)$ \\
\hline Committee Membership (32.3\%) & Academic Course-non-degree (27.0\%) \\
\hline School Evaluation Team (28.4\%) & Academic Course - degree $(25.8 \%)$ \\
\hline Educational Travel (27.9\%) & Non-academic Course $(23.9 \%)$ \\
\hline Mentoring (27.2\%) & School-based Educational Research (13.9\%) \\
\hline Non-academic Course (27.2\%) & Teacher Learning Communities (12.8\%) \\
\hline Viewing Educational Video (25.6\%) & Committee Membership (6.1\%) \\
\hline Peer Observation - another school (25.0\%) & Mentoring (3.9\%) \\
\hline Peer Observation—own school (24.6\%) & Educational Travel (2.9\%) \\
\hline Academic Course-degree $(22.6 \%)$ & Presenting at Conference/Inservice (2.8\%) \\
\hline Academic Course - non-degree $(22.6 \%)$ & Publication of Article or Book (2.7\%) \\
\hline Presenting at Conference/Inservice (22.3\%) & School Evaluation Team (1.6\%) \\
\hline Supervision of a Student Teacher (17.2\%) & Field-testing NAD Curriculum (1.6\%) \\
\hline School-based Educational Research (12.4\%) & Teaching a University Course $(1.5 \%)$ \\
\hline Field-testing NAD Curriculum (8.8\%) & Peer Observation-another school (1.2\%) \\
\hline Teaching a University Course $(6.8 \%)$ & Supervision of a Student Teacher $(0.9 \%)$ \\
\hline Publication of Article or Book (2.4\%) & Peer Observation—own school (0.8\%) \\
\hline
\end{tabular}

\section{Research Question \#2}

Question \#2 focuses on whether differences exist in the professional learning practices of millennial and non-millennial educators. The data collected shows that, in general, non-millennials spend a few more days in learning activities each year, but more millennials report spending 20 days or more annually. There are some differences in the types of professional learning that both groups participate in, though there are more similarities than differences. Non-millennials tend to participate in more types of professional learning $-24.1 \%$ report 11 types or more, while only $15.2 \%$ of millennials report the same. The numbers of millennials and non-millennials participating in ten or fewer types of activities are much the same. Further details can be found in Table 12 . 
Table 12

Time and Variety in Types of Professional Learning Participation: A Comparison of Millennials and Non-Millennials

\begin{tabular}{|c|c|c|c|c|c|c|}
\hline \multirow[b]{2}{*}{ Types of Activities } & \multicolumn{3}{|c|}{ Millennials } & \multicolumn{3}{|c|}{ Non-Millennials } \\
\hline & $\mathrm{n}$ & $\%$ & Cum $\%$ & $\mathrm{n}$ & $\%$ & Cum\% \\
\hline Time spent annually in professional learning & $* 133$ & 100.0 & -- & $* 573$ & 100.0 & -- \\
\hline 20 days or more & 28 & 21.1 & 21.1 & 113 & 19.7 & 19.7 \\
\hline 17-19 days & 4 & 3.0 & 24.1 & 8 & 1.4 & 21.1 \\
\hline 14-16 days & 3 & 2.3 & 26.4 & 47 & 8.2 & 29.3 \\
\hline 11-13 days & 5 & 3.6 & 30.0 & 26 & 4.5 & 33.8 \\
\hline 8-10 days & 17 & 12.8 & 42.8 & 108 & 18.8 & 52.6 \\
\hline 5-7 days & 43 & 32.3 & 75.1 & 150 & 26.2 & 78.8 \\
\hline 2-4 days & 28 & 21.1 & 96.2 & 108 & 18.9 & 97.7 \\
\hline Fewer than 2 days & 5 & 3.8 & 100.0 & 13 & 2.3 & 100.0 \\
\hline $\begin{array}{l}\text { Number of different types of professional } \\
\text { learning participated in }\end{array}$ & $* 133$ & 100.0 & -- & $* 571$ & 100.0 & -- \\
\hline $29-30$ & 0 & 0.0 & 0.0 & 1 & 0.2 & 0.2 \\
\hline $27-28$ & 0 & 0.0 & 0.0 & 0 & 0.0 & 0.2 \\
\hline $25-26$ & 0 & 0.0 & 0.0 & 2 & 0.3 & 0.5 \\
\hline $23-24$ & 0 & 0.0 & 0.0 & 2 & 0.3 & 0.8 \\
\hline $21-22$ & 2 & 0.8 & 0.8 & 4 & 0.7 & 1.5 \\
\hline $19-20$ & 3 & 1.5 & 2.3 & 6 & 1.0 & 2.5 \\
\hline $17-18$ & 5 & 3.0 & 5.3 & 10 & 1.8 & 4.3 \\
\hline $15-16$ & 6 & 3.8 & 9.1 & 27 & 4.7 & 9.0 \\
\hline $13-14$ & 4 & 2.3 & 11.4 & 33 & 5.8 & 14.8 \\
\hline $11-12$ & 6 & 3.8 & 15.2 & 63 & 9.3 & 24.1 \\
\hline $9-10$ & 18 & 13.5 & 28.7 & 78 & 13.7 & 37.8 \\
\hline $7-8$ & 32 & 24.0 & 52.7 & 104 & 18.2 & 56.0 \\
\hline $5-6$ & 31 & 23.3 & 76.0 & 122 & 21.4 & 77.4 \\
\hline $3-4$ & 24 & 18.0 & 94.0 & 101 & 17.7 & 95.1 \\
\hline $1-2$ & 8 & 6.0 & 100.0 & 28 & 4.9 & 100.0 \\
\hline
\end{tabular}

*only valid responses included

Table 13 provides a comparison of millennial and non-millennial participation in the various types of professional learning, both face-to-face and online. Overall, more non-millennials than millennials report participation in the following activities: teaching a university course, presenting at conferences or inservice events, serving on school evaluation teams, being members of committees, viewing educational videos, taking non- 
Table 13

Professional Learning Participation by Type: A Comparison of Millennials and Non-Millennials

\begin{tabular}{|c|c|c|c|c|c|c|}
\hline & $\mathrm{F} 2 \mathrm{~F}$ & $\%$ & Online & $\%$ & $\begin{array}{l}\mathrm{F} 2 \mathrm{~F}+ \\
\text { Online }\end{array}$ & $\%$ \\
\hline \multicolumn{7}{|c|}{ Workshop/Seminar/Conference } \\
\hline Millennials & 85 & 63.4 & 3 & 2.2 & 36 & 26.9 \\
\hline Non-Millennials & 361 & 62.8 & 35 & 6.1 & 152 & 26.4 \\
\hline \multicolumn{7}{|l|}{ Professional Reading } \\
\hline Millennials & 24 & 17.9 & 41 & 30.6 & 17 & 12.7 \\
\hline Non-Millennials & 176 & $* * * 30.6$ & 139 & 24.2 & 92 & 16.0 \\
\hline \multicolumn{7}{|c|}{ Viewing of Educational Video } \\
\hline Millennials & 7 & 5.2 & 50 & 37.3 & 19 & 14.2 \\
\hline Non-Millennials & 93 & $* 16.2$ & 223 & 38.8 & 73 & 12.7 \\
\hline \multicolumn{7}{|c|}{ Teacher Learning Communities } \\
\hline Millennials & 38 & 28.4 & 12 & 9.0 & 6 & 4.5 \\
\hline Non-Millennials & 201 & 35.0 & 46 & 8.0 & 30 & 5.2 \\
\hline \multicolumn{7}{|c|}{ Academic Course (non-degree) } \\
\hline Millennials & 27 & 20.1 & 29 & 21.6 & 6 & 4.5 \\
\hline Non-Millennials & 93 & 16.2 & 124 & 21.6 & 42 & 7.3 \\
\hline \multicolumn{7}{|c|}{ Non-Academic Course (CEU) } \\
\hline Millennials & 27 & 20.1 & 13 & 9.7 & 8 & 6.0 \\
\hline Non-Millennials & 112 & 19.5 & 102 & $* * 17.7$ & 55 & 9.6 \\
\hline \multicolumn{7}{|c|}{ Academic Course (part of degree) } \\
\hline Millennials & 20 & $* * * 14.9$ & 20 & $* 14.9$ & 26 & $* * 19.4$ \\
\hline Non-Millennials & 57 & 9.9 & 83 & 14.4 & 63 & 11.0 \\
\hline \multicolumn{7}{|l|}{ Committee Membership } \\
\hline Millennials & 34 & 25.4 & 0 & 0.0 & 3 & 2.2 \\
\hline Non-Millennials & 174 & 30.3 & 13 & $* 2.3$ & 30 & 5.2 \\
\hline \multicolumn{7}{|l|}{ School Evaluation Team } \\
\hline Millennials & 29 & 21.6 & 0 & 0.0 & 0 & 0.0 \\
\hline Non-Millennials & 179 & $* 31.1$ & 7 & 1.2 & 4 & 0.7 \\
\hline \multicolumn{7}{|l|}{ Educational Travel } \\
\hline Millennials & 34 & 25.4 & 0 & 0.0 & 4 & 3.0 \\
\hline Non-Millennials & 163 & 28.3 & 9 & 1.6 & 8 & 1.4 \\
\hline \multicolumn{7}{|l|}{ Mentoring } \\
\hline Millennials & 32 & 23.9 & 1 & 0.7 & 5 & 3.7 \\
\hline Non-Millennials & 153 & 26.6 & 9 & 1.6 & 13 & 2.3 \\
\hline \multicolumn{7}{|c|}{ Peer Observation (another school) } \\
\hline Millennials & 38 & 28.4 & 1 & 0.7 & 1 & 0.7 \\
\hline Non-Millennials & 145 & 25.2 & 3 & 0.5 & 3 & 0.5 \\
\hline \multicolumn{7}{|c|}{ Peer Observation (own school) } \\
\hline Millennials & 34 & 25.4 & 0 & 0.0 & 0 & 0.0 \\
\hline Non-Millennials & 150 & 26.1 & 5 & 0.9 & 0 & 0.0 \\
\hline \multicolumn{7}{|l|}{ Presenting at a Conference } \\
\hline Millennials & 23 & 17.2 & 2 & 1.5 & 1 & 0.7 \\
\hline Non-Millennials & 127 & 22.1 & 2 & 0.3 & 15 & 2.6 \\
\hline
\end{tabular}


Table 13--Continued

\begin{tabular}{lrrrrrr}
\hline $\begin{array}{l}\text { School-based Educ. Research } \\
\quad \text { Millennials }\end{array}$ & 10 & 7.5 & 20 & 14.9 & 3 & 2.2 \\
$\quad \begin{array}{l}\text { Non-Millennials } \\
\text { Supervision of a Student Teacher }\end{array}$ & 49 & 8.5 & 49 & 8.5 & 31 & 5.4 \\
$\quad$ & & & & & \\
$\quad \begin{array}{l}\text { Millennials } \\
\quad \text { Non-Millennials }\end{array}$ & 104 & 16.4 & 0 & 0.0 & 0 & 0.0 \\
$\begin{array}{l}\text { Field-testing NAD Curriculum } \\
\quad \text { Millennials }\end{array}$ & 11 & 8.2 & 1 & 0.7 & 1 & 0.7 \\
$\quad$ Non-Millennials & 52 & 9.0 & 8 & 1.4 & 1 & 0.2 \\
$\quad$ & & & & & & \\
Teaching a University Course & 4 & 3.0 & 1 & 0.7 & 2 & 1.5 \\
$\quad \begin{array}{l}\text { Millennials } \\
\quad \text { Non-Millennials }\end{array}$ & 41 & 7.1 & 3 & 0.5 & 4 & 0.7 \\
$\begin{array}{l}\text { Publication of Article or Book } \\
\quad \text { Millennials }\end{array}$ & 0 & 0.0 & 5 & 3.7 & 0 & 0.0 \\
$\quad$ Non-Millennials & 16 & $* 2.8$ & 10 & 1.7 & 2 & 0.3 \\
\hline
\end{tabular}

Note: Millennials $N=134$; Non-Millennials $N=575$

$* \mathrm{p}<.05, * * \mathrm{p}<.01, * * * \mathrm{p}<.001$

academic courses, attending workshops and seminars, and face-to-face reading of professional materials. More millennials report participation in academic courses as part of a degree, and in online professional reading.

Millennials and non-millennials tend to participate most often in the same types of learning, with a few notable exceptions. More millennials report reading online rather than face-to-face, while more non-millennials report face-to-face reading. Also, greater numbers of millennials report taking academic courses, both face-to-face and online, as part of a degree. Non-millennials participate more often in non-academic activities, and much more often than millennials in leadership-type activities (e.g., committee members, school evaluation teams). More millennial educators report spending time observing peers outside of their school. In general, however, non-millennials report greater satisfaction with the professional learning opportunities they have. The top ten activities reported by both millennials and non-millennials are summarized in Table 14. 
Table 14

Professional Learning Participation by Popularity: A Comparison of Millennials and Non-Millennials

\begin{tabular}{|c|c|}
\hline Millennials & Non-Millennials \\
\hline Workshops/Seminars-F2F (90.3\%) & Workshops/Seminars-F2F (89.2\%) \\
\hline Viewing of education video- online $(51.5 \%)$ & Viewing of educational video- online $(51.5 \%)$ \\
\hline Professional reading-online $(43.3 \%)$ & Professional reading-F2F $(46.6 \%)$ \\
\hline Academic Course (degree)—F2F (34.3\%) & Professional reading — online $(40.2 \%)$ \\
\hline Academic Course (degree)—online (34.3\%) & Teacher learning communities-F2F $(40.2 \%)$ \\
\hline Teacher Learning Communities-F2F (32.8\%) & Committee membership_-F2F (35.5\%) \\
\hline Professional reading-F2F (30.6\%) & Workshops/Seminars - online $(32.5 \%)$ \\
\hline Peer Observation, another school-F2F (29.1\%) & School evaluation team-F2F (31.8\%) \\
\hline Workshops/Seminars—online (29.1\%) & Educational travel-F2F (29.7\%) \\
\hline Educational travel-F2F (28.4\%) & Non-academic course-F2F (29.0\%) \\
\hline
\end{tabular}

When asked what might influence them to participate more often in professional learning, educators most often identified time and opportunities, especially during the school day. Opportunity for collaboration in various forms was also mentioned, more frequently by millennials than by non-millennials. Additional funding, for both academic and non-academic activities, was another important influence, again with more millennials selecting this aspect as important. In addition, almost half of the millennial teachers who responded expressed a desire for mentoring/coaching, almost twice as many as the non-millennial respondents. A summary of the responses of both millennials and non-millennials can be found in Table 15.

\section{Research Question \#3}

The third research question asked what factors influenced the professional learning practices of educators in the SDA school system across North America. The factor analysis described earlier identified five main factors (collaborative practice, 
Table 15

"I would be more involved if . . ": A Comparison of Millennials and Non-Millennials

\begin{tabular}{lcccccc}
\hline & \multicolumn{2}{c}{$\begin{array}{c}\text { Millennials } \\
(\mathrm{n}=134)\end{array}$} & \multicolumn{2}{c}{$\begin{array}{c}\text { Non-Millennials } \\
(\mathrm{n}=575)\end{array}$} & \multicolumn{2}{c}{$\begin{array}{c}\text { Total } \\
(\mathrm{n}=749)\end{array}$} \\
\hline Demographic Variable & $\mathrm{n}$ & $\%$ & $\mathrm{n}$ & $\%$ & $\mathrm{n}$ & $\%$ \\
\hline Scheduled time to meet with colleagues & 83 & 62 & 314 & 55 & 339 & 53.3 \\
Workshops onsite & 63 & 47 & 279 & 49 & 345 & 46.1 \\
Salary scale increases or bonuses & 80 & 60 & 256 & 45 & 337 & 45.0 \\
Opportunities during the school day & 71 & 53 & 228 & 40 & 300 & 40.1 \\
Additional funds for nonacademic PD & 57 & 43 & 230 & 40 & 288 & 38.5 \\
Interschool/classroom visitation options & 67 & 50 & 212 & 37 & 280 & 37.4 \\
Teacher input in planning & 63 & 47 & 204 & 36 & 267 & 35.6 \\
Tuition reimbursement (for academic) & 70 & 52 & 185 & 32 & 255 & 34.0 \\
Collaborative curriculum development & 45 & 34 & 200 & 35 & 245 & 32.7 \\
Mentoring/Coaching & 57 & 43 & 130 & 23 & 188 & 25.1 \\
Collaborative in-school action research & 36 & 27 & 130 & 23 & 166 & 22.2 \\
Required professional growth plans & 20 & 15 & 79 & 14 & 99 & 13.2 \\
Induction program for new teachers & 28 & 21 & 65 & 11 & 93 & 12.4 \\
Video of teacher lessons for reflection & 13 & 10 & 69 & 12 & 82 & 10.9 \\
Additional compulsory requirements & 11 & 8 & 54 & 9 & 65 & 8.7 \\
\hline
\end{tabular}

*only valid responses included

institutional support, activity content/coherence, teacher beliefs, teacher self-efficacy), each made up of several items which were targeted by specific survey questions.

Descriptive statistics for the responses to these five factors are summarized below, followed by the results of the regression analyses.

\section{Descriptive Results}

Table 16 shows the mean, standard deviation, and skewness for each of the five factors. Skewness numbers show that the five variables fall within the normality range, though some are slightly skewed either positively (Factor 1: Collaborative Practice) or negatively (Factor 2: Institutional Support, Factor 4: Teacher Beliefs). Morgan, Leech, 
Gloeckner, and Barrett (2013) suggest a "somewhat arbitrary guideline" that skewness statistics that fall between -1.0 and +1.0 are considered normal (p. 51). All five variables have skewness numbers that fall within these limits.

Table 16

Descriptive Statistics for Factors

\begin{tabular}{lcccc}
\hline Factors & $\begin{array}{c}\text { Number of } \\
\text { items }\end{array}$ & $\begin{array}{c}\text { Mean } \\
\text { (All respondents) }\end{array}$ & SD & Skewness \\
\hline Factor 1: Collaborative Practice & 17 & 2.69 & .769 & .322 \\
Factor 2: Institutional Support & 14 & 3.62 & .719 & -.464 \\
Factor 3: Activity Content/Coherence & 15 & 3.19 & .664 & -.024 \\
Factor 4: Teacher Beliefs & 6 & 4.29 & .570 & -.683 \\
Factor 5: Teacher Self-Efficacy & 5 & 3.72 & .588 & .029 \\
\hline
\end{tabular}

The results suggest that, in general, educators believe strongly in the value of professional learning. Respondents also tend to be confident in their abilities, as indicated by the self-efficacy scores, and believe that institutional support for professional learning is generally high. The activities educators are involved in have a reasonably high level of content focus and coherence with individual and school goals, but views on collaborative practice are moderate. Descriptive statistics for the individual items in each of the five factors are summarized in Tables 17-21.

Results show that of the five factors identified by the factor analysis, scores for the items that contribute to the teacher factor (both teacher beliefs and teacher selfefficacy) are higher than those that contribute to either the activity factor (collaborative practice and content/coherence) or the school factor (institutional support). Responses to the six teacher belief items show that most of the educators who responded to the survey 
believe strongly in the importance of professional learning to assist teachers in staying current and becoming more effective in improving student learning. More than $75 \%$ believe there is a positive correlation between professional learning and student achievement. Similarly, the majority of educators who responded are confident in their mastery of content, their ability to share the Biblical perspective, their use of technology, and their skills to address student learning differences. Few, however, have demonstrated their mastery by leading out in academic presentations, either orally or in writing.

Table 17

Descriptive Statistics for Factor 1: Collaborative Practice

\begin{tabular}{llcccc}
\hline Survey Item & $N$ & $S D$ & Mean & $\begin{array}{c}\text { \%espondents } \\
\text { Reporting } \\
\text { "Always" or } \\
\text { "Most times" }\end{array}$ \\
\hline Educators hold each other accountable. & & & & & \\
Ongoing PL included in regular staff meetings. & 739 & 1.17 & 3.16 & 41.6 \\
Experienced educators work closely with educators. & 744 & 1.16 & 3.10 & 36.3 \\
Feedback given to help improve. & 741 & 1.17 & 2.90 & 30.8 \\
Participation in setting goals and planning for PL. & 744 & 1.32 & 2.68 & 30.0 \\
Staff engaged in PL for 40+ hours annually. & 737 & 1.11 & 2.88 & 29.0 \\
Opportunities to plan instruction with other educators. & 747 & 1.21 & 2.82 & 28.8 \\
Formal sharing of PL with colleagues. & 745 & 1.16 & 2.86 & 28.1 \\
Opportunities provided to visit other schools. & 745 & 1.32 & 2.74 & 27.2 \\
Recognition given for expertise and leadership. & 745 & 1.14 & 2.69 & 23.7 \\
New initiatives followed up with ongoing. & 744 & 1.05 & 2.65 & 21.6 \\
Opportunities to collaboratively examine student work. & 740 & 1.11 & 2.58 & 20.3 \\
Opportunities provided to observe and critique others. & 745 & 1.12 & 2.58 & 20.1 \\
Training provided on how to collaborate with others. & 745 & 1.09 & 2.51 & 18.3 \\
Peer coaching provided. & 740 & 1.18 & 2.36 & 17.1 \\
Weekly time provided for professional learning (PL). & 739 & 1.03 & 2.40 & 14.5 \\
Time provided in work day for PL activities & 746 & 1.10 & 1.95 & 10.4 \\
& & & & 30.5 \\
\hline
\end{tabular}


Table 18

Descriptive Statistics for Factor 2: Institutional Support

\begin{tabular}{lllcc}
\hline Survey Item & $N$ & $S D$ & Mean & $\begin{array}{c}\text { \% of } \\
\text { Repondents } \\
\text { "Always" or } \\
\text { "Most times" }\end{array}$ \\
\hline Expectation of annual participation in PL. & & & & \\
PL part of school/conference improvement plan. & 743 & 0.96 & 4.36 & 84.3 \\
Most educators open to new ideas to improve learning.* & 744 & 1.04 & 4.13 & 76.4 \\
Employer who values experience and learning.* & 745 & 1.03 & 3.90 & 72.9 \\
Supervisor encourages application of new learning.* & 744 & 1.04 & 3.82 & 69.6 \\
Most educators participate regularly in PL.* & 744 & 0.96 & 3.71 & 71.1 \\
Supervisor who participates regularly in PL. & 740 & 1.10 & 3.69 & 60.0 \\
Substitutes provided to facilitate participation. & 743 & 1.29 & 3.66 & 60.7 \\
Specific provision for ongoing PL in budget. & 737 & 1.25 & 3.60 & 56.8 \\
Opportunities provided to practice new skills. & 744 & 0.96 & 3.58 & 53.1 \\
Access to the kinds of professional learning needed. & 742 & 1.05 & 3.37 & 45.3 \\
Adequate funding to assist with ongoing PL. & 743 & 1.25 & 3.30 & 46.3 \\
Mentoring programs provided for new educators. & 740 & 1.39 & 3.00 & 39.1 \\
Incentives to encourage participation in PL. & 745 & 1.30 & 2.70 & 29.0 \\
\hline
\end{tabular}

* used "strongly agree" and "agree" rather than "always" and "most times"

Responses on items relating to the activity factor (collaborative practice and activity content/coherence) are not as strong. Though $41.6 \%$ of respondents believe they hold each other accountable for reaching high standards, few have opportunities to collaborate with each other or time during the work day to do so. These results agree with Bassett et al.'s (2013) finding that no time is “built into the school day for teachers to collaborate and far more often, teaching schedules are not constructed to give teachers who teach the same students or the same subjects or grades time to work together 
Table 19

Descriptive Statistics for Factor 3: Activity Content/Coherence

\begin{tabular}{llccc}
\hline Survey Item & $N$ & $S D$ & Mean & $\begin{array}{c}\text { \% of } \\
\text { Repondents } \\
\text { "Always" or } \\
\text { "Most times" }\end{array}$ \\
\hline PL aligned with SDA philosophy of education. & & & & \\
PL activities aligned with the curriculum used. & 744 & 0.84 & 4.25 & 83.4 \\
Ability to use learning directly in work assignment. & 744 & 0.94 & 3.64 & 60.2 \\
PL includes strategies to share Biblical perspective. & 745 & 1.05 & 3.45 & 56.8 \\
PL helps to identify areas for improvement. & 741 & 0.97 & 3.44 & 47.3 \\
PL is directly related to current needs. & 745 & 1.07 & 3.28 & 43.0 \\
PL includes Biblical worldview in content areas. & 743 & 1.08 & 3.19 & 38.5 \\
PL include integrating technology in content areas. & 742 & 0.90 & 3.17 & 33.4 \\
PL focused on how students learn in content areas. & 746 & 0.96 & 3.11 & 34.5 \\
PL selected based on analysis of educator needs. & 739 & 0.99 & 3.04 & 33.4 \\
PL focused on content of academic disciplines. & 745 & 1.02 & 2.99 & 31.3 \\
PL selected based on analysis of students' needs. & 741 & 0.95 & 2.98 & 29.4 \\
Educators' experience considered in planning PL. & 736 & 1.10 & 2.83 & 27.2 \\
Selection of PL influenced by performance evaluations. & 742 & 1.18 & 2.46 & 20.3 \\
Data used to monitor effectiveness of PL. & 731 & 1.12 & 2.35 & 17.0 \\
\hline
\end{tabular}

(horizontal collaboration) or to inform and learn from those who have taught or will teach the same students (vertical collaboration)" (p. 11).

In addition, fewer than half of the survey respondents said they participated in setting goals and planning for professional learning. More than half report that they rarely or never have peer coaching opportunities. Once again, this finding echoes earlier research. Darling-Hammond et al. (2009) found that "fewer than one-fourth of teachers feel they have great influence over school decisions and policies" and "fewer than half 
Table 20

Descriptive Statistics for Factor 4: Teacher Beliefs

\begin{tabular}{lccccc}
\hline Survey Item & $N$ & $S D$ & Mean & $\begin{array}{c}\text { \% of } \\
\text { Respondents } \\
\text { Reporting } \\
\text { "Strongly } \\
\text { Agree" or } \\
\text { "Agree" }\end{array}$ \\
\hline All educators should be expected to participate in PL. & 746 & 0.74 & 4.50 & 92.5 \\
Ongoing PL needed to stay current with education. & 746 & 0.71 & 4.47 & 93.0 \\
Improving student learning is main reason for PL. & 746 & 0.73 & 4.39 & 91.2 \\
Ongoing PL assists in meeting future career goals. & 744 & 0.81 & 4.26 & 84.0 \\
I am more effective because of PL. & 745 & 0.94 & 4.07 & 78.5 \\
Positive correlation of PL \& student achievement. & 745 & 0.81 & 4.06 & 77.5 \\
\hline
\end{tabular}

Table 21

Descriptive Statistics for Factor 5: Teacher Self-Efficacy

\begin{tabular}{lccccc}
\hline Survey Item & $N$ & $S D$ & Mean $\begin{array}{c}\text { \% of } \\
\text { Respondents } \\
\text { Reporting } \\
\text { "Always" or } \\
\text { "Most times" }\end{array}$ \\
\hline Confident in ability to share the Biblical perspective. & 743 & 0.71 & 4.39 & 90.3 \\
Confident in my mastery of content. & 743 & 0.71 & 4.10 & 83.6 \\
Confident in use of technologies to support instruction. & 741 & 0.82 & 3.93 & 73.0 \\
Have skills to address student learning differences. & 743 & 0.82 & 3.71 & 63.2 \\
Mastery demonstrated by academic presentations. & 744 & 1.34 & 2.47 & 24.4 \\
\hline
\end{tabular}

perceived that they had some influence over the content of their in-service professional development" (p. 6).

As far as the content of professional learning activities is concerned, more than $80 \%$ of respondents believe that the opportunities provided align with the Adventist philosophy of education. Of concern are the low numbers who believe that these 
activities are selected based on an analysis of student and educator needs and the rare use of data to monitor the effectiveness of professional learning.

Most of the items that pertain to the school factor (i.e., institutional support) are mixed. The majority of the educators who responded report that their employers expect them to participate annually in professional learning and that professional learning is part of school or conference improvement plans. Most report that budgeted funds, substitutes, and the support of supervisors are provided, but almost half believe their employers rarely or never provide incentives to encourage participation.

\section{Multiple Linear Regression}

Two MLR analyses were conducted to evaluate how well the five factors affecting educator professional learning predicted (1) the time spent on professional learning, and (2) the variety in types of professional learning that educators choose to participate in. The independent (predictor) variables were the five factors identified by the factor analysis: collaborative practice, institutional support, activity content and coherence, teacher beliefs, and teacher self-efficacy. A significant regression equation was found for both time spent and professional learning types:

Time Spent $\quad\left(\mathrm{F}_{(5,699)}=10.112, \mathrm{p}<.001\right)$, with an $\mathrm{R}^{2}$ of .067

\# of PL Types $\left(\mathrm{F}_{(5,700)}=38.672, \mathrm{p}<.001\right)$, with an $\mathrm{R}^{2}$ of .216

$\mathrm{R}^{2}$ represents the amount of variance that can be explained between the dependent variable and the set of independent variables. It shows that the five factors accounted for only $6.7 \%$ of the variance in time spent on professional learning, and $21.6 \%$ of the variance in types of professional learning. 


\section{Time Spent}

Table 22 shows the mean, standard deviation, and correlations between the variables. Correlation coefficients are weak between all five factors and time spent on professional learning. The correlations between independent (predictor) variables are mostly weak; the exceptions are between collaborative practice and institutional support (.76), between collaborative practice and activity content/coherence (.80), and between institutional support and activity content/coherence (.70), all of which are strong.

Table 22

MLR Descriptive Statistics: Time Spent on Professional Learning

\begin{tabular}{lccccccc}
\hline \multirow{2}{*}{ Variable } & Mean & $S D$ & \multicolumn{5}{c}{ Correlation } \\
& & & 2 & 3 & 4 & 5 & 6 \\
\hline 1 Time spent & 4.30 & 2.207 & .18 & .10 & .09 & .11 & .21 \\
2 Collaborative Practice & 2.68 & .765 & & .76 & .80 & .29 & .37 \\
3 Institutional Support & 3.62 & .714 & & & .70 & .27 & .25 \\
4 Activity Content/Coherence & 3.19 & .659 & & & & .35 & .30 \\
5 Teacher Beliefs & 4.30 & .569 & & & & & .23 \\
6 Teacher Self-Efficacy & 3.72 & .578 & & & & & \\
\hline
\end{tabular}

Participants' predicted time spent on professional learning is equal to $1.105+$ $.743(\mathrm{~F} 1)-.132(\mathrm{~F} 2)-.523(\mathrm{~F} 3)+.265(\mathrm{~F} 4)+.593(\mathrm{~F} 5)$, where $\mathrm{F} 1=$ collaborative practice, F2 = institutional support, F3 = activity content/coherence, F4 = teacher beliefs, and F5 = teacher self-efficacy. All factors are represented by the means of the various items that made up these factors. A summary of the regression results is found in Table 23.

The results indicate that collaborative practice $(p<.001)$, activity content and coherence $(p=.014)$, and teacher self-efficacy $(p<.001)$ are significant predictors of the 
Table 23

MLR Results: Five Factors on Time Spent in Professional Learning

\begin{tabular}{lcrrrrrrr}
\hline \multicolumn{1}{c}{ Variable } & \multicolumn{1}{c}{$b$} & $S E$ & \multicolumn{2}{c}{ CI 95 } & $\beta$ & $t$ & $\rho$ \\
\hline Collaborative Practice & .743 & .203 & .345 & 1.141 & .258 & 3.667 & $<.001$ \\
Institutional Support & -.132 & .180 & -.485 & .222 & -.043 & -.731 & .465 \\
Activity Content/Coherence & -.523 & .212 & -.939 & -.108 & -.156 & -2.471 & .014 \\
Teacher Beliefs & .265 & .153 & -.035 & .566 & .068 & 1.733 & .084 \\
Teacher Self-Efficacy & .593 & .152 & .295 & .891 & .155 & 3.906 & $<.001$ \\
\hline
\end{tabular}

Note: $\mathrm{F}_{(5,699)}=10.112, \mathrm{p}<.001, \mathrm{R}^{2}=.067$

time spent in professional learning. Institutional support $(p=.465)$ and teacher beliefs $(p$ $=.084)$ are not. The more opportunities available for collaborative practice, the more time educators spend in professional learning. Similarly, the more confidence teachers have in their own abilities, the more time they spend in professional learning. Less time was spent when activities were content-based or when activities were aligned with school and/or conference goals. Of the five factors, collaborative practice appears to be the most important predictor.

\section{Types of Professional Learning}

Participants' predicted variety in types of professional learning activities is equal to $-4.053+2.695(\mathrm{~F} 1)-.596(\mathrm{~F} 2)-1.511(\mathrm{~F} 3)+1.304(\mathrm{~F} 4)+1.627(\mathrm{~F} 5)$, where $\mathrm{F} 1=$ collaborative practice, F2 = institutional support, F3 = activity content/coherence, F4 = teacher beliefs, and F5 = teacher self-efficacy. All factors are represented by the means of the various items that made up these factors.

Table 24 shows the mean, standard deviation, and correlations between the variables. Correlation coefficients are weak between all five factors and the variety in 
Table 24

MLR Descriptive Statistics: Types of Professional Learning

\begin{tabular}{lccccccc}
\hline \multirow{2}{*}{ Variable } & Mean & SD & \multicolumn{5}{c}{ Correlation } \\
& & & 2 & 3 & 4 & 5 & 6 \\
\hline 1 PD Types (F2F and online) & 7.87 & 4.36 & .35 & .21 & .21 & .25 & .34 \\
2 Collaborative Practice & 2.69 & .772 & & .77 & .80 & .29 & .38 \\
3 Institutional Support & 3.63 & .712 & & & .71 & .27 & .26 \\
4 Activity Content/Coherence & 3.19 & .663 & & & & .36 & .31 \\
5 Teacher Beliefs & 4.30 & .569 & & & & & .23 \\
6 Teacher Self-Efficacy & 3.72 & .583 & & & & & \\
\hline
\end{tabular}

types of professional learning which educators participate in. As was the case with time spent (Table 22), the correlations between independent (predictor) variables are mostly weak; the exceptions are between collaborative practice and institutional support (.77), between collaborative practice and activity content/coherence (.80), and between institutional support and activity content/coherence (.71), all of which are strong.

The results (Table 25) indicate that collaborative practice, activity content/coherence, teacher beliefs, and teacher self-efficacy are all significant predictors of the variety in types of professional learning that educators participated in. Institutional support is not. The more opportunities available for collaborative practice, the more positive teachers' beliefs were regarding professional learning; the more confidence teachers had in their own abilities, the more types of professional learning activities they participated in. Beta numbers suggest that activity content/coherence is negatively correlated with the variety in types of activities participated in. 
Table 25

MLR Results: Five Factors on Types of Professional Learning

\begin{tabular}{|c|c|c|c|c|c|c|c|}
\hline \multirow{2}{*}{ Variable } & \multirow{2}{*}{$b$} & \multirow{2}{*}{$S E$} & \multicolumn{2}{|c|}{ CI 95} & \multirow{2}{*}{$\beta$} & \multirow{2}{*}{$t$} & \multirow{2}{*}{$\rho$} \\
\hline & & & lower & upper & & & \\
\hline Collaborative Practice & 2.695 & .365 & 1.978 & 3.412 & .477 & 7.378 & $<.001$ \\
\hline Institutional Support & -.596 & .329 & -1.241 & .050 & -.097 & -1.811 & .071 \\
\hline Activity Content/Coherence & -1.511 & .384 & -2.266 & -.756 & -.230 & -3.931 & $<.001$ \\
\hline Teacher Beliefs & 1.304 & .277 & .761 & 1.848 & .170 & 4.711 & $<.001$ \\
\hline Teacher Self-Efficacy & 1.627 & .273 & 1.091 & 2.164 & .218 & 5.956 & $<.001$ \\
\hline
\end{tabular}

Note: $F_{(5,700)}=38.672, p<.001, \mathrm{R}^{2}=.216$

\section{Research Question \#4}

Research question \#4 focuses on the extent to which differences exist in the factors that impact the professional learning practices of millennial and non-millennial educators. The independent t-test results, summarized in Table 26, indicate that these differences are significant.

Table 27 compares the responses of millennial and non-millennial educators to each of the items that make up the five factors. The items are grouped by factor, and ordered within each factor by mean, from highest to lowest. Survey items have been abbreviated to facilitate the reporting of the data. The shaded columns provide a summary of the responses of the total group of participants for comparison purposes. A summary of the descriptive results and the results of the regression analyses follow.

\section{Descriptive Results}

Some minor differences are apparent in the responses obtained from millennial and non-millennial educators, though no major differences appear. For most items, more non-millennials than millennials report responses of "always" or "most times" with three 
Table 26

Independent Sample T-Test Results

\begin{tabular}{|c|c|c|c|c|c|c|c|c|}
\hline \multirow{2}{*}{ Variable } & \multirow{2}{*}{$N$} & \multirow{2}{*}{ Mean } & \multirow{2}{*}{$S D$} & \multirow{2}{*}{$t$} & \multirow{2}{*}{$d f$} & \multirow{2}{*}{ Sig } & \multicolumn{2}{|c|}{$95 \% \mathrm{CI}$} \\
\hline & & & & & & & Lower & higher \\
\hline \multicolumn{9}{|l|}{ F1: Collaborative Practice } \\
\hline Millennials & 134 & 2.452 & .735 & -3.927 & 705 & $<.001$ & -.430 & -.143 \\
\hline Non-Millennials & 573 & 2.739 & .767 & & & & & \\
\hline \multicolumn{9}{|l|}{ F2: Institutional Support } \\
\hline Millennials & 134 & 3.429 & .722 & -3.445 & 706 & .001 & -.368 & -.101 \\
\hline Non-Millennials & 574 & 3.664 & .706 & & & & & \\
\hline \multicolumn{9}{|c|}{ F3: Activity Content/Coherence } \\
\hline Millennials & 134 & 2.987 & .682 & -3.877 & 705 & $<.001$ & -.366 & -.120 \\
\hline Non-Millennials & 573 & 3.230 & .646 & & & & & \\
\hline \multicolumn{9}{|l|}{ F4: Teacher Beliefs } \\
\hline Millennials & 134 & 4.108 & .617 & -4.327 & 705 & $<.001$ & -.339 & -.128 \\
\hline Non-Millennials & 573 & 4.342 & .549 & & & & & \\
\hline \multicolumn{9}{|l|}{ F5: Teacher Self-Efficacy } \\
\hline Millennials & 134 & 3.550 & .508 & -3.692 & 703 & $<.001$ & -.313 & -.096 \\
\hline Non-Millennials & 571 & 3.754 & .591 & & & & & \\
\hline
\end{tabular}

exceptions. More millennials believe that adequate funding is provided for professional learning, slightly more report spending weekly time in professional learning, and, not surprisingly, more millennials report confidence in their use of technology to support instruction.

The biggest differences between the responses of millennials and non-millennials can be seen in the items that represent collaborative practice (Factor 1). Twice the number of non-millennials report having opportunities to visit other schools and to participate in learning during the regular workday. Twenty-five percent or fewer millennial teachers report opportunities to collaborate, including opportunities to observe, to receive training on how to collaborate, and to work in conferences or schools where experienced educators work with new ones. More non-millennials report having access to professional learning that meets their current needs, and believe that data 
Table 27

Summary of Responses: A Comparison of Millennials and Non-Millennials

Survey Question

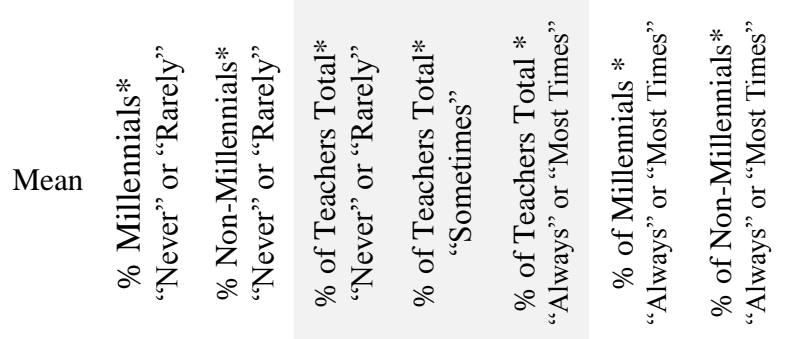

FACTOR 1: Collaborative Practice

Educators hold each other accountable.

$\begin{array}{llllllll}3.16 & 32.8 & 28.5 & 28.8 & 29.6 & 41.5 & 29.9 & 43.7\end{array}$

Ongoing PL included in regular staff meetings.

$\begin{array}{llllllll}3.10 & 42.5 & 28.4 & 30.7 & 32.9 & 36.3 & 34.3 & 36.1\end{array}$

$\begin{array}{lllllllll}\text { Experienced educators work with new educators. } & 2.90 & 53.0 & 35.0 & 38.8 & 30.4 & 30.8 & 18.7 & 33.6\end{array}$

Feedback given to help improve.

$\begin{array}{llllllll}2.89 & 47.0 & 38.0 & 39.5 & 30.0 & 30.5 & 29.1 & 30.3\end{array}$

Staff engaged in PL for 40+ hours annually.

$\begin{array}{llllllll}2.88 & 44.7 & 38.6 & 39.9 & 31.1 & 29.0 & 25.4 & 28.8\end{array}$

Formal sharing of PL with colleagues.

$\begin{array}{llllllll}2.86 & 43.3 & 39.2 & 39.5 & 32.5 & 28.1 & 20.2 & 29.6\end{array}$

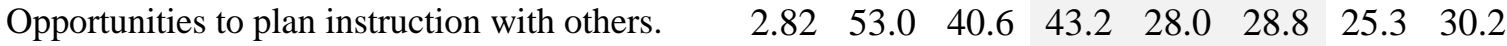

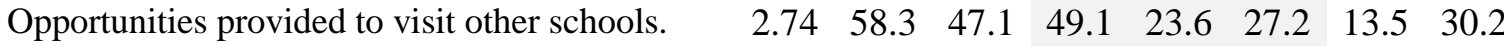

Recognition given for expertise and leadership. $\quad \begin{array}{lllllllll}2.69 & 53.0 & 39.8 & 42.7 & 33.6 & 23.8 & 15.7 & 25.5\end{array}$

Participation in setting goals and planning for professional learning.

$\begin{array}{llllllll}2.68 & 55.9 & 47.6 & 48.9 & 21.1 & 30.0 & 23.1 & 31.0\end{array}$

New initiatives followed up with ongoing support.

$\begin{array}{llllllll}2.65 & 52.6 & 46.0 & 47.0 & 31.3 & 21.6 & 15.0 & 22.6\end{array}$

Opportunities to collaboratively examine student work.

$\begin{array}{llllllll}2.58 & 56.7 & 49.8 & 51.2 & 28.5 & 20.3 & 16.4 & 21.4\end{array}$

Opportunities provided to observe and critique others.

$\begin{array}{llllllll}2.58 & 66.4 & 51.3 & 53.9 & 25.9 & 20.1 & 12.6 & 21.7\end{array}$

$\begin{array}{lllllllll}\text { Training provided on collaborating with others. } \quad 2.51 & 68.7 & 48.1 & 52.2 & 29.5 & 18.3 & 11.9 & 19.4\end{array}$

Weekly time spent on professional learning. $\quad \begin{array}{lllllllll}2.40 & 69.2 & 58.3 & 60.0 & 25.4 & 14.5 & 15.8 & 14.1\end{array}$

$\begin{array}{lllllllll}\text { Peer coaching provided. } & 2.36 & 71.2 & 57.3 & 59.4 & 23.4 & 17.2 & 12.1 & 18.3\end{array}$

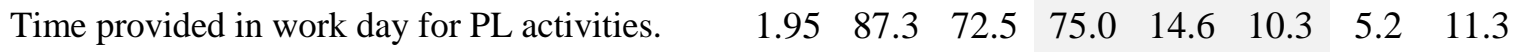

FACTOR 2: Institutional Support

\begin{tabular}{|c|c|c|c|c|c|c|c|}
\hline Expectation of annual participation in PL. & 4.36 & 8.2 & 6.2 & 6.3 & 9.4 & 84.3 & 82.1 \\
\hline PL part of school/conference improvement plan. & 4.13 & 12.1 & 7.7 & 8.5 & 15.2 & 76.3 & 65.4 \\
\hline $\begin{array}{l}\text { Educators open to new ideas to improve } \\
\text { learning.** }\end{array}$ & 3.93 & 8.9 & 7.4 & 8.0 & 14.7 & 77.4 & 71.7 \\
\hline Employer values past experience and learning. $* *$ & 3.90 & 11.2 & 10.2 & 10.5 & 16.6 & 72.9 & 68.6 \\
\hline
\end{tabular}


Table 27--Continued

\begin{tabular}{|c|c|c|c|c|c|c|c|c|}
\hline Supervisor encourages application of learning.** & 3.82 & 15.8 & 12.1 & 12.7 & 17.7 & 69.6 & 62.4 & 71.2 \\
\hline participate regular & 3.71 & 23.9 & 12.8 & 14.6 & 14.4 & 71.1 & 61.9 & 73.0 \\
\hline 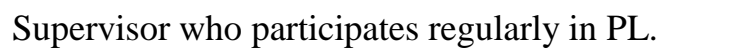 & 9 & 3 & .9 & .9 & 4.1 & 0.0 & 9 & 63.2 \\
\hline ubst & 3.66 & 26.1 & 20.4 & 21.3 & 18.0 & 60.7 & 56.0 & 7 \\
\hline pecif & 3.60 & 23.3 & 20.0 & 20.8 & 22.4 & 56.8 & 52.6 & 8.1 \\
\hline $\mathrm{pp}$ & 3.58 & 18.7 & 10.9 & 12.1 & 34.8 & 53.1 & 45.5 & 54.0 \\
\hline ng & 3.37 & 27.6 & 19.2 & 20.5 & 34.2 & 45.3 & 31.3 & 48. \\
\hline ed to & 3.30 & 32.8 & 28.6 & 29.2 & 24.5 & 46.3 & 49.3 & 45.6 \\
\hline programs provided for new & 3.00 & 49.6 & 38.5 & 40.6 & 20.4 & 39.1 & 34.5 & 40 \\
\hline age partupat & 2.70 & 54.5 & 46.3 & 48.0 & 23.0 & 9.0 & 22.4 & \\
\hline
\end{tabular}

FACTOR 3: Activity Content/Coherence

\begin{tabular}{|c|c|c|c|c|c|c|c|c|}
\hline PL aligned with SDA philosophy of education. & 4.25 & 5.2 & 3.2 & 3.5 & 13.2 & 83.3 & 79.1 & 84.6 \\
\hline culum used. & 3.64 & 14.9 & 10.5 & 11.4 & 28.4 & 60.2 & .3 & 60 - \\
\hline 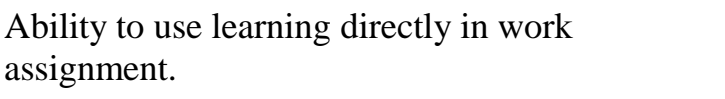 & 3 & 9.7 & 4.6 & .5 & 7.8 & 6.8 & 1.8 & 0.2 \\
\hline iblical & 5 & 21.6 & 15.8 & 17.2 & 32.9 & 49.9 & 39.5 & 52.0 \\
\hline PL helps to identify areas for improvement. & 4 & 14.2 & 12.7 & 13.4 & 39.3 & 47.4 & 42.5 & 48.3 \\
\hline $\mathrm{PL}$ is & 3.28 & 33.6 & 22.6 & 24.7 & 32.3 & 43.0 & 28.4 & 46.1 \\
\hline L includes Biblic & 3.19 & 35.4 & 23.7 & 26.2 & 35.3 & 38.5 & 29.3 & 40.3 \\
\hline 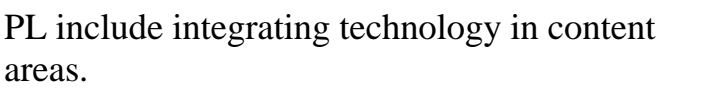 & .17 & 24.6 & 19.5 & 20.4 & 46.2 & 33.4 & 29.1 & 34. \\
\hline at & 3.11 & 34.3 & 24.1 & 25.5 & 40.1 & 34.5 & 26.1 & 36.0 \\
\hline PL sele & 3.04 & 36.1 & 27.0 & 28.8 & 37.8 & 33.4 & 24.8 & 35.3 \\
\hline$f$ & 2.99 & 47.7 & 28.1 & 31.3 & 37.4 & 31.3 & 23.1 & 32 \\
\hline PL sel & 2.98 & 37.6 & 28.7 & 30.2 & 40.4 & 29.4 & 25.6 & 30.3 \\
\hline $\begin{array}{l}\text { Educators' experience considered in planning } \\
\text { PL. }\end{array}$ & 2.83 & 43.6 & 34.0 & 36.0 & 36.8 & 27.2 & 21.8 & 28. \\
\hline luenced by performance & 2.46 & 54.5 & 54.1 & 53.2 & 26.5 & 20.2 & 17.1 & 20 \\
\hline Data used to monitor effectiveness of PL. & 2.35 & 72.0 & 56.8 & 58.9 & 24.1 & 17.0 & 8.4 & 18 \\
\hline
\end{tabular}

FACTOR 4: Teacher Beliefs

All educators should be expected to participate $\quad \begin{array}{llllllll}4.50 & 6.0 & 1.6 & 2.4 & 5.1 & 92.5 & 85.8 & 94.3\end{array}$ in PL.** 
Table 27-Continued

Ongoing PL needed to stay current with education.**

Improving student learning is main reason for professional learning.**

Ongoing PL assists in meeting future career goals. $* *$

I am more effective because of PL.**

There is a positive correlation of PL and student achievement.** $\begin{array}{llllllll}4.47 & 4.4 & 1.0 & 1.8 & 5.2 & 93.0 & 88.1 & 93.9\end{array}$

$\begin{array}{llllllll}4.39 & 4.4 & 1.5 & 2.1 & 6.7 & 91.2 & 85.0 & 92.4\end{array}$

$\begin{array}{llllllll}4.26 & 4.5 & 2.6 & 2.8 & 13.2 & 84.0 & 78.3 & 85.5\end{array}$

$\begin{array}{llllllll}4.07 & 14.9 & 4.5 & 6.9 & 14.5 & 78.5 & 63.4 & 82.6\end{array}$

$\begin{array}{llllllll}4.06 & 6.7 & 2.5 & 3.5 & 19.1 & 77.4 & 68.0 & 80.3\end{array}$

FACTOR 5: Teacher Self-Efficacy

\begin{tabular}{llllllllll}
\hline $\begin{array}{l}\text { Confident in ability to share the Biblical } \\
\text { perspective. }\end{array}$ & 4.39 & 14.1 & 0.9 & 0.1 & 1.3 & 90.3 & 85.8 & 91.4 \\
$\begin{array}{l}\text { Confident in mastery of content. } \\
\begin{array}{l}\text { Confident in use of technologies to support } \\
\text { instruction. }\end{array}\end{array}$ & 4.10 & 24.6 & 2.0 & 2.1 & 14.4 & 83.6 & 75.4 & 85.8 \\
$\begin{array}{l}\text { Have skills to address student learning } \\
\text { differences. }\end{array}$ & 3.71 & 18.6 & 4.8 & 4.8 & 22.3 & 73.0 & 81.4 & 70.7 \\
$\begin{array}{l}\text { Mastery demonstrated by academic } \\
\text { presentations. }\end{array}$ & 2.47 & 74.6 & 51.2 & 55.3 & 20.3 & 24.4 & 13.4 & 27.2 \\
\hline
\end{tabular}

* only valid responses included

** used "strongly agree" and "agree" rather than "always" and "most times"

Note: Total column includes all responses, whether the respondent identified birth year or not

is used to monitor its effectiveness (Factor 3). Not surprisingly, more than double the number of non-millennials report presenting at educational conferences or publishing educational articles in order to demonstrate mastery (Factor 5), and more non-millennials report feeling confident in their abilities overall.

\section{Multiple Linear Regression}

The results of the regression analyses showed a few differences between millennials and non-millennials in how well the five factors affecting educator professional learning predicted both the time spent on professional learning and the 
variety in types of professional learning. The regression equation for time spent on professional learning was significant for non-millennials, but not for millennials:

Time Spent Millennials $\left(\mathrm{F}_{(5,127)}=1.352, \mathrm{p}=.247\right)$, with an $\mathrm{R}^{2}$ of .051

Non-Millennials $\left(\mathrm{F}_{(5,563)}=11.335, \mathrm{p}<.001\right)$, with an $\mathrm{R}^{2}$ of .091

The regression equation for variety in types of professional learning was significant for both millennials and non-millennials:

\# of PL Types Millennials $\left(\mathrm{F}_{(5,127)}=7.144, \mathrm{p}<.001\right)$, with an $\mathrm{R}^{2}$ of .220

Non-Millennials $\left(\mathrm{F}_{(5,563)}=29.705, \mathrm{p}<.001\right)$, with an $\mathrm{R}^{2}$ of .209

\section{Time Spent}

Millennials' predicted time spent on professional learning is equal to $3.599+$ $.318(\mathrm{~F} 1)+.684(\mathrm{~F} 2)-1.106(\mathrm{~F} 3)-.008(\mathrm{~F} 4)+.216(\mathrm{~F} 5)$, where $\mathrm{F} 1=$ collaborative practice, F2 = institutional support, F3 = activity content/coherence, F4 = teacher beliefs, and F5 = teacher self-efficacy. Non-millennials' predicted time spent on professional learning is equal to $.489+.838(\mathrm{~F} 1)-.390(\mathrm{~F} 2)-.323(\mathrm{~F} 3)+.386(\mathrm{~F} 4)+.625(\mathrm{~F} 5)$. All factors are represented by the means of the various items that made up these factors.

Tables 28 and 29 compare the mean, standard deviation, and correlations between the variables for millennials and non-millennials. In general, the numbers are higher for non-millennials than millennials. Non-millennials spend more time participating in professional learning, and they report more opportunities for collaboration, greater institutional support, activities that are more content-based and coherent, greater belief in the effectiveness of professional learning, and more confidence in their abilities.

Correlation coefficients are weak between all five factors and time spent on professional learning for both groups. The correlations between independent (predictor) 
Table 28

MLR Descriptive Statistics: Time Spent in Professional Learning (Millennials)

\begin{tabular}{lccccccc}
\hline \multirow{2}{*}{ Variable } & Mean & SD & \multicolumn{5}{c}{ Correlation } \\
& & & 2 & 3 & 4 & 5 & 6 \\
\hline 1 Time spent & 4.16 & 2.299 & .02 & .08 & -.09 & -.05 & .04 \\
2 Collaborative Practice & 2.44 & .716 & & .74 & .78 & .27 & .29 \\
3 Institutional Support & 3.42 & .717 & & & .67 & .15 & .17 \\
4 Activity Content/Coherence & 2.98 & .675 & & & & .35 & .22 \\
5 Teacher Beliefs & 4.10 & .617 & & & & & .05 \\
6 Teacher Self-Efficacy & 3.55 & .509 & & & & & \\
\hline
\end{tabular}

Table 29

MLR Descriptive Statistics: Time Spent in Professional Learning (Non-Millennials)

\begin{tabular}{lccccccc}
\hline \multirow{2}{*}{ Variable } & Mean & SD & \multicolumn{5}{c}{ Correlation } \\
& & & 2 & 3 & 4 & 5 & 6 \\
\hline 1 Time spent & 4.33 & 2.742 & .21 & .10 & .13 & .15 & .24 \\
2 Collaborative Practice & 2.74 & .767 & & .76 & .80 & .27 & .37 \\
3 Institutional Support & 3.67 & .707 & & & .70 & .28 & .25 \\
4 Activity Content/Coherence & 3.23 & .647 & & & & .34 & .30 \\
5 Teacher Beliefs & 4.34 & .549 & & & & & .25 \\
6 Teacher Self-Efficacy & 3.76 & .587 & & & & & \\
\hline
\end{tabular}

variables are mostly weak; the exceptions are between collaborative practice and institutional support (.76), between collaborative practice and activity content/coherence (.80), and between institutional support and activity content/coherence (.70), all of which are strong for both groups, slightly stronger for non-millennials than millennials. 
The results, summarized in Tables 30 and 31, indicate that for millennials, only activity content/coherence $(p=.028)$ is a significant predictor of the time spent in professional learning (with a negative correlation), with the more content-based activities aligned with school goals resulting in less time spent on professional learning. For nonmillennials, collaborative practice $(p<.001)$, teacher beliefs $(p=.026)$, and teacher selfefficacy $(p<.001)$ are all significant predictors of the time spent in professional learning. For non-millennials, the more opportunities available for collaborative practice, the more time they spend in professional learning. Similarly, the more confidence that nonmillennial educators have in their own abilities, the more time they spend in professional learning. Of the five factors, collaborative practice appears to be the most important predictor for non-millennials.

Table 30

MLR Results: Time Spent in Professional Learning (Millennials)

\begin{tabular}{|c|c|c|c|c|c|c|c|}
\hline \multirow{2}{*}{ Variable } & \multirow{2}{*}{$\mathrm{b}$} & \multirow{2}{*}{$\mathrm{SE}$} & \multicolumn{2}{|c|}{ CI 95} & \multirow{2}{*}{$\beta$} & \multirow[b]{2}{*}{ 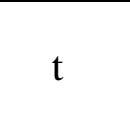 } & \multirow{2}{*}{$\rho$} \\
\hline & & & Lower & Upper & & & \\
\hline Collaborative Practice & 0.318 & 0.507 & -0.685 & 1.321 & 0.099 & 0.627 & .532 \\
\hline Institutional Support & 0.684 & 0.428 & -0.162 & 1.531 & 0.213 & 1.600 & .112 \\
\hline Activity Content/Coherence & -1.106 & 0.497 & -2.089 & -0.123 & -0.325 & -2.227 & .028 \\
\hline Teacher Beliefs & -0.008 & 0.347 & -0.695 & 0.680 & -0.002 & -0.022 & .983 \\
\hline Teacher Self-Efficacy & 0.216 & 0.410 & -0.595 & 1.027 & 0.048 & 0.528 & .599 \\
\hline
\end{tabular}

Note: $\mathrm{F}_{(5,127)}=1.352, \mathrm{p}=.247, \mathrm{R}^{2}=.051$

\section{Types of Professional Learning}

Millennials' predicted types of professional learning activities is equal to $-3.358+$ $2.810(\mathrm{~F} 1)-1.213(\mathrm{~F} 2)-1.286(\mathrm{~F} 3)+1.490(\mathrm{~F} 4)+1.599(\mathrm{~F} 5)$, where $\mathrm{F} 1=$ collaborative 
Table 31

MLR Results: Time Spent in Professional Learning (Non-Millennials)

\begin{tabular}{lrrrrrrrr}
\hline \multicolumn{1}{c}{ Variable } & \multirow{2}{c}{$\mathrm{b}$} & SE & \multicolumn{2}{c}{ CI 95 } & \multirow{2}{*}{$\beta$} & \multirow{2}{*}{$\mathrm{t}$} & \multicolumn{1}{c}{$\rho$} \\
\hline Collaborative Practice & 0.838 & 0.220 & 0.405 & 1.270 & 0.294 & 3.802 & $<.001$ \\
Institutional Support & -0.390 & 0.198 & -0.780 & 0.000 & -0.126 & -1.964 & .050 \\
Activity Content/Coherence & -0.323 & 0.235 & -0.785 & 0.139 & -0.096 & -1.373 & .170 \\
Teacher Beliefs & 0.386 & 0.172 & 0.047 & 0.724 & 0.097 & 2.237 & .026 \\
Teacher Self-Efficacy & 0.625 & 0.163 & 0.304 & 0.945 & 0.168 & 3.831 & $<.001$ \\
\hline
\end{tabular}

Note: $\mathrm{F}_{(5,563)}=11.335, \mathrm{p}<.001, \mathrm{R}^{2}=.091$

practice, $\mathrm{F} 2=$ institutional support, $\mathrm{F} 3=$ activity content/coherence, $\mathrm{F} 4=$ teacher beliefs, and F5 = teacher self-efficacy. Non-millennials' predicted types of professional learning activities is equal to $-4.207+2.610(\mathrm{~F} 1)-.420(\mathrm{~F} 2)-1.525(\mathrm{~F} 3)+1.229(\mathrm{~F} 4)+1.647$ (F5). All factors are represented by the means of the various items that made up these factors.

Tables 32 and 33 compare the mean, standard deviation, and correlations between the variables for millennials and non-millennials. As it was for the analysis using time spent as the dependent variable, the correlation coefficients are weak between all five factors and the variety in types of professional learning which educators participate in, for both millennials and non-millennials. Similarly, the correlations between independent (predictor) variables are mostly weak; the exceptions are between collaborative practice and institutional support (.75 for millennials and .76 for non-millennials), between collaborative practice and activity content/coherence ( .78 for millennials and .80 for nonmillennials), and between institutional support and activity content/coherence (.69 for millennials and .70 for non-millennials), all of which are strong. 
Table 32

MLR Descriptive Statistics: Types of Professional Learning (Millennials)

\begin{tabular}{lccccccc}
\hline \multirow{2}{*}{ Variable } & Mean & $S D$ & \multicolumn{5}{c}{ Correlation } \\
& & & 2 & 3 & 4 & 5 & 6 \\
\hline 1 Types of PL & 7.32 & 4.060 & .31 & .09 & .16 & .27 & .28 \\
2 Collaborative Practice & 2.46 & .737 & & .75 & .78 & .29 & .30 \\
3 Institutional Support & 3.44 & .714 & & & .69 & .17 & .18 \\
4 Activity Content/Coherence & 2.99 & .684 & & & & .36 & .23 \\
5 Teacher Beliefs & 4.11 & .619 & & & & & .05 \\
6 Teacher Self-Efficacy & 3.55 & .510 & & & & & \\
\hline
\end{tabular}

Table 33

MLR Descriptive Statistics: Types of Professional Learning (Non-Millennials)

\begin{tabular}{lccccccc}
\hline \multirow{2}{*}{ Variable } & Mean & $S D$ & \multicolumn{5}{c}{ Correlation } \\
& & & 2 & 3 & 4 & 5 & 6 \\
\hline 1 Types of PL & 8.00 & 4.411 & .35 & .22 & .21 & .24 & .34 \\
2 Collaborative Practice & 2.74 & .768 & & .76 & .80 & .27 & .37 \\
3 Institutional Support & 3.67 & .705 & & & .70 & .27 & .25 \\
4 Activity Content/Coherence & 3.23 & .647 & & & & .34 & .30 \\
5 Teacher Beliefs & 4.34 & .549 & & & & & .24 \\
6 Teacher Self-Efficacy & 3.75 & .592 & & & & & \\
\hline
\end{tabular}

The results, summarized in Tables 34 and 35, indicate that collaborative practice, teacher beliefs, and teacher self-efficacy are all significant predictors of the variety in types of professional learning that educators participated in, for both millennials and nonmillennials. Institutional support is not significant for either group. Activity 
Table 34

MLR Results: Types of Professional Learning (Millennials)

\begin{tabular}{lccrrrrr}
\hline \multicolumn{1}{c}{ Variable } & \multirow{2}{c}{$b$} & \multirow{2}{*}{$S E$} & \multicolumn{2}{c}{ CI 95 } & \multirow{2}{*}{$\beta$} & \multirow{2}{*}{$\rho$} \\
\hline Collaborative Practice & 2.810 & 0.800 & 1.227 & 4.393 & 0.510 & 3.513 & .001 \\
Institutional Support & -1.213 & 0.701 & -2.600 & 0.174 & -0.213 & -1.731 & .086 \\
Activity Content/Coherence & -1.286 & 0.800 & -2.870 & 0.298 & -0.217 & -1.607 & .111 \\
Teacher Beliefs & 1.490 & 0.556 & 0.390 & 2.591 & 0.227 & 2.680 & .008 \\
Teacher Self-Efficacy & 1.599 & 0.656 & 0.301 & 2.898 & 0.201 & 2.437 & .016 \\
\hline
\end{tabular}

Note: $F_{(5,127)}=7.144, p<.001, R^{2}=.220$

Table 35

MLR Results: Types of Professional Learning (Non-Millennials)

\begin{tabular}{lrrrrrrrr}
\hline \multicolumn{1}{c}{ Variable } & \multicolumn{7}{c}{ C } & \multicolumn{7}{c}{ CI 95 } & \multicolumn{2}{c}{ Upper } & $\beta$ & $t$ & $\rho$ \\
& & & Lower & & & & \\
\hline Collaborative Practice & 2.610 & 0.415 & 1.796 & 3.425 & 0.455 & 6.295 & $<.001$ \\
Institutional Support & -0.420 & 0.376 & -1.159 & 0.318 & -0.067 & -1.117 & .264 \\
Activity Content/Coherence & -1.525 & 0.444 & -2.398 & -0.653 & -0.224 & -3.435 & .001 \\
Teacher Beliefs & 1.229 & 0.325 & 0.591 & 1.866 & 0.153 & 3.785 & $<.001$ \\
Teacher Self-Efficacy & 1.647 & 0.306 & 1.047 & 2.248 & 0.221 & 5.391 & $<.001$ \\
\hline
\end{tabular}

Note: $\mathrm{F}_{(5,563)}=29.705, \mathrm{p}<.001, \mathrm{R}^{2}=.209$

content/coherence is significant for non-millennials and negatively correlated with types of professional learning, but it is not significant for millennials.

\section{Summary of Major Findings}

This study explored the professional learning practices of educators in the SDA school system in North America and the factors that impact them, including a comparison 
between millennials and non-millennials. The following key findings about professional learning in the Adventist system emerged from this study:

- Educators participate most often in traditional forms of professional learning (e.g., workshops, conferences, seminars).

- Educators, in general, do not spend the sustained time in ongoing teacher professional learning that the literature suggests is needed to sustain instructional improvement.

- Non-millennials participate in a greater variety of activities and report greater satisfaction with the professional learning opportunities they have.

- Non-millennials participate more often in non-academic activities, and much more often than millennials in leadership-type activities; millennials participate more often in academic courses with more enrolled in online than in face-to-face courses.

- Educators in all generations, but especially millennials, report a desire, but few opportunities, to collaborate with colleagues.

- Collaborative practice and teacher self-efficacy are the most significant predictors of time spent in professional learning.

- Institutional support is not a significant predictor of either time spent in professional learning or the variety of types of professional learning that educators participate in.

- Teacher factors (both beliefs and self-efficacy) are rated higher than either Activity or School factors. 
- Few educators participate in the planning of professional learning, and few believe activities are selected based on an analysis of student and/or educator needs.

- The factors that predicted time spent were different for millennials and nonmillennials; the factors that predicted the variety in types of activities participated in were similar, with small differences, for millennials and non-millennials.

- Although collaborative practice has the greatest impact on both time spent in professional learning and the variety of types of activities selected, few nonmillennials and even fewer millennials report opportunities for collaboration.

- Non-millennials report higher levels of efficacy than millennials in most areas, with the exception of technology use to support instruction. 


\section{CHAPTER 5}

\section{DISCUSSION, CONCLUSIONS, AND RECOMMENDATIONS}

\section{Purpose of the Study}

The purpose of this study was to explore the professional learning practices of educators in the SDA school system in North America and the factors that impact those practices. For the purpose of this study, the professional learning practice of teachers has been conceptualized as the time teachers spend participating in professional learning activities and the number and types of activities they participate in.

\section{Research Methodology}

A descriptive quantitative research design was selected because it best fits the research questions of this study which describes learning practices and explores the measurable factors that impact these practices. An invitation to participate in an anonymous online survey was sent to approximately 4,500 K-12 educators in the Adventist school system across North America. Participation was voluntary. Out of the 1033 responses received, 749 were complete enough to form the basis for this study.

The data collected was organized to address the four research questions that guided this study. Data was collected using a researcher-designed instrument which was administered through Survey Monkey ${ }^{\mathrm{TM}}$. To complete the statistical analyses, SPSS ${ }^{\mathrm{TM}}$ was used. Factors were identified using exploratory factor analysis, and both descriptive results and multiple linear regression analyses were used to assess the impact of these 
factors on the time spent and the number of types of professional learning that educators participate in.

\section{Summary of the Literature}

Two decades of research have provided evidence that effective learning, for both students and teachers, involves the learners as participants in the creation of knowledge rather than simply as recipients of knowledge transmitted by experts (Borko, 2004). Adult learning theory suggests that adults, in particular, need to be actively involved in constructing meaning, so the most effective professional learning options will be tied to previous knowledge, relevant to current contexts, and problem-centered (Knowles et al., 2012; Merriam et al., 2007). Such learning is complex and involves factors beyond the activity itself (Opfer \& Pedder, 2011).

In short, current literature suggests three main factor groups to be considered when conducting research on professional learning for teachers: the professional learning activity, which should be active, coherent, sustained, collaborative, and focused on content; the school context, including school structures and support, standards and expectations regarding learning, incentives and accountability measures, and the general culture of teaching and learning; and the teachers themselves, including their prior experiences and knowledge, their beliefs about learning, their purposes for learning, and their sense of self-efficacy. These three factor groups (activity, school, and teacher) provided the conceptual framework for this research study.

In addition, much has been written about millennials and how their needs and expectations often differ from older generations in the workforce. A study by Coggshall et al. (2011), for example, described key millennial characteristics, some of which could 
impact the participation of millennial teachers in ongoing professional learning. These include an orientation toward collaboration, desire for feedback, use of technology, and expectation for customization. As more and more millennial teachers enter the workforce, it will be increasingly important for school leaders to identify how they can best meet the ongoing professional learning needs of these new teachers.

\section{Discussion of Findings}

Many of the findings of this study are consistent with the findings of large national studies on teacher learning in public schools (Coggshall et al., 2010; DarlingHammond et al., 2009) as well as smaller studies of the learning practices of teachers in independent schools (Headley, 2003; Montoro, 2012; Murray, 2010). The new findings regarding the differences in professional learning practice between millennial and nonmillennial teachers will add to the body of knowledge focused on the needs and expectations of millennials in the workplace, particularly teachers in faith-based schools.

The four research questions that guided this study focus on describing the professional learning practices of educators and identifying the factors that impact these practices, including the differences between millennial and non-millennial educators. Several findings from this study can contribute to the understanding of these practices in the K-12 SDA school system in North America, and can assist in systemic efforts to improve professional learning policy and practice.

In general, there is a high level of expectation in the system for annual participation in professional learning. $84 \%$ of respondents believe that such participation is always or most times expected by their employer. This may be due, in part, to the requirements imposed by the system for maintaining a denominational teaching 
certificate. While evidence of continued learning is not currently mandated to renew many state or provincial teaching certificates, teachers in the SDA school system are required to participate in ongoing professional learning to maintain their denominational teaching certificates, including academic courses for those who do not have master's degrees (NAD, K-12 Educators' Certification Manual, 2017).

Most (83.3\%) of the respondents believe that their learning experiences are aligned with the Adventist philosophy of education, and almost all (90.3\%) have confidence in their ability to share Biblical perspectives with their students. While this is not surprising given the underlying philosophy of a faith-based educational system that emphasizes a Biblical worldview, it is encouraging that the data supports a focus on this mission.

Most of the educators who completed the survey participate regularly in professional learning, and most believe that this is also true for the other teachers and administrators in their schools. This would be expected in a system that requires ongoing learning requirements for recertification purposes. The majority $(78.5 \%)$ of respondents believe that such learning makes them better educators. This commitment is important in building a culture of learning throughout the system, especially since research has shown that beliefs and values affect the results of professional learning (Avalos, 2011).

The findings of this study provide a first step in addressing the effectiveness of current professional learning practices in the SDA school system in North America. Descriptive statistics provided a clear picture of professional learning practices in the system, both time spent and types of activities. The exploratory factor analysis identified five factors that impacted this practice: collaborative practice, institutional support, 
activity content and coherence, teacher beliefs, and teacher self-efficacy. Multiple linear regression analyses assessed the impact of these factors on both the time spent and the types of activities selected. A discussion of these findings follows, organized by the four research questions that guided the study. This discussion provides a springboard for further discussion regarding implications for practice. Recognizing the importance of ongoing teacher learning for the improvement of instruction and consequently, of student success, educational leaders can use the results of this study to improve the professional learning opportunities available to the teachers they are responsible for supporting.

\section{Research Question \#1}

The results of this study reveal a wide variation in the professional learning practices of teachers in the Adventist school system, both in time spent and in the types of activities selected. Like their public and independent school counterparts (DarlingHammond et al., 2009; Murray, 2010), teachers in the Adventist school system participate mostly in traditional forms of professional learning (e.g., workshops, seminars, conferences, reading), in spite of research and experience that suggests that these forms are ineffective in improving instructional practice (Desimone et al., 2002).

Various studies in the past two decades have concluded that this ineffectiveness may be due, in part, to the focus of traditional forms on top-down knowledge transmission without the provision of sustained and supported opportunities for teachers to implement what they have learned (Jaquith et al., 2010). Like teachers in a 2014 study sponsored by the Gates Foundation, teachers in the Adventist school system believe that professional learning should focus less on presentations by outside experts and more on collaborative opportunities to apply and practice what they have learned. 
"I feel as though most 'professional development' is sitting in a room listening to a teacher talk about their pet theory/project that they're presenting in order to get a commendation/pay raise," wrote one teacher. "If you want me to actually use something," he went on, "I have to try it out for myself in a classroom situation, and how often do I get that during professional development?” (Respondent 589). Fewer than half of the educators surveyed in this study believe that their professional learning is directly related to their current needs. $60 \%$ of respondents report that the learning opportunities they have are aligned with the curriculum being used, but only $33 \%$ believe these activities are selected based on an analysis of educator needs.

Concerning types of professional learning activities, survey results show that though Adventist educators participate in more face-to-face than online learning activities, the difference is not large. $96 \%$ of respondents report participation in face-toface activities, while $81 \%$ report participation in online activities. Of the respondents who took academic courses in the past two years, more took them online than face-to-face. This suggests that it may be time to consider more seriously other online models of professional learning. Cator, Schneider, and Vander Ark (2014) report that "educators who join online communities, and who connect via social media as a professional learning tool, represent an important trend in professional development" (p. 11). Other researchers also describe thriving online teacher communities, both formal and informal, and their importance in providing sustained opportunities for teachers to connect professionally (Lieberman \& Pointer Mace, 2010; Schalger \& Fusco, 2003).

A related finding suggests that teachers want opportunities to collaborate with each other but few actually have such opportunities. All but two of the mean scores for 
the items which comprised the Collaborative Practice factor were less than 3 (on a 5point scale). On items that focused on collaboration, $30 \%$ or fewer educators answered "most times" or "always." This includes items such as opportunities to collaboratively examine student work, peer coaching, opportunities to plan instruction with others, and experienced educators working with new educators. "Every teacher is an island," lamented one survey respondent (Respondent 734).

This finding concurs with the work of Darling-Hammond et al. (2009), Andrews et al. (2006), and Coggshall et al. (2010). The NSDC study, for example, found that “teachers lack time and opportunities to view each other's classrooms, learn from mentors, and work collaboratively" (Darling-Hammond et al., 2009, p. 2). Fullan (2016) adds that most teachers find that "daily demands crowd out serious sustained improvements" (p. 98). Responses from Adventist teachers suggest that this lack of time and opportunity is also true in the Adventist school system. Teachers in the many small schools in rural communities often experience even more isolation than would teachers in larger schools. "Our system is not set up for one room teachers," wrote one respondent. "As a teacher in a one room school over 5 hours away from my conference office, it is difficult to find 'extra' time to pursue professional development" (Respondent 562).

Meaningful collaboration takes time, and the literature makes it clear that sustained time in learning and collaborative practice to support that learning is necessary for new knowledge to "stick" and be effectively applied in the classroom (Frost, 2012; Loucks-Horsley et al., 1987). Though $20 \%$ of respondents report spending 20 days or more annually on professional learning, 50\% spend less than a week, and there is no evidence that the time spent is focused time on a single initiative. In contrast, Singapore's 
teachers are required to spend 100 hours in professional learning every year (Kempton, 2013, para. 2). Such sustained time is recognized as part of the teacher's contract. Rather than being focused, one respondent described his experience as "too 'helter skelter"” with "much left up to chance and individual opportunities" (Respondent 718). Lack of focus, combined with limited time and opportunity, leads to frustrated teachers (Bassett et al., 2013), and teachers in the Adventist school system are no exception. A language arts teacher captures the frustration of time constraints:

My biggest issue with professional learning is that every new thing becomes another chore and a new expectation piled on top of the mountain of expectations. And there's never enough time to practice a new strategy to achieve mastery before we're hit with something new. It leaves me exhausted and feeling like my hard work, long hours, and sincere efforts are never good enough. (Respondent 290)

Providing time and opportunity for collaboration is challenging. Several survey responses from Adventist educators mentioned lack of time as the reason they do not participate more often in professional learning. In the words of a millennial respondent:

"The bottom line for me is that I don't have time for much professional development with everything else that needs to be done" (Respondent 478). Change will require Elmore's (2002) "reciprocity of accountability" (p. 89), where educational leaders take responsibility for building teacher agency, even if it means adjusting workloads and schedules. It may also mean exploring new models of delivering professional learning and using technology to build professional learning communities and to provide online opportunities for educators to connect and to support each other.

\section{Research Question \#2}

The professional learning practices of millennial and non-millennial educators are similar in many ways. Though non-millennials report spending a few more days per year 
in professional learning, the distribution of teachers is proportionately similar. For example, $21 \%$ of millennials and $20 \%$ of non-millennials report 20 days or more, and $21 \%$ of millennials and $19 \%$ of non-millennials report spending 2-4 days per year. Similarly, only $9 \%$ of both groups participate in 15 or more different types of learning activities with the majority of both groups participating in 5-10 types.

The differences in professional learning practices between the two groups may reflect, to some extent, a difference in career stages and the system's expectations for teachers at each stage. For example, more millennial teachers report taking academic courses, both face-to-face and online, which may be a result of the NAD requirement that new teachers complete additional academic credit within the first three years of teaching in order to upgrade to the next certificate level. Non-millennials report more participation in non-academic activities--a reflection, perhaps, of the fact that those educators who hold professional certificates are not required to complete academic credit to renew their teaching and administrator certificates. Non-millennials tend to participate in a greater variety of activities; $24 \%$ report 11 types of activities or more, while only $15 \%$ of millennials report the same.

Not surprisingly, non-millennials report more involvement in activities that involve leadership and the sharing of expertise (e.g., committee membership, school evaluation teams, formal presentations on education themes). While it is natural for more experienced teachers to be given leadership roles, it is also important for younger teachers to have these opportunities. Hargreaves and Goodson (2006) suggest that teaching is often driven by what they call a "generational center of gravity, a dominant demographic of teachers who are of a particular age and career stage” (p. 23). Non- 
millennial teachers with more experience are likely the "center of gravity" that dominate, to a large extent, the leadership options available in the system. Ensuring that leadership options are available for less-experienced millennials will require intentional planning.

It is no surprise that millennials participate in more online activities than do nonmillennials; $87 \%$ of millennials report participating in online professional learning activities in the past two years compared to $79 \%$ of non-millennials. This may be due in part to the greater accessibility and flexibility that technology affords, qualities that are important to millennials (Hershatter \& Epstein, 2010; Meier \& Crocker, 2010). It may also reflect millennials' comfort with technology, having grown up as "digital natives" (Prensky, 2001).

Although educators in all generations expressed a desire for more time to collaborate with colleagues, more millennials reported both a desire for additional collaboration and fewer opportunities to do so. Coggshall et al. (2010) found that millennial teachers view collaboration as an opportunity to learn. $62 \%$ of the millennials who responded in the current study said they would be more involved in professional learning if they had scheduled time to meet with colleagues. This finding supports the notion that millennials, having grown up in a connected, socially-networked world, expect to be part of collaborative work environments (Coggshall et al., 2011; Luscombe, Lewis, \& Biggs, 2013; Wong \& Wong, 2007).

Perhaps the biggest difference in millennial and non-millennial responses concerns their perceptions of the effectiveness of the professional learning activities they have participated in. Fewer millennials believe they are more effective teachers as a result of their participation in professional learning. In general, they tend to see their 
experiences as less relevant, less related to their current needs. This is especially apparent in the items that deal with collaborative practice. $58 \%$ of millennials report rarely or never visiting other schools compared to $47 \%$ of non-millennials. $66 \%$ report rarely or never observing other teachers (51\% of non-millennials report the same), and $71 \%$ report rarely or never having opportunity to work with a peer coach (57\% of non-millennials report the same).

Millennials express similar concerns regarding the activities themselves. Only $28 \%$ of millennials report that the activities are always or most times related to their current needs compared to $46 \%$ of non-millennials who believe the same. Only $42 \%$ say they are able to use their learning directly in their work assignment always or most times; $60 \%$ of non-millennials report the same. Several expressed concern that the activities provided were not specific to the level or the content they teach. One millennial described the activities as "nothing but a review from college classes" (Respondent 12). Another claimed they were a "waste of my time" (Respondent 252). A first year teacher commented, at the end of the survey, "I almost resent the amount of (seemingly) unnecessary non-content area-specific information I'm expected to sit through" (Respondent 425).

These comments mirror the research that shows that one-size-fits-all approaches are rarely effective (Avalos, 2011; Mockler, 2013). One millennial respondent sums it up well: “I'm a fairly new teacher, and I'm positive that what I need out of professional development is completely different from [what] the twenty-year veterans in my school need. I am fresh out of college, and I barely know my content area, much less how to apply that in the classroom" (Respondent 589). 
Providing a differentiated model of professional learning for teachers in the Adventist school system will be challenging given the isolation and workload of multigrade teachers and the constraints of time, distance, and limited resources. Several experts recommend that technology can assist in differentiating professional learning (Coggshall et al., 2011; Dede et al., 2016; Richardson, 2011). This may provide an option that would work in the Adventist school system. In addition, this differentiation may, in turn, help in the retention of teachers in the teaching profession (Coggshall et al., 2010; Shaw \& Fairhurst, 2008).

\section{Research Question \#3}

The third research question focused on the factors that impact the professional learning practices of teachers. Of the five factors identified in the factor analysis, collaborative practice, activity content/coherence, and teacher efficacy were all significant predictors of time spent in professional learning; collaborative practice, activity content/coherence, teacher beliefs, and teacher efficacy were all significant predictors of the variety in types of professional learning that educators participate in. Institutional support was not a significant predictor of either.

Of these factors, collaborative practice is the most important predictor of both time spent and types of participation. In short, the more opportunities available for collaborative practice, the more time educators spend in professional learning and the more types of activities they participate in. "Being able to network and share experiences among teachers in small schools is at the top of my list," wrote one survey respondent (Respondent 190). "Creating an environment of sharing new things would do more for me than most anything else," wrote another (Respondent 142). This finding supports the 
work of Andrews et al. (2006) who found that the learning experiences teachers valued the most were the ones that gave them opportunities to collaborate with and learn from other teachers (p. 8).

This finding also reflects the theoretical underpinnings of this study. Through collaboration, teachers are able to create meaning as they apply their learning to their practice and share their findings with others. This emphasis on the context of the learner is grounded in a constructivist approach to learning where "knowledge is not the result of passive reception" but rather a process whereby learners actively construct their own meaning (Noddings, 2012, p. 127). By collaborating, teachers engage their own contexts to shape their learning. They make decisions about what to keep, what to discard, and what to adapt. They reflect on their current beliefs and practice and may decide to give some things up in order to accommodate their new learning. This process is complex and acknowledges the learner, as complexity theorists point out, as "a complex unity that is capable of adapting itself to ... new and diverse circumstances" (Davis \& Sumara, 2006, p. 14). The meaning created in this complex process is more likely to result in sustainable and meaningful change.

Second to collaborative practice in predicting time spent and variety in types of participation is teacher efficacy. The more confidence teachers had in their abilities, the greater the variety of learning activities they participated in and the more time they spent doing so. This finding aligns with the literature on self-efficacy. In his work on how selfefficacy contributes to academic development, Bandura (1993) reviewed the research on personal efficacy and concluded that people with a high sense of efficacy see difficulties as challenges to be overcome. They set challenging goals for themselves and have strong 
motivation to pursue those goals. They see failure as the result of a lack of knowledge or skills that they then set out to acquire.

It would follow, then, that teachers with a high sense of self-efficacy would likely participate more in professional learning activities as they seek solutions to problems. Referring to several research studies, Hoy, Sweetland, and Smith (2002) concluded that there are "strong links between teacher efficacy and teacher behaviors that foster student achievement" (p. 78). Survey responses showed that $91 \%$ of educators in the Adventist system believe that improving student learning is always or most times their main reason for participating in professional learning. That belief, coupled with a strong sense of confidence in their abilities to help students succeed, leads to more time spent on professional learning and a greater variety of activities from which to learn. In this study, non-millennials, who have a higher sense of self-efficacy than millennials, also spend more time in professional learning and participate in more types of activities.

Given the impact of self-efficacy on teacher motivation and student success, school leaders would do well to consider ways of increasing the efficacy of all teachers, especially millennials. Good leaders can do much to build teacher confidence by providing opportunities that build agency. Bandura's (1993) observation that, in addition to setting high standards for their children, parents must also build their "sense of efficacy" so that the children see those standards as possible rather than beyond their reach is also true of teachers (p. 137). Leaders can build efficacy by building agency in teachers-involving them in decision-making, recognizing expertise, empowering choice and self-direction, allowing them to take ownership of their learning. 
Darling-Hammond et al. (2009) found that this type of teacher empowerment is often lacking in school systems. In their study, fewer than $25 \%$ of teachers believed they had any influence over school decisions and policies, and fewer than half believed they had some influence over their professional learning (p. 6). Similarly, fewer than half of the SDA educators who contributed to this research study said that they participated in setting goals and planning for professional learning. "The most positive professional learning opportunities typically come when I have some choice in addressing professional growth and then have the resources to be able to access that training," wrote one teacher (Respondent 404). "It is time," wrote another, "to empower teachers as primary assets to accomplish this goal" (Respondent 250).

Though the factors described above were significant predictors of time spent and types of activities, the correlations between these variables was weak. The correlation between collaborative practice and activity content/coherence, however, was strong. This supports the notion that collaborative practice usually involves a focus on content that aligns with what teachers are doing in the classroom. In addition, though institutional support was not a significant predictor of either time spent or types of activities, there was a strong correlation between institutional support and both collaborative practice and activity content/coherence. This suggests, perhaps, that higher institutional support leads to more collaborative practice and to activities that are content-focused and aligned with district goals.

That institutional support was not a significant predictor of the time educators spend and the types of professional learning they participate in is somewhat surprising. On the survey items relating to institutional support, the majority of respondents agreed 
that their employers valued ongoing learning and provided some budget and supports like substitute teachers to facilitate the process. Most teachers believe, however, that additional funding is needed, along with access to more relevant options and incentives to participate. This suggests, perhaps, that teachers value ongoing professional learning enough that institutional support does not have much impact on their participation. Though they may wish for additional support, they would choose to participate with or without it. The ongoing recertification requirements, often absent in public school systems, may also provide the motivation for teachers to participate, with or without institutional support to do so. This may not, however, be the best motivator for professional learning.

Data collected from conference superintendents showed a wide variation in resources earmarked for professional learning, with annual budget amounts that range from $\$ 0$ to $\$ 75,000$. This, too, has been found to be true in other educational systems (Gulamhussein, 2013; Murray, 2010; National Commission on Teaching, 1996). Comparisons are difficult to make, however, since there is no consistency in what is included in the budgeted numbers. Some budgets include a flat rate amount per teacher per year. Others budget only for district-wide conferences which all teachers are expected to attend. The costs for transportation and substitute teachers are included by some but not by all. Policy-makers should attend, not only to the funds set aside for ongoing professional learning, but also to how these funds are being used. Institutional support also means paying greater attention to empowering teachers with both voice and choice so that they can take ownership of their learning. 
Even more puzzling, perhaps, is the negative correlation of content-based activities with the variety in types of activities that educators participate in. The data suggests that the more content-based the activities are, and the more they align with school and/or conference goals, the fewer types of activities educators participate in. Perhaps those educators who participate in fewer types of learning activities are those that attend only the events mandated by the conference for all educators, while those who spend more time and participate in a greater variety of activities are the ones who choose to go beyond the required "PD days," selecting a variety of activities according to their own interests. The negative correlation may also be the result of the randomness of professional learning practices in the system, where "much is left up to chance" (Respondent 718).

\section{Research Question \#4}

Survey results show a few differences in the factors that influence the professional learning practices of millennials and non-millennials. None of these differences are surprising. Most, however, underline the importance of differentiating learning opportunities to ensure that individual needs are met.

Several differences between millennials and non-millennials are noted in terms of the factors that influence time spent in professional learning. As discussed earlier, institutional support was not a significant factor for either group; the other four factors were significant for one group but not the other. Collaborative practice, teacher beliefs, and teacher self-efficacy were significant factors for non-millennials; activity content/coherence was a significant factor, negatively correlated, for millennials. Again, it is possible that teachers who spend the least time in professional learning are those who 
participate only in the required activities sponsored by the conference; these activities are likely more intentionally content-based and driven by conference-wide goals.

Millennials, especially those who are in their first few years of teaching, may not have the time, and may not even be as aware of the requirements and opportunities, as their more experienced colleagues. In addition, the literature on millennials suggests that they may put more importance on a work-life balance (Hershatter \& Epstein, 2010) and may be unwilling to commit extra time beyond the minimum requirement to participate in professional learning. Recently graduated, they may be spending considerable time, to use Schön's (1995) metaphor, simply translating the "high ground" of research-based theory to the "swamp" of everyday practice (p. 28). Non-millennials, having survived those early years, may be more open to spending additional time in professional learning, and be more likely to participate in a random variety of activities that match their interests, not necessarily those that are content-based or aligned with conference-wide initiatives.

When it comes to self-efficacy, millennials may lack the self-confidence in their own skills and knowledge that non-millennials have attained; hence, this factor did not correlate with time spent in professional learning for millennials. School leaders may need to be more intentional about building the efficacy of these teachers. One millennial observed, "opportunities are given to the oldest teachers at our school. New teachers need to 'pay their dues' too long" (Respondent 287). Collaborative practice also did not correlate with time spent for millennials, perhaps because newer teachers may not have frequent opportunities to collaborate. On the survey items having to do with collaborative practice, more than half of the millennial respondents said that they rarely or never had 
those opportunities. As a result, collaborative practice would not have the same impact on the time spent as it would for non-millennials.

Not surprisingly, when it comes to technology, more millennials than nonmillennials reported that they were always or most times confident in their skills. A Pew Research Center survey found that many millennials believe their use of technology is what distinguishes them from older generations, and millennials with a college education use technology even more frequently than those without one (Taylor \& Keeter, 2010). This may be an area that leaders can capitalize on, not only by recognizing millennial teachers' natural use of technology to enhance instruction, but also by using that technology to support them in their ongoing professional learning. Coggshall et al. (2011) suggest that technology can be used to provide meaningful feedback, support collaboration and shared practice, and enhance teacher evaluation (p. 29).

Regarding the types of professional learning that educators participate in, collaborative practice, teacher beliefs, and teacher self-efficacy were significant predictors for both millennials and non-millennials. The only real difference between the generational groups was that activity content/coherence was also a significant predictor (with a negative correlation) for non-millennials, but not for millennials. This would suggest that the less content-focused the activities were, and the less they aligned with district goals, the more types of activities non-millennials participated in. Perhaps this means that non-millennials, with higher self-efficacy and additional experience, also have access to a greater variety of types of learning. Many, having attained professional certification status, also have greater freedom to participate in activities of their choosing. This finding relates to Huberman's (1995) conclusion that "teachers have different aims 
and different dilemmas at various moments in their professional cycle, and their desires to reach out for more information, knowledge, expertise and technical competence will vary accordingly" (p. 193).

\section{Recommendations for Practice}

As a descriptive study, these findings provide only a snapshot of what professional learning practices look like among educators in the SDA school system in North America at this point in time. It is encouraging that the majority of teachers in the system believe in the importance of ongoing professional learning and are committed to participating regularly. But it is also clear that more can be done to better meet the individual learning needs of teachers across generations and career stages. Similar to the findings of the 2015 study by The New Teacher Project, much of what needs to be done next involves school systems "creating the conditions that foster growth, not finding quick-fix professional development solutions" (p. 3). Thus, though more research is needed, the findings of this study, supported by the literature, do provide the basis for the following recommendations.

\section{Recommendation 1: Meeting Millennial Needs}

The findings regarding the differences between millennial and non-millennial educators are significant enough to warrant more intentional efforts to better meet the professional learning needs of millennial teachers in particular. Fullan (2016) urges educational leaders to attend to the needs of new teachers, many of whom leave before they have reached their peak performance level. "It should be abundantly clear by now," he writes, "that learning to teach effectively takes time, and the way in which one gets 
started on the job dramatically affects the rest of one's career, including driving out potentially good teachers in the early years" (p. 246).

More freedom to choose which activities would best meet their needs, rather than being restricted by specific academic recertification requirements in the early years of teaching, may result in more relevant learning and more positive experiences. Crossgenerational learning communities, technology applications for connecting, new models for timetabling, and a reconsideration of workloads to provide time during the school day for teacher collaboration may provide the motivation millennial teachers need to not only spend more time in professional learning, but also recognize the importance of such learning to improve their practice. It may also assist in keeping them in the profession.

Leask and Younie (2013) assert that "the education sector is considerably behind in harnessing the power of technology to support ongoing professional development, knowledge-sharing and evidence-building" (p. 276). Considering this option may give education leaders an effective opportunity to provide "just-in-time" learning as well as a platform for millennials to connect with each other and with coaches or mentors, and may go a long way in providing the flexibility, the customization, and the collaboration that millennials crave using a medium that is both familiar and expected.

In addition, by looking for new ways to involve millennials in leadership activities, school leaders would assist in building the capacity of these teachers, thus increasing their self-efficacy. Emerging research suggests that this efficacy, often referred to in the literature as agency or capacity, is the key to transforming professional learning (Calvert, 2016; Fullan, 2016). This may mean exploring new models of teacher leadership and different types of career ladders that allow for lateral movement instead of 
the traditional, and limiting, teacher-to-principal model. It may also mean addressing ways of building in opportunities for more voice and choice so that these teachers have more control over and take increased ownership of their own learning. Bandura (1993) stressed that "among the mechanisms of agency, none is more central or pervasive than people's beliefs about their capabilities to exercise control over their own level of functioning and over events that affect their lives" (p. 118). The findings suggest that increased self-efficacy will lead to increased participation in ongoing learning.

\section{Recommendation 2: Increased Collaboration}

Closely related to the recommendation to better meet millennial needs is the need to increase opportunities for all teachers to collaborate. Research suggests that millennials have a particular affinity for collaboration, and this study found that millennial educators often have fewer opportunities to collaborate at work than do non-millennials educators. Findings also show that educators of all ages crave additional opportunities to collaborate with each other. This corroborates a key finding of a study done by Coggshall et al. (2010), that all teachers desire meaningful collaboration with their colleagues. When asked if they preferred to teach where there was lots of collaboration among teachers or where they had freedom to design lessons independently, two-thirds of the teachers surveyed by Coggshall and her associates said they preferred collaboration (p. 15). In fact, Bassett et al. (2013) found that the lack of opportunities to collaborate is one of the reasons given by teachers who leave the profession (p. 11).

Approximately half of all respondents in the current study said that they rarely or never have opportunities to participate in various types of collaboration, and $53 \%$ said they would be more involved in professional learning if they were given time to meet 
with colleagues. Danielson (2016) found that most teachers believe they learn more from their colleagues than they do from external "experts." She asserts that "when teachers work together to solve problems of practice, they have the benefit of their colleagues' knowledge and experience to address a particular issue they're facing in their classroom" (p. 24). This is the kind of learning that many educators in the SDA school system have described as being effective for them.

Educational experts are increasingly pointing to professional learning communities as a more effective model for teacher professional learning (Fullan, 2016; Jensen, Sonnemann, Roberts-Hull, \& Hunter, 2016). Fewer than half of the Adventist teachers surveyed report opportunities to participate in such a community. Several who do have these opportunities commented on their value. One respondent observed that this opportunity to share ideas, struggles, and successes was especially important for teachers in small schools who benefit from the knowledge that "they are not alone and others face the same issues they do" (Respondent 13). Various ways of increasing these opportunities for teachers to connect must be explored.

\section{Recommendation 3: Job-Embedded Learning}

To facilitate this increased collaboration among educators, attention will need to be given to providing opportunities to learn during the regular work day. Fifteen years ago, Elmore (2002) lamented that a typical work day for teachers was "still designed around the expectation that teachers' work is composed exclusively of delivering content to students, not, among other things, to cultivating knowledge and skill about how to improve their work" (p. 4). Adventist teachers in this study provide evidence that little has changed. $75 \%$ of respondents said they rarely or never have time for learning during 
their work day, and almost half said they would be more involved if they did. Research supports job-embedded learning (Corcoran, 2007; Gulamhussein, 2013; Jensen et al., 2016; McGill, 2013; Wiliam \& Leahy, 2014; Zhang, Ding, \& Xu, 2016). Adjusted schedules to allow for common prep times, early dismissals, regularly scheduled substitutes, and other means must be considered if meaningful collaboration among teachers is a priority.

As the numbers of millennial teachers rise, along with the desire for a work-life balance, it will become increasingly important to look for ways of making ongoing learning part of the job. Cohen (2016) reminds us that "we are ill-equipped to help students understand a so-called $21^{\text {st }}$ century workplace if we don't work in one, if we lack opportunities to collaborate, create, and engage in critical thinking about our work" (para. 4). Change will not be easy. But recognizing the importance of ongoing learning in the process of school improvement, school leaders must be committed to implementing the changes required.

\section{Recommendation 4: Institutional Support}

Just because the data did not show institutional support as a significant predictor of the time spent or the number of types of professional learning that teachers participate in, educational leaders should not assume that no attention is needed in this area. A review of the data collected, including the optional teacher comments, identifies several important areas for attention. Support goes beyond providing funds and incentives and substitutes, the items touched on by the survey questions for this factor. Support also involves the provision of opportunities for collaboration, as discussed above. It involves a willingness to consider new models and to find more effective ways of differentiating 
learning for teachers at different career stages. It will mean more intentional planning for new teachers, including opportunities for cross-generational and cross-curricular planning, as well as new opportunities for leadership. It may even mean a reconsideration of the recertification requirements, especially for these new teachers.

"I feel very discouraged in my teaching," wrote one millennial, "because I don't feel helped in my professional goals by my leaders" (Respondent 363). New models of learning, like professional learning communities, may assist. As Carroll et al. (2010) assert, "Learning teams can stop the flow of beginning teachers out the door, create new roles for experienced teachers, and provide a way for schools to capitalize on the expertise and interest of retiring Baby Boomers" (p. 6). The importance of leadership in the change process cannot be overstated.

Calvert (2016) makes it clear: "As leaders of schools and systems, we must acknowledge that until we find ways to address the variation in what teachers need, we will continue to undermine the potential for professional learning to adequately prepare teachers for the challenge of improving education and the profession" (p. 20). Until educational leaders and policy-makers in the system make professional learning a priority, little will change. This study shows high systemic expectations for ongoing learning, but it also reveals a limited use of data, little teacher input, and the challenges of time, money, and opportunities. These areas must be addressed if professional learning is to fulfill its intended purpose of ongoing instructional improvement and increased student learning.

Wiliam (2016) goes so far as to suggest that "the time spent trying to evaluate teachers would be far more effectively spent supporting teacher improvement" (p. 176). 
"I hope that the result of this study contributes to help to foster a culture of learning in our schools," wrote a non-millennial teacher in response to the survey in the current study. "I have learned that there is a lot to be done in this area in my work environment. I believe that the major problem has been the vision of the leadership. It is time to empower teachers as primary assets to accomplish this goal" (Respondent 304).

\section{Recommendations for Further Research}

This study, with its description of the professional learning practices of educators in one faith-based school system in North America, is only a first step in addressing the ongoing learning needs of educators in that system. As Darling-Hammond et al. (2009) said of their 2009 study of public schools, by examining the opportunities currently available in a variety of contexts, educational leaders can begin to assess the needs of the system and consider how teachers can be further supported. The current study provides that initial step for the SDA school system. Its findings suggest that when it comes to professional learning opportunities for educators, the SDA school system is not much different from other systems, both public and private. It also suggests the importance of further exploration in several related areas.

A description of the time spent and the types of activities that teachers participate in, while important, does not address the quality of those experiences. Further study is needed to determine the quality of the professional learning provided and how effective that learning is in meeting teacher, school, and system goals. Research in this area is lacking, partly because the effectiveness of professional learning is hard to measure. For this reason, most studies, including this one, rely on the self-reporting of teachers regarding their experiences rather than on some kind of measurable means of assessing 
the effectiveness of professional learning in improving practice. "It is important," writes Penuel et al. (2007), "to validate self-report data on instructional practice against direct observation or some other independent measure of practice” (p. 926). Follow-up research is needed in this area. The possible relationship between the quality of the professional learning opportunities provided and the retention of teachers, especially millennial teachers, may also be helpful.

Further exploration of more non-traditional forms of professional learning would also be beneficial. The current study included reference to a variety of activities, many of which can be described as traditional forms, but several that are more non-traditional in nature. While most teachers reported that they never or rarely had such opportunities, a few described school cultures that make collaboration a priority. Such non-traditional models currently being introduced in a few Adventist schools in the system, need further study to determine their effectiveness when compared with more traditional models. Nontraditional, informal types of professional learning that were not addressed in this study also require further study. Murray and Zoul (2015) point out that activities such as blogging, social media, Twitter chats, and Edcamps are "recognized as valuable learning experiences" (p. 37). New models not currently in use can also be introduced in specific school settings with studies in place to determine their impact on instructional practice and student success. These may include models specifically targeted at assisting teachers who work in small multi-grade schools. They may also include emerging technology models designed to connect teachers with each other.

A related area of research is the pre-service preparation of teachers in teacher education programs at universities and the connection between pre-service and in-service 
professional learning. Some authors believe that teacher education programs are often out of touch with the realities of today's classrooms; in some cases, the pressure on universities to increase their research output has led to a decline in the status and quality of teacher education (Fullan, 2016; Levine, 2006). Others stress that collaborative skills and the importance of continuous learning must be fostered from the beginning of teacher education programs (Avalos, 2011; Fullan, 1995) and that university faculties of education can do much to continue to support this learning even after teachers graduate (Leask \& Younie, 2013). Better understanding of the connection between teacher preparation programs and ongoing professional learning in school systems might also assist in improving the lifelong learning of teachers.

The current study also invites further research in other faith-based school systems. Is the description given here typical of all faith-based schools? Are there characteristics that are unique to all faith-based systems? What can be learned from other systems that may assist leaders to better meet the needs of educators in this system?

Further study is also needed specific to current certification practices in the system. To what extent do these requirements align with the professional learning needs of Adventist educators in diverse contexts? To what extent do they reflect current research? To what extent do they adequately address the differences in the learning needs of educators along a career continuum?

The ultimate goal of all studies focused on the professional learning of teachers is to find ways to increase the effectiveness of that learning in order to improve classroom instruction and increase student success. It is important to note that this study, with its focus on professional learning practices (both time spent and the types of activities) does 
not capture how much of the learning actually results in improved instruction or greater student success. Little research has been done in this area. Much more study is needed to determine the connection between teacher learning and student learning. 
APPENDIX A

SUBSCALE ITEMS 
The purpose of this project is to develop a scale to measure what factors impact teacher participation in professional learning in the Seventh-day Adventist school system.

Construct: What factors impact teacher participation in professional learning in the Seventh-day Adventist school system?

Conceptual background: Professional learning is dynamic and social, defying a simple process-product approach, and requiring instead a consideration of learning activity factors, school factors, and teacher factors. In addition, effective

\begin{tabular}{|c|c|c|c|}
\hline Variable & Conceptual definition & Operational definition & References \\
\hline \multicolumn{4}{|c|}{ Learning Activity factors: } \\
\hline $\begin{array}{l}\text { Active } \\
\text { Learning }\end{array}$ & $\begin{array}{l}\text { Professional learning } \\
\text { that involves teachers in } \\
\text { active practice is more } \\
\text { effective than passive } \\
\text { learning. }\end{array}$ & $\begin{array}{l}\text { - TPC activities occur onsite at my school. } \\
\text { - Most of the TPC activities that I } \\
\text { participate in are in the form of } \\
\text { conferences or workshops. } \\
\text { - I am able to use most of what I learn in } \\
\text { TPL activities directly in my classroom. } \\
\text { - TPL activities include opportunities for } \\
\text { teachers to observe and critique each } \\
\text { other. } \\
\text { - TPL activities at our school are } \\
\text { selected/designed based on an analysis } \\
\text { of our students' needs. } \\
\text { - I have opportunities to visit other } \\
\text { schools as part of my TPL. }\end{array}$ & $\begin{array}{l}\text { Archibald et al., } \\
\text { 2011; Buczynski \& } \\
\text { Hansen, 2010; } \\
\text { Desimone et al., } \\
\text { 2002; Garet et al., } \\
\text { 2001; Lieberman, } \\
\text { 1995; Loucks- } \\
\text { Horseley et al., } \\
1987\end{array}$ \\
\hline Coherence & $\begin{array}{l}\text { Effective professional } \\
\text { learning is consistent } \\
\text { with school and district } \\
\text { reforms and policies, } \\
\text { and with teachers' } \\
\text { knowledge and beliefs. }\end{array}$ & $\begin{array}{l}\text { - Specific teacher needs inform the } \\
\text { selection/design of TPL at our school. } \\
\text { - TPL activities are aligned with the } \\
\text { curriculum. } \\
\text { - TPL activities include strategies for } \\
\text { integrating faith and learning. } \\
\text { - TPL activities related directly to our } \\
\text { conference/school's mission and goals. } \\
\text { - TPL activities at my school are aligned } \\
\text { with NAD mission and goals. }\end{array}$ & $\begin{array}{l}\text { Desimone, 2009; } \\
\text { Garet et al., 2001; } \\
\text { Lieberman, } 1995\end{array}$ \\
\hline Duration & $\begin{array}{l}\text { Professional learning } \\
\text { that is sustained over } \\
\text { time is associated with } \\
\text { stronger impact on } \\
\text { teachers and student } \\
\text { learning. }\end{array}$ & $\begin{array}{l}\text { - Teachers in my school spend time every } \\
\text { week participating in professional } \\
\text { learning. } \\
\text { - Some TPL activities at my school } \\
\text { continue on an ongoing basis for } \\
\text { several weeks. } \\
\text { - Teachers have opportunities to practice } \\
\text { new skills gained in TPL activities. } \\
\text { - Over the course of the school year, } \\
\text { most teachers are engaged in TPL } \\
\text { activities for } 40 \text { hours or more. }\end{array}$ & $\begin{array}{l}\text { Yoon et al., 2007; } \\
\text { Desimone, 2011; } \\
\text { Darling- } \\
\text { Hammond et al., } \\
\text { 2009; Loucks- } \\
\text { Horsley et al., } \\
\text { 1987; Garet et al., } \\
2001\end{array}$ \\
\hline
\end{tabular}




\begin{tabular}{|c|c|c|c|}
\hline & & $\begin{array}{l}\text { - TPL activities that introduce new } \\
\text { initiatives are followed up with ongoing } \\
\text { support for a period of time. }\end{array}$ & \\
\hline $\begin{array}{l}\text { Collective } \\
\text { Participation }\end{array}$ & $\begin{array}{l}\text { Working together } \\
\text { provides the support } \\
\text { teachers need to } \\
\text { implement and } \\
\text { integrate new } \\
\text { knowledge into the } \\
\text { school program, and } \\
\text { contributes to the } \\
\text { creation of a shared } \\
\text { school culture of } \\
\text { professional learning. }\end{array}$ & $\begin{array}{l}\text { - Teachers participate in setting the goals } \\
\text { of the TPL program. } \\
\text { - Teachers plan instruction together. } \\
\text { - Teachers meet by content area or } \\
\text { grade level to discussion instruction } \\
\text { and student learning. } \\
\text { - Teachers in our school meet in regularly } \\
\text { scheduled study groups as part of TPL } \\
\text { activities. } \\
\text { - TPL activities at our school include peer } \\
\text { coaching. } \\
\text { - Experienced teachers work closely with } \\
\text { new teachers at our school. } \\
\text { - TPL activities at our school include } \\
\text { opportunities for teachers to } \\
\text { collaboratively examine and discuss } \\
\text { student work. }\end{array}$ & $\begin{array}{l}\text { Desimone, 2009, } \\
\text { 2011; Desimone } \\
\text { et al., 2002; Garet } \\
\text { et al., 2001; } \\
\text { Hargreaves \& } \\
\text { Fullan, 2009; } \\
\text { Hargreaves \& } \\
\text { Shirley, 2009; } \\
\text { Andrews, Gilbert, } \\
\text { \& Martin, 2006; } \\
\text { Clandinin et al., } \\
\text { 2012; Coggshall } \\
\text { et al., 2010; } \\
\text { Schlager \& Fusco, } \\
2003\end{array}$ \\
\hline Content Focus & $\begin{array}{l}\text { Pre-service programs } \\
\text { cannot fully provide all } \\
\text { the knowledge and skills } \\
\text { required by classroom } \\
\text { teachers, so ongoing } \\
\text { professional learning is } \\
\text { required to ensure that } \\
\text { teachers have the } \\
\text { knowledge they need } \\
\text { regarding subject } \\
\text { matter, instructional } \\
\text { practices, and how } \\
\text { students learn. }\end{array}$ & $\begin{array}{l}\text { - TPL is focused on helping teachers } \\
\text { better understand the content of their } \\
\text { academic discipline. } \\
\text { - TPL activities focus on specific } \\
\text { pedagogical skills. } \\
\text { - TPL activities are focused on helping } \\
\text { teachers understand how students } \\
\text { learn best in specific content areas. } \\
\text { - TPL activities at my school include a } \\
\text { focus on integrating technology in } \\
\text { specific content areas. } \\
\text { - TPL activities at my school include a } \\
\text { focus on reflecting the Adventist } \\
\text { worldview in specific content areas. } \\
\text { - Teachers at my school belong to } \\
\text { subject area professional organizations. }\end{array}$ & $\begin{array}{l}\text { Hammerness et } \\
\text { al., 2005; Loucks- } \\
\text { Horsley et al, } \\
\text { 2010; Mott, 2000; } \\
\text { Guskey, 2000; } \\
\text { Darling- } \\
\text { Hammond \& } \\
\text { McLaughlin, } \\
\text { 1999; Desimone, } \\
\text { 2009; Borko, } \\
\text { 2004; Little, 1999; } \\
\text { Archibald et al., } \\
\text { 2011; Buczynski \& } \\
\text { Hansen, 2010 }\end{array}$ \\
\hline Delivery & $\begin{array}{l}\text { Research has shown } \\
\text { that the traditional "sit } \\
\text { and get" kind of } \\
\text { professional learning } \\
\text { teachers have been } \\
\text { given in the past has not } \\
\text { been effective in } \\
\text { changing teaching } \\
\text { practice or improving } \\
\text { student learning and } \\
\text { researchers recommend } \\
\text { a more individualized } \\
\text { and job-embedded }\end{array}$ & $\begin{array}{l}\text { - Outside experts conduct most of the } \\
\text { TPL activities I participate in during } \\
\text { conferences and/or workshops. } \\
\text { - Teachers take university courses as part } \\
\text { of the TPL program. } \\
\text { - I prefer online delivery options for my } \\
\text { TPL. } \\
\text { - Independent reading is a large part of } \\
\text { my ongoing TPL. } \\
\text { - I have access to various technology } \\
\text { resources for professional learning. } \\
\text { - I prefer face to face types of teacher } \\
\text { professional learning activities. }\end{array}$ & $\begin{array}{l}\text { Darling- } \\
\text { Hammond et al., } \\
\text { 2009; Hunzicker, } \\
\text { 2012; Guskey, } \\
\text { 2000; Harris and } \\
\text { Muijs, 2005; } \\
\text { Ingvarson, } 2003\end{array}$ \\
\hline
\end{tabular}




\begin{tabular}{|c|c|c|c|}
\hline & $\begin{array}{l}\text { approach to ongoing } \\
\text { learning. }\end{array}$ & $\begin{array}{l}\text { - Teacher professional learning at my } \\
\text { school includes both onsite and off-site } \\
\text { activities. }\end{array}$ & \\
\hline \multicolumn{4}{|l|}{ School factors: } \\
\hline School culture & $\begin{array}{l}\text { To be effective, } \\
\text { professional learning } \\
\text { must occur in } \\
\text { collaborative } \\
\text { communities that are } \\
\text { committed to } \\
\text { continuous } \\
\text { improvement. }\end{array}$ & $\begin{array}{l}\text { - Most of the teachers in my school } \\
\text { participate regularly in professional } \\
\text { learning. } \\
\text { - My principal encourages me to apply } \\
\text { the new things I learn in my classroom, } \\
\text { even if it means taking some risks. } \\
\text { - My principal participates regularly in } \\
\text { professional learning activities. } \\
\text { - Teachers in my school expect to adjust } \\
\text { teaching practices using what is learned } \\
\text { from TPL activities. } \\
\text { - I receive specific feedback from my } \\
\text { school leaders and/or colleagues to } \\
\text { help me refine and improve my } \\
\text { teaching practice. } \\
\text { - Most teachers in my school are open to } \\
\text { new ideas to improve student learning. }\end{array}$ & $\begin{array}{l}\text { Fullan, 2006, } \\
\text { 2011a; Schein, } \\
\text { 2010; Burke, } \\
\text { 2011; Leithwood, } \\
\text { Jantzi, \& } \\
\text { Steinbach, 1999; } \\
\text { Schlechty, 2009; } \\
\text { Mitchell \& } \\
\text { Sackney, } 2011\end{array}$ \\
\hline $\begin{array}{l}\text { School } \\
\text { standards and } \\
\text { expectations }\end{array}$ & $\begin{array}{l}\text { Schools that maintain } \\
\text { high expectations for } \\
\text { ongoing professional } \\
\text { learning for their } \\
\text { teachers generally } \\
\text { produce teachers who } \\
\text { are more actively } \\
\text { involved in ongoing } \\
\text { professional learning. }\end{array}$ & $\begin{array}{l}\text { - Research-based best practices inform } \\
\text { the TPL activities in my school. } \\
\text { - My school's budget includes provision } \\
\text { for ongoing TPL. } \\
\text { - My employer expects me to participate } \\
\text { in TPL activities annually. } \\
\text { - TPL is part of our school improvement } \\
\text { plan. } \\
\text { - My school builds in more than ?? } \\
\text { school days specifically for TPL } \\
\text { activities. } \\
\text { - Ongoing professional learning is a } \\
\text { frequent topic for discussion during } \\
\text { faculty meetings. }\end{array}$ & $\begin{array}{l}\text { OECD, 2005; } \\
\text { Wiliam, 2013; } \\
\text { Darling- } \\
\text { Hammond, Wei, } \\
\text { Andree, } \\
\text { Richardson, \& } \\
\text { Orphanos, 2009; } \\
\text { Ingvarson, 2003 }\end{array}$ \\
\hline $\begin{array}{l}\text { School } \\
\text { supports }\end{array}$ & $\begin{array}{l}\text { Teachers participate } \\
\text { more frequently and } \\
\text { report greater change in } \\
\text { their knowledge and } \\
\text { skills when professional } \\
\text { learning activities are } \\
\text { supported by their } \\
\text { employing } \\
\text { organizations-time, } \\
\text { financial assistance, } \\
\text { support for taking risks, } \\
\text { support for new } \\
\text { teachers. }\end{array}$ & $\begin{array}{l}\text { - TPL activities are built into the regular } \\
\text { work day of teachers. } \\
\text { - My school provides adequate funding } \\
\text { to assist me with ongoing professional } \\
\text { learning. } \\
\text { - My school provides training for } \\
\text { teachers on how to effectively } \\
\text { collaborate with each other. } \\
\text { - My school provides induction programs } \\
\text { for new teachers. } \\
\text { - My school provides a mentoring } \\
\text { program for new teachers. } \\
\text { - I have access to the kind of TPL that I } \\
\text { need. }\end{array}$ & $\begin{array}{l}\text { Hammerness et } \\
\text { al., 2005; OECD, } \\
\text { 2005; Rebore \& } \\
\text { Walmsley, 2010; } \\
\text { Guarino, } \\
\text { Santibanez, \& } \\
\text { Daley, 2006; } \\
\text { Archibald et al., } \\
\text { 2011; Beach, } \\
2012\end{array}$ \\
\hline
\end{tabular}




\begin{tabular}{|c|c|c|c|}
\hline Incentives & $\begin{array}{l}\text { Teachers respond } \\
\text { positively to incentives } \\
\text { that encourage } \\
\text { participation in TPL } \\
\text { opportunities. }\end{array}$ & $\begin{array}{l}\text { - Teachers can apply for sabbaticals to } \\
\text { complete specific TPL goals. } \\
\text { - My school provides substitutes to } \\
\text { facilitate my participation in TPL } \\
\text { activities during school hours. } \\
\text { - Financial assistance is provided by my } \\
\text { employer to facilitate my participation } \\
\text { in TPL activities. } \\
\text { - Advanced degrees carry an increase in } \\
\text { salary for teachers at my school. } \\
\text { - Teachers who participate in TPL } \\
\text { activities are recognized for their } \\
\text { expertise and leadership. }\end{array}$ & $\begin{array}{l}\text { Stodolsky, Dorph, } \\
\text { \& Rosov, 2008; } \\
\text { Ingvarson, 2003; } \\
\text { Jaquith Mindich, } \\
\text { Wei, \& Darling- } \\
\text { Hammond, 2010; } \\
\text { Knapp, } 2003\end{array}$ \\
\hline Accountability & $\begin{array}{l}\text { To be effective, } \\
\text { professional learning } \\
\text { activities must have } \\
\text { accountability measures } \\
\text { built in so that teachers } \\
\text { apply new learning to } \\
\text { the classroom in ways } \\
\text { that benefit student } \\
\text { learning. Mandated } \\
\text { certification and } \\
\text { renewal requirements } \\
\text { do not in themselves } \\
\text { guarantee effective } \\
\text { professional learning for } \\
\text { teachers. }\end{array}$ & $\begin{array}{l}\text { - Soon after returning from off-site TPL } \\
\text { experiences, teachers formally share } \\
\text { their learning with their colleagues. } \\
\text { - My employer requires me to complete } \\
\text { an annual professional growth plan. } \\
\text { - My selection of TPL activities is related } \\
\text { to the performance evaluations } \\
\text { completed by my principal or } \\
\text { superintendent. } \\
\text { - My school uses a variety of data to } \\
\text { monitor the effectiveness of } \\
\text { professional learning. } \\
\text { - The teachers at my school hold each } \\
\text { other accountable to high standards. }\end{array}$ & $\begin{array}{l}\text { Hirsch, Koppich, } \\
\text { \& Knapp, 2001; } \\
\text { Knapp, 2003; } \\
\text { Jaquith et al., } \\
\text { 2010; Alexandrou } \\
\text { \& Swaffield, } \\
2012 \text {; Guskey, } \\
2000\end{array}$ \\
\hline \multicolumn{4}{|l|}{ Teacher factors: } \\
\hline $\begin{array}{l}\text { Prior } \\
\text { education and } \\
\text { experiences }\end{array}$ & $\begin{array}{l}\text { Professionals must be } \\
\text { able to recognize the } \\
\text { connection between } \\
\text { new knowledge and } \\
\text { their experience. Adult } \\
\text { learning theory suggests } \\
\text { that learning must be } \\
\text { tied to adults' previous } \\
\text { knowledge and } \\
\text { experience, relevant to } \\
\text { their current situation, } \\
\text { and problem-centered } \\
\text { rather than subject- } \\
\text { centered. }\end{array}$ & $\begin{array}{l}\text { - My employers value my past } \\
\text { experience and learning. } \\
\text { - Teachers' experience level and learning } \\
\text { needs are considered when planning } \\
\text { TPL activities. } \\
\text { - The TPL activities that I have } \\
\text { participated in have been directly } \\
\text { related to my past experience and } \\
\text { current needs. } \\
\text { - All teachers participate in the same TPL } \\
\text { activities at my school. } \\
\text { - Most of the TPL experiences I } \\
\text { participate in reinforce learning I have } \\
\text { previously done. }\end{array}$ & $\begin{array}{l}\text { Daley, 2000; } \\
\text { Opfer \& Pedder, } \\
\text { 2011; Hawley \& } \\
\text { Valli, 1999; } \\
\text { Knowles et al., } \\
2011\end{array}$ \\
\hline $\begin{array}{l}\text { Beliefs about } \\
\text { learning }\end{array}$ & $\begin{array}{l}\text { Teachers are more likely } \\
\text { to adopt practices that } \\
\text { align with their own } \\
\text { beliefs and practices. } \\
\text { Effective professional } \\
\text { learning activities create }\end{array}$ & $\begin{array}{l}\text { - I am a better teacher today because of } \\
\text { my participation in ongoing TPL } \\
\text { activities over the past two years. } \\
\text { - TPL activities are more important for } \\
\text { new teachers than they are for } \\
\text { experienced teachers. }\end{array}$ & $\begin{array}{l}\text { Thompson \& } \\
\text { Zeuli, 1999; } \\
\text { Timperley \& } \\
\text { Alton-Lee, 2008; } \\
\text { Opfer \& Pedder, }\end{array}$ \\
\hline
\end{tabular}




\begin{tabular}{|c|c|c|c|}
\hline & $\begin{array}{l}\text { dissonance between } \\
\text { current and new } \\
\text { practice while providing } \\
\text { opportunity for } \\
\text { teachers to reflect on } \\
\text { instruction and beliefs } \\
\text { and examine the impact } \\
\text { of various forms of } \\
\text { instruction on student } \\
\text { learning. }\end{array}$ & $\begin{array}{l}\text { - TPL activities are necessary only when } \\
\text { new initiatives requiring training are } \\
\text { introduced. } \\
\text { - There is a connection between ongoing } \\
\text { TPL and improved student } \\
\text { achievement. } \\
\text { - All teachers should be expected to } \\
\text { participate in TPL activities annually. }\end{array}$ & $\begin{array}{l}\text { 2011; Ingvarson, } \\
\text { 2003; Frost, } 2012\end{array}$ \\
\hline $\begin{array}{l}\text { Purposes for } \\
\text { professional } \\
\text { learning }\end{array}$ & $\begin{array}{l}\text { Teachers participate in } \\
\text { ongoing TPL for various } \\
\text { reasons. The most } \\
\text { effective is the desire to } \\
\text { positively impact } \\
\text { student learning. }\end{array}$ & $\begin{array}{l}\text { - I participate in professional learning } \\
\text { primarily because my employer } \\
\text { requires me to do so. } \\
\text { - Ongoing TPL activities are needed to } \\
\text { assist teachers in staying current with } \\
\text { trends in education. } \\
\text { - Ongoing TPL activities help me to meet } \\
\text { my future career goals. } \\
\text { - My primary reason for participating in } \\
\text { TPL activities is to improve the } \\
\text { achievement of my students. } \\
\text { - I participate in ongoing TPL activities to } \\
\text { qualify for a promotion or salary } \\
\text { increase. }\end{array}$ & $\begin{array}{l}\text { Knapp, 2003; } \\
\text { Mockler, 2013; } \\
\text { Murray, 2010; } \\
\text { Richter, 2011; } \\
\text { Torff, } 2008\end{array}$ \\
\hline $\begin{array}{l}\text { Sense of self- } \\
\text { efficacy }\end{array}$ & $\begin{array}{l}\text { Effective professional } \\
\text { learning, particularly } \\
\text { that done in } \\
\text { collaborative } \\
\text { professional } \\
\text { communities, increase } \\
\text { teacher efficacy. A } \\
\text { sense of efficacy-the } \\
\text { belief that teachers can } \\
\text { make a difference-is a } \\
\text { powerful motivator for } \\
\text { ongoing participation in } \\
\text { TPL. }\end{array}$ & $\begin{array}{l}\text { - I am confident in my mastery of the } \\
\text { content that I teach. } \\
\text { - I am involved in setting the goals for } \\
\text { the TPL program in my school. } \\
\text { - I am confident in my ability to integrate } \\
\text { faith and learning in my classroom. } \\
\text { - I am confident in my ability to use } \\
\text { various technologies to support } \\
\text { instruction. } \\
\text { - I am respected professionally by my } \\
\text { colleagues. } \\
\text { - I have presented at workshops, } \\
\text { conferences, or in-school training. } \\
\text { - I have the skills I need to address } \\
\text { various learning differences among my } \\
\text { students. }\end{array}$ & $\begin{array}{l}\text { Avalos, 2011; } \\
\text { Ingvarson, } \\
\text { Meiers, \& Beavis, } \\
\text { 2005; Loucks- } \\
\text { Horsley et al., } \\
\text { 1987; Talbert \& } \\
\text { McLaughlin, } 2002\end{array}$ \\
\hline
\end{tabular}


APPENDIX B

INSTRUCTION TO JUDGES

AND

SURVEY FOR FEEDBACK 


$\begin{array}{ll}\begin{array}{ll}\text { From: } \\ \text { To: }\end{array} & \text { Bayer, Betty } \\ \text { Subject: } & \text { Request for feedback } \\ \text { Date: } & \text { April-02-15 3:19:00 PM } \\ \text { Attachments: } & \text { Expert Request-fillable.pdf }\end{array}$

$\mathrm{Hi}$

I am currently enrolled in the course EDRM 704 Design and Analysis of Surveys at Andrews University. One of the requirements for the course is to develop and design a survey/scale to measure something I am interested in, and part of this process requires feedback from experts in the field. Naturally, I thought of you!

For now, this survey is simply part of a class assignment. It deals with a topic I am interested in pursuing for my dissertation, however, so I may decide at a later point to further develop it for that purpose.

Attached is a fillable pdf that asks for your feedback on whether the items listed are valid measures of teacher professional learning (please see Description given on the form). Please follow the Instructions to complete the form. If possible, please email the completed form back to me by Wednesday, April 8. I very much appreciate your expert help.

Betty

Betty Bayer, M.A.

Associate Director, Office of Education

Seventh-day Adventist Church in Canada

1148 King Street East, Oshawa, ON L1H 1H8

(905) 433-0011 ext. 2074

http://www.adventist.ca/education

http://catnet.adventist.ca/ 


\section{Teacher Professional Learning Feedback Request}

Description: Professional learning is dynamic and social, defying a simple process-product approach. Research suggests that it requires a consideration of learning activity factors (active rather than passive, coherence, duration, collective participation, content focus, delivery method), school factors (school culture, standards and expectations, supports, incentives, accountability), and teacher factors (prior experience, beliefs about learning, purposes for participation, sense of self-efficacy). The items below are intended to measure these factors from a teacher's perspective, and you are being asked to assess the validity of the items as measures of these factors. Respondents will be asked to respond to each question using a Likert scale.

Instructions: Please indicate if each of the following items is a reasonable measure of the factors impacting teachers' involvement in ongoing teacher professional learning (TPL). Please circle ' $\gamma$ ' if it is, ' $N$ ' if it is not, and 'NS' if you are not sure. Please feel free to comment or recommend revisions as you see fit.

\begin{tabular}{|c|c|}
\hline Learning Activity Factors \\
\hline 1. Teacher professional learning activities occur onsite at my school. \\
\hline 2. Most of the teacher professional learning activities that I participate in \\
are in the form of conferences or workshops.
\end{tabular}




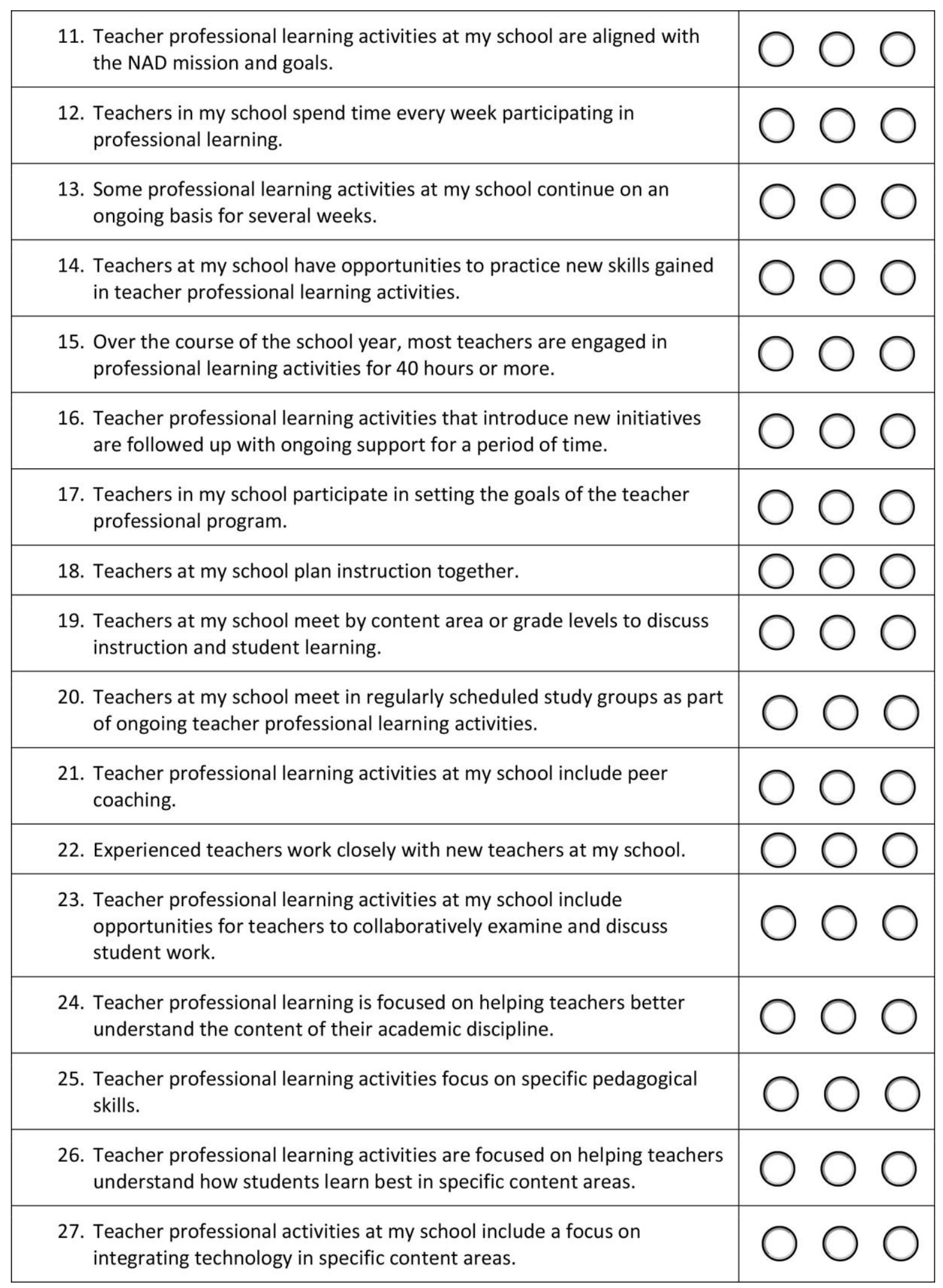




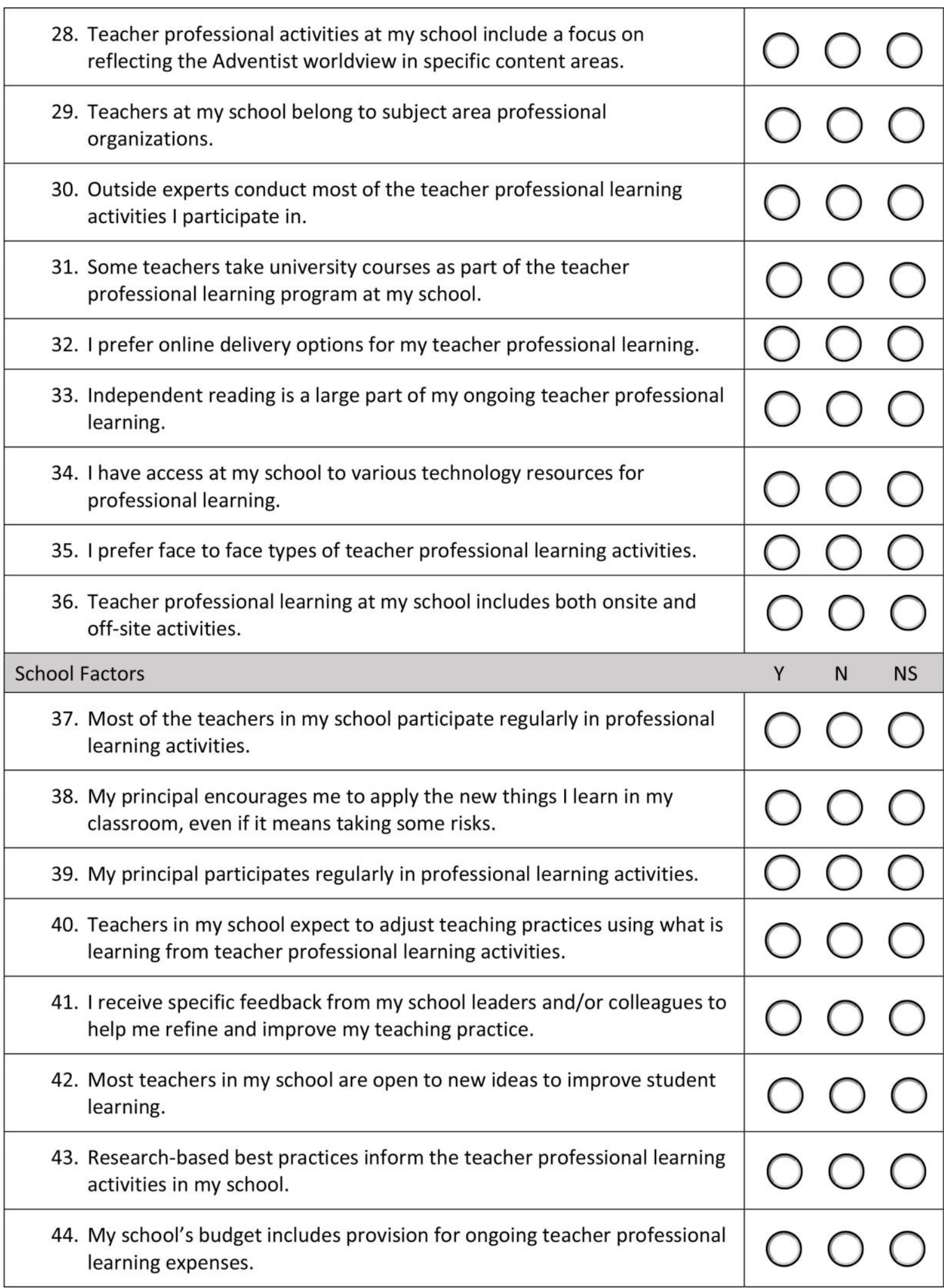




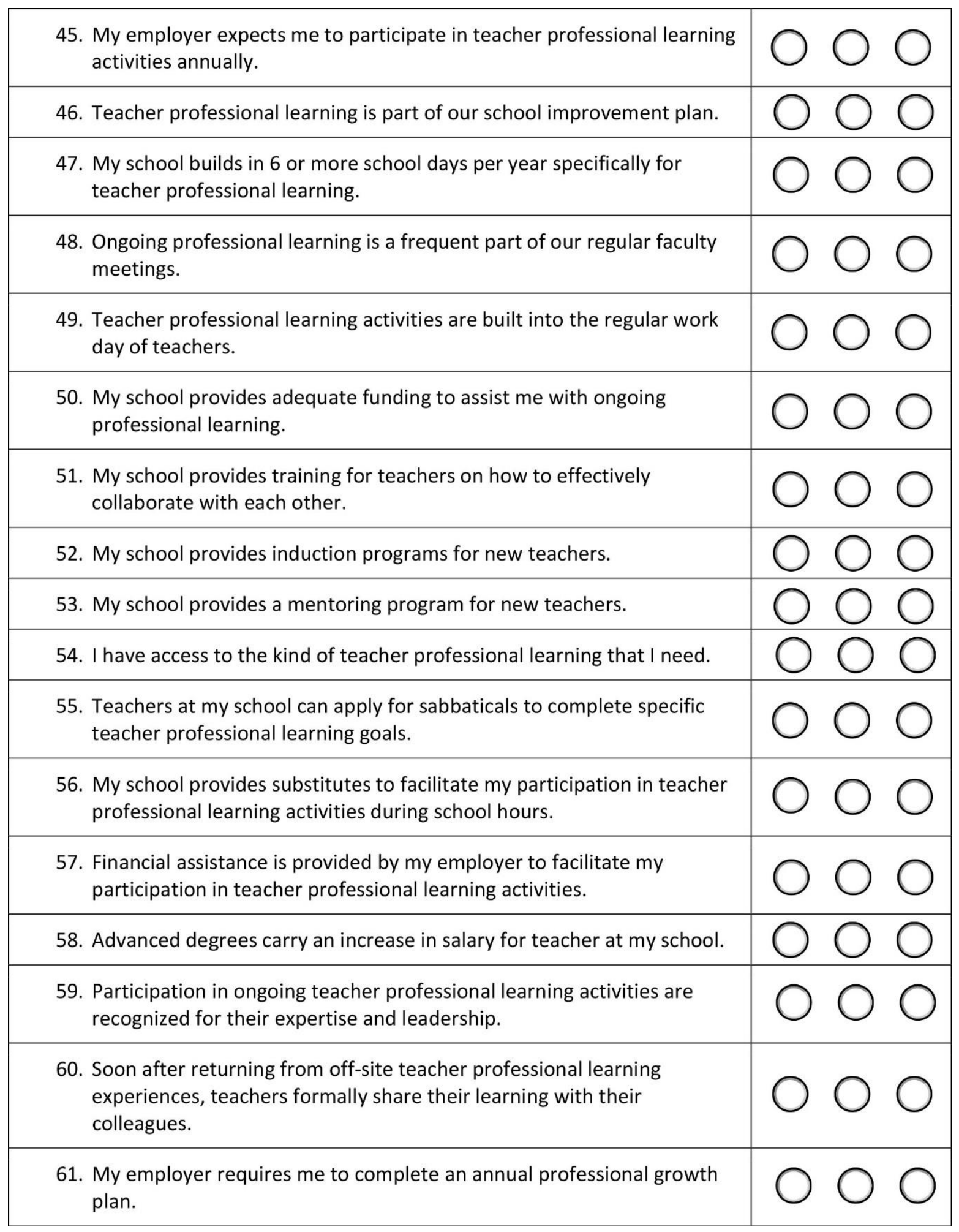




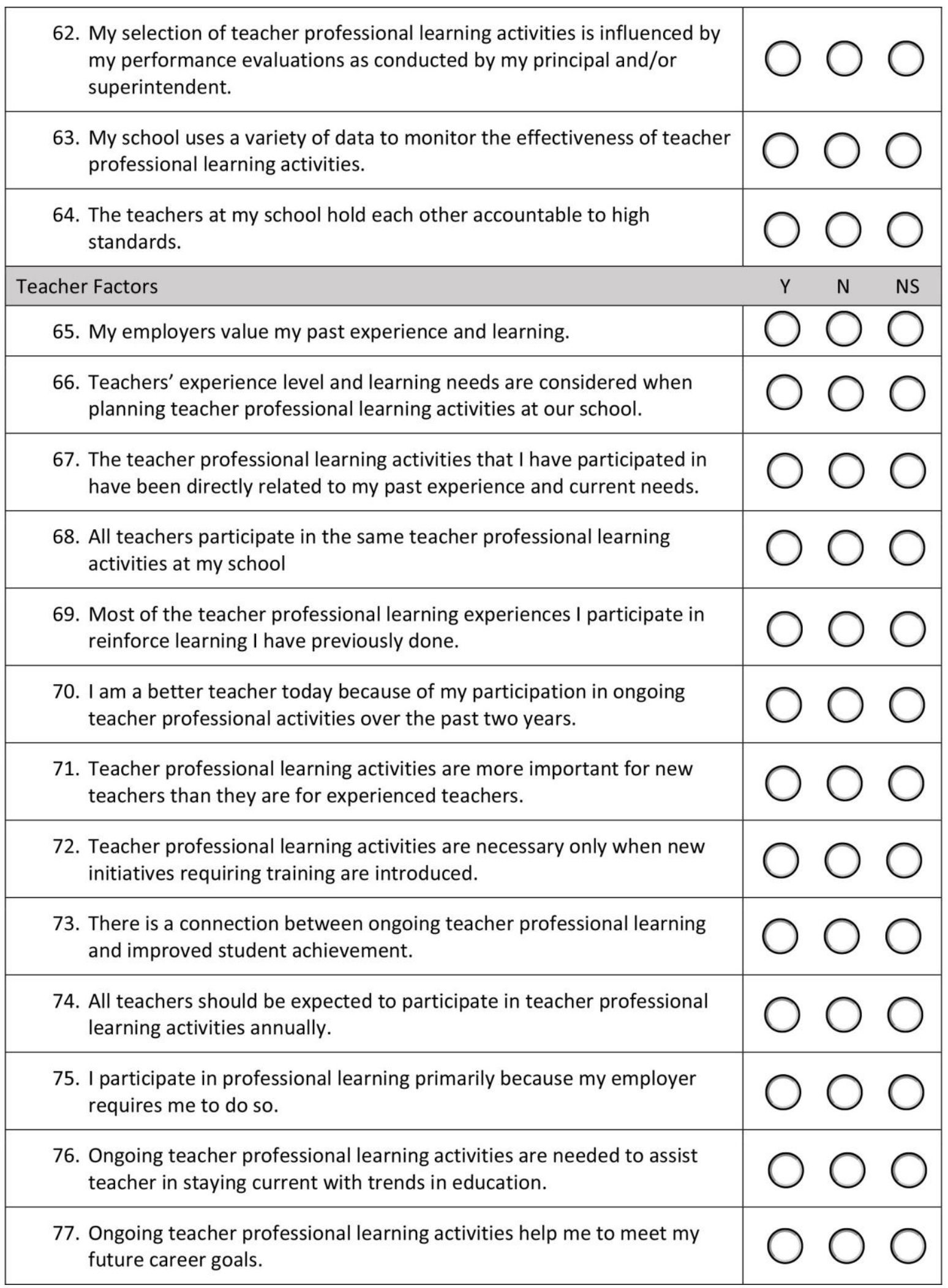




\begin{tabular}{|l|l|}
\hline $\begin{array}{l}\text { 78. My primary reasaon for participating in teacher professional learning } \\
\text { activities is to improve the achievement of my students. }\end{array}$ \\
\hline $\begin{array}{l}\text { 79. I participate in ongoing teacher professional learning activities in order } \\
\text { to qualify for a promotion or salary increase. }\end{array}$ \\
\hline 80. I am confident in my mastery of the content that I teach. \\
\hline $\begin{array}{l}\text { 81. I am involved in setting the goals for the teacher professional learning } \\
\text { program at my school. }\end{array}$ \\
\hline $\begin{array}{l}\text { 82. I am confident in my ability to integrate faith and learning in my } \\
\text { classroom. }\end{array}$ \\
\hline $\begin{array}{l}\text { 83. I am confident in my ability to use various technologies to support } \\
\text { instruction. }\end{array}$ \\
\hline 84. I am respected professionally by my colleagues. \\
\hline 85. I have presented at workshops, conferences, or in-school training. \\
\hline 86. I have the skills I need to address various learning differences among \\
my students.
\end{tabular}

List any suggestions you have for additional items that you believe should be included as measures of these factors:

General observations:

Name of expert:

Position/Title:

Thank you for your feedback! 
APPENDIX C

CONTENT VALIDITY INDEX

\author{
AND \\ SUMMARY OF COMMENTS
}




\section{Teacher Professional Learning Feedback Request}

Description: Professional learning is dynamic and social, defying a simple process-product approach. Research suggests that it requires a consideration of learning activity factors (active rather than passive, coherence, duration, collective participation, content focus, delivery method), school factors (school culture, standards and expectations, supports, incentives, accountability), and teacher factors (prior experience, beliefs about learning, purposes for participation, sense of self-efficacy). The items below are intended to measure these factors from a teacher's perspective, and you are being asked to assess the validity of the items as measures of these factors. Respondents will be asked to respond to each question using a Likert scale.

Instructions: Please indicate if each of the following items is a reasonable measure of the factors impacting teachers' involvement in ongoing teacher professional learning (TPL). Please circle ' $Y$ ' if it is, ' $N$ ' if it is not, and 'NS' if you are not sure. Please feel free to comment or recommend revisions as you see fit.

\begin{tabular}{|c|c|c|c|}
\hline Learning Activity Factors & Y & $\mathrm{N}$ & NS \\
\hline 1. Teacher professional learning activities occur onsite at my school. & 6 & & 1 \\
\hline $\begin{array}{l}\text { 2. Most of the teacher professional learning activities that I participate in } \\
\text { are in the form of conferences or workshops. }\end{array}$ & 5 & & 2 \\
\hline $\begin{array}{l}\text { 3. I am able to use most of what I learn in professional learning activities } \\
\text { directly in my classroom. }\end{array}$ & 7 & & \\
\hline $\begin{array}{l}\text { 4. At my school, teachers have opportunities to observe and critique each } \\
\text { other. }\end{array}$ & 7 & & \\
\hline $\begin{array}{l}\text { 5. Teacher professional learning activities at my school are } \\
\text { selected/designed based on an analysis of our students' needs. }\end{array}$ & 7 & & \\
\hline $\begin{array}{l}\text { 6. I have opportunities to visit other schools as part of my ongoing } \\
\text { professional learning activities. }\end{array}$ & 7 & & \\
\hline $\begin{array}{l}\text { 7. Specific teacher needs inform the selection/design of teacher } \\
\text { professional learning at my school. }\end{array}$ & 6 & & 1 \\
\hline $\begin{array}{l}\text { 8. Teacher professional learning activities at my school are aligned with } \\
\text { the curriculum used. }\end{array}$ & 5 & & 2 \\
\hline $\begin{array}{l}\text { 9. Teacher professional learning activities at my school/conference } \\
\text { regularly include strategies for integrating faith and learning. }\end{array}$ & 7 & & \\
\hline $\begin{array}{l}\text { 10. The teacher professional activities offered at my school relate directly } \\
\text { to our school/conference mission and goals. }\end{array}$ & 5 & 1 & 1 \\
\hline
\end{tabular}




\begin{tabular}{|c|c|c|c|}
\hline $\begin{array}{l}\text { 11. Teacher professional learning activities at my school are aligned with } \\
\text { the NAD mission and goals. }\end{array}$ & 5 & 1 & 1 \\
\hline $\begin{array}{l}\text { 12. Teachers in my school spend time every week participating in } \\
\text { professional learning. }\end{array}$ & 6 & & 1 \\
\hline $\begin{array}{l}\text { 13. Some professional learning activities at my school continue on an } \\
\text { ongoing basis for several weeks. }\end{array}$ & 6 & & 1 \\
\hline $\begin{array}{l}\text { 14. Teachers at my school have opportunities to practice new skills gained } \\
\text { in teacher professional learning activities. }\end{array}$ & 6 & & 1 \\
\hline $\begin{array}{l}\text { 15. Over the course of the school year, most teachers are engaged in } \\
\text { professional learning activities for } 40 \text { hours or more. }\end{array}$ & 5 & & 2 \\
\hline $\begin{array}{l}\text { 16. Teacher professional learning activities that introduce new initiatives } \\
\text { are followed up with ongoing support for a period of time. }\end{array}$ & 7 & & \\
\hline $\begin{array}{l}\text { 17. Teachers in my school participate in setting the goals of the teacher } \\
\text { professional program. }\end{array}$ & 7 & & \\
\hline 18. Teachers at my school plan instruction together. & 6 & & 1 \\
\hline $\begin{array}{l}\text { 19. Teachers at my school meet by content area or grade levels to discuss } \\
\text { instruction and student learning. }\end{array}$ & 6 & & 1 \\
\hline $\begin{array}{l}\text { 20. Teachers at my school meet in regularly scheduled study groups as part } \\
\text { of ongoing teacher professional learning activities. }\end{array}$ & 6 & & 1 \\
\hline $\begin{array}{l}\text { 21. Teacher professional learning activities at my school include peer } \\
\text { coaching. }\end{array}$ & 6 & & 1 \\
\hline 22. Experienced teachers work closely with new teachers at my school. & 7 & & \\
\hline $\begin{array}{l}\text { 23. Teacher professional learning activities at my school include } \\
\text { opportunities for teachers to collaboratively examine and discuss } \\
\text { student work. }\end{array}$ & 6 & & 1 \\
\hline $\begin{array}{l}\text { 24. Teacher professional learning is focused on helping teachers better } \\
\text { understand the content of their academic discipline. }\end{array}$ & 6 & & 1 \\
\hline $\begin{array}{l}\text { 25. Teacher professional learning activities focus on specific pedagogical } \\
\text { skills. }\end{array}$ & 7 & & \\
\hline $\begin{array}{l}\text { 26. Teacher professional learning activities are focused on helping teachers } \\
\text { understand how students learn best in specific content areas. }\end{array}$ & 6 & & 1 \\
\hline $\begin{array}{l}\text { 27. Teacher professional activities at my school include a focus on } \\
\text { integrating technology in specific content areas. }\end{array}$ & 6 & & 1 \\
\hline
\end{tabular}




\begin{tabular}{|c|c|c|c|}
\hline $\begin{array}{l}\text { 28. Teacher professional activities at my school include a focus on } \\
\text { reflecting the Adventist worldview in specific content areas. }\end{array}$ & 7 & & \\
\hline $\begin{array}{l}\text { 29. Teachers at my school belong to subject area professional } \\
\text { organizations. }\end{array}$ & 5 & & 2 \\
\hline $\begin{array}{l}\text { 30. Outside experts conduct most of the teacher professional learning } \\
\text { activities I participate in. }\end{array}$ & 5 & & 2 \\
\hline $\begin{array}{l}\text { 31. Some teachers take university courses as part of the teacher } \\
\text { professional learning program at my school. }\end{array}$ & 6 & & 1 \\
\hline 32. I prefer online delivery options for my teacher professional learning. & 6 & & 1 \\
\hline $\begin{array}{l}\text { 33. Independent reading is a large part of my ongoing teacher professional } \\
\text { learning. }\end{array}$ & 6 & & 1 \\
\hline $\begin{array}{l}\text { 34. I have access at my school to various technology resources for } \\
\text { professional learning. }\end{array}$ & 7 & & \\
\hline 35. I prefer face to face types of teacher professional learning activities. & 7 & & \\
\hline $\begin{array}{l}\text { 36. Teacher professional learning at my school includes both onsite and } \\
\text { off-site activities. }\end{array}$ & 6 & & 1 \\
\hline School Factors & r & $\mathrm{N}$ & NS \\
\hline $\begin{array}{l}\text { 37. Most of the teachers in my school participate regularly in professional } \\
\text { learning activities. }\end{array}$ & 7 & & \\
\hline $\begin{array}{l}\text { 38. My principal encourages me to apply the new things I learn in my } \\
\text { classroom, even if it means taking some risks. }\end{array}$ & 7 & & \\
\hline 39. My principal participates regularly in professional learning activities. & 6 & & 1 \\
\hline $\begin{array}{l}\text { 40. Teachers in my school expect to adjust teaching practices using what is } \\
\text { learning from teacher professional learning activities. }\end{array}$ & 5 & 1 & 1 \\
\hline $\begin{array}{l}\text { 41. I receive specific feedback from my school leaders and/or colleagues to } \\
\text { help me refine and improve my teaching practice. }\end{array}$ & 7 & & \\
\hline $\begin{array}{l}\text { 42. Most teachers in my school are open to new ideas to improve student } \\
\text { learning. }\end{array}$ & 7 & & \\
\hline $\begin{array}{l}\text { 43. Research-based best practices inform the teacher professional learning } \\
\text { activities in my school. }\end{array}$ & 6 & 1 & \\
\hline $\begin{array}{l}\text { 44. My school's budget includes provision for ongoing teacher professional } \\
\text { learning expenses. }\end{array}$ & 6 & & 1 \\
\hline
\end{tabular}




\begin{tabular}{|c|c|c|c|}
\hline $\begin{array}{l}\text { 45. My employer expects me to participate in teacher professional learning } \\
\text { activities annually. }\end{array}$ & 7 & & \\
\hline 46. Teacher professional learning is part of our school improvement plan. & 7 & & \\
\hline $\begin{array}{l}\text { 47. My school builds in } 6 \text { or more school days per year specifically for } \\
\text { teacher professional learning. }\end{array}$ & 6 & & 1 \\
\hline $\begin{array}{l}\text { 48. Ongoing professional learning is a frequent part of our regular faculty } \\
\text { meetings. }\end{array}$ & 6 & & 1 \\
\hline $\begin{array}{l}\text { 49. Teacher professional learning activities are built into the regular work } \\
\text { day of teachers. }\end{array}$ & 7 & & \\
\hline $\begin{array}{l}\text { 50. My school provides adequate funding to assist me with ongoing } \\
\text { professional learning. }\end{array}$ & 7 & & \\
\hline $\begin{array}{l}\text { 51. My school provides training for teachers on how to effectively } \\
\text { collaborate with each other. }\end{array}$ & 6 & & 1 \\
\hline 52. My school provides induction programs for new teachers. & 7 & & \\
\hline 53. My school provides a mentoring program for new teachers. & 7 & & \\
\hline 54. I have access to the kind of teacher professional learning that I need. & 7 & & \\
\hline $\begin{array}{l}\text { 55. Teachers at my school can apply for sabbaticals to complete specific } \\
\text { teacher professional learning goals. }\end{array}$ & 6 & & 1 \\
\hline $\begin{array}{l}\text { 56. My school provides substitutes to facilitate my participation in teacher } \\
\text { professional learning activities during school hours. }\end{array}$ & 7 & & \\
\hline $\begin{array}{l}\text { 57. Financial assistance is provided by my employer to facilitate my } \\
\text { participation in teacher professional learning activities. }\end{array}$ & 6 & 1 & \\
\hline 58. Advanced degrees carry an increase in salary for teacher at my school. & 5 & & 2 \\
\hline $\begin{array}{l}\text { 59. Participation in ongoing teacher professional learning activities are } \\
\text { recognized for their expertise and leadership. }\end{array}$ & 5 & 1 & 1 \\
\hline $\begin{array}{l}\text { 60. Soon after returning from off-site teacher professional learning } \\
\text { experiences, teachers formally share their learning with their } \\
\text { colleagues. }\end{array}$ & 7 & & \\
\hline $\begin{array}{l}\text { 61. My employer requires me to complete an annual professional growth } \\
\text { plan. }\end{array}$ & 6 & & 1 \\
\hline
\end{tabular}




\begin{tabular}{|c|c|c|c|}
\hline $\begin{array}{l}\text { 62. My selection of teacher professional learning activities is influenced by } \\
\text { my performance evaluations as conducted by my principal and/or } \\
\text { superintendent. }\end{array}$ & 6 & 1 & \\
\hline $\begin{array}{l}\text { 63. My school uses a variety of data to monitor the effectiveness of teacher } \\
\text { professional learning activities. }\end{array}$ & 6 & 1 & \\
\hline $\begin{array}{l}\text { 64. The teachers at my school hold each other accountable to high } \\
\text { standards. }\end{array}$ & 7 & & \\
\hline Teacher Factors & $Y$ & $\mathrm{~N}$ & NS \\
\hline 65. My employers value my past experience and learning. & 6 & & \\
\hline $\begin{array}{l}\text { 66. Teachers' experience level and learning needs are considered when } \\
\text { planning teacher professional learning activities at our school. }\end{array}$ & 6 & & 1 \\
\hline $\begin{array}{l}\text { 67. The teacher professional learning activities that I have participated in } \\
\text { have been directly related to my past experience and current needs. }\end{array}$ & 6 & & 1 \\
\hline $\begin{array}{l}\text { 68. All teachers participate in the same teacher professional learning } \\
\text { activities at my school }\end{array}$ & 4 & & 3 \\
\hline $\begin{array}{l}\text { 69. Most of the teacher professional learning experiences I participate in } \\
\text { reinforce learning I have previously done. }\end{array}$ & 5 & & 2 \\
\hline $\begin{array}{l}\text { 70. I am a better teacher today because of my participation in ongoing } \\
\text { teacher professional activities over the past two years. }\end{array}$ & 7 & & \\
\hline $\begin{array}{l}\text { 71. Teacher professional learning activities are more important for new } \\
\text { teachers than they are for experienced teachers. }\end{array}$ & 4 & 3 & \\
\hline $\begin{array}{l}\text { 72. Teacher professional learning activities are necessary only when new } \\
\text { initiatives requiring training are introduced. }\end{array}$ & 4 & 3 & \\
\hline $\begin{array}{l}\text { 73. There is a connection between ongoing teacher professional learning } \\
\text { and improved student achievement. }\end{array}$ & 7 & & \\
\hline $\begin{array}{l}\text { 74. All teachers should be expected to participate in teacher professional } \\
\text { learning activities annually. }\end{array}$ & 7 & & \\
\hline $\begin{array}{l}\text { 75. I participate in professional learning primarily because my employer } \\
\text { requires me to do so. }\end{array}$ & 4 & 2 & 1 \\
\hline $\begin{array}{l}\text { 76. Ongoing teacher professional learning activities are needed to assist } \\
\text { teacher in staying current with trends in education. }\end{array}$ & 7 & & \\
\hline $\begin{array}{l}\text { 77. Ongoing teacher professional learning activities help me to meet my } \\
\text { future career goals. }\end{array}$ & 6 & 1 & \\
\hline
\end{tabular}




\begin{tabular}{|l|l|}
\hline $\begin{array}{l}\text { 78. My primary reasaon for participating in teacher professional learning } \\
\text { activities is to improve the achievement of my students. }\end{array}$ & 7 \\
\hline $\begin{array}{l}\text { 79. I participate in ongoing teacher professional learning activities in order } \\
\text { to qualify for a promotion or salary increase. }\end{array}$ & 4 \\
\hline 80. I am confident in my mastery of the content that I teach. & 6 \\
\hline $\begin{array}{l}\text { 81. I am involved in setting the goals for the teacher professional learning } \\
\text { program at my school. }\end{array}$ & 6 \\
\hline $\begin{array}{l}\text { 82. I am confident in my ability to integrate faith and learning in my } \\
\text { classroom. }\end{array}$ & 7 \\
\hline $\begin{array}{l}\text { 83. I am confident in my ability to use various technologies to support } \\
\text { instruction. }\end{array}$ & 7 \\
\hline 84. I am respected professionally by my colleagues. & 7 \\
\hline 85. I have presented at workshops, conferences, or in-school training. & 7 \\
\hline $\begin{array}{l}\text { 86. I have the skills I need to address various learning differences among } \\
\text { my students. }\end{array}$ & 7 \\
\hline
\end{tabular}

List any suggestions you have for additional items that you believe should be included as measures of these factors:

see pages following

General observations:

see pages following

Name of expert:

Position/Title:

Thank you for your feedback! 


\section{Summary of Comments}

\section{Comments on specific questions:}

- \#1. Based on your definition, this seems like a school factor to me. (JL)

- \#1. Teacher factor? (CG)

- \#2. Is this a negative measure? (JL)

- \#2. Teacher factor? (CG)

- \#3. Teacher factor? (CG)

- \#4. School factor? Change "critique" to "evaluate" (CG)

- \#5. Teacher factor? Insert "Some" at the beginning of the statement (CG)

- \#6. Teacher factor? (CG)

- \#7. Reword \#5 to include this? (CG)

- \#8. School factor? (CG)

- \#9. Recommend changing "integrating faith and learning" to "Biblical perspective" or "Biblical foundations of learning" (CG)

- \#10, 11. How much are the NAD, conference and/or school mission and goals spelled out, referred to, or have become part of the day-to-day life of teachers? Are the NAD and conference mission and goals too distant or vague? Perhaps the school mission/goals should be a separate question from the conference mission/goals on the survey, especially as a local school faculty hopefully has a hand in developing the local school's mission and goals. For conference and NAD mission/goals, what PD is available on those? For the NAD, would that be part of what occurs at NAD teachers' conventions? (LS)

- \#10, 11. For school factors, should conference support or lack thereof also be included? Many items like a teacher mentor or inductee program are run from the conference level. (LC)

- $\# 10,11$. I struggle with the inclusion of conference mission and goals. The system as a whole is a major part of the mission of the church therefore by definition it already supports the conference mission and goals. I have seen many teachers' conventions that lump teachers with pastors in an effort to help teachers promote the conference agendas when the focus should be on integrating faith and learning specifically in a school setting. (LC)

- \#10, 11. Begin with \#10 and combine with \#11 (CG)

- \#11. Do you think teachers will be able to know whether or not they are as they are filling out a survey? (JL)

- I think that you should add two questions similar to question \#11 for Union mission/goals and Conference mission/goals. It would be interesting to see if the answers vary by division, union conference (DL)

- \#12. TF (CG)

- \#13. TF (CG)

- \#14. TF (CG)

- \#15. SF? (CG)

- \#16. SF? (CG) 
- \#17. TF (CG)

- \#18. What options will you have for small schools or one teacher schools? (JL)

- \#28. I like this one better than the integrating faith \& learning wording... it's specific on what type of faith. (JL)

- \#28. I suggest 'biblical worldview' rather than 'Adventist', then this question could be combined with the previous on faith integration activities. (GB)

- \#28-31. All items in this section are worded carefully and do address different factors on the topic, but some are so close that I suggest revisiting clusters and determining how much data you will really get that is meaningful on the specific shades. Is it possible one question out of 4 could be omitted to shorten and achieve the same purpose? It was agonizing to do this in my dissertation survey development, but analyzing the reliability (Chronbach's alpha) with pilot data would help find which items add little to the constructs you have in mind within each section. (GB)

- \#32-36. so \#32-36 are a different construct - data on course delivery preferences mixed with realities -- connected, but the items serve different purposes (GB)

- \#36. There's a lot in here - they mostly sound good - but there are too many for a regular survey. Will need to narrow down and focus. I also didn't see clear alignment with your definition and the options - but not sure if you were going for that... (JL)

- \#37. Need to define further the school \& learning factors - they seem a little fuzzy to me (JL)

- \#39. If he/she teaches (CG)

- \#40. How is this a SCHOOL factor? (JL)

- \#40. possibly OK with rewording - too complex -- item 43 similar enough - need both? (GB)

- \#41. some overlap here with items in the first section, such as \#22 -- these would be correlated strongly together so hard to justify testing a different construct (GB)

- \#43. Isn't this more about the content? (JL)

- \#47. \#47 is dependent on provincial regulations (LC)

- \#47. very similar to \#45 - choose one or the other - this one more specific, so better choice I think (GB)

- \#52. will 'induction' be standardly understood? perhaps a few more words would increase validity of the responses (GB)

- \#52, 53. Change "school" to "conference/district" (CG)

- \#55. If you are going to give this to an Adventist audience, it might not be good to ask them questions that are highly unlikely that they have access to... just a thought... (JL)

- \#57. Duplicate of 50 (GB)

- \#59. This one needs rewording. Who is "their"? (JL)

- \#79. Is this appropriate? (CG)

- \#81. Move to school section (CG)

- \#82. Change "integrate faith and learning" to "share the Biblical perspective" (CG)

List any suggestions you have for additional items that you believe should be included as measures of these factors: 
- I am actively involved in local public school professional development opportunities or learning communities. (LS)

- I am actively involved in provincial professional development organizations. (I envision this question as being more than being a member of a professional organizationinstead, active participation and involvement). (LS)

- I am actively involved in local educational content area initiatives (e.g.: local science or socials fairs, Lego League, Odyssey of the Mind, etc.) (LS)

- I have attended off-site, multiple session local public school professional development workshops. (LS)

- I choose professional development opportunities based upon where my personal interests intersect with my classroom practice. (E.g.: a teacher who loves fishing and teaches salmon migration as part of science curriculum doing a PD day on how to set up a classroom fish hatchery). (LS)

- I have submitted articles for educational journals or online educational sites in the past year. (LS)

- I regularly maintain a professional blog. (LS)

- I regularly follow professional development ideas through social media such as Twitter, Facebook or Pinterest. (LS)

- I maintain a professional presence, regularly contributing on social media such as Twitter, Facebook, Google+ or Pinterest. (LS)

- I regularly participate in professional conversations through online educational forums (e.g.: Edutopia). (LS)

- I have been involved this past year in local educational TEDx, EdmodoCon or EdCamp professional development. (LS)

- May want to consider whether state or denominational certification affects practice and the implications for professional learning. (CC)

- Would you want to include anything on personal learning networks? Their ability to build, network, and participate in social media based learning networks? Could be in the $1^{\text {st }}$ and $3^{\text {rd }}$ sections. (JL)

- An item may be a reasonable measure of the factors impacting teachers' involvement in ongoing teacher professional learning, but may be a negative impact! The Likert Scale should reveal that. (GB)

- Perhaps a little more emphasis on teacher coaching. I've seen tremendous improvement in teachers through coaching. (GB)

- I am not sure if this would be included in the demographics section, but will you be asking teachers to identify how many pro-D activities they participate in each year? It would be interesting to be able to compare the viewpoints of the teachers compared to the number of pro-D activities they complete. (LC)

- It would be interesting to ask whether teachers feel there is too much or too little pro-D required? (LC)

- Some teachers would do pro-D all the time whereas others do not participate at all. (LC)

- Will you also look at what the teachers believe are appropriate pro-D activities? Given the issues of trying to pass off First Aid as pro-D. :-) (LC) 
- So I've had a look at the survey. Very nice! I feel like there is not enough information gathered about the teacher . . . like level of education, years of experience, etc. . . I I think I would add a few lines that address several school specific issues, such as level of grade taught, or some position qualifiers. (SA)

- Also, is this teaching multi-grade, or one room or two room schools? Having professional development support in this type of school may be very different than traditional 1 grade per room schools. (SA)

- Also, there is a question that asks if student performance improves based on professional development learning. THIS is a question that needs more isolation. Two years ago, I actually applied to one of the top grant providers for research in Canada to discover this issue specifically. I was told that the factors for measurement are too many to be able to link student performance with teacher development. This also create a scary scenario for a teacher, if a student is performing badly because of student issues outside of the teachers control, but the teacher is being measured on the student success - based on professional learning that has been provided, or worse, if the teacher will be instructed to do more professional learning as a direct result of student poor performance. (SA)

\section{General observations:}

- I know that teachers often attend PD based on their interests (not necessarily for increasing their classroom professionalism). You may want to throw in a question or two to gauge that as well, because that is one reason that teachers choose the PD they choose. See my suggestion above. We may not light it, but that is the reality...! Of course, the superintendent may reject that PD; as registrar, though you probably have the final say (??) (LS)

- Often PD centers (rightly) around content area, teaching strategies and curricular change. I believe strongly that we need to also build up PD resources for integration of faith and learning. I see this happening as we look to the new curriculum and at "global learning literacy" from our SDA, Christ-centered perspective. Global learning literacies (climate change/environmental action, world peace initiatives, literacy for girls, child labour practices, etc.) are becoming components of the larger curriculum. We have an eternal and global perspective as we look at the great controversy perspective that only SDA education is able to share...we need to develop a way to help teachers integrate our worldview into their classes. That is where I like the ability to create "big ideas" as part of the new way of looking at curriculum. (LS)

- Quite a comprehensive survey! (CC)

- Not sure how to interpret some of the statements, however. Some of the items affect professional learning, but not necessarily in a positive context. Wasn't sure how to mark these items. Perhaps the directions could address this issue. (CC)

- I think your instrument is very well done and will be useful in the staff development process. (GB)

- I believe that this is an important study as the teacher is the most valuable resource in the classroom and it is imperative that teachers are including best practices. (LC) 
- If you decide to continue with instrument development you may find my dissertation useful as I did educational design research creating the Growing Disciples Inventory. (GB)

- You have thoroughly researched the factors in effective professional development carefully crafted items, and organized them in a meaningful way. Have you considered wording about $15-20 \%$ in the negative, interspersed to keep users focused and answering each? There are mixed findings on the importance of reverse scoring, but some items could naturally be written negatively and teachers would likely identify with them in the negative. (GB)

- Keep on!!! (GB)

- I think the questions are excellent and address all aspects of PD (DL)

- I think that using Yes No and Not sure may limit your ability to get accurate data and may force responders to default to not sure because their answers aren't a definite yes or no. I've attached a resource that I use when developing surveys and rating scales. Maybe going with always most times sometimes rarely never would give you better data. Just a thought. (DL)

- Will this survey be used with teachers from small schools? It seems more appropriate for teachers at schools of more than 4 teachers. Too many not appropriate questions for small school teachers. (CG)

- This is a really long survey and the length may reduce your completion rate. (CG)

- Is there a real difference between these factors? They seem to be redundant. (CG) 
APPENDIX D

FINAL DRAFT OF INSTRUMENT 


\section{Andrews $\$$ University PROFESSIONAL LEARNING SURVEY (final)}

Assessing the Factors Impacting Professional Learning for Teachers in Seventh-day Adventist Schools

The purpose of this survey is to collect data for a research study on the professional learning practices of K-12 educators in the Seventh-day Adventist school system. The information you provide will increase awareness and understanding of educators' professional learning needs and will provide data that will assist in better meeting those needs.

Your participation in this survey is completely voluntary. You may refuse to participate altogether or may choose to withdraw at any time without any negative consequences. Should you agree to participate, the information you provide will remain confidential and will be used only to make generalizations in the analysis of the data. The survey is anonymous. No specific personal or school identifiable data will be collected. Only the researcher will have access to the individual survey responses. The research results will be presented only as a summary of aggregated information.

Only those who answer Yes to the following two questions will have access to the survey.

* 1. I am currently employed within the Seventh-day Adventist education system in the North American Division.

Yes

No

* 2. I agree to participate voluntarily in this research study by completing the following survey.

Yes

No

Thank you for your willingness to participate in this research study by providing your opinions and perceptions. Please respond to the following questions, marking the responses that most accurately reflect your professional learning experiences. It is best to complete this survey in one sitting with no interruptions. It should take you about 15-20 minutes to complete.

Please note: For the purposes of this survey, "professional learning" is used to refer to a wide range of experiences, both formal and informal, which educators use to transform current beliefs and practices into improved practice for the purpose of increasing student learning. 


\section{Andrews $\$$ University PROFESSIONAL LEARNING SURVEY (final)}

\section{Professional Learning Practices}

1. For each of the following statements, mark the response that most accurately reflects your professional learning experiences at your school/conference.

I am able to use what I learn in
professional learning activities
directly in my classroom or work
assignment.

In my school/conference, teachers have opportunities to observe and critique each other.

Professional learning activities in my school and/or conference are selected or designed based on an analysis of our students' specific needs.

I have opportunities to visit other schools and/or conferences as part of my ongoing professional learning activities.

Professional learning activities in my school and/or conference are selected or designed based on an analysis of specific educator needs.

Professional learning activities in my school/conference are aligned with the curriculum used.

Professional learning activities in my school/conference are aligned with the Adventist philosophy of education.

Professional learning activities in my school/conference include strategies for sharing the Biblical perspective.

Educators in my school/conference spend time every week participating in some kind of professional learning. 


\begin{tabular}{|c|c|c|c|c|c|}
\hline & Never & Rarely & Sometimes & Most times & Always \\
\hline $\begin{array}{l}\text { Educators in my school/conference } \\
\text { have opportunities to practice new } \\
\text { skills gained in professional } \\
\text { learning activities. }\end{array}$ & & & & & \\
\hline $\begin{array}{l}\text { Most educators in my } \\
\text { school/conference are engaged in } \\
\text { professional learning activities for } \\
40 \text { hours or more over the course of } \\
\text { the school year. }\end{array}$ & & & & & \\
\hline $\begin{array}{l}\text { Professional learning activities that } \\
\text { introduce new initiatives are } \\
\text { followed up with ongoing support } \\
\text { for a period of time. }\end{array}$ & & & & & \\
\hline $\begin{array}{l}\text { I participate in setting the goals and } \\
\text { in the planning of the professional } \\
\text { program in my school and/or } \\
\text { conference. }\end{array}$ & & & & & \\
\hline $\begin{array}{l}\text { I have opportunities to plan } \\
\text { instiuction together with other } \\
\text { educators (at my school or other } \\
\text { schools/conferences). }\end{array}$ & & & & & \\
\hline $\begin{array}{l}\text { Professional learning activities in } \\
\text { my school/conference are focused } \\
\text { on helping educators better } \\
\text { understand the content of their } \\
\text { academic discipline. }\end{array}$ & & & & & \\
\hline $\begin{array}{l}\text { Professional learning activities in } \\
\text { my school and/or conference are } \\
\text { focused on helping educators } \\
\text { understand how students learn best } \\
\text { in specific content areas. }\end{array}$ & & & & & \\
\hline $\begin{array}{l}\text { Professional learning activities in } \\
\text { my school/conference include a } \\
\text { focus on integrating technology in } \\
\text { specific content areas. }\end{array}$ & & & & & \\
\hline $\begin{array}{l}\text { Professional learning activities in } \\
\text { my school/conference include a } \\
\text { focus on reflecting the Biblical } \\
\text { worldview in specific content areas. }\end{array}$ & & & & & \\
\hline $\begin{array}{l}\text { My } \\
\text { principal/superintendent/employer } \\
\text { encourages me to apply the new } \\
\text { things I learn, even if it means } \\
\text { taking some risks. }\end{array}$ & & & & & \\
\hline $\begin{array}{l}\text { My employer expects me to } \\
\text { participate annually in professional } \\
\text { learning activities. }\end{array}$ & & & & & \\
\hline
\end{tabular}




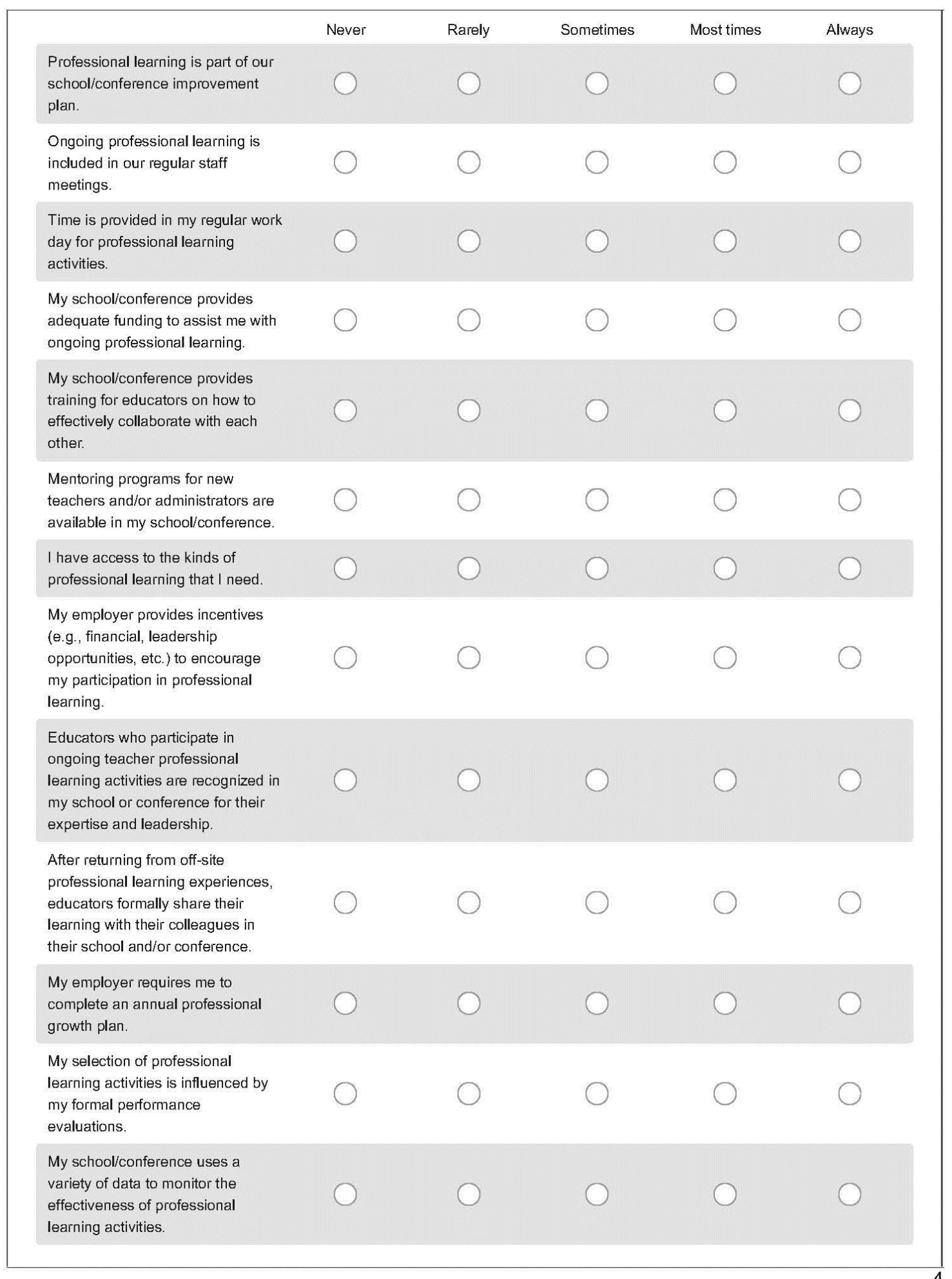




\begin{tabular}{|c|c|c|c|c|c|}
\hline & Never & Rarely & Sometimes & Most times & Always \\
\hline $\begin{array}{l}\text { The educators in my } \\
\text { school/conference hold each other } \\
\text { accountable to high performance } \\
\text { standards. }\end{array}$ & & & & & \\
\hline $\begin{array}{l}\text { Educators' experience levels are } \\
\text { considered in the planning of } \\
\text { professional learning activities for } \\
\text { our school and/or conference. }\end{array}$ & & & & & \\
\hline $\begin{array}{l}\text { The professional learning activities } \\
\text { that I have participated in have } \\
\text { been directly related to my current } \\
\text { needs. }\end{array}$ & & & & & \\
\hline $\begin{array}{l}\text { Most of the professional learning } \\
\text { activities I have participated in have } \\
\text { reinforced my previous leaming } \\
\text { rather than adding something new. }\end{array}$ & & & & & \\
\hline $\begin{array}{l}\text { Professional learning activities help } \\
\text { me identify areas I need to improve } \\
\text { in my own teaching/administrative } \\
\text { practice. }\end{array}$ & & & & & \\
\hline $\begin{array}{l}\text { I am confident in my mastery of the } \\
\text { content that I teach and/or the } \\
\text { duties I am called upon to perform. }\end{array}$ & & & & & \\
\hline $\begin{array}{l}\text { I am confident in my ability to share } \\
\text { the Biblical perspective in the } \\
\text { subjects I teach and/or the duties I } \\
\text { am called upon to perform. }\end{array}$ & & & & & \\
\hline $\begin{array}{l}\text { I am confident in my ability to use } \\
\text { various technologies to support } \\
\text { instruction. }\end{array}$ & & & & & \\
\hline $\begin{array}{l}\text { I have demonstrated mastery by } \\
\text { presenting at workshops, } \\
\text { conferences, or in-school training, } \\
\text { or by submitting journal articles for } \\
\text { publication. }\end{array}$ & & & & & \\
\hline $\begin{array}{l}\text { I have the skills I need to address } \\
\text { various learning differences among } \\
\text { students. }\end{array}$ & & & & & \\
\hline $\begin{array}{l}\text { Professional learning activities in } \\
\text { my school/conference include peer } \\
\text { coaching. }\end{array}$ & & & & & \\
\hline $\begin{array}{l}\text { In my school/conference, } \\
\text { experienced educators work closely } \\
\text { with new teachers/administrators. }\end{array}$ & & & & & \\
\hline
\end{tabular}




\begin{tabular}{|c|c|c|c|c|c|}
\hline & Never & Rarely & Sometimes & Most times & Always \\
\hline \multicolumn{6}{|l|}{$\begin{array}{l}\text { Professional learning activities in } \\
\text { my school and/or conference } \\
\text { include opportunities to } \\
\text { collaboratively examine and } \\
\text { discuss student work. }\end{array}$} \\
\hline \multicolumn{6}{|c|}{$\begin{array}{l}\text { I receive specific feedback from my } \\
\text { school leaders and/or colleagues to } \\
\text { help me refine and improve my } \\
\text { teaching and/or administrative } \\
\text { practice. }\end{array}$} \\
\hline \multicolumn{6}{|l|}{$\begin{array}{l}\text { My school/conference budget } \\
\text { includes specific provision for } \\
\text { ongoing professional learning } \\
\text { expenses. }\end{array}$} \\
\hline \multicolumn{6}{|l|}{$\begin{array}{l}\text { My school and/or conference } \\
\text { provides substitutes as needed to } \\
\text { facilitate my participation in } \\
\text { professional learning activities } \\
\text { during the school/work day. }\end{array}$} \\
\hline \multicolumn{6}{|c|}{$\begin{array}{l}\text { My supervisor } \\
\text { (principal/superintendent/employer) } \\
\text { participates regularly in } \\
\text { professional learning activities. }\end{array}$} \\
\hline \multicolumn{6}{|c|}{ 2. For each of the following statements, indicate the extent to which you agree or disagree. } \\
\hline & Strongly disagree & Disagree & $\begin{array}{l}\text { Neither agree nor } \\
\text { disagree }\end{array}$ & Agree & Strongly agree \\
\hline \multicolumn{6}{|l|}{$\begin{array}{l}\text { Most of the educators } \\
\text { (teachers and administrators) } \\
\text { in my school/conference } \\
\text { participate regularly in } \\
\text { professional learning activities. }\end{array}$} \\
\hline \multicolumn{6}{|l|}{$\begin{array}{l}\text { My supervisor } \\
\text { (principal/supervisor/president) } \\
\text { encourages me to apply the } \\
\text { new things I learn in my } \\
\text { classroom, even if it means } \\
\text { taking some risks. }\end{array}$} \\
\hline \multicolumn{6}{|l|}{$\begin{array}{l}\text { Most educators in my } \\
\text { school/conference are open to } \\
\text { new ideas to improve student } \\
\text { learning. }\end{array}$} \\
\hline $\begin{array}{l}\text { I am a more effective educator } \\
\text { today because of my } \\
\text { participation in ongoing } \\
\text { professional learning activities. }\end{array}$ & & & & & \\
\hline
\end{tabular}




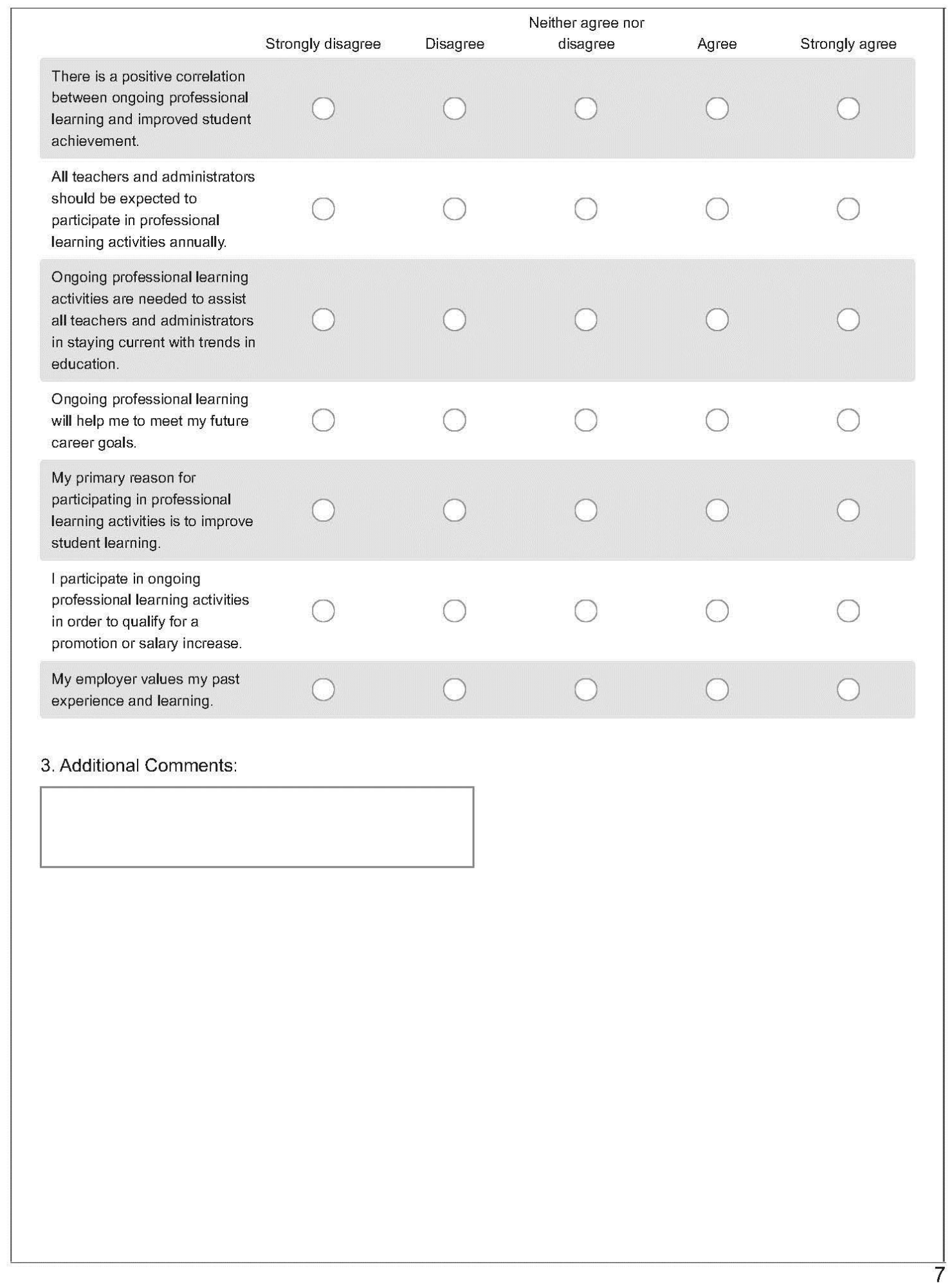




\section{Andrews University PRofessional LEARNIng SURVEY (final)}

\section{Demographic Information}

1. Your Birth year

1980-1999

(1960-1979

1940-1959

before 1940

2. Your Gender

female

$\bigcirc$ male

3. Your Employer

Union

Conference

4. Your Current Employment Status

Full-time

Part-time 


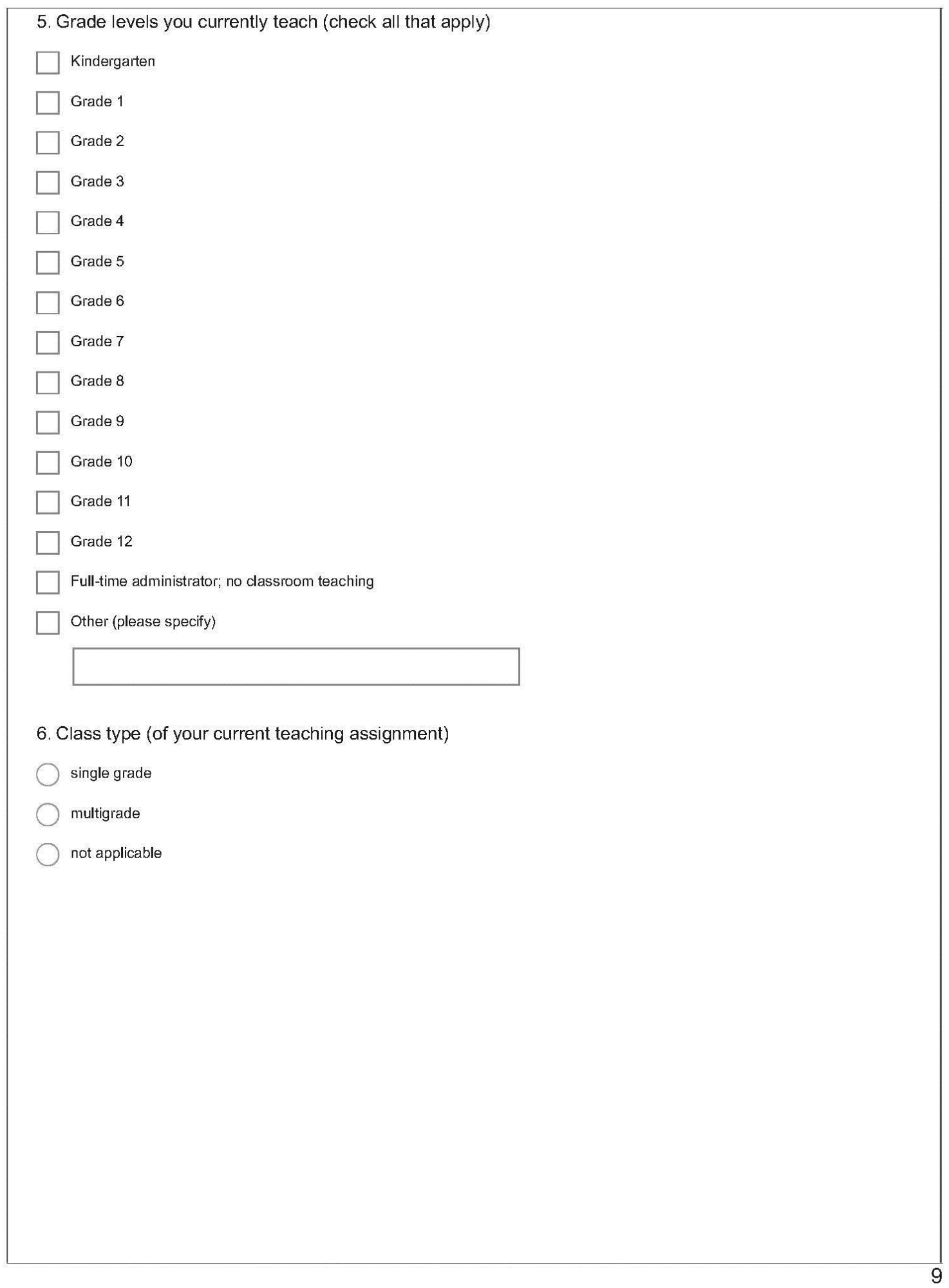




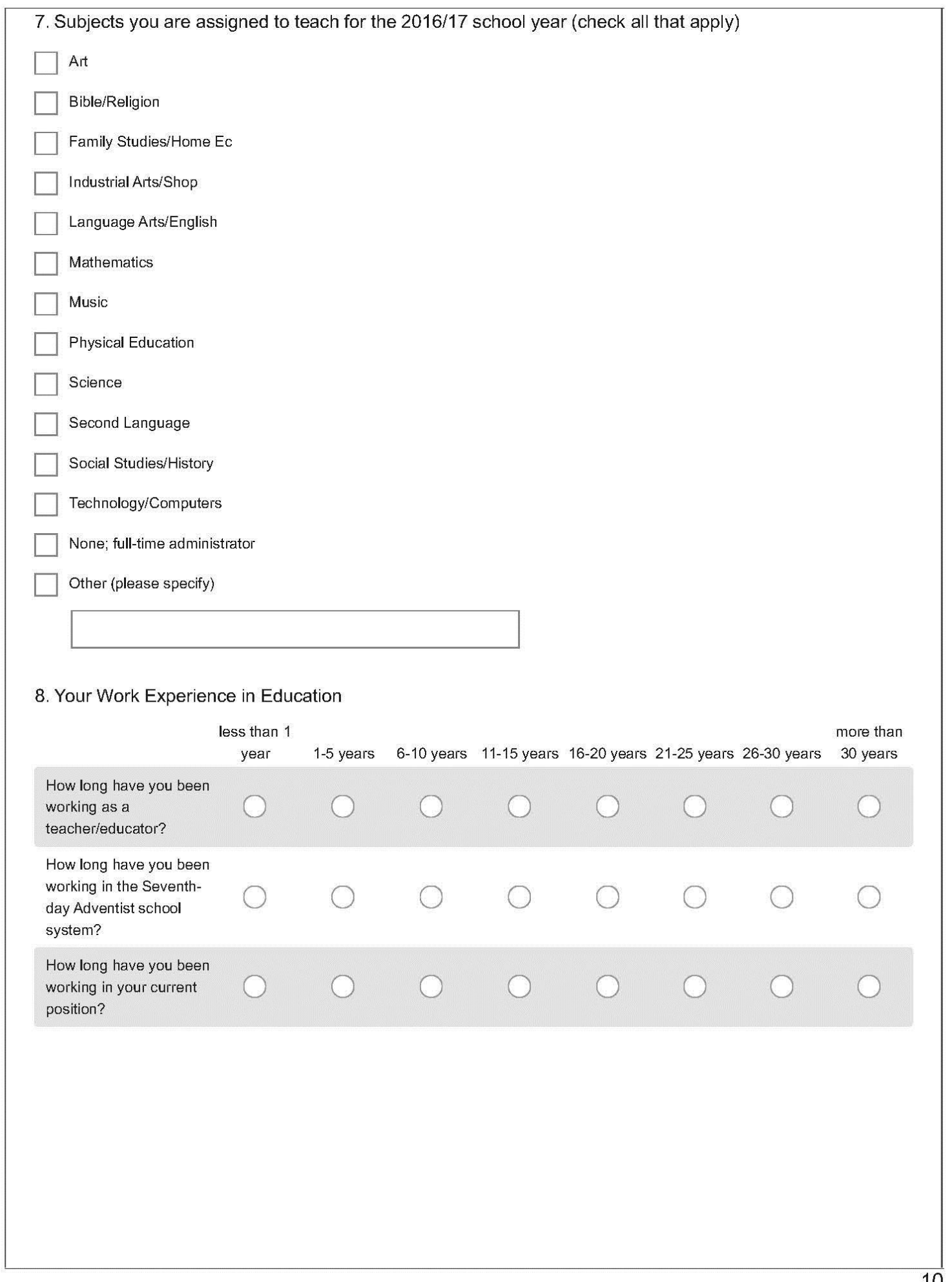




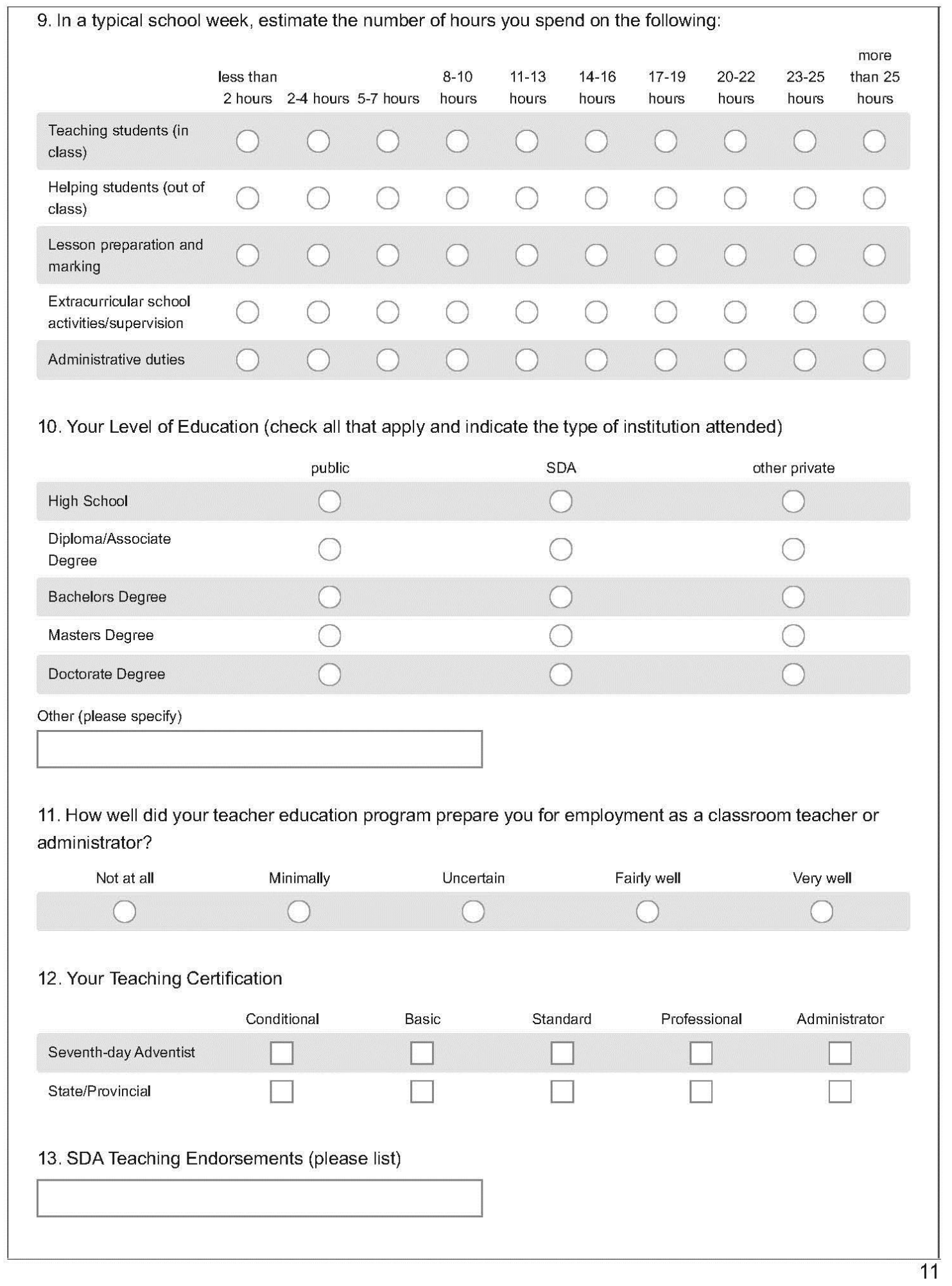




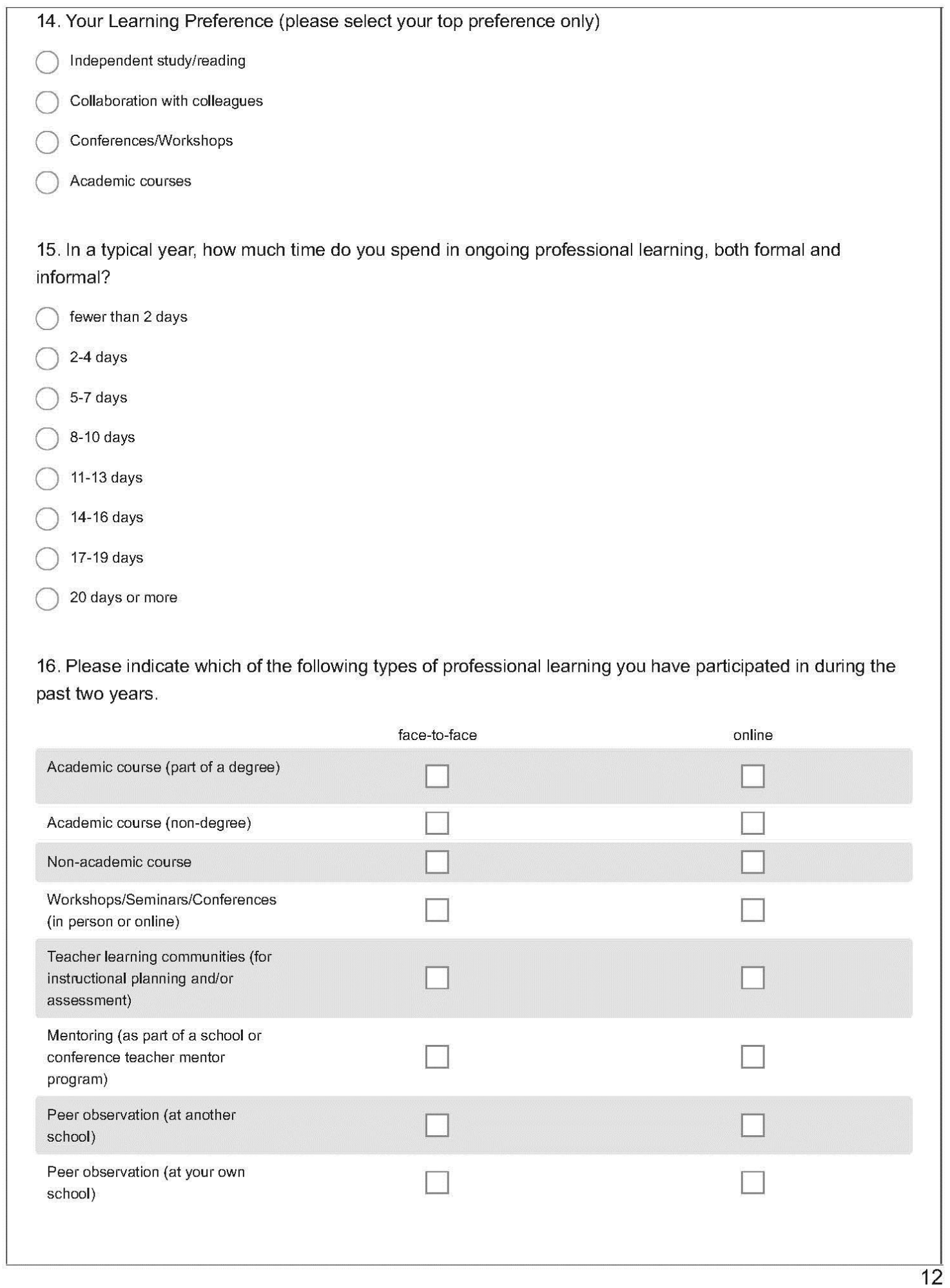




\begin{tabular}{|c|c|c|}
\hline & face-to-face & online \\
\hline \multicolumn{3}{|l|}{$\begin{array}{l}\text { Out-of-school committee } \\
\text { membership (e.g., NAD policy, } \\
\text { curriculum, K- } 12 \text { board) }\end{array}$} \\
\hline $\begin{array}{l}\text { School evaluation team (not your } \\
\text { own school) }\end{array}$ & & \\
\hline \multicolumn{3}{|l|}{$\begin{array}{l}\text { Field-testing NAD curriculum } \\
\text { materials }\end{array}$} \\
\hline \multicolumn{3}{|l|}{ Supervision of a student teacher } \\
\hline \multicolumn{3}{|l|}{ Teaching a university course } \\
\hline \multicolumn{3}{|l|}{$\begin{array}{l}\text { Presenting at a professional } \\
\text { conference or for a local in-service }\end{array}$} \\
\hline \multicolumn{3}{|l|}{$\begin{array}{l}\text { Publication of an academic article } \\
\text { or book }\end{array}$} \\
\hline \multicolumn{3}{|l|}{$\begin{array}{l}\text { Professional reading on current } \\
\text { educational topics }\end{array}$} \\
\hline \multicolumn{3}{|l|}{$\begin{array}{l}\text { Viewing of audio/visual content on } \\
\text { current educational topics }\end{array}$} \\
\hline $\begin{array}{l}\text { School-based educational } \\
\text { research }\end{array}$ & & \\
\hline Educational travel & & \\
\hline
\end{tabular}

Other (please specify) 

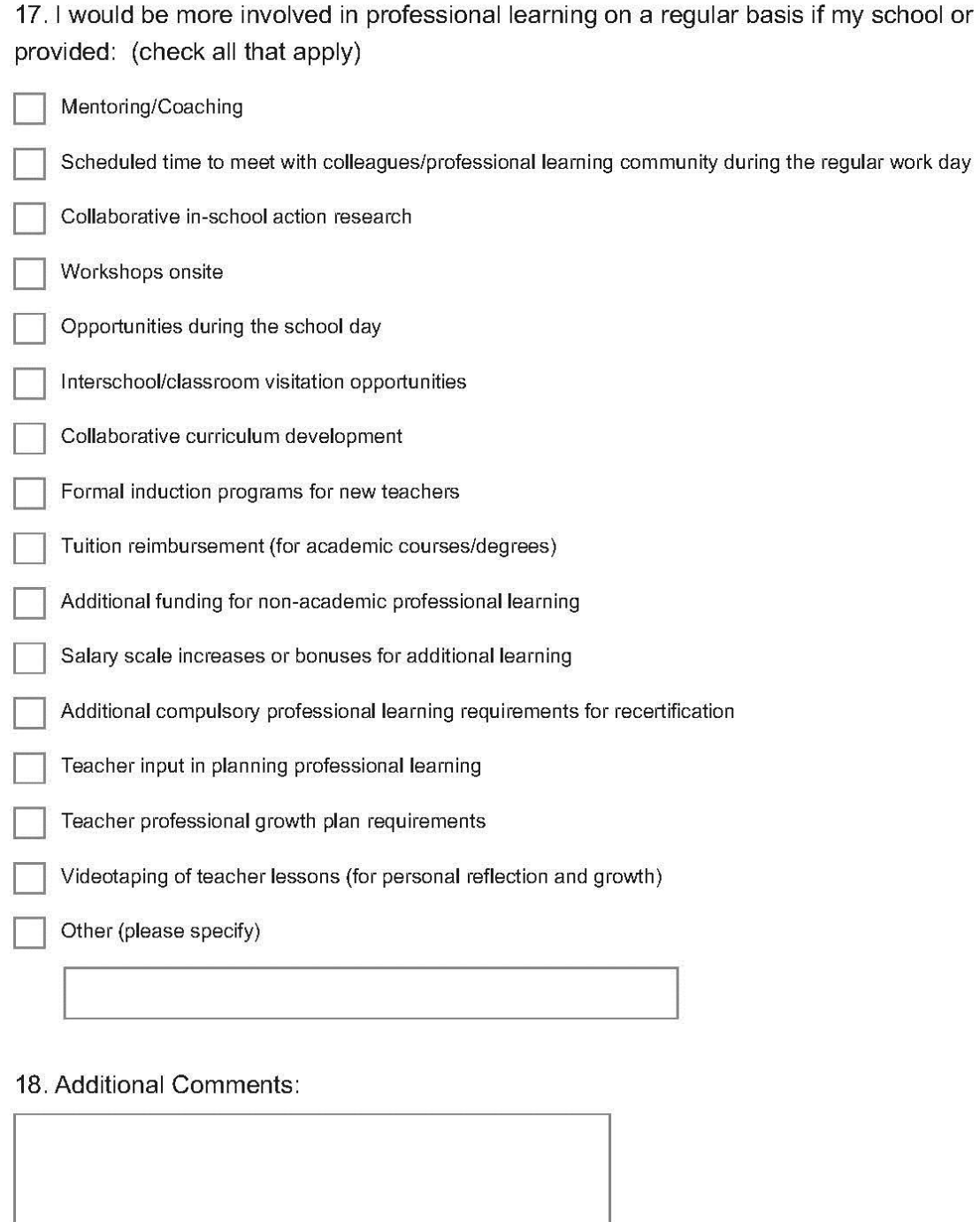

* 19. I am currently employed as a:

teacher or principal

conference superintendent or associate 


\section{Andrews $\mathbf{Q}$ University PRofessional LeARning SURVer (final)}

\section{Conference Level Policy}

1. Please indicate whether your conference provides the following and, if so, how effective you consider each one to be improving teacher practice.

Our conference does not provide this

Not effective

Moderately effective

Very effective

A teacher orientation
program designed to
prepare new teacher
for their first teaching
assignment

A formal $1-2$ year mentor program that pairs new

teachers/principals with veteran educators and

allows for regular

observation and

interaction

Video taping services for

teachers who wish to

record a lesson

0
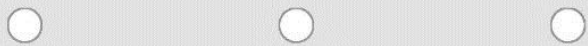

O

Access to a professional

library of resources that

can be borrowed or

accessed electronically

A policy requiring

professional growth

plans from teachers and

administrators, to be

updated annually

Release time for

educators to participate

in professional learning

opportunities

Paid substitutes for

educators who wish to

participate in

professional learning

opportunities during

school hours 


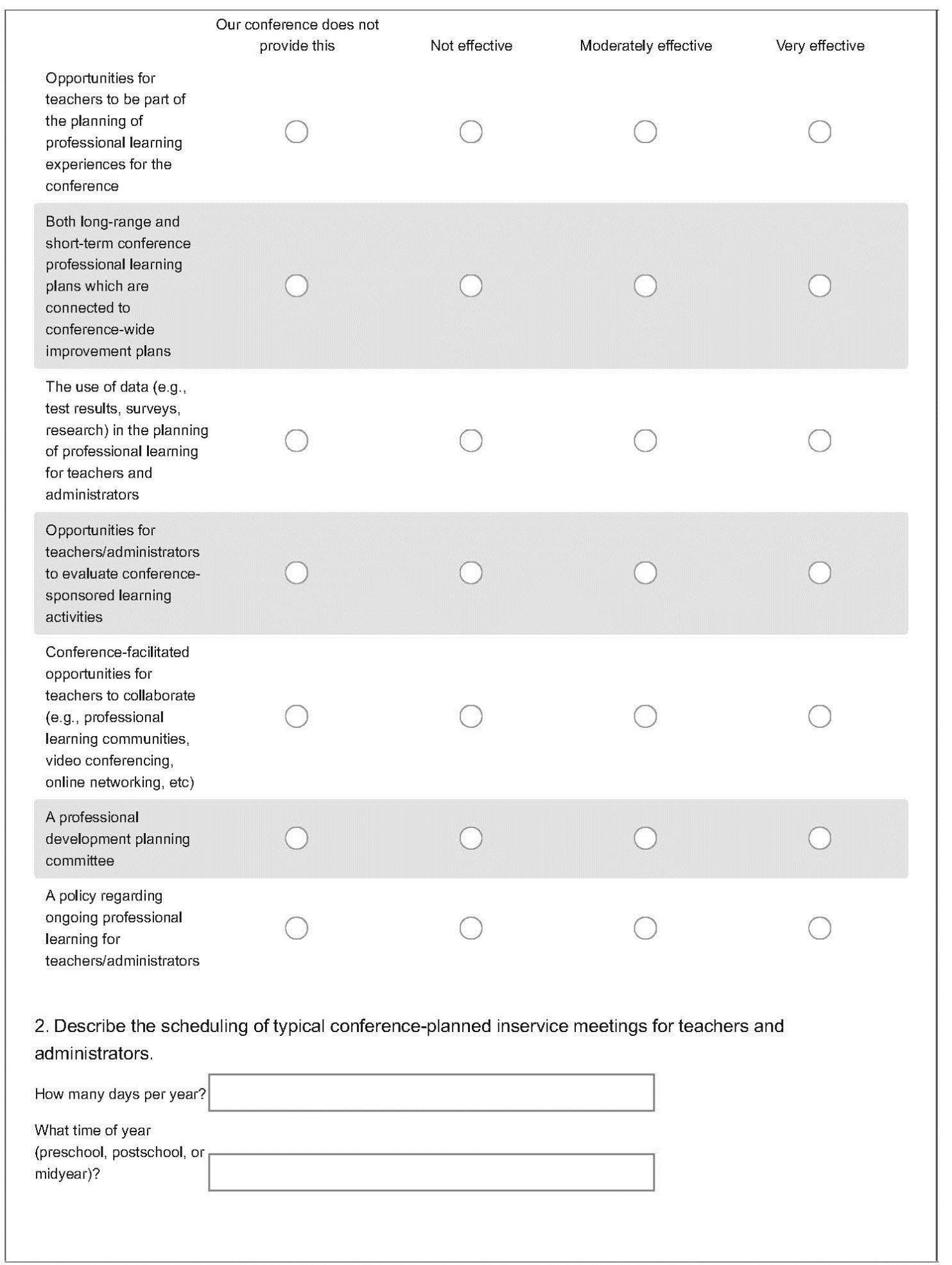


3. Does your conference education budget include a line item for professional learning? If so, how much is budgeted annually? Please indicate also what this amount includes (e.g., travel, substitute teachers, entrance fees, professional memberships, academic courses, etc).

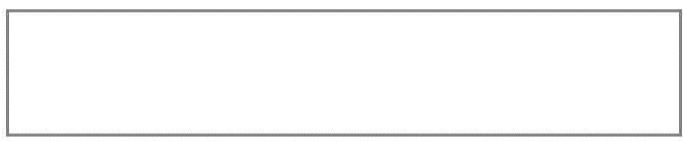

4. Additional Comments: 


\section{Andrews University PRofessional LEARNing SURVEY (final)}

\section{End of Survey}

Thank you for your valuable contribution to this research study.

If you would like to share further information regarding your professional learning experiences, please feel free to contact Betty Bayer (bayer.betty@adventist.ca). 
APPENDIX E

SUMMARY OF SURVEY RESPONSES 
Table 36

Summary of All Survey Responses

\begin{tabular}{|c|c|c|c|c|c|c|}
\hline Survey Question & Mean & Never & Rarely & $\begin{array}{l}\text { Some- } \\
\text { times }\end{array}$ & $\begin{array}{l}\text { Most } \\
\text { times }\end{array}$ & Always \\
\hline \multirow{2}{*}{$\begin{array}{l}\text { I am able to use what I learn in } \\
\text { professional learning activities directly } \\
\text { in my classroom or work assignment. } \\
(\mathrm{n}=744)\end{array}$} & \multirow[b]{2}{*}{3.63} & 3 & 38 & 281 & 330 & 92 \\
\hline & & $0.4 \%$ & $5.1 \%$ & $37.8 \%$ & $44.4 \%$ & $12.4 \%$ \\
\hline \multirow{2}{*}{$\begin{array}{l}\text { In my school/conference, teachers } \\
\text { have opportunities to observe and } \\
\text { critique each other. }(n=745)\end{array}$} & \multirow{2}{*}{2.58} & 115 & 287 & 193 & 96 & 54 \\
\hline & & $15.4 \%$ & $38.5 \%$ & $25.9 \%$ & $12.9 \%$ & $7.2 \%$ \\
\hline \multirow{2}{*}{$\begin{array}{l}\text { Professional learning activities in my } \\
\text { school and/or conference are selected } \\
\text { or designed based on an analysis of our } \\
\text { students' specific needs. }(n=741)\end{array}$} & \multirow[b]{2}{*}{2.98} & 43 & 181 & 299 & 184 & 34 \\
\hline & & $5.8 \%$ & $24.4 \%$ & $40.4 \%$ & $24.8 \%$ & $4.6 \%$ \\
\hline \multirow{2}{*}{$\begin{array}{l}\text { I have opportunities to visit other } \\
\text { schools and/or conferences as part of } \\
\text { my ongoing professional learning } \\
\text { activities. }(n=745)\end{array}$} & \multirow[b]{2}{*}{2.74} & 146 & 220 & 176 & 88 & 115 \\
\hline & & $19.6 \%$ & $29.5 \%$ & $23.6 \%$ & $11.8 \%$ & $15.4 \%$ \\
\hline \multirow{2}{*}{$\begin{array}{l}\text { Professional learning activities in my } \\
\text { school and/or conference are selected } \\
\text { or designed based on an analysis of } \\
\text { specific educator needs. }(n=739)\end{array}$} & \multirow[b]{2}{*}{3.04} & 45 & 168 & 279 & 205 & 42 \\
\hline & & $6.1 \%$ & $22.7 \%$ & $37.8 \%$ & $27.7 \%$ & $5.7 \%$ \\
\hline \multirow{2}{*}{$\begin{array}{l}\text { Professional learning activities in my } \\
\text { school/conference are aligned with the } \\
\text { curriculum used. }(n=746)\end{array}$} & \multirow{2}{*}{3.64} & 15 & 70 & 212 & 319 & 130 \\
\hline & & $2.0 \%$ & $9.4 \%$ & $28.4 \%$ & $42.8 \%$ & $17.4 \%$ \\
\hline \multirow{2}{*}{$\begin{array}{l}\text { Professional learning activities in my } \\
\text { school/conference are aligned with the } \\
\text { Adventist philosophy of education. } \\
(\mathrm{n}=744)\end{array}$} & \multirow[b]{2}{*}{4.25} & 5 & 20 & 98 & 281 & 339 \\
\hline & & $0.8 \%$ & $2.7 \%$ & $13.2 \%$ & $37.8 \%$ & $45.6 \%$ \\
\hline \multirow{2}{*}{$\begin{array}{l}\text { Professional learning activities in my } \\
\text { school/conference include strategies } \\
\text { for sharing the Biblical perspective. } \\
(n=745)\end{array}$} & \multirow[b]{2}{*}{3.45} & 33 & 95 & 245 & 248 & 124 \\
\hline & & $4.4 \%$ & $12.8 \%$ & $32.9 \%$ & $33.3 \%$ & $16.6 \%$ \\
\hline \multirow{2}{*}{$\begin{array}{l}\text { Educators in my school/conference } \\
\text { spend time every week participating in } \\
\text { some kind of professional learning. } \\
(n=739)\end{array}$} & \multirow[b]{2}{*}{2.40} & 137 & 307 & 188 & 77 & 30 \\
\hline & & $18.5 \%$ & $41.5 \%$ & $25.4 \%$ & $10.4 \%$ & $4.1 \%$ \\
\hline \multirow{2}{*}{$\begin{array}{l}\text { Educators in my school/conference } \\
\text { have opportunities to practice new } \\
\text { skills gained in professional learning } \\
\text { activities. }(n=744)\end{array}$} & \multirow[b]{2}{*}{3.58} & 12 & 78 & 259 & 256 & 139 \\
\hline & & $1.6 \%$ & $10.5 \%$ & $34.8 \%$ & $34.4 \%$ & $18.7 \%$ \\
\hline
\end{tabular}


Most educators in my

school/conference are engaged in professional learning activities for 40 hours or more over the course of the school year. $(n=737)$

Professional learning activities that introduce new initiatives are followed up with ongoing support for a period of time. $(n=744)$

I participate in setting the goals and in the planning of the professional program in my school and/or conference. $(n=744)$

I have opportunities to plan instruction together with other educators (at my school or other schools/conferences). $(\mathrm{n}=747)$

Professional learning activities in my school/conference are focused on helping educators better understand the content of their academic discipline $(\mathrm{n}=745)$

Professional learning activities in my school and/or conference are focused on helping educators understand how students learn best in specific content areas. $(n=746)$

Professional learning activities in my school/conference include a focus on integrating technology in specific content areas. $(n=742)$

Professional learning activities in my school/conference include a focus on reflecting the Biblical worldview in specific content areas. $(n=743)$

My employer expects me to participate annually in professional learning activities. $(n=743)$

Professional learning is part of our school/conference improvement plan. $(n=739)$

Ongoing professional learning is included in our regular staff meetings. $(n=744)$

$\begin{array}{llllll} & 72 & 222 & 229 & 149 & 65 \\ 2.88 & 9.8 \% & 30.1 \% & 31.1 \% & 20.2 \% & 8.8 \%\end{array}$

$\begin{array}{llllll} & 103 & 247 & 233 & 132 & 29 \\ 2.65 & 13.8 \% & 33.2 \% & 31.3 \% & 17.7 \% & 3.9 \%\end{array}$

$\begin{array}{lllll}181 & 183 & 157 & 142 & 81\end{array}$

$\begin{array}{lllll}24.3 \% & 24.6 \% & 21.1 \% & 19.1 \% & 10.9 \%\end{array}$

$\begin{array}{llllll} & 110 & 213 & 209 & 133 & 82 \\ 2.82 & 14.7 \% & 28.5 \% & 28.0 \% & 17.8 \% & 11.0 \%\end{array}$

$\begin{array}{lllll}57 & 176 & 279 & 187 & 46\end{array}$

2.99

$\begin{array}{lllll}7.7 \% & 23.6 \% & 37.4 \% & 25.1 \% & 6.2 \%\end{array}$

3.11

$\begin{array}{lllll}32 & 158 & 299 & 208 & 49\end{array}$

$\begin{array}{lllll}4.3 \% & 21.2 \% & 40.1 \% & 27.9 \% & 6.6 \%\end{array}$

3.17

$\begin{array}{lllll}22 & 129 & 343 & 197 & 51\end{array}$

$\begin{array}{lllll}3.0 \% & 17.4 \% & 46.2 \% & 26.5 \% & 6.9 \%\end{array}$

3.19

$\begin{array}{lllll}41 & 154 & 262 & 192 & 94\end{array}$

$\begin{array}{lllll}5.5 \% & 20.7 \% & 35.3 \% & 25.8 \% & 12.7 \%\end{array}$

4.36

$\begin{array}{lllll}14 & 33 & 70 & 179 & 447\end{array}$

$\begin{array}{lllll}1.9 \% & 4.4 \% & 9.4 \% & 24.1 \% & 60.2 \%\end{array}$

$\begin{array}{llllll}18 & 45 & 112 & 211 & 353\end{array}$

$2.4 \% \quad 6.1 \% \quad 15.2 \% \quad 28.6 \% \quad 47.8 \%$

$\begin{array}{lllll}68 & 161 & 245 & 168 & 102\end{array}$

3.10 
Time is provided in my regular work day for professional learning activities. $(\mathrm{n}=746)$

My school/conference provides adequate funding to assist me with ongoing professional learning. $(n=743)$

My school/conference provides training for educators on how to effectively collaborate with each other. $(\mathrm{n}=745)$

Mentoring programs for new teachers and/or administrators are available in my school/conference. $(n=740)$

I have access to the kinds of professional learning that I need. $(\mathrm{n}=742)$

My employer provides incentives (e.g., financial, leadership opportunities, etc.) to encourage my participation in professional learning. $(\mathrm{n}=745)$

Educators who participate in ongoing teacher professional learning activities are recognized in my school or conference for their expertise and leadership. $(n=745)$

After returning from off-site professional learning experiences, educators formally share their learning with their colleagues in their school and/or conference. $(n=745)$

My employer requires me to complete an annual professional growth plan. $(\mathrm{n}=742)$

My selection of professional learning activities is influenced by my formal performance evaluations. $(n=742)$

My school/conference uses a variety of data to monitor the effectiveness of professional learning activities. $(\mathrm{n}=731)$

The educators in my school/conference hold each other accountable to high performance standards. $(n=739)$
1.95

$\begin{array}{lllll}330 & 230 & 109 & 46 & 31\end{array}$

$\begin{array}{lllll}44.2 \% & 30.8 \% & 14.6 \% & 6.2 \% & 4.2 \%\end{array}$

3.27

$\begin{array}{lllll}73 & 144 & 182 & 197 & 147\end{array}$

$\begin{array}{lllll}9.8 \% & 19.4 \% & 24.5 \% & 26.5 \% & 19.8 \%\end{array}$

2.51

$\begin{array}{lllll}144 & 245 & 220 & 102 & 34\end{array}$

$\begin{array}{lllll}19.3 \% & 32.9 \% & 29.5 \% & 13.7 \% & 4.6 \%\end{array}$

2.99

$\begin{array}{lllll}136 & 164 & 151 & 148 & 141\end{array}$

$\begin{array}{lllll}18.4 \% & 22.2 \% & 20.4 \% & 20.0 \% & 19.1 \%\end{array}$

3.37

$\begin{array}{lllll}28 & 124 & 254 & 221 & 115\end{array}$

$\begin{array}{lllll}3.8 \% & 16.7 \% & 34.2 \% & 29.8 \% & 15.5 \%\end{array}$

$\begin{array}{lllll}173 & 185 & 171 & 136 & 80\end{array}$

2.69

$\begin{array}{lllll}23.2 \% & 24.8 \% & 23.0 \% & 18.3 \% & 10.7 \%\end{array}$

$\begin{array}{lllll}134 & 184 & 250 & 132 & 45\end{array}$

$24.7 \%$

$33.6 \%$

$17.7 \% \quad 6.0 \%$

$\begin{array}{lllll}96 & 198 & 242 & 136 & 73\end{array}$

2.86

$\begin{array}{lllll}12.9 \% & 26.6 \% & 32.5 \% & 18.3 \% & 9.8 \%\end{array}$

3.36

$\begin{array}{lllll}147 & 110 & 92 & 118 & 275\end{array}$

$19.8 \% \quad 14.8 \% \quad 12.4 \% \quad 15.9 \% \quad 37.1 \%$

2.46

$\begin{array}{lllll}196 & 199 & 197 & 111 & 39\end{array}$

$26.4 \% \quad 26.8 \% \quad 26.5 \% \quad 15.0 \% \quad 5.3 \%$

$\begin{array}{lllll}197 & 234 & 176 & 98 & 26\end{array}$

2.35

$26.9 \% \quad 32.0 \% \quad 24.1 \% \quad 13.4 \% \quad 3.6 \%$

3.16

$\begin{array}{lllll}9.9 \% & 18.9 \% & 29.6 \% & 28.6 \% & 13.0 \%\end{array}$


Educators' experience levels are considered in the planning of professional learning activities for our 2.83 school and/or conference. $(n=736)$

The professional learning activities that I have participated in have been directly related to my current needs. $(n=745)$

Most of the professional learning activities I have participated in have reinforced my previous learning rather than adding something new. $(n=744)$

Professional learning activities help me identify areas I need to improve in my own teaching/administrative practice. $(n=741)$

I am confident in my mastery of the content that I teach and/or the duties I am called upon to perform. $(n=743)$

I am confident in my ability to share the Biblical perspective in the subjects I teach and/or the duties I am called upon to perform. $(n=743)$

I am confident in my ability to use various technologies to support instruction. $(\mathrm{n}=741)$

I have demonstrated mastery by presenting at workshops, conferences, or in-school training, or by submitting journal articles for publication. $(n=744)$

I have the skills I need to address various learning differences among students. $(n=743)$

Professional learning activities in my school/conference include peer coaching. $(\mathrm{n}=740)$

In my school/conference, experienced educators work closely with new teachers/administrators. $(n=740)$

Professional learning activities in my school and/or conference include opportunities to collaboratively examine and discuss student work.

$\begin{array}{lllll}104 & 161 & 271 & 155 & 45\end{array}$

$\begin{array}{lllll}14.1 \% & 21.9 \% & 36.8 \% & 21.1 \% & 6.1 \%\end{array}$

3.28

32

152

241

219

101

$\begin{array}{lllll}4.3 \% & 20.4 \% & 32.3 \% & 29.4 \% & 13.6 \%\end{array}$

\subsection{4}

20

111

365

204

44

$2.7 \% \quad 14.9 \% \quad 49.1 \% \quad 27.4 \% \quad 5.9 \%$

4.10

$\begin{array}{lllll}28 & 71 & 291 & 250 & 101\end{array}$

$\begin{array}{lllll}3.8 \% & 9.6 \% & 39.3 \% & 33.7 \% & 13.6 \%\end{array}$

$\begin{array}{lllll}1 & 14 & 107 & 410 & 211\end{array}$

$\begin{array}{lllll}0.1 \% & 1.9 \% & 14.4 \% & 55.2 \% & 28.4 \%\end{array}$

$\begin{array}{llllll}1 & 10 & 61 & 299 & 372\end{array}$

$\begin{array}{lllll}0.1 \% & 1.3 \% & 8.2 \% & 40.2 \% & 50.1 \%\end{array}$

$\begin{array}{llllll}3.93 & 2 & 33 & 165 & 353 & 188 \\ & 0.3 \% & 4.5 \% & 22.3 \% & 47.6 \% & 25.4 \% \\ & 243 & 168 & 151 & 108 & 74 \\ 2.47 & 32.7 \% & 22.6 \% & 20.3 \% & 14.5 \% & 9.9 \%\end{array}$

$\begin{array}{llllll}3.71 & 5 & 44 & 224 & 357 & 113 \\ & 0.7 \% & 5.9 \% & 30.1 \% & 48.0 \% & 15.2 \% \\ 2.36 & 206 & 234 & 173 & 81 & 46 \\ & 27.8 \% & 31.6 \% & 23.4 \% & 10.9 \% & 6.2 \% \\ 2.90 & 93 & 194 & 225 & 154 & 74 \\ & 12.6 \% & 26.2 \% & 30.4 \% & 20.8 \% & 10.0 \% \\ & 128 & 251 & 211 & 105 & 45 \\ 2.58 & 17.3 \% & 33.9 \% & 28.5 \% & 14.2 \% & 6.1 \%\end{array}$


$(\mathrm{n}=740)$

I receive specific feedback from my school leaders and/or colleagues to help me refine and improve my teaching and/or administrative $2.89 \quad 10.9 \% \quad 28.6 \% \quad 30.0 \% \quad 21.3 \% \quad 9.2 \%$ practice. $(\mathrm{n}=741)$

My school/conference budget includes specific provision for ongoing professional learning expenses. $(\mathrm{n}=737)$

$\begin{array}{llllll} & 52 & 101 & 165 & 194 & 225 \\ 3.60 & 7.1 \% & 13.7 \% & 22.4 \% & 26.3 \% & 30.5 \%\end{array}$

My school and/or conference provides substitutes as needed to facilitate my participation in professional learning activities during the school/work day. 58

$\begin{array}{llll}100 & 134 & 193 & 258\end{array}$
$(\mathrm{n}=7443)$

My supervisor (principal/superintendent/employer) participates regularly in professional learning activities. $(n=740)$

\begin{tabular}{|c|c|c|c|c|c|c|}
\hline Survey Question & Mean & $\begin{array}{l}\text { Strongly } \\
\text { Disagree }\end{array}$ & Disagree & $\begin{array}{l}\text { Neither } \\
\text { Agree } \\
\text { nor } \\
\text { Disagree }\end{array}$ & Agree & $\begin{array}{c}\text { Strongly } \\
\text { Agree }\end{array}$ \\
\hline \multirow{2}{*}{$\begin{array}{l}\text { Most of the educators (teachers and } \\
\text { administrators) in my } \\
\text { school/conference participate regularly } \\
\text { in professional learning activities. } \\
(\mathrm{n}=744)\end{array}$} & & 16 & 92 & 107 & 404 & 125 \\
\hline & 3.71 & $2.2 \%$ & $12.4 \%$ & $14.4 \%$ & $54.3 \%$ & $16.8 \%$ \\
\hline \multirow{2}{*}{$\begin{array}{l}\text { My supervisor } \\
\text { (principal/supervisor/president) } \\
\text { encourages me to apply the new things } \\
\text { I learn in my classroom, even if it } \\
\text { means taking some risks. }(n=744)\end{array}$} & & 22 & 72 & 132 & 309 & 209 \\
\hline & 3.82 & $3.0 \%$ & $9.7 \%$ & $17.7 \%$ & $41.5 \%$ & $28.1 \%$ \\
\hline \multirow{2}{*}{$\begin{array}{l}\text { Most educators in my } \\
\text { school/conference are open to new } \\
\text { ideas to improve student learning. } \\
(n=744)\end{array}$} & & 8 & 51 & 109 & 397 & 179 \\
\hline & 3.93 & $1.1 \%$ & $6.9 \%$ & $14.7 \%$ & $53.4 \%$ & $24.1 \%$ \\
\hline \multirow{2}{*}{$\begin{array}{l}\text { I am a more effective educator today } \\
\text { because of my participation in ongoing } \\
\text { professional learning activities. } \\
(n=745)\end{array}$} & & 13 & 39 & 108 & 309 & 276 \\
\hline & 4.07 & $1.7 \%$ & $5.2 \%$ & $14.5 \%$ & $41.5 \%$ & $37.0 \%$ \\
\hline \multirow{2}{*}{$\begin{array}{l}\text { There is a positive correlation between } \\
\text { ongoing professional learning and } \\
\text { improved student achievement. } \\
(\mathrm{n}=745)\end{array}$} & & 2 & 24 & 142 & 338 & 239 \\
\hline & 4.06 & $0.3 \%$ & $3.2 \%$ & $19.1 \%$ & $45.4 \%$ & $32.1 \%$ \\
\hline
\end{tabular}


All teachers and administrators should be expected to participate in professional learning activities annually. $(\mathrm{n}=746)$

Ongoing professional learning activities are needed to assist all teachers and administrators in staying current with trends in education. $(n=746)$

Ongoing professional learning will help me to meet my future career goals. $(n=744)$

My primary reason for participating in professional learning activities is to improve student learning. $(\mathrm{n}=746)$

I participate in ongoing professional learning activities in order to qualify for a promotion or salary increase. $(n=746)$

My employer values my past experience and learning. $(n=745)$

$\begin{array}{llllll} & 6 & 12 & 38 & 241 & 449 \\ 4.50 & 0.8 \% & 1.6 \% & 5.1 \% & 32.3 \% & 60.2 \% \\ & & & & & \\ & 5 & 8 & 39 & 273 & 421 \\ 4.47 & 0.7 \% & 1.1 \% & 5.2 \% & 36.6 \% & 56.4 \%\end{array}$

$\begin{array}{llllll}3 & 3 & 18 & 98 & 288 & 337\end{array}$

$0.4 \% \quad 2.4 \%$

$13.2 \%$

$38.7 \% \quad 45.3 \%$

$\begin{array}{lllll}4 & 12 & 50 & 307 & 373\end{array}$

$\begin{array}{lllll}0.5 \% & 1.6 \% & 6.7 \% & 41.2 \% & 50.0 \%\end{array}$

2.50

$\begin{array}{lllll}197 & 187 & 193 & 127 & 42\end{array}$

$25.1 \% \quad 25.9 \%$

$17.0 \% \quad 5.6 \%$

3.90

$\begin{array}{lllll}25 & 53 & 124 & 312 & 231\end{array}$

$3.4 \% \quad 7.1 \% \quad 16.6 \% \quad 41.9 \% \quad 31.0 \%$

*only valid responses included 


\section{REFERENCES}

Alberta Teachers' Association. (2012, November). Creating possibilities, balancing priorities - the 2012 professional development survey (ATA Research Report PD86-25 20121131 pp). Retrieved from http://www.teachers.ab.ca/About\%20the \%20ATA/Education\%20Research/Pages/Research\%20Publications.aspx

Alexandrou, A., \& Swaffield, S. (2012). Teacher leadership and professional development: Perspectives, connections and prospects. Professional Development in Education, 38(2), 159-167. doi:10.1080/19415257.2012.657557

Andrews, S. P., Gilbert, L. S., \& Martin, E. P. (2006). The first years of teaching: Disparities in perceptions of support. Action in Teacher Education, 28(4), 4-13.

Archibald, S., Coggshall, J. G., Croft, A., \& Goe, L. (2011, February). High-quality professional development for all teachers: Effectively allocating resources (Research and Policy Brief). Washington, DC: National Comprehensive Center for Teacher Quality.

Association of Supervision and Curriculum Development. (2013). Professional development needs. [when live, it was accessible on the ASCD website at http://survey.ascd.org/ TakeSurvey.aspx?SurveyID=n23K372]

Avalos, Beatrice. (2011). Teacher professional development in teaching and teacher education over ten years. Teaching and Teacher Education, 27(1), 10-20.

Ball, D. L., \& Cohen, D. K. (1999). Developing practice, developing practitioners: Toward a practice-based theory of professional education. In L. Darling-Hammond \& G. Sykes (Eds.), Teaching as the learning profession: Handbook of policy and practice (pp. 3-32). San Francisco, CA: Jossey-Bass Publishers.

Bandura, A. (1993). Perceived self-efficacy in cognitive development and functioning. Educational Psychologist, 28(2), 117-148.

Bangs, J., \& MacBeath, J. (2012). Collective leadership: The role of teacher unions in encouraging teachers to take the lead in their own learning and in teacher policy. Professional Development in Education, 38(2), 331-343.

Barber, M., \& Mourshed, M. (2007). How the world's best-performing school systems come out on top. New York, NY: McKinsey \& Company. 
Bassett, K., Grossman, T., Allan, P., Allen, M., Cook, S., \& Olney, J. (2013, October 4). Re-imagining teaching: Five structures to transform the profession [White Paper]. Arlington, VA: National Network of State Teachers of the Year (NNSTOY).

Beach, R. (2012, March). Can online learning communities foster professional development? Language Arts, 89(4), 256-262.

Beatty, B. R. (2000). Teachers leading their own professional growth: Self-directed reflection and collaboration and changes in perception of self and work in secondary school teachers. Journal of In-Service Education, 26(1), 73-97.

Behrstock-Sherratt, E., \& Coggshall, J. G. (2010, May). Realizing the promise of Generation Y. Educational Leadership, 67(8), 28-34.

Bennett, S., Maton, K., \& Kervin, L. (2008). The "digital natives" debate: A critical review of the evidence. British Journal of Educational Technology, 39(5), 775-786.

Bill and Melinda Gates Foundation. (2014). Teachers know best: Teachers'views on professional development. Seattle, WA: Author.

Bloomberg, L. D., \& Volpe, M. (2008). Completing your qualitative dissertation: A roadmap from beginning to end. Los Angeles, CA: Sage.

Borko, H. (2004). Professional development and teacher learning: Mapping the terrain. Educational Researcher, 33(8), 3-15. doi:10.3102/0013189X033008003

Borko, H., \& Putnam, R. T. (1995). Expanding a teacher's knowledge base: A cognitive psychological perspective on professional development. In T. R. Guskey and M. Huberman (Eds.), Professional development in education: New paradigms and practices (pp. 35-65). New York, NY: Teachers College, Columbia University.

Broadbridge, A., Maxwell, G. A., \& Ogden, S. M. (2007). Experiences, perceptions and expectations of retail employment for Generation Y. Career Development International, 12(6), 523-544.

Brock, B. L., \& Chatlain, G. (2008). The status of teacher induction in Catholic schools: Perspectives from the United States and Canada. Catholic Education, 11(3), 370384.

Brown, J. S., Collins, A., \& Duguid, P. (1989). Situated cognition and the culture of learning. Educational Researcher, 18(1), 32-42.

Buczynski, S., \& Hansen, C. B. (2010). Impact of professional development on teacher practice: Uncovering connections. Teaching and Teacher Education, 26(2010), 599-607. 
Burke, W. W. (2011). Organization change: Theory and practice (3rd ed.). Los Angeles, CA: Sage.

Burton, L. (2012). Seventh-day Adventist schools. In T. C. Hunt and J. C. Carper (Eds.), The Praeger handbook of faith-based schools in the United States, K-12 (pp. 189200). Santa Barbara, CA: ABC-CLIO, LLC.

Calvert, L. (2016). Moving from compliance to agency: What teachers need to make professional learning work. Oxford, OH: Learning Forward and NCTAF.

Carroll, T. G., Fulton, K., \& Doerr, H. (Eds). (2010, June). Team up for 21 st century teaching and learning: What research and practice reveal about professional learning (Condensed excerpts). Washington, D.C.: National Commission on Teaching and America's Future.

Cator, K., Schneider, C., \& Vander Ark, T. (2014, April). Preparing teachers for deeper learning: Competency-based teacher preparation and development. Washington, DC: Digital Promise.

Cervero, R. M. (1992). Professional practice, learning, and continuing education: An integrated perspective. International Journal of Lifelong Education, 11(2), 91-101. doi:10.1080/0260137920110202

Clandinin, D. J., Schaefer, L., Long, J., Steeves, P., McKenzie-Robblee, S., Pinnegar, E., ... Downey, C. A. (2012, April 30). Early career teacher attrition: Problems, possibilities, potentials (final report). Retrieved from http://www.elementaryed.ualberta.ca/en/ Centres/CRTED/ /media/elementaryed/ Documents/Centres/CRTED/ECA_-_FINAL_Report.pdf

Cobb, P., Wood, T., \& Yackel, E. (1990). Classrooms as learning environments for teachers and researchers. In R. B. Davis, C. A. Maher, \& N. Noddings (Eds.), Constructivist views on the teaching and learning of mathematics (pp. 125-146). Reston, VA: National Council of Teachers of Mathematics.

Coburn, Cynthia E. (2001). Collective sensemaking about reading: How teachers mediate reading policy in their professional communities. Educational Evaluation and Policy Analysis, 23(2), 145-170.

Coggins, C., Zuckerman, S., \& McKelvey, L. A. (2010, May). Holding on to Gen Y. Educational Leadership, 67(8), 70-74.

Coggshall, J.G., Behrstock-Sherratt, E., \& Drill, K. (2011, April). Workplaces that support high-performing teaching and learning: Insights from Generation $Y$ teachers. Washington, D.C.: American Federation of Teachers and American Institutes for Research. 
Coggshall, J. G., Ott, A., Behrstock E., \& Lasagna, M. (2010). Retaining teacher talent: The view from Generation $Y$ (4070R_01/10: 1-21). Retrieved from $\mathrm{http}: / / \mathrm{www}$.air.org/project/retaining-teacher-talent

Cohen, D. (2016, April 4). Teachers need less training, more learning [Blog post]. EdWeek. Retrieved from http://blogs.edweek.org/teachers/capturing-the-sparkengagement-and-teaching/2016/04/less_training_more_learning.html

Coley, D. C. (2009). Leading generation Y. Education Digest, 74(9), 20.

Cook, C., Heath, F., \& Thompson, R. L. (2000, December). Meta-analysis of response rates in web- or internet-based surveys. Educational and Psychological Measurement, 60(6), 821-836.

Corcoran, T. B. (2007, February). Teaching matters: How state and local policymakers can improve the quality of teachers and teaching [Policy Brief]. Philadelphia, PA: Consortium for Policy Research in Education (CPRE).

Daley, B. J. (2000, Summer). Learning in professional practice. In V. W. Mott \& B. J. Daley (Eds.), Charting a course for continuing professional education: Reframing professional practice (pp. 33-42). New York, NY: Jossey-Bass.

Danielson, C. (2016). It's time to rethink teacher evaluation. Education Week, 35(28), 20, 24.

Darling-Hammond, L. (2009). Teaching and the change wars: The professionalism hypothesis. In A. Hargreaves \& M. Fullan (Eds.), The change wars (pp. 44-68). Bloomington, IN: Solution Tree.

Darling-Hammond, L., \& McLaughlin, M. W. (1999). Investing in teaching as a learning profession. In L. Darling-Hammond \& G. Sykes (Eds.), Teaching as the learning profession (pp. 376-411). San Francisco, CA: Jossey-Bass.

Darling-Hammond, L., Wei, R. C., Andree, A., Richardson, N., \& Orphanos, S. (2009). Professional learning for the learning profession: A status report on teacher development in the United States and abroad. Retrieved from http://www.learningforward.org/ docs/pdf/nsdcstudy2009.pdf?sfvrsn=0

Dauksas, L., \& White, J. (2010). Should I stay or should I go? How teacher leadership can improve teacher retention. AASA Journal of Scholarship \& Practice, 7(2), 2732 .

Davis, B., \& Sumara, D. (2006). Complexity and education: Inquiries into learning, teaching, and research. New York, NY: Routledge. 
Deal, J. J., Altman, D. G., \& Rogelberg, S. G. (2010). Millennials at work: What we know and what we need to do (if anything). Journal of Business Psychology, 25(2), 191-199.

Dede, C. (2005). Planning for neomillennial learning styles. Educause Quarterly, 28(1), n.p.

Dede, C. (2006). Introduction. In C. Dede (Ed.), Online professional development for teachers: Emerging models and methods (pp. 1-11). Cambridge, MA: Harvard University Press.

Dede, C., Eisenkraft, A., Frumin, K., \& Hartley, A. (Eds). (2016). Teacher learning in the digital age: Online professional development in STEM education. Cambridge, MA: Harvard Education Press.

DeMonte, J. (2013, July). High-quality professional development for teachers: Supporting teacher training to improve student learning. Washington, DC: Center for American Progress.

Denmark, V., \& Weaver, S. R. (2012). Technical report: Redesign and psychometric evaluation of the Standards Assessment Inventory. Alpharetta, GA: AdvancED.

Desimone, L. M. (2009). Improving impact studies of teachers' professional development: Toward better conceptualizations and measures. Educational Researcher, 38(3), 181-199. doi:10.3102/0013189X08331140

Desimone, L. M. (2011, March). A primer on effective professional development. Phi Delta Kappan, 92(6), 68-71.

Desimone, L. M., \& Le Floch, K. C. (2004). Are we asking the right questions? Using cognitive interviews to improve surveys in education research. Educational evaluation and Policy Analysis, 26(1), 1-22. doi:10.3102/01623737026001001

Desimone, L. M., Porter, A. C., Garet, M. S., Yoon, K. S., \& Birman, B. F. (2002, Summer). Effects of professional development on teachers' instruction: Results from a three-year longitudinal study. Educational Evaluation and Policy Analysis, 24(2), 81-112.

DeVellis, R. F. (2012). Scale development: Theory and applications ( $3^{\text {rd }}$ ed.). Los Angeles, CA: Sage.

Donley, A. (2012). Student handbook to sociology: Research methods. New York, NY: Facts On File.

Donnison, S. (2007). Unpacking the millennials: A cautionary tale for teacher education. Australian Journal of Teacher Education, 32(3), 1-13. 
Donnison, S. (2009). Discourses in conflict: The relationship between Gen Y pre-service teachers, digital technologies and lifelong learning. Australian Journal of Educational Technology, 25(3), 336-350.

Easton, L. B. (2008, June). From professional development to professional learning. Phi Delta Kappan, 89(10), 755-761.

Edmunds, J., \& Turner, B. (2005). Global generations: Social change in the twentieth century. The British Journal of Sociology, 56(4), 559-577. doi:10.1111/j.14684446.2005.00083.x

Elmore, Richard. (2002). Bridging the gap between standards and achievement: The imperative for professional development in education. Washington, DC: The Albert Shanker Institute.

Ezzeldine, O. M. (2004). Factors at religious schools that affect retention. (Doctoral Dissertation). Available from ProQuest Dissertations and Theses database. (UMI No. 3146588)

Farkas, S., Johnson, J., \& Foleno, T. (2000). A sense of calling: Who teaches and why. New York, NY: Public Agenda.

Fink, A. (2013). How to conduct surveys: A step-by-step guide. Thousand Oaks, CA: Sage.

Finn, D., Swezey, J., \& Warren, D. (2010). Perceived professional development needs of teachers and administrators in PS-12 Christian schools. Journal of Research on Christian Education, 19(1), 7-26.

Fishman, B. J., Marx, R. W., Best, S., \& Tal, R. T. (2003). Linking teacher and student learning to improve professional development in systemic reform. Teaching and Teacher Education, 19(6), 643-658.

Frost, D. (2012). From professional development to system change: Teacher leadership and innovation. Professional Development in Education, 38(2), 205-227. doi:10.1080/19415257.2012.657861

Fullan, M. (1995). The limits and the potential of professional development. In T. R. Guskey \& M. Huberman (Eds.), Professional development in education: New paradigms and practices (pp. 253-267). New York, NY: Teachers College, Columbia University.

Fullan, M. (2003). The moral imperative of school leadership. Thousand Oaks, CA: Corwin. 
Fullan, M. (2006). Leading professional learning: Think "system" and not "individual school" if the goal is to fundamentally change the culture. School Administrator, 63(10).

Fullan, M. (2007). The new meaning of educational change (4th ed.). New York, NY: Teachers College.

Fullan, M. (2010). All systems go: The change imperative for whole system reform. Thousand Oaks, CA: Corwin.

Fullan, M. (2011a). Change leaders: Learning to do what matters most. San Francisco, CA: Jossey-Bass.

Fullan, M. (2011b). The moral imperative realized. Thousand Oaks, CA: Corwin.

Fullan, M. (2016). The new meaning of educational change $\left(5^{\text {th }}\right.$ ed.). New York, NY: Routledge.

Fullan, M., \& Hargreaves, A. (1992). Teacher development and educational change. In M. Fullan \& A. Hargreaves, Teacher development and educational change (pp. 19). London, England: Falmer Press.

Furst, L. G. (2012). The Seventh-day Adventist schools: Organizational support. In Hunt, Thomas C., and Carper, James C. (Eds.) (2012). The Praeger handbook of faith-based schools in the United States, K-12. Santa Barbara, CA: ABC-CLIO, LLC

Gall, M. D., Gall, J. P., \& Borg, W. R. (2007). Educational research: An introduction (8th ed.). Toronto, Canada: Pearson Education, Inc.

Garet, M. S., Birman, B. F., Porter, A. C., Desimone, L., \& Herman, R. (1999). Designing effective professional development: Lessons from the Eisenhower program (Research Report No. ED/OUS99-3). Washington, DC: U.S. Department of Education.

Garet, M. S., Porter, A. C., Desimone, L., Birman, B. F., \& Yoon K. S. (2001). What makes professional development effective? Results from a national sample of teachers. American Educational Research Journal, 38(4), 915-945.

Goldschmidt, P. \& Phelps, G. (2010). Does teacher professional development affect content and pedagogical knowledge: How much and for how long? Economics of Education Review, 29(2010), 432-439.

Grace, G. (2003). Educational studies and faith-based schooling: Moving from prejudice to evidence-based argument. British Journal of Educational Studies, 51(2), 149167. doi:10.1111/1467-8527.t01-1-00231 
Green, W., \& Whitsed, C. (2013). Reflections on an alternative approach to continuing professional learning for internationalization of the curriculum across disciplines. Journal of Studies in International Education, 17(2), 148-164. doi:

$10.1177 / 102831531246.3825$

Guarino, C. M., Santibañez, L., \& Daley, G. A. (2006). Teacher recruitment and retention: A review of the recent empirical literature. Review of Educational Research, 76(2), 173-208.

Gulamhussein, A. (2013). Teaching the teachers: Effective professional development in an era of high stakes accountability. Alexandria, VA: Center for Public Education.

Guskey, T. R. (1986, May). Staff development and the process of teacher change. Educational Researcher, 15(5), 5-12.

Guskey, T. R. (2000). Evaluating professional development. Thousand Oaks, CA: Corwin.

Guskey, T. R., \& Sparks, D. (2002, April). Linking professional development to improvements in student learning. Paper presented at the annual meeting of the American Educational Research Association, New Orleans, LA. Retrieved from ERIC database. (ED464112)

Hammerness, K., Darling-Hammond, L., Bransford, J. (with Berliner, D., CochranSmith, M., McDonald, M., and Zeichner, K.). (2005). How teachers learn and develop. In L. Darling-Hammond, \& J. Bransford (Eds.), Preparing teachers for a changing world: What teachers should learn and be able to do (pp. 358-389). San Francisco, CA: Jossey-Bass.

Hargreaves, A. (2009). The fourth way of change: Towards an age of inspiration and sustainability. In A. Hargreaves \& M. Fullan (Eds.), Change wars (pp. 1-9). Bloomington, IN: Solution Tree.

Hargreaves, A., \& Fullan. M. (2012). Professional capital: Transforming teaching in every school. New York, NY: Teachers College, Columbia University.

Hargreaves, A., \& Goodson, I. (2006). Educational change over time? The sustainability and nonsustainability of school change and continuity. Educational Administration Quarterly, 42(1), 3-41. doi: 1177/0013161X05277975

Hargreaves, A., \& Shirley, D. (2009). The fourth way: The inspiring future for educational change. Thousand Oaks, CA: Corwin.

Harris, A. \& Mucijs, D. (2005). Improving schools through teacher leadership. Berkshire, England: Open University Press. 
Hawley, W. D., \& Valli, L. (1999). The essentials of effective professional development: A new consensus. In L. Darling-Hammond \& G. Sykes (Eds.), Teaching as the learning profession (pp. 127-150). San Francisco, CA: Jossey-Bass.

Headley, S. (2003). Professional development policies and practices in schools affiliated with the Association of Christian Schools International. Journal of Research on Christian Education, 12(2), 95-215.

Hershatter, A., \& Epstein, M. (2010). Millennials and the world of work: An organization and management perspective. Journal of Business Psychology, 25(2), 211-223.

Hiemstra, J. L., \& Brink, R. A. (2006). The advent of a public pluriformity model: Faithbased school choice in Alberta. Canadian Journal of Education, 29(4), 1157-1190.

Hill, H. C. (2009, March). Fixing teacher professional development. Phi Delta Kappan, 90(7), 470-476.

Hill, H C., Beisiegel, M., \& Jacob, R. (2013, December 1). Professional development research: Consensus, crossroads, and challenges. Educational Researcher, 42(9), 476-487. doi:10.3102/0013189X13512674

Hirsch, E., Koppich, J. E., \& Knapp, M. S. (2001). Revisiting what states are doing to improve the quality of teaching: An update on patterns and trends. Seattle, WA: University of Washington, Center for the Study of Teaching and Policy.

Hooper, D. (2012). Exploratory factor analysis. In H. Chen (Ed.), Approaches to quantitative research-Theory and its practical application: A guide to dissertation students. Cork, Ireland: Oak Tree Press.

Howe, N., \& Strauss, W. (2000). Millennials rising. New York, NY: Vintage Books.

Hoy, W. K., Sweetland, S. R., \& Smith, P. A. (2002). Toward an organizational model of acheivement in high schools: The significance of collective efficacy. Educational Administration Quarterly, 38(1), 77-93.

Huberman, M. (1995). Professional careers and professional developments: Some intersections. In T. R. Guskey \& M. Huberman, Professional development in education: New paradigms and practices (pp.193-224). New York, NY: Teachers College, Columbia University.

Hunzicker, J. (2011). Effective professional development for teachers: A checklist. Professional Development in Education, 37(2), 177-179. doi:10.1080/19415257.2010.523955 
Hurst, J.L., \& Good, L.K. (2009). Generation Y and career choice: The impact of retain career perceptions, expectations and entitlement perceptions. Career Development International, 14 (6): 570-593. doi: 10.1108/13620430910997303

Hutchens, D. (2000). Outlearning the wolves: Surviving and thriving in a learning organization. Waltham, MA: Pegasus Communications, Inc.

Ingersoll, R. (2003, September). Is there really a teacher shortage? (Research Report). Philadelphia, PA: The Consortium for Policy Research in Education.

Ingersoll, R. M., \& Strong, M. (2011). The impact of induction and mentoring programs for beginning teachers: A critical review of the research. Review of Educational Research, 81(2), 201-233. doi:10.3102/0034654311403323

Ingvarson, L. (2003). Building a learning profession. ACER Policy Briefs, Issue 3. New South Wales, Australia: Australian Council for Educational Research. (ISSN 14471957)

Ingvarson, L., Meiers, M., \& Beavis, A. (2005). Factors affecting the impact of professional development programs on teachers' knowledge, practice, student outcomes \& efficacy. Education Policy Analysis Archives, 13(10), 1-28.

Jaquith, A., Mindich, D., Wei, R. C., \& Darling-Hammond, L. (2010, November). Teacher professional learning in the United States: Case studies of state policies and strategies. Dallas, TX: National Staff Development Council/Learning Forward.

Jarvis, P. (2006). Towards a comprehensive theory of human learning. New York, NY: Routledge.

Jarvis, P. (2007). Globalisation, lifelong learning and the learning society: Sociological perspectives. New York, NY: Routledge.

Jarvis, P. (2008). Democracy, lifelong learning and the learning society: Active citizenship in a late modern age. New York, NY: Routledge.

Jensen, B., Sonnemann, J., Roberts-Hull, K., \& Hunter, A. (2016). Beyond PD: Teacher professional learning in high-performing systems [Report]. Washington, DC: National Center on Education and the Economy.

Jeynes, W. H. (2012). A meta-analysis on the effects and contributions of public, public charter, and religious schools on student outcomes. Peabody Journal of Education, 87(3), 305-335. doi:10.1080/0161956X.2012.679542

Johnson, R. B., \& Christensen, L. (2013). Educational research: Quantitative, qualitative, and mixed approaches (5th ed.). Los Angeles, CA: Sage. 
Johnson, S. M. (2004). Finders and keepers: Helping new teachers survive and thrive in our schools. San Francisco, CA: Jossey-Bass.

Johnson, S. M., \& Kardos, S. M. (2005, May). Bridging the generation gap. Educational Leadership, 62(8), 8-14.

Kempton, James. (2013, November 21). Teachers taking control: A new vision for professional development. [Blog post]. The Guardian. Retrieved from http://www.theguardian.com/ teacher-network/teacher-blog/2013/nov/21/teachercontrol-professional-development-raising-standards

Kinnaman, D. (2007). UnChristian: What a new generation really thinks about Christianity and why it matters. Grand Rapids, MI: Baker Books.

Kinnaman, D. (2011). You lost me: Why young Christians are leaving church and rethinking faith. Grand Rapids, MI: Baker Books.

Knapp, M. S. (2003). Professional development as a policy pathway. Review of Research in Education, 27(1), 109-157. doi:10.3102/0091732X027001109

Knowles, M. S., Holton, E. F., \& Swanson, R. A. (2012). The adult learner: The definitive classic in adult education and human resource development (7th ed.). New York, NY: Routledge.

Kwakman, K. (2003). Factors affecting teachers' participation in professional learning activities. Teaching and Teacher Education, 19(2), 149-170. doi:10.1016/S0742051X(02)00101-4

Lawler, E. E. (2008). Strategic talent management: Lessons from the corporate world (Research report). Madison, WI: Consortium for Policy Research in Education.

Learning Forward. (2011). Standards for professional learning. Oxford, OH: Author.

Leask, M., \& Younie, S. (2013). National models for continuing professional development: The challenges of twenty-first-century knowledge management. Professional Development in Education, 39(2), 273-287. doi:

10.1080/19415257.2012.749801

Leithwood, K. A. (1992). The principal's role in teacher development. In M. Fullan and A. Hargreaves (Eds.), Teacher development and educational change (pp. 86-103). London, England: Falmer Press.

Leithwood, K., Jantzi, D., \& Steinbach, R. (1999). Changing leadership for changing times. Philadelphia, PA: Open University Press. 
Leithwood, K., \& Louis, K.S. (2012). Linking leadership to student learning. San Francisco, CA: John Wiley and Sons.

Levine, A. (2006). Education school teachers [Report]. Washington, DC: The Education Schools Project.

Levine, M. (2002, March). Why invest in professional development schools? Educational Leadership, 59(6), 65-68.

Lieberman, A. (1995, April). Practices that support teacher development: Transforming conceptions of professional learning. Phi Delta Kappan, 76(8), 591-596.

Lieberman, A., \& Miller, L. (2008). Teachers in professional communities: Improving teaching and learning. New York, NY: Teachers College Press.

Lieberman, A., \& Pointer-Mace, D. (2010). Making practice public: Teacher learning in the twenty-first century. Journal of Teacher Education, 61(2), 1-19.

Little, J. W. (1992). Teacher development and educational policy. In M. Fullan \& A. Hargreaves (Eds.), Teacher development and educational change (pp. 170-193). London, England: Falmer Press.

Little, J. W. (1999). Organizing schools for teacher learning. In L. Darling-Hammond \& G. Sykes (Eds.), Teaching as the learning profession (pp. 233-262). San Francisco, CA: Jossey-Bass.

Long, J. S., McKenzie-Robblee, S., Schaefer, L., Steeves, P., Wnuk, S., Pinnegar, E., \& Clandinin, D. J. (2012). Literature review on induction and mentoring related to early career teacher attrition and retention, mentoring \& tutoring. Partnership in Learning, 20(1), 7-26.

Lortie, Dan C. (2002). Schoolteacher (2nd ed.). Chicago, IL: University of Chicago Press. (Original work published in 1975).

Loucks-Horsley, S., Harding, C. K., Arbuckle, M. A., Murray, L, B., Dubea, C. \& Williams, M, K. (1987). Continuing to learn: A guidebook for teacher development. Oxford, OH: National Staff Development Council.

Loucks-Horsley, S., Stiles, K. E., Mundry, S., Love, N., \& Hewson, P. W. (2010). Designing professional development for teachers of science and mathematics (3rd ed.). Thousand Oaks, CA: Corwin.

Lovely, S. (2012). Boomers and millennials: Vive la différence. Journal of Staff Development, 33(5), 56-59. 
Lowe, D., Levitt, K. J., \& Wilson, T. (2008). Solutions for retaining Generation Y employees in the workplace. Business Renaissance Quarterly, 3(3), 43-57.

Luscombe, J., Lewis, I., \& Biggs, H. C. (2013). Essential elements for recruitment and retention: Generation Y. Education and Training, 55(3), 272-290.

Mannheim, K. (1998). The sociological problem of generations. In K. Mannheim, Essays on the sociology of knowledge (pp. 163-195). Gottingen, Germany: Steidl. (Original work published in 1923).

Martin, C. A. (2005). From high maintenance to high productivity: What managers need to know about Generation Y. Industrial and Commercial Training, 37(1), 39-44. doi:10.1108/00197850510699965

Martin, C. A., \& Tulgan, B. (2006). Managing the generation mix: From urgency to opportunity. Amherst, MA: HRD Press.

McCrindle, M. (2006). New generations at work: Attracting, recruiting, retraining \& training Generation Y (ABN 99105510 772). New South Wales, Australia: McCrindle Research.

McGill, R. M. (2013, January 29). Professional development for teachers: How can we take it to the next level? [Blog post]. The Guardian. Retrieved from http://www.theguardian. com/teacher-network /teacherblog/2013/jan/29/professional-development-teacher-training-needs

Meier, J., \& Crocker, M. (2010, June). Generation Y in the workforce: Managerial challenges. The Journal of Human Resource and Adult Learning, 6(1), 68-78.

Merriam, S.B., Caffarella, R. S., \& Baumgartner, L. M. (2007). Learning in adulthood: A comprehensive guide (3rd ed.). San Francisco, CA: John Wiley \& Sons.

Mindich, D., \& Lieberman, A. (2012). Building a learning community: A tale of two schools. Stanford, CA: Stanford Center for Opportunity Policy in Education.

Mitchell, C., \& Sackney, L. (2011). Profound improvement: Building capacity for a learning community (2nd ed.). New York, NY: Routledge.

Mockler, N. (2005). Transforming teachers: New professional learning and transformative teacher professionalism. Journal of In-service Education, 31(4), 733-746.

Mockler, N. (2013). Teacher professional learning in a neoliberal age: Audit, professionalism and identity. Australian Journal of Teacher Education, 38(10), 35 47. 
Mokoena, S. (2012, March). Recruiting and retaining generation Y teachers: Emerging strategies for school administrators. International Journal for Cross-Disciplinary Subjects in Education, 3(2), 687-691.

Montoro, V. (2012). Professional development, teacher learning, and national standards: A mixed-method multiple-case study of the professional learning experiences of evangelical Christian school teachers. (Doctoral dissertation). Available from ProQuest Dissertations and Theses database. (UMI No. 3519356)

Morgan, G. A., Leech, N. L., Gloeckner, G. W., \& Barrett, K. C. (2013). IBM SPSS for introductory statistics: Use and interpretation. New York, NY: Routledge.

Mott, V.W. (2000). The development of professional expertise in the workplace. In Mott, V. W. \& Daley, B. J. (Eds.), Charting a course for continuing professional education: Reframing professional practice (pp. 23-31). New York, NY: JosseyBass.

Murray, J. M. (2010). Assessing the status of professional learning opportunities in U.S. independent schools. (Doctoral dissertation). Available from ProQuest Dissertations and Theses database. (UMI No. 3446185)

Murray, T. C., \& Zoul, J. (2015). Leading professional learning: Tools to connect and empower teachers. Thousand Oaks, CA: Corwin.

National Commission on Teaching \& America's Future. (1996, September). What matters most: Teaching for America's future. New York, NY: National Commission on Teaching \& America's Future.

Neuzil, L. M. (2010). Part II: Professional development activities and professional learning community in the Mid-America region of the Association of Christian Schools International. ICCTE Journal, 5(2).

Noddings, N. (2012). Philosophy of education (3rd ed.). Boulder, CO: Westview Press.

North American Division of Seventh-day Adventists. (2017). K-12 educators' certification manual. Silver Spring, MD: North American Division Office of Education.

Oblinger, D. G. (2010). From the campus to the future. EDUCAUSE Review, 45(1), 4244, 46-52.

Oblinger, D., Oblinger J. L., \& Lippincott, J. K. (2005). Educating the Net Generation. Boulder, CO: EDUCAUSE.

Opfer, V. D., \& Pedder, D. (2011, July). Conceptualizing teacher professional learning. Review of Educational Research, 81(3), 376-407. Doi:10.3102/0034654311413609 
Organisation for Economic Co-operation and Development. (2005). Teachers matter: Attracting, developing and retaining effective teachers. Paris, France: Author.

Organisation for Economic Co-operation and Development. (2009). Creating effective teaching and learning environments: First results from TALIS (Teaching and learning international survey). Retrieved from http://www.oecd.org/edu/school/ 43023606.pdf

Osborne, J. W., \& Costello, A. B. (2009). Best practices in exploratory factor analysis: Four recommendations for getting the most from your analysis. Pan-Pacific Management Review, 12(2), 131-146.

Penuel, W. R., Fishman, B., Yamaguchi, R., \& Gallagher, L. P. (2007). What makes professional development effective? Strategies that foster curriculum implementation. American Educational Research Journal, 44(4), 921-958.

Pham, V. H., Bosak, B., Miyake, L., Case, J., \& Gil, S. (2010). The guide to managing and developing young professionals. Fullerton, CA: California State University.

Pham, V. H., Miyake, L., Case, J., \& Gil, S. (2008). The Gen Y perceptions study. Fullerton, CA: California State University.

Phellas, C. N., Bloch, A., \& Seale, C. (2012). Structured methods: Interviews, questionnaires and observation. In C. Seale (Ed.), Researching society and culture ( $3^{\text {rd }}$ ed.) (pp. 181-205). Thousand Oaks, CA: Sage.

Prensky, M. (2001). Digital natives, digital immigrants. On the Horizon, 9(5), 1-6.

Rainer, T. S., \& Rainer, S. S. (2008). Essential church? Reclaiming a generation of dropouts. Nashville, TN: B \& H Publishing Group.

Rebore, R. W., \& Walmsley, A. L. E. (2010). Recruiting and retaining Generation $Y$ teachers. Thousand Oaks, CA: Corwin.

Richardson, J. (2011, May). Tune in to what the new generation of teachers can do. The Phi Delta Kappan, 92(8), 14-19.

Richter, D., Kunter, M., Klusmann, U., Ludtke, O., \& Baumert, J. (2011). Professional development across the teaching career: Teachers' uptake of formal and informal learning opportunities. Teaching and Teacher Education, 27(1), 116-126.

Rudduck, J. (1992). Universities in partnership with schools and school systems: Les liaisons dangereuses? In M. Fullan and A. Hargreaves (Eds.), Teacher development and educational change (pp. 194-212). London, England: Falmer Press. 
Schalock, M., Ayres, R., \& Cuthbertson, L. (2008). Oregon statewide teacher professional development survey. Monmouth, OR: Teaching Research Institute, Western Oregon University.

Schein, E. H. (2010). Organizational culture and leadership ( $4^{\text {th }}$ ed.). San Francisco, CA: Jossey-Bass.

Schlager, M.S. \& Fusco, J. (2003). Teacher professional development, technology, and communities of practice: Are we putting the cart before the horse? The Information Society: An International Journal, 19(3), 203-220.

Schlechty, P. C. (2009). Leading for learning: How to transform schools into learning organizations. San Francisco, CA: John Wiley and Sons.

Schön, D. A. (1995, November/December). Knowing-in-action: The new scholarship requires a new epistemology. Change, 27(6), 26-34.

Shaw, S., \& Fairhurst, D. (2008). Engaging a new generation of graduates. Education + Training, 50(5), 366-378. doi: 10.1108/00400910810889057

Sikes, P. (1992). Imposed change and the experienced teacher. In M. Fullan \& A. Hargreaves (Eds.), Teacher development and educational change (pp. 36-55). London, England: Falmer Press.

Smylie, M. A., Allensworth, E., Greenberg, R. C., Harris, R., \& Luppescu, S. (2001). Teacher professional development in Chicago: Supporting effective practice. Chicago, IL: Consortium on Chicago School Research.

Spicer, N. (2012). Combining qualitative and quantitative methods. In C. Seale (Ed.), Researching society and culture ( $3^{\text {rd }}$ ed.) (pp. 479-493). Thousand Oaks, CA: Sage.

Spitzer, A. B. (1973, December). The historical problem of generations. The American Historical Review, 78(5), 1353-1385.

Stodolsky, S, Dorph, G. Z., \& Rosov, W. (2008). Teacher professional development in congregational settings. Religious Education: The Official Journal of the Religious Education Association, 103(2), 240-260.

Stoll, L. (1992). Teacher growth in the effective school. In M. Fullan and A. Hargreaves (Eds.), Teacher development and educational change (pp. 104-122). London, England: Falmer Press. 
Suhr, D., \& Shay, M. (2009, September). Guidelines for reliability, confirmatory and exploratory factor analysis. Paper presented at the Western users of SAS software conference, San Jose. Retrieved from http://old.wuss.org/proceedings09/09WUSSProceedings/papers/anl/ANLSuhrShay.pdf

Sullivan, J. (2006). Faith schools: A culture within a culture in a changing world. In M. de Souza, K. Engebretson, G. Durka, R. Jackson, \& A. McGrady (Eds.), International handbook of the religious, moral and spiritual dimensions in education (pp. 937-947). Dordrecht, Netherlands: Springer.

Talbert, J. E. \& McLaughlin, M. W. (2002). Professional communities and the artisan model of teaching. Teachers and Teaching: Theory and Practice, 8(3), 325-343. doi:10.1080/135406002100000477

Tamir, E., \& de Kramer, R. M. (2011). Teacher retention and career commitments among DeLeT graduates: The intersection of teachers' background, preparation for teaching, and school context. Journal of Jewish Education, 77(2), 76-97. doi:10.1080/15244113.2011.572268

Taylor, P., \& Keeter, S. (2010). Millennials-A portrait of generation next: Confident. Connected. Open to change. Washington, DC: Pew Research Center.

The New Teacher Project. (2015). The mirage: Confronting the hard truth about our quest for teacher development [Report]. Retrieved from tntp.org/assets/documents/TNTP-Mirage_2015.pdf

Thompson, C. L., \& Zeuli, J. S. (1999). The frame and the tapestry: Standards-based reform and professional development. In L. Darling-Hammond and G. Sykes (Eds.), Teaching as the learning profession (pp. 341-375). San Francisco, CA: Jossey-Bass.

Timperley, H., \& Alton-Lee, A. (2008). Reframing teacher professional learning: An alternative policy approach to strengthening valued outcomes for diverse learners. Review of Research in Education, 32(1), 328-369.

Tom, A. R. (1986). Response to Guskey. Educational Researcher, 15(10), 12-15.

Torff, B., \& Sessions, D. (2008). Factors associated with teachers' attitudes about professional development. Teacher Education Quarterly, 35(2), 123-133.

Trim, D. (Director). (2015). Annual statistical report: $151^{\text {st }}$ report of the General Conference of Seventh-day Adventists for 2013 and 2014. Nampa, ID: Pacific Press. 
Tulgan, B. (2011). Generation Y: All grown up and now emerging as new leaders. Journal of Leadership Studies, 5(3), 77-81. doi:10.1002/jls.20237

Twenge, J. M. (2010). A review of the empirical evidence on generational differences in work attitudes. Journal of Business Psychology, 25(2), 201-210.

Van Pelt, D. A. N., Sikkink, D., Pennings, R., and Seel, J. (2012). Private religious protestant and Catholic schools in the United States and Canada: Introduction, overview, and policy implications. Journal of School Choice: Research, Theory, and Reform, 6(1), 1-19.

Wey Smola, K., \& Sutton, C. D. (2002). Generational differences: Revisiting generational work values for the new millennium. [Special Issue: Brave New Workplace: Organizational Behavior in the Electronic Age]. Journal of Organizational Behavior, 23(4), 363-382. doi:10.1002/job.147

Wheatley, K. F. (2002). The potential benefits of teacher efficacy doubts for educational reform. Teaching and Teacher Education, 18(1), 5-22.

White, E. G. (1903). Education. Mountain View, CA: Pacific Press.

Whitehouse, P. L., Breit, L. A., McCloskey, E. M., Ketelhut, D. J., \& Dede, C. (2006). An overview of current findings from empirical research on online teacher professional development. In C. Dede (Ed.), Online professional development for teachers: Emerging models and methods (pp. 13-28). Cambridge, MA: Harvard University Press.

Wideen, M. F., Mayer-Smith, J. A., \& Moon, B. J. (1996). Knowledge, teacher development and change. In I. F. Goodson \& A. Hargreaves (Eds.), Teachers' professional lives (pp. 187-204). London, England: Falmer Press.

Wiliam, D. (2010, March). Teacher quality: Why it matters, and how to get more of it. Paper presented at Spectator "Schools Revolution" Conference, London, England. Retrieved from http://www.dylanwiliam.org/Dylan_Wiliams_website/Papers.html

Wiliam, D. (2014). Optimizing talent: Closing educational gaps worldwide. West Palm Beach, FL: Learning Sciences Dylan Wiliam Center.

Wiliam, D. (2016). Leadership for teacher learning. West Palm Beach, FL: Learning Sciences International.

Wiliam, D., \& Leahy, S. (2014). Sustaining formative assessment with teacher learning communities [White Paper]. West Palm Beach, FL: Learning Sciences Dylan Wiliam Center. 
Williams, B., Brown, T., \& Onsman, A. (2010). Exploratory factor analysis: A five-step guide for novices. Australasian Journal of Paramedicine, 8(3), 1-13.

Wiske, M. S., Perkins, D., \& Spicer, D. E. (2006). Piaget goes digital: Negotiating accommodation of practice to principles. In C. Dede (Ed.), Online professional development for teachers: Emerging models and methods (pp. 49-67). Cambridge, MA: Harvard Education Press.

Wong, H., \& Wong R. (2007). Teachers, the next generation. ASCD Express, 2(13).

Wright, J. (2008). Reframing quality and impact: The place of theory in education research. The Australian Educational Researcher, 35(1), 1-16.

Wuthnow, R. (2007). After the baby boomers: How twenty-and thirty-somethings are shaping the future of American religion. Princeton, NJ: Princeton University Press.

Yoon, K. S., Duncan, T., Lee, S. W., Scarloss, B., \& Shapley, K. (2007). Reviewing the evidence on how teacher professional development affects student achievement (Issues \& Answers Report, REL 2007-No. 033). Washington, DC: U.S. Department of Education.

Zemke, R., Raines, C., \& Filipczak, B. (2013). Generations at work (2nd ed.). New York, NY: American Management Association.

Zhang, M., Ding, X., \& Xu, J. (2016). Developing Shanghai's teachers [Report]. Washington, DC: National Center on Education and the Economy. 
VITA

223 


\section{BETTY LAVERNE (JURIANSZ) BAYER}

918 Copperfield Drive $\quad$ • Oshawa, ON Canada $\quad$ • bayer.betty@adventist.ca

\section{EDUCATION}

2014-2017 Ph.D. (Educational Leadership), Andrews University, Berrien Springs, MI

2011-2014 Ed.D. coursework (Educational Leadership), University of Calgary, Calgary, AB

1979-1980 M.A. (major: English), Andrews University, Berrien Springs, MI

1975-1979 B.A. (major: English), Andrews University, Berrien Springs, MI

\section{PROFESSIONAL EXPERIENCE}

2016-present Director of Education, Seventh-day Adventist Church in Canada, Oshawa, ON

2007-2016 Associate Director of Education, Seventh-day Adventist Church in Canada, Oshawa, ON

1991-2007 V.P. Academics, Kingsway College, Oshawa, ON

1980-1991 Teacher/Department Head, Kingsway College, Oshawa, ON

\section{CERTIFICATION}

Ontario College of Teachers

- Basic Qualifications: Junior, Intermediate, Senior Divisions (English, Dramatic Arts)

- Additional Qualifications: English Honour Specialist, ESL, Guidance, Co-operative Education, Special Education

North American Division of Seventh-day Adventists

- Professional Teaching Certificate (English, Biology, Special Education, Guidance)

- Administrator Certificate

\footnotetext{
Zapara Award for Excellence in Teaching, 1989

Kingsway College Alumnus of the Year, 2003
}

AWARDS 